\title{
DEPTH PROFILES OF GEOCHEMISTRY AND ORGANIC CARBON FROM PERMAFROST AND ACTIVE LAYER SOILS IN TUNDRA LANDSCAPES NEAR LAC DE GRAS, NORTHWEST TERRITORIES, CANADA
}

\author{
By
}

Rupesh Subedi, B.Sc.

\begin{abstract}
A thesis submitted to the
Faculty of Graduate and Postdoctoral Studies

in partial fulfillment of the requirements

for the degree of

Master of Science in Geography
\end{abstract}

\author{
Carleton University \\ Department of Geography \\ (c) Rupesh Subedi, Ottawa, Canada, 2016.
}




\begin{abstract}
The geochemistry of permafrost is relevant for understanding impacts of thaw and for unraveling landscape dynamics. This study aimed to contribute to knowledge of permafrost geochemistry from the Lac de Gras region, Northwest Territories, Canada. The area represents a contrasting geomorphic and climatic setting from other more intensively studied permafrost areas in northwestern Canada. Permafrost and active layer samples from 24 sites were collected to examine the vertical and spatial distribution of water content, organic matter content and soluble cations. These varied between the active layer, nearsurface permafrost and the permafrost at depth. Near-surface solute enrichment of permafrost was evident at some sites in each terrain type, but the majority of sites had lower cation contents in near-surface permafrost than in the active layer. Active layer organic materials from peatlands and wetlands terrain were solute rich in comparison to mineral soils of till blanket, till veneer or esker terrains at similar depth. In the Lac de Gras area, organic soils are enriched with solutes relative to tills or glaciofluvial deposits, and since the organics are primarily near the surface, active layers often are solute rich with respect to underlying mineral soil permafrost.
\end{abstract}




\section{ACKNOWLEDGMENTS}

This research reported here was supported by the Canadian Northern Economic Development Agency, and by the Dominion Diamond Corporation. The Northwest Territories Geological Survey supported the successful completion of this project.

First and foremost, I am very much thankful to my supervisor Dr. Stephan Gruber for his immense support and guidance. I could have never done this without you, Stephan. Thanks a lot for introducing me to permafrost science, and for everything. I would also like to extend my gratitude towards my thesis committee: Dr. Chris Burn and Dr. Steve Kokelj. Thank you both for your valuable feedback and comments during this process. I am also very thankful to Dr. Denis Lacelle for his detailed feedbacks on my thesis.

I would like to extend my sincere thanks to Barrett Elliott and Dr. Kumari Karunaratne for their overwhelming support in this project. Also many thanks to Nick Brown for his support during the field campaign. Field assistance from Julia Riddick, Luca Heim, Rosaille Davreux and Christian Peart was magnificent, thank you very much guys. I would also like to thank Cameron Samson for helping with LiDAR data used in this project. Also many thanks to Bin Cao for helping with coding.

I thank the Taiga Lab at Yellowknife, N.W.T for their assistance with the laboratory analysis of the samples. From Carleton University, I owe my sincere thanks to Dr. Murray Richardson for allowing me to use the lab equipment for LOI analysis. Phew.. I didn't put the LOEB building on fire. I would also like to thank Jerry Demorcy for his lab assistance during LOI analysis. I am very much thankful to Dr. Elyn Humphreys for helping me during laboratory analysis of samples.

To all my friends from batch 2014, MSc. Geography, I remember you all, and I am very much thankful to you for motivating and always giving me helpful ideas. I survived in Ottawa guys, as winter isn't bad and people have warm hearts. To all my other friends from Ottawa, thank you so much, you guys are awesome.

Last, but certainly not least, I would like to extend my gratitude to my family, and to someone I know from the last 9 years. Words cannot describe how much I owe you. Thank you very much for believing me and always motivating me to do things, and to be a problem solver every day. Love you so much!! Jay Shree Ganesh!! 


\section{TABLE OF CONTENTS}

ABSTRACT

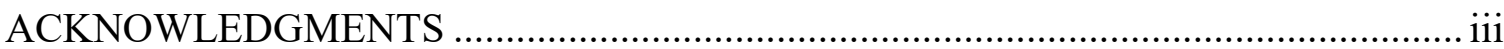

TABLE OF CONTENTS .................................................................................. iv

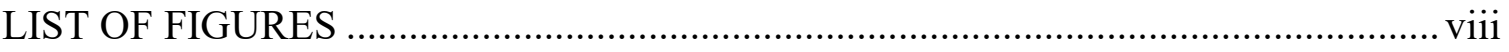

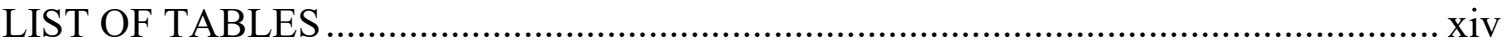

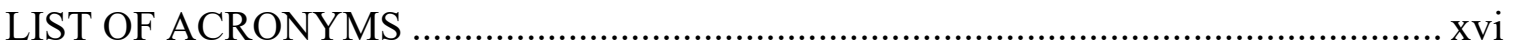

CHAPTER 1. INTRODUCTION ........................................................................ 1

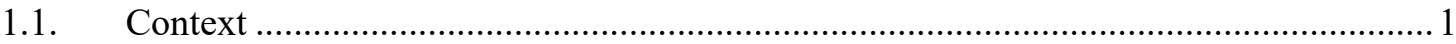

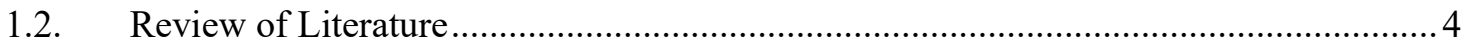

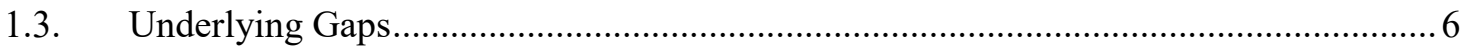

1.4. Research Objectives and Research Questions .......................................................... 7

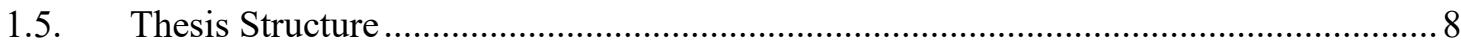

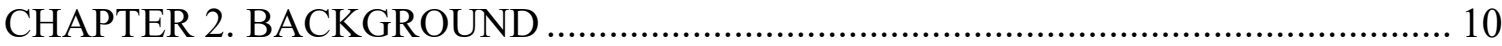

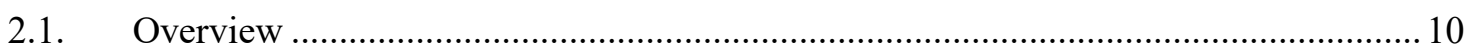

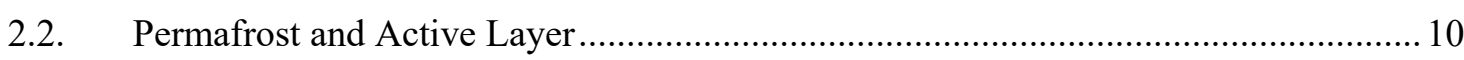

2.2.1. Ground Thermal Regime of Permafrost at Equilibrium .................................... 10

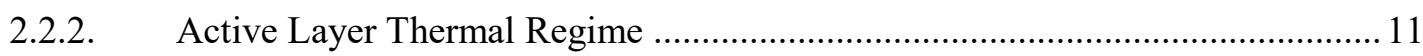

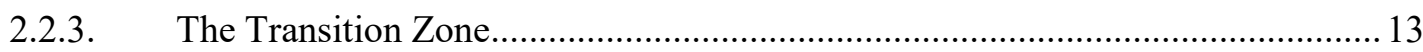

2.3. Moisture Content of Permafrost and Active Layer.................................................. 13

2.3.1. Unfrozen Water Content in Permafrost ............................................................. 13

2.3.2. Water Movement in Permafrost and Active Layer .......................................... 17

2.4. Solute and Organic Matter Content in Permafrost and Active Layer Soils ................. 20

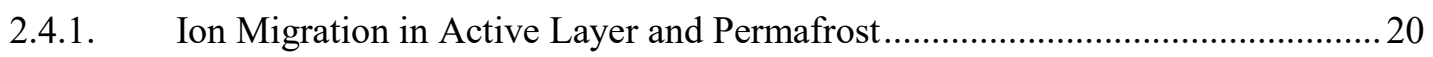

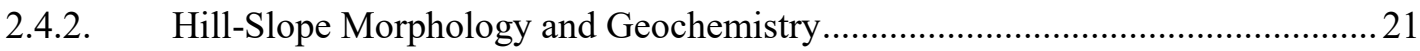

2.4.3. Organic Matter in the Active Layer and in Permafrost.......................................26

CHAPTER 3. STUDY AREA AND METHODS …................................................... 28

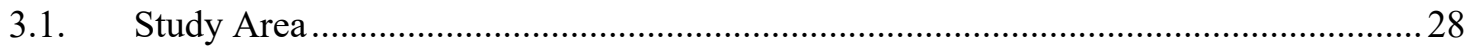

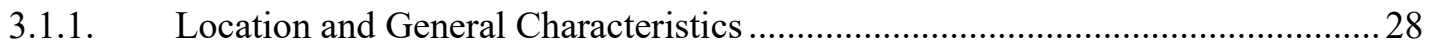

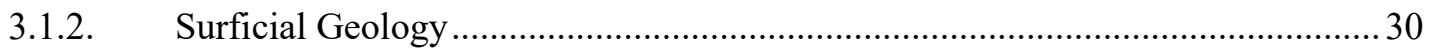




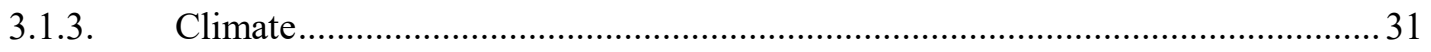

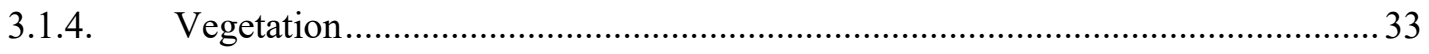

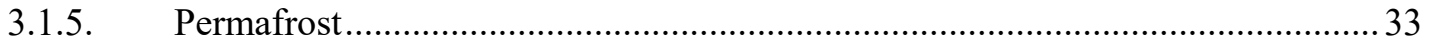

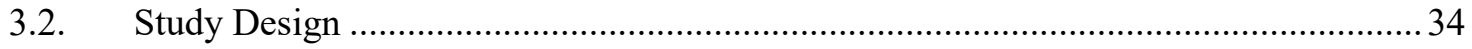

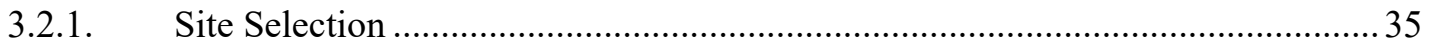

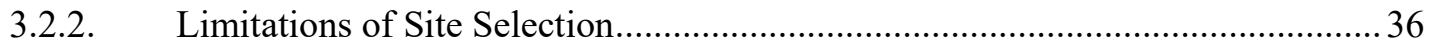

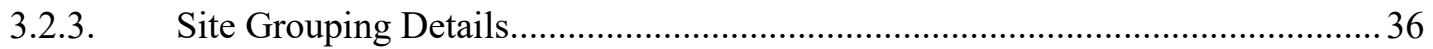

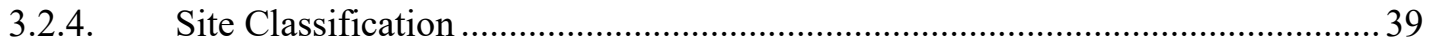

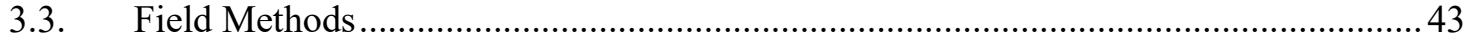

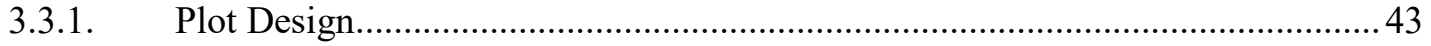

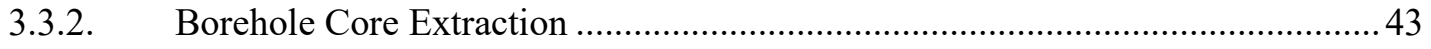

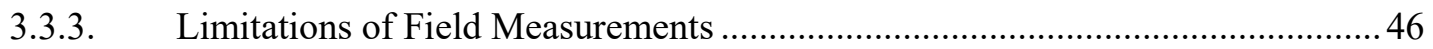

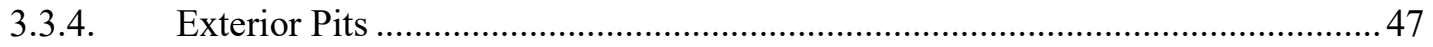

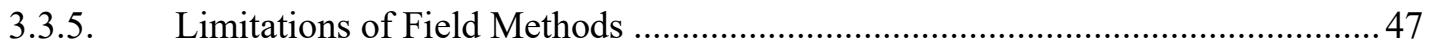

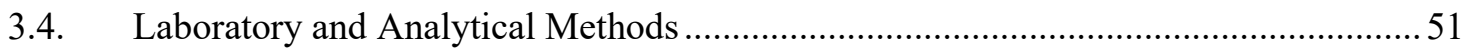

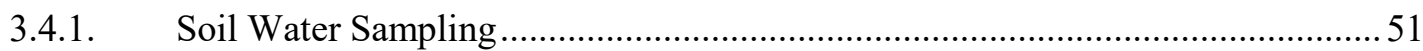

3.4.2. Core Samples (Boreholes + Exterior Pits) .......................................................... 54

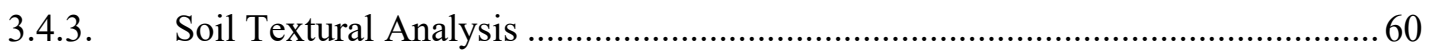

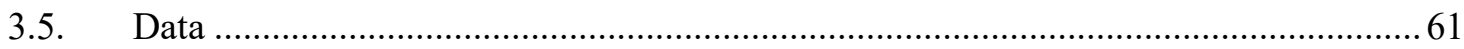

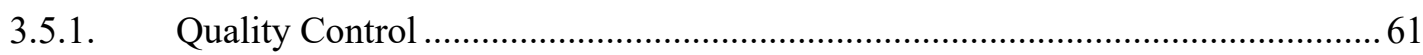

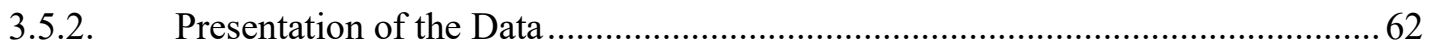

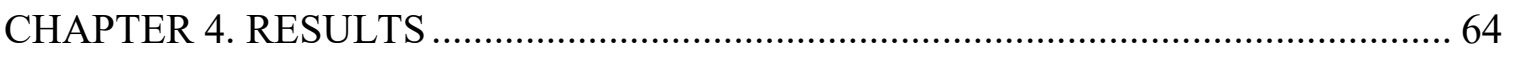

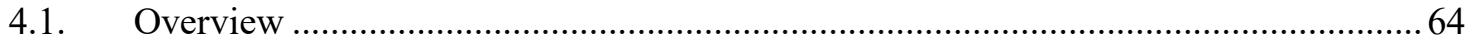

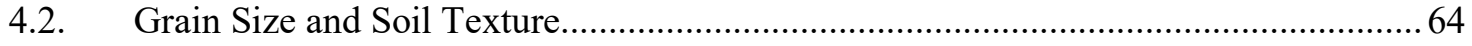

4.3. Depth Profiles: Moisture Content, Organic Matter and Soluble Cations ......................66

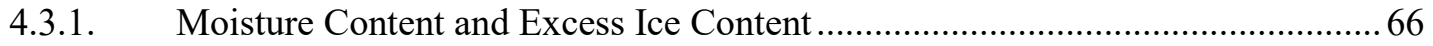

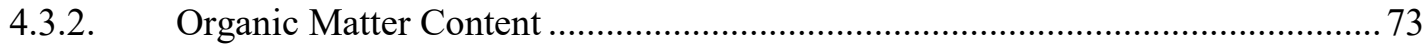

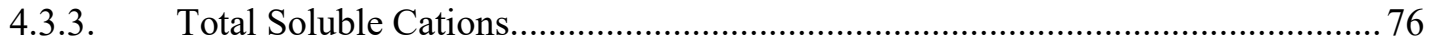

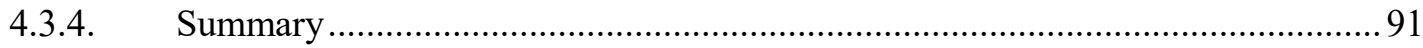

4.3.5. Relation Between Electrical Conductivity and Total Soluble Cations ............... 103

4.3.6. Relation Between Water Content GWB and Total Soluble Cations................... 105

4.3.7. Relation Between Organic Matter Content and Total Soluble Cations .............. 105

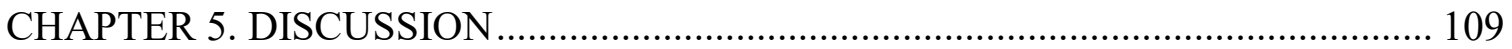


5.1. Overview

5.2. Effect of Soil-Water Extraction Method on the Concentration of Soluble Cations ... 110

5.3. Relation Between Gravimetric Water Content GWB and Soil Texture

5.4. Vertical and Spatial Distribution: Gravimetric Water Content GWB, Organic Matter Content and Total Soluble Cations

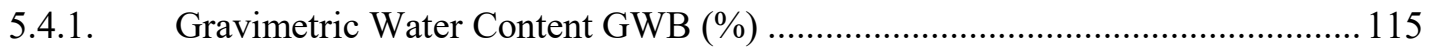

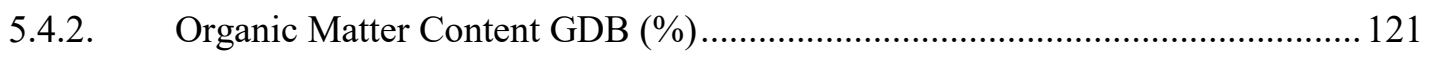

5.4.3. Total Soluble Cations (meq/100 g dry soil) .................................................... 122

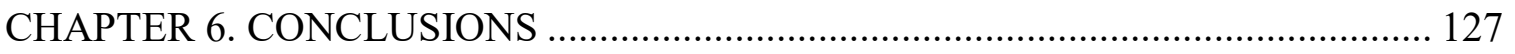

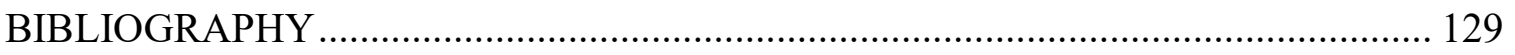

APPENDIX A: Drill log sheet used for recording the core information ...................... 139

APPENDIX B: Log sheet used for recording soil pit information ............................ 140

APPENDIX C: Protocols for sample preparation and analysis ............................... 141

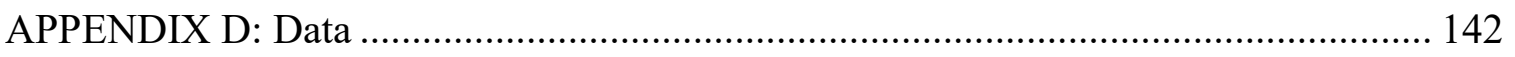

APPENDIX E: Grain size analysis of active layer and permafrost samples from various

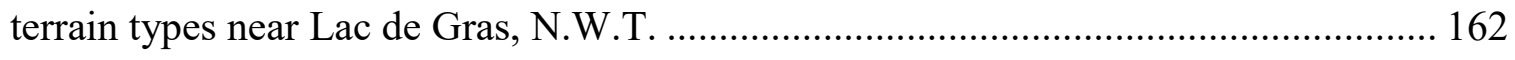

APPENDIX F1: Summary statistics of gravimetric water content GWB (\%) in the top 0.5 $\mathrm{m}, 1 \mathrm{~m}, 2 \mathrm{~m}, 4 \mathrm{~m}, 6 \mathrm{~m}$ and $10 \mathrm{~m}$ of 24 sites near Lac de Gras, N.W.T. N is the number of samples, PS (\%) is the percentage of total sampling that was considered and N/A values delineate depth intervals where no samples were recovered or core lengths that did not reach the specified depths. 163

APPENDIX F2: Summary statistics of organic matter content (\%) in the top $0.5 \mathrm{~m}, 1 \mathrm{~m}, 2$ m, 4 m, $6 \mathrm{~m}$ and $10 \mathrm{~m}$ of 24 sites near Lac de Gras, N.W.T. N is the number of samples, PS (\%) is the percentage of total sampling that was considered and N/A values delineate depth intervals where no samples were recovered or core lengths that did not reach the specified depths 164

APPENDIX F3: Summary statistics of total soluble cations (meq/100 g dry soil) in the top $0.5 \mathrm{~m}, 1 \mathrm{~m}, 2 \mathrm{~m}, 4 \mathrm{~m}, 6 \mathrm{~m}$ and $10 \mathrm{~m}$ of 24 sites near Lac de Gras, N.W.T. N is the number of samples, PS (\%) is the percentage of total sampling that was considered and N/A values 
delineate depth intervals where no samples were recovered or core lengths that did not

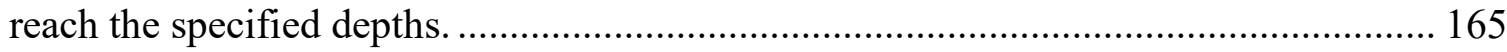




\section{LIST OF FIGURES}

Figure 1.1 Location of the study area (Modified from Heginbottom et al., 1995) ........... 2

Figure 2.1 Ground thermal regime of permafrost at equilibrium (after Burn, 2004, Figure

Figure 2.2 Unfrozen water content at temperatures below $0{ }^{\circ} \mathrm{C}$ for different soil types (from Williams and Smith, 1991, Figure 1.4).

Figure 2.3 Mechanisms of water adsorption by clay surfaces: (a) hydrogen bonding, (b) ion hydration, (c) attraction by osmosis, and (d) dipole attraction (from Mitchell and Soga, 2005, Figure 6.4).

Figure 2.4 Hydraulic conductivities of different soil types below $0{ }^{\circ} \mathrm{C}$ (from Burt and Williams, 1976) 19

Figure 2.5 (a) A turf-banked solifluction terrace formed by the slow movement of soil downslope (near Holman, western Victoria Island, NWT, Canada) (from French, 2007), and (b) mean annual soil movement (cm/year) for the tops of plastic tubes inserted at Garry Island, N.W.T. for the (1964-1977) period (from Mackay, 1981).

Figure 2.6 The possible relation between hill slope morphology and geochemistry as explained by mass movement process (solifluction). 25

Figure 2.7 The possible relation between hill slope morphology and geochemistry as explained by water movement along the flow path. The darker longer arrows towards the slope and near the bottom of the hill represent increasing water content due to increase in the catchment area, and hence the potential for more leaching due to higher acidity. 25

Figure 3.1 Surficial sediments and terrain units in the Lac de Gras area (circle). Modified from Dredge et al. (1999).

Figure 3.2 Mean monthly air temperature (circles), and mean monthly precipitation (bars) for Yellowknife Airport (1981-2010), Lupin Airport (1982-2006) and Ekati Airport (1998-2008) respectively (Environment Canada 2016). 32

Figure 3.3 Locations of boreholes used for this study in the Lac de Gras area. The grey hillshade shows the area covered by the LiDAR DEM. The diamond mine (Ekati) 
infrastructure as well as areas not covered in the DEM acquisition are shown by white spaces. 37

Figure 3.4 Borehole locations from the Control group, Hill 1 and Hill 3 40

Figure 3.5 Borehole locations Hill 2 and Valley. The Valley group contains the largest number of boreholes drilled in two transects across various regional conditions. ... 40

Figure 3.6 Esker 1, where 3 boreholes were drilled in proximity to compare the small-scale variability in geochemistry and organic carbon. 41

Figure 3.7 Location of Esker 2 containing a single borehole in its terrain. 41

Figure 3.8 (a) Graphical representation of the plot design; (b) the position of the exterior pit varies at each site depending upon the surface conditions. 44

Figure 3.9 (a) Field use of diamond drilling rig (Kryotek Compact Diamond Sampler); (b) typical core segment.

Figure 3.10 (a) Calcium concentration; (b) magnesium concentration; (c) potassium concentration; and (d) sodium concentration measured with three methods. (e) relative difference of Method 2 with Methods 1 and 3. Square represents 2 with 1, while triangles represent 2 with 3 . Orange, green, blue and red denotes sodium, calcium, potassium and magnesium ions respectively. Concentrations obtained from Method 2 and Method 3 were corrected to original "field" water contents. 53

Figure 3.11 (a) Sample being weighed in a crucible; (b) crucibles inside a muffle furnace ready to undergo LOI 550. 59

Figure 4.1 A textural ternary plot (from USDA soil classification system) indicating soil textures of various terrain types near Lac de Gras, N.W.T. Larger icons represent the mean soil texture of each terrain, while smaller icons denote soil textures of individual samples from each type. 65

Figure 4.2 Gravimetric water content (GWB) and excess ice profiles from the active layer and permafrost at peatlands and wetlands sites, near Lac de Gras, N.W.T. Blue triangles represent water content GWB while dark blue upside down triangles represent excess ice content. The dashed line represents the thickness of the active layer at the time of sampling while the dotted line represents the lower boundary of the near-surface permafrost (See Figure 3.4 to 3.7 for location context). 67 
Figure 4.3 Gravimetric water content (GWB) and excess ice profiles from the till blanket sites, near Lac de Gras, N.W.T. Blue triangles represent water content GWB while dark blue upside down triangles represent excess ice content. The dashed line represents the thickness of the active layer at the time of sampling while the dotted line represents the lower boundary of the near-surface permafrost (See Figure 3.4 to 3.7 for location context).

Figure 4.4 Gravimetric water content (GWB) and excess ice profiles from the active layer and permafrost, till veneer sites, near Lac de Gras, N.W.T. Blue triangles represent water content GWB while dark blue upside down triangles represent excess ice content. The dashed line represents the thickness of the active layer at the time of sampling while the dotted line represents the lower boundary of the near-surface permafrost (See Figure 3.4 to 3.7 for location context). 71

Figure 4.5 Gravimetric water content (GWB) profiles from the esker sites, near Lac de Gras, N.W.T. The dashed line represents the thickness of the active layer at the time of sampling while the dotted line represents the lower boundary of the near-surface permafrost (See Figure 3.4 to 3.7 for location context). 72

Figure 4.6 Soil Organic-matter contents in the active layer and permafrost, peatlands and wetlands site, near Lac de Gras, N.W.T. The dashed line represents the represents the thickness of the active layer at the time of sampling while the dotted line represents the lower boundary of the near-surface permafrost (See Figure 3.4 to 3.7 for location context). 74

Figure 4.7 Soil Organic-matter content profiles from the till blanket sites, near Lac de Gras, N.W.T. The dashed line represents the thickness of the active layer at the time of sampling while the dotted line represents the lower boundary of the near-surface permafrost (See Figure 3.4 to 3.7 for location context). 75

Figure 4.8 Soil Organic-matter contents in the active layer and permafrost, till veneer sites, near Lac de Gras, N.W.T. The dashed line represents the thickness of the active layer at the time of sampling while the dotted line represents the lower boundary of the near-surface permafrost (See Figure 3.4 to 3.7 for location context). 77

Figure 4.9 Soil Organic-matter content profiles from the esker sites, near Lac de Gras, N.W.T. The dashed line represents the thickness of the active layer at the time of 
sampling while the dotted line represents the lower boundary of the near-surface permafrost (See Figure 3.4 to 3.7 for location context). 78

Figure 4.10 Profiles of total soluble cations in the active layer and permafrost, peatlands and wetlands sites, near Lac de Gras, N.W.T. The dashed line represents the thickness of the active layer at the time of sampling while the dotted line represents the inferred depth of the near-surface permafrost while the dotted line represents the lower boundary of the near-surface permafrost (See Figure 3.4 to 3.7 for location context). 80

Figure 4.11 Profiles of total soluble cations from till blanket sites, near Lac de Gras, N.W.T. The dashed line represents the thickness of the active layer at the time of sampling while the dotted line represents the lower boundary of the near-surface permafrost (See Figure 3.4 to 3.7 for location context). 83

Figure 4.12 Profiles of total soluble cations in the active layer and permafrost, till veneer sites, near Lac de Gras, N.W.T. The dashed line represents the thickness of the active layer at the time of sampling while the dotted line represents the lower boundary of the near-surface permafrost (See Figure 3.4 to 3.7 for location context). 86

Figure 4.13 Profiles of total soluble cations from the esker sites, near Lac de Gras, N.W.T. The dashed line represents the thickness of the active layer at the time of sampling while the dotted line represents the lower boundary of the near-surface permafrost (See Figure 3.4 to 3.7 for location context). 89

Figure 4.14 Gravimetric water content GWB (\%) variations (A) between the active layer, near-surface permafrost and the permafrost at depth of four different surface types; and (B) between the Unitcodes. In cases where $\mathrm{N} \leq 5$ all data points have been represented using dots 95

Figure 4.15 Organic matter content GDB (\%) variations (A) between the active layer, nearsurface permafrost and the permafrost at depth of four different surface types; and (B) between the Unitcodes. Organic matter content (\%) values for Figure A and B are transformed logarithmically. In cases where $\mathrm{N} \leq 5$ all data points have been represented using dots. 95

Figure 4.16 (A) Soluble cation concentration variations between the active layer, nearsurface permafrost and the permafrost at depth; and (B) median total soluble cation 
concentrations in mineral soils of the active layer and in the top $1 \mathrm{~m}$ of underlying permafrost $(\mathrm{N}=15)$. In cases where $\mathrm{N} \leq 5$ all data points in Figure 4.16A have been represented using dots.

Figure 4.17 Active layer soluble cation contents compared between organic and mineral soils

Figure 4.18 Comparison of logarithm soluble cation enrichment ratios between the icerich and ice-poor permafrost. A non-parametric (Mann-Whitney U) test showed the median enrichment ratios between ice-rich and ice-poor sites to be significantly different $(\mathrm{p}$-value $=0.009)$.

Figure 4.19 Soluble cation concentration variations between the Unitcodes, for the cores obtained near Lac de Gras, N.W.T. 104

Figure 4.20 The relation between electrical conductivity $\left(\mathrm{C}_{\mathrm{pw}}\right)$ and total soluble cation concentrations $\left(\mathrm{S}_{\mathrm{pw}}\right.$ ) (sum of soluble $\mathrm{Ca}^{2+}, \mathrm{Mg}^{2+}, \mathrm{K}^{+}$and $\mathrm{Na}^{+}$) in pore-water extractions from the active layer and permafrost samples, near Lac de Gras, N.W.T. The relation between two variables is summarized by $\mathrm{S}_{\mathrm{pw}}=8.83 \mathrm{C}_{\mathrm{pw}}+0.253\left(\mathrm{R}^{2}=\right.$ $0.90, \mathrm{~N}=313$ ). 104

Figure 4.21 The relation between gravimetric water content GWB (\%) and total soluble cations meq/ 100g dry soil (A) for the entire depths, i.e., in the active layer, nearsurface permafrost and at depth in permafrost; (B) in the active layer; and (C) in the near-surface permafrost for the cores obtained from various terrain in near Lac de Gras, N.W.T. 106

Figure 4.22 The relation between organic matter content (\%) and total soluble cations meq/ $100 \mathrm{~g}$ dry soil (A) with respect to terrain types for the entire cores in the active layer, near-surface permafrost and at depth in permafrost; (B) with respect to UnitCodes; (C) in the active layer; (D) in near-surface permafrost; and (E) in permafrost at depth for the cores obtained near Lac de Gras, N.W.T. 108

Figure 5.1 Relative difference of soluble cations obtained from Method 3 and Method 2. The relative difference is defined by subtracting the concentration of soluble cations obtained from Method 2 from the concentration of Method 3. 
Figure 5.2 Comparison of water content GWB with Clay Content (\%), Silt Content (\%) and Sand Content (\%) in samples obtained from various terrain types from Lac de

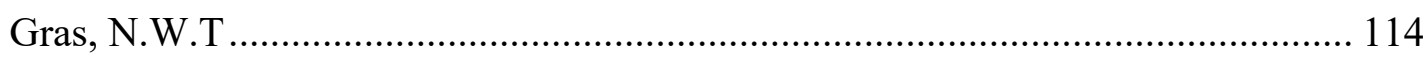

Figure 5.3 Core photos showing ice lenses present in the near-surface permafrost at two different sites from peatlands and wetlands terrain near Lac de Gras, N.W.T....... 117

Figure 5.4 Core photos showing high excess ice contents in permafrost at depth for the till blanket terrain near Lac de Gras, N.W.T. ........................................................ 120 


\section{LIST OF TABLES}

Table 3.1 Site groups representing boreholes located within proximity and similar regional setting..... 38

Table 3.2 Site classification of boreholes based on the terrain units 42

Table 3.3 Measuring the concentration of major ions $(\mathrm{mg} / \mathrm{l})$ at different dilution limits 50

Table 3.4 Trial experiment reporting the mass of frozen cores before and after dipping in a foam mixture 50

Table 4.1 Mean total soluble cation concentrations of various sites located within the peatlands and wetlands sites

Table 4.2 Mean total soluble cation concentrations of various sites located within the till blanket sites 84

Table 4.3 Mean total soluble cation concentrations of various sites located within the till veneer sites.

Table 4.4 Mean total soluble cation concentrations of various sites located within the esker sites 90

Table 4.5 and Table 4.6: Summary statistics of gravimetric water content GWB (\%) and organic matter content GDB (\%) in the active layer, near-surface permafrost and at depth in permafrost of 24 sites near Lac de Gras, N.W.T. N is the number of samples, PS (\%) is the percentage of total sampling that was considered and N/A values delineate depth intervals where no samples were recovered or core lengths that did not reach the specified depths.

Table 4.7 Summary statistics of total soluble cations (meq/100 g dry soil) in the active layer, near-surface permafrost and at depth in permafrost of 24 sites near Lac de Gras, N.W.T. $\mathrm{N}$ is the number of samples, PS (\%) is the percentage of total sampling that was considered and N/A values delineate depth intervals where no samples were recovered or core lengths that did not reach the specified depths.

Table 4.8 Enrichment ratio of soluble cation concentration of near-surface permafrost for several sites in various terrains, near Lac de Gras, N.W.T. 100

Table 4.9 Classification of soil types with respect to organic matter content of the active layer according to the Canadian System of Soil Classification (CSSC, 1978). 101 
Table 5.1 Concentration of soluble cations reported from the mineral soils of active layer and permafrost from previous studies in northwestern Canada..............................125 


\section{LIST OF ACRONYMS}

$\begin{array}{ll}\text { AES } & \text { Alcohol ethoxy sulphate } \\ \text { APHA } & \text { American Public Health Association } \\ \text { AWWA } & \text { American Water Works Association } \\ \text { DEM } & \text { Digital elevation model } \\ \text { GDB } & \text { Gravimetric dry basis } \\ \text { GPS } & \text { Global positioning system } \\ \text { GWB } & \text { Gravimetric water content, Wet-Basis } \\ \text { GWC } & \text { Gravimetric water content, Dry-Basis } \\ \text { LD } & \text { Laser diffraction } \\ \text { LiDAR } & \text { Light detection and ranging } \\ \text { MAAT } & \text { Mean annual air temperature } \\ \text { PPP } & \text { Precise point positioning } \\ \text { SD } & \text { Standard deviation } \\ \text { SOC } & \text { Soil organic carbon } \\ \text { SSA } & \text { Specific surface area } \\ \text { TWI } & \text { Topographic wetness index } \\ \text { USDA } & \text { United States Department of Agriculture } \\ \text { USEPA } & \text { US Environmental Protection Agency } \\ \text { WEF } & \text { Water Environment Federation } \\ \end{array}$




\section{CHAPTER 1. INTRODUCTION}

\subsection{Context}

This thesis examines the vertical and spatial patterns of soluble cations and organic carbon in permafrost and active layer soils near Lac de Gras, Northwest Territories, Canada (Figure 1.1). Geochemical studies of permafrost and the active layer provide opportunities to infer present and past geomorphic activity for a given area (O'Sullivan 1966; Pewe and Sellmann, 1973) and to investigate geochemical impacts of permafrost thaw (Kokelj and Lewkowicz, 1999; Kokelj et al., 2002; Kokelj et al., 2005; Malone et al., 2013). Quantifying soil organic carbon (SOC) assists understanding potential carbon emissions from cryosols (Tarnocai, 1999).

Thawing permafrost is a major concern in the Arctic (Schuur et al., 2008; Kokelj and Jorgenson, 2013) and as a result interest has focused on evaluating the impacts of permafrost degradation on emissions of $\mathrm{CO}_{2}$ and $\mathrm{CH}_{4}$ (Hugelius et al., 2010; Schuur et al., 2008), and on changing soil biogeochemistry (Frey and McClelland, 2009; Hinzman et al., 2013). Most recent studies from northern Canada, especially from Herschel Island and the Mackenzie Delta, have observed distinct geochemical characteristics between the permafrost and the active layer of different soil types (Kokelj et al., 2002; Kokelj and Burn, 2003; Kokelj and Burn, 2005). The concentrations of the major cations $\mathrm{Ca}^{2+}, \mathrm{Mg}^{2+}, \mathrm{K}^{+}$and $\mathrm{Na}^{+}-$hereafter termed 'soluble cations'- are much higher in pore water obtained from near-surface permafrost than in that from the overlying active layer. This is likely caused by two main processes: First, leaching removes solutes from the active layer by lateral water flow. Changes in the soil $\mathrm{pH}$, in part driven by soil forming processes can accelerate 


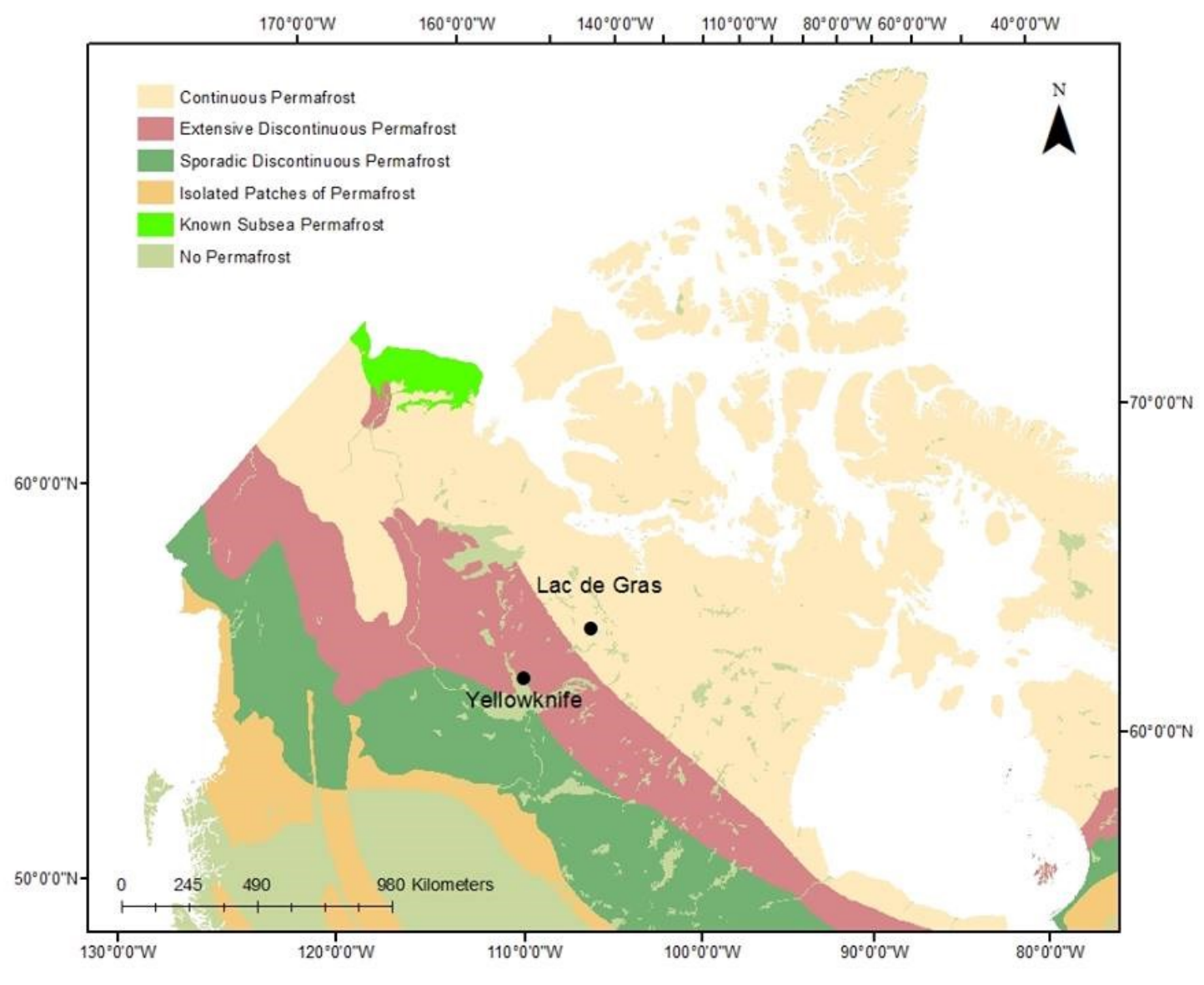

Figure 1.1 Location of the study area (Modified from Heginbottom et al., 1995) 
leaching. Second, during soil freezing, thermally-induced moisture migration is accompanied by ion redistribution (Cary and Mayland, 1972; Qui et al., 1988), leading to the enrichment of near-surface permafrost with solutes (Kokelj and Burn, 2005). As a result, ion concentrations in the active layer and permafrost may differ strongly.

This near-surface geochemical contrast is relevant because the release of water and nutrients from degrading permafrost as a result of geomorphic disturbance, forest fire or atmospheric warming may have a significant impact on the chemistry of soils and surface water, and provoke noticeable ecological effects (Mackay, 1995; Leibman and Streletskaya 1997; Kokelj and Lewkowicz, 1999). Some of these effects are described in studies from Herschel Island, Inuvik and the Mackenzie Delta region (Kokelj et al., 2002; Kokelj and Burn, 2003; Kokelj and Burn, 2005).

High-latitude soils hold large stocks of soil organic carbon (SOC), an important component of the global carbon cycle (Hugelius et al., 2010). Much of this storage occurs in cryosols due to reduced decomposition rates caused by low temperature and lack of liquid water (Hugelius et al., 2010). Cryoturbation, soil movement due to frost action (French, 2007), is a major cause for the vertical re-distribution of organic carbon in the active layer and near-surface permafrost (Bockheim, 2007). Permafrost carbon has potentially significant climate feedbacks because of its amount and the intensity of climate forcing at high latitudes (Schuur et al., 2008). Permafrost thawing will make existing carbon available for decomposition, combustion and hydrologic re-distribution (Kuhry et al., 2013). Therefore, measurements of the amount and distribution of organic matter in the active layer, near-surface permafrost and in permafrost at depth are important. 


\subsection{Review of Literature}

The study of the chemical composition of ice and sediments in permafrost was initiated in North America by O'Sullivan (1966) near Barrow, on the coastal plain of northern Alaska. His work established relationships between electrical conductivity and ion concentration from water-extracts of sediment at a number of locations. Later, several studies were conducted on permafrost samples from Fairbanks (Brown, 1969), based upon techniques developed at Barrow. Several Russian papers were published in the early 1960's on the chemistry of sediments and soils associated with permafrost (see references in Bakhman and Efemiov, 1962). More recently, interest has focused on the concentration of soluble ions in the permafrost and active layer, and the effect of permafrost degradation on soils (Kokelj and Lewkowicz, 1999; Kokelj et al., 2002), surface waters (Kokelj et al., 2005; Keller et al., 2007; Malone et al., 2013) and terrestrial (Lantz et al., 2009) and aquatic ecosystems (Theinpont et al., 2012; Chin et al., 2016).

A contrast in geochemical composition between permafrost and the active layer was observed already by O'Sullivan (1966), finding considerable leaching of cations up to the depth of $3.04 \mathrm{~m}$ in Barrow, Alaska, in an area dominated by marine sediments of midto late-Wisconsinan age. This was attributed to enhanced freshwater leaching during the Holocene. Brown et al. (1967) identified a series of fluctuations in ion concentration with depth in a detailed sampling of a 25 -m-deep core. In particular, they found that the soluble cation concentration was less in the active layer and increased in step-like fashion at depth in the permafrost.

Recently, studies from various permafrost environments in northern Canada reported geochemical differences between permafrost and the active layer. Kokelj et al. 
(2002) reported an increase in soluble cation concentration with depth at undisturbed sites on Herschel Island. In addition, past permafrost conditions at these undisturbed sites were inferred through the identification of paleo-active layers (thaw unconformity), indicated by the distribution of soluble cations, moisture and organic matter content. At disturbed sites, cation concentrations in the active layer were greater than in the undisturbed active layer. Leaching of salts from disturbed areas over time was observed to allow the succession of vegetation types, contributing to the floristic diversity of Herschel Island. Cation concentrations were observed up to ten times higher in near-surface permafrost than in the active layer at Inuvik, N.W.T (Kokelj and Burn, 2003). This study concluded that the zone of near-surface ice-rich permafrost was a sink for the deposition of soluble material. Similarly, Kokelj and Burn (2005) in their assessment of permafrost geochemistry from aggrading delta surfaces of the Mackenzie Delta region observed near-surface permafrost to be solute rich throughout their study locations. Cation enrichment in near-surface permafrost was up to 7.5 times compared with the overlying active layer. This near-surface ion enrichment was attributed to leaching of solutes from the active layer and to convective transport of soluble materials along thermal gradients in near-surface permafrost. The aforementioned studies from northern Canada used pore water extraction methods to characterize the active layer and permafrost geochemistry. The aim of using these methods is the quantification of readily available ions in soil water or ground ice, that may reach ground and surface water through transport in the soil environment. 


\subsection{Underlying Gaps}

To date, the majority of the permafrost literature on geochemistry and carbon quantification is concerned with processes within the active and transient layers (Lacelle and Vasil'chuk, 2013). However, increasing ground temperature, active-layer thicknesses, and permafrost degradation (i.e. Jorgenson et al., 2006; Smith et al., 2010) generate a need to better understand permafrost characteristics, also at depths greater than a few meters below the surface. For example, during past warm intervals, such as the early Holocene, the depth of the active layer was found to be greater than today, by about 2.5 times (Burn, 1997). The active layer comprised both the modern day active layer, as well as a "relict active layer" (ground immediately below the modern active layer that was once part of the active layer but is now perennially frozen). The relict active layer (now a part of permafrost) likely experienced intermittent thawing and leaching during the Holocene, and therefore may have different chemical signatures.

Although there is relatively a good understanding of the permafrost carbon pool in the upper $3 \mathrm{~m}$ of soils, carbon contents at greater depths are less well understood. In the context of the present research area, little or no information is available on the carbon pool in permafrost. It is important to estimate these underground storages, as they are an important component of the global carbon stock.

Most studies of permafrost geochemistry were conducted in similar environmental conditions from the western Arctic. Most geochemical studies of permafrost in Canada, have been conducted on the Peel Plateau, in the Mackenzie Delta, on Herschel Island or near Inuvik. However, geochemical studies in areas with differing environmental conditions are currently lacking. The present study aims to address this gap by investigating 
permafrost geochemistry from the Slave province, which represents a contrasting geomorphic and climatic setting. The area consists of a different regional setting, and is underlain by igneous rocks where glacial deposits form the most prevalent surface materials (Dredge et al., 1999). Similarly, erosion or accumulation processes are of mostly local scale (e.g. hillslopes).

\subsection{Research Objectives and Research Questions}

The present study aims to investigate the patterns of soluble cation concentration and organic carbon in a till environment on the Canadian Shield. Samples for this study were obtained to depths of 2-10 meters below the surface. Twenty-four sites with varying surface and terrain conditions were sampled through borehole drilling. Terrain types include: peatlands and wetlands, till blanket, till veneer and eskers to examine landscapescale variability.

The goal of this thesis is to examine the water content, ionic characteristics and carbon contents of the active layer and permafrost near Lac de Gras, N.W.T.

Three main themes with several research questions (RQ) arise from this objective.

Theme 1: Vertical distribution of water content, soluble cations and organic carbon.

RQ (1) What are the patterns in carbon and cation concentrations between active layer, transient layer and permafrost?

RQ (2) Are there correlations between water content, organic carbon and soluble cations?

Theme 2: Spatial variability of permafrost geochemistry and organic carbon contents. 
RQ (3) How do water content, organic carbon and soluble cation characteristics vary between the active layer, near-surface permafrost and the permafrost depth of different terrain types?

RQ (4) How do vertical patterns of cations and carbon vary between terrain types?

Theme 3: A comparison of permafrost geochemistry and organic carbon with previous studies.

RQ (5) Is near-surface permafrost in tills, eskers and organics in the Slave province enriched in soluble ion concentrations similar to observations from other regions?

\subsection{Thesis Structure}

This thesis is comprised of six chapters. Following the introduction, Chapter 2 introduces permafrost and reviews the processes that govern the geochemical characteristics of permafrost and active layer soils, and their relations with terrain morphology, ecology, and hydrology. Chapter $\mathbf{3}$ describes the study area, study design, field methods, and analytical methods used in this study. This chapter also includes the results of an intermediate analysis performed in order to select a suitable soil-water extraction method. The results obtained from three different water extraction methods are compared here, which directed the lab procedures for processing soil samples. In addition, the chapter also shows results of a lab experiment that was conducted to determine the level of contamination on permafrost samples due to the use of Halliburton Quik-Foam in the drilling process. Chapter 4 discusses the vertical and spatial distribution of water, organic matter and soluble cations, and the relations of controlling factors with water, cation and 
organic matter. Chapter 5 is a discussion of the study results. Chapter $\mathbf{6}$ provides a summary and conclusions of the present research. 


\section{CHAPTER 2. BACKGROUND}

\subsection{Overview}

This chapter provides an overview of the hydraulic conductivity of frozen soils, controlling mechanisms of solute migration in permafrost and the active layer, and the processes that are associated with hill slope morphology in a periglacial environment. To provide context for this study of active layer and permafrost geochemistry and organic carbon, the following topics are reviewed: (1) Permafrost and active layer characteristics and ground thermal regime; (2) soil texture and composition; (3) moisture contents of permafrost and the active layer including unfrozen water content in permafrost; (4) processes responsible for ion migration, and organic carbon sequestration in permafrost and the active layer; and (5) the relations between terrain morphology and geochemical characteristics in a permafrost environment.

\subsection{Permafrost and Active Layer}

\subsubsection{Ground Thermal Regime of Permafrost at Equilibrium}

The behavior of soils, particularly in cold regions, is strongly influenced by temperature and hence the analysis of the ground thermal regime is important for understanding ground properties (Williams and Smith, 1991). Permafrost terrain can be classified as a two-layered system comprised of permafrost and the active layer. Permafrost is defined as ground that lies at or below $0{ }^{\circ} \mathrm{C}$ for at least two consecutive years (ACGR, 1988 ) and it is usually overlain by a layer of ground that freezes in winter and thaws during summer known as the active-layer (French, 2007). The thickness of the active layer is controlled by a number of factors, including air temperature, vegetation, snow cover, soil and/or rock type, slope, aspect, and water content (French, 2007). The top few meters of 
permafrost are usually referred to as near-surface permafrost. The ground thermal regime of permafrost (Figure 2.1) has two principal components: (1) the thermal gradient, which is the change in temperature with depth; and (2) the temperature envelope, which is the area in the graph bounded by the maximum and the minimum temperature at each depth, until the depth of zero-annual amplitude where there is no longer annual temperature variation. The base of the permafrost occurs where the maximum ground temperature rises above $0{ }^{\circ} \mathrm{C}$ at depth (Osterkamp and Burn, 2002).

\subsubsection{Active Layer Thermal Regime}

The freezing and thawing of the active layer occurs on an annual basis. The thawing of the active layer is a one-sided process, i.e. from the surface downwards in late spring and summer when ground surface temperatures rise above $0{ }^{\circ} \mathrm{C}$. The rate of thawing is initially rapid due to steep temperature gradients near the ground surface, and declines with time as the depth of thaw increases and reaches the ice-rich zone at the base of the active layer (Burn, 2004). The autumn freeze-back is a more complex process because in regions underlain by permafrost, freezing can be two-sided, which occurs both downwards from the surface and upwards from the perennially-frozen ground beneath (French, 2007). The rate of upfreezing depends on the temperature in the permafrost (Burn, 2004). As freezing commences, the active layer often remains in a near-isothermal state, just below $0{ }^{\circ} \mathrm{C}$ (Burn, 2004), for an extended period of time. 


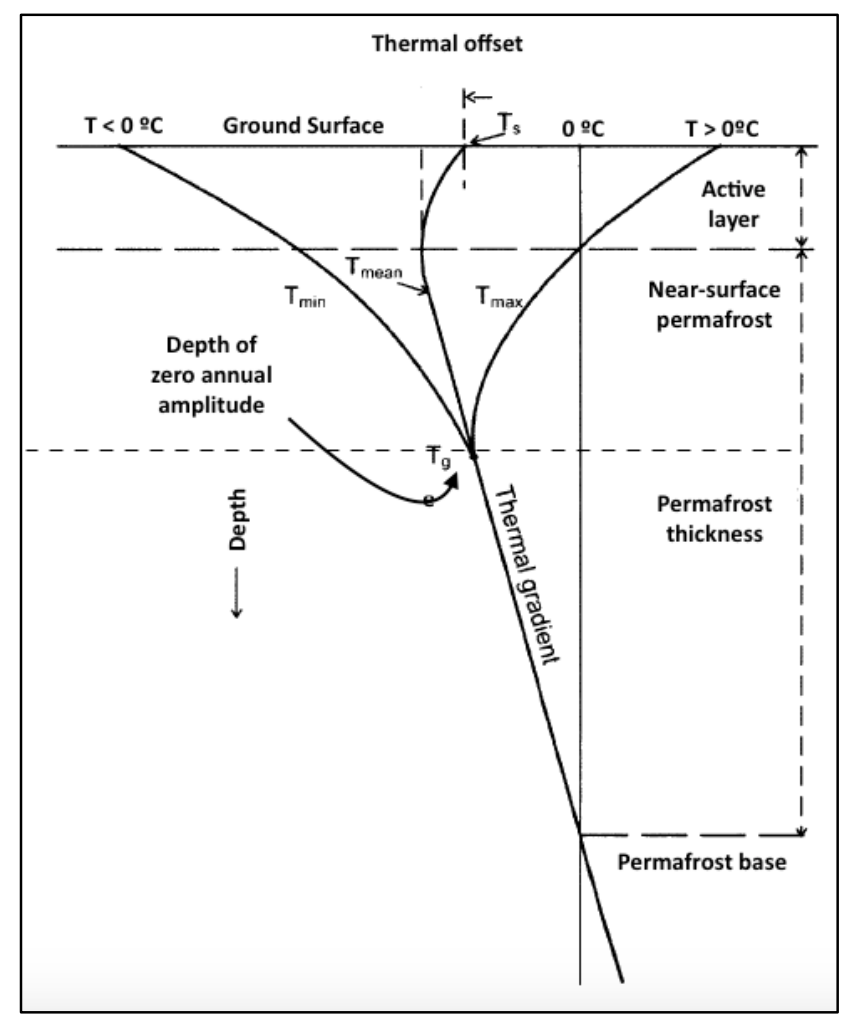

Figure 2.1 Ground thermal regime of permafrost at equilibrium (after Burn, 2004, Figure 3.3.2). 


\subsubsection{The Transition Zone}

Shur et al. (2005), based on work in Russia, proposed a three-layer conceptual model to explain the behavior of the active layer-permafrost system over long periods, particularly in ice-rich terrain. This three-layer conceptual model includes a layer termed the "transition zone", which is the top layer of permafrost below the active layer (Shur et al., 2005). The upper part of the transition zone at the top of the permafrost and the base of the active layer is known as the transient layer which joins the active layer intermittently at the sub-decadal to multi-centennial time scales (Shur et al., 2005). There are several factors that control its development, degradation and reestablishment. Deep thaw in the transition zone is largely controlled by climatic changes at long timescales (Shur et al., 2005). Similarly, surface disturbances can cause the active layer thickness to increase, degrading near-surface permafrost. In contrast, climate cooling, ecological succession or sedimentation can all cause the permafrost table to aggrade upwards leading to an increase in the thickness of the transient layer. This layer has a strong influence upon the processes that govern the formation of soil, and on the thermal stability of permafrost in the face of climatic variation (Shur et al., 2005). According to Lacelle and Vasil'chuk, (2013) the majority of permafrost literature on geochemistry and water movement is concerned within the active and transient layers, and there is a need for research to understand the permafrost characteristics at greater depth to infer past conditions.

\subsection{Moisture Content of Permafrost and Active Layer}

\subsubsection{Unfrozen Water Content in Permafrost}

Significant amounts of water can remain unfrozen in soil-water systems in equilibrium with ice at temperatures considerably below $0{ }^{\circ} \mathrm{C}$ (Williams and Smith, 1991). 
This water exists in small capillaries or as films adsorbed on the surfaces of soil particles. The unfrozen water content at subzero temperatures is determined by adsorption forces of soil particles and pore geometry, which reduces the free energy and depresses the freezing point of the soil water (Williams and Smith, 1991; Watanabe and Mizoguchi, 2002). The freezing point of the soil water is further depressed if it includes solutes, and this depends on the concentration of the solutes (Watanabe and Mizoguchi, 2002). As a result, a considerable amount of water can remain unfrozen in fine-grained soils at temperatures several degrees below $0{ }^{\circ} \mathrm{C}$ (Figure 2.2). The specific surface area (SSA)-the surface area of particles per unit volume of soil-is the primary factor controlling the amount of adsorptive forces in the soil. Clay has the highest SSA followed by silt and sand. This together with the charged pore-size characteristics, is why clay holds more unfrozen water than silt or sand at temperatures below $0{ }^{\circ} \mathrm{C}$.

Adsorption is caused by forces emanating from the mineral particles surfaces, that reduces the free energy in a thin layer, 'the adsorbed layer' of water on the particles (Williams and Smith, 1991). The importance of this layer (also referred as interfacial premelted layer) has also been studied in terms of liquid transport and frost heave (Rempel, 2010). The adsorbed water exhibits a premelting effect, which prevents it from forming ice. Several possible mechanisms of water adsorption as films on soil particles are described here from Mitchell and Soga (2005). First, the surface of soil particles has an uneven charge distribution. Due to this charge, they attract positively charged sides of bipolar water molecules (Figure 2.3a). As a result, this prevents the hydrogen bonding necessary for the formation of an ice lattice. Second, the hydration energy between mineral particle surfaces and pore-water solutes restricts the formation of ice (Figure 2.3b). Third, 


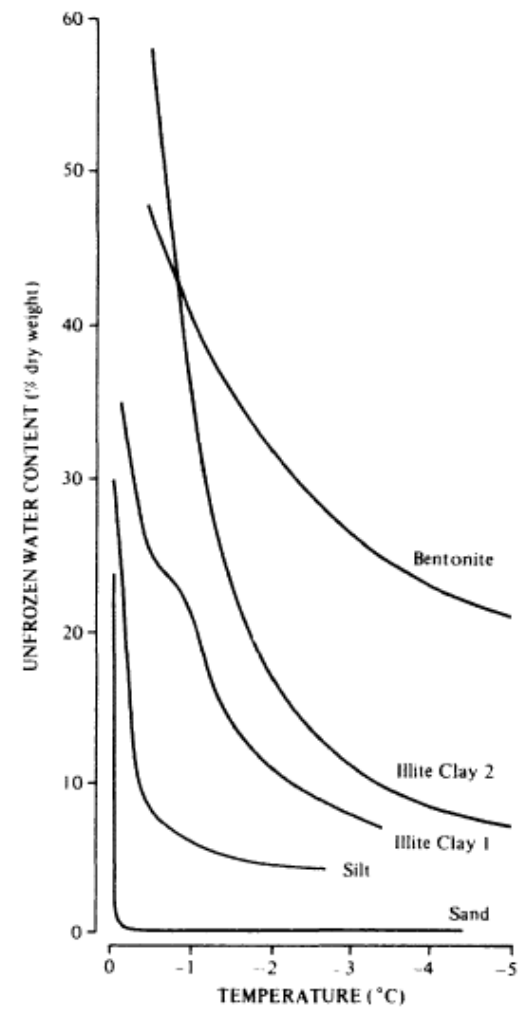

Figure 2.2 Unfrozen water content at temperatures below $0{ }^{\circ} \mathrm{C}$ for different soil types (from Williams and Smith, 1991, Figure 1.4). 

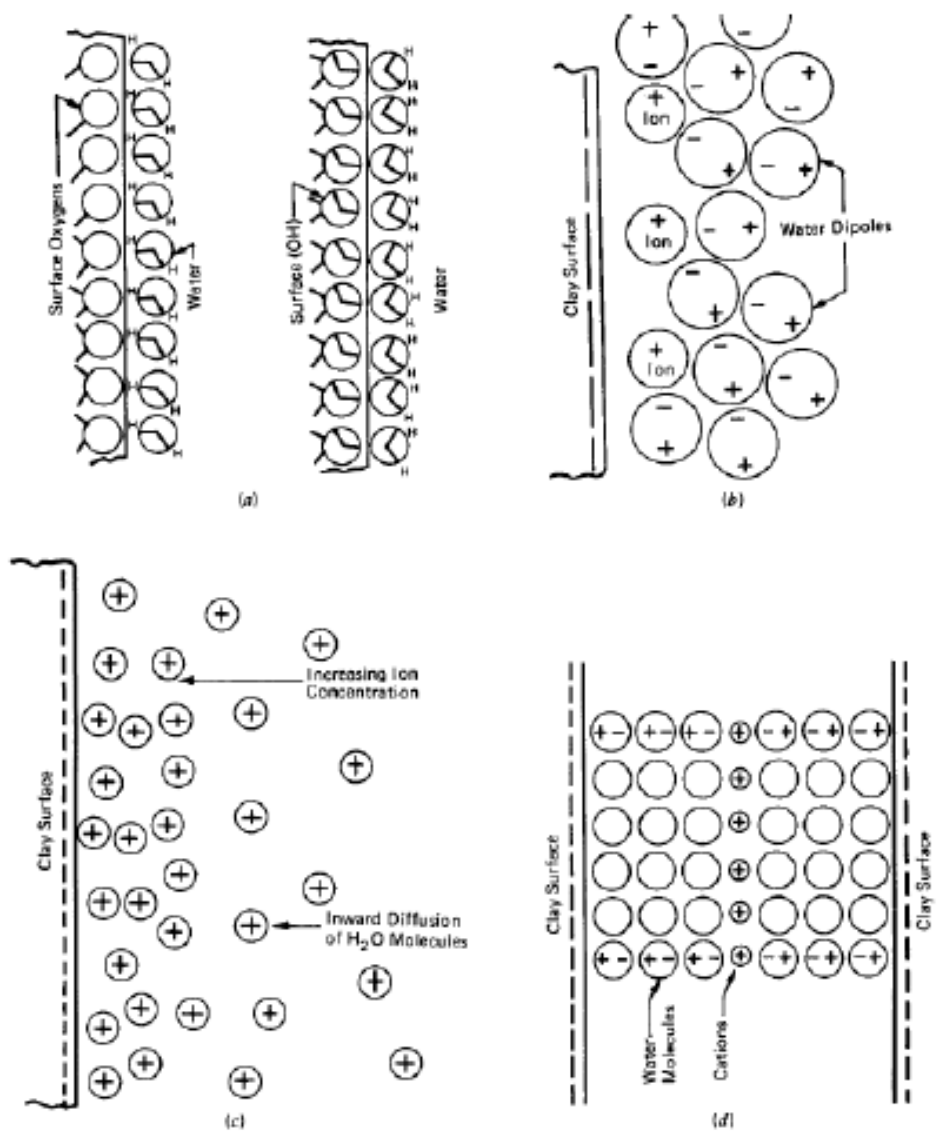

Figure 2.3 Mechanisms of water adsorption by clay surfaces: (a) hydrogen bonding, (b) ion hydration, (c) attraction by osmosis, and (d) dipole attraction (from Mitchell and Soga, 2005, Figure $6.4)$. 
the negatively charged surfaces of a soil particle also attract cations present in the pore water. This increased concentration of cations near the soil particle surface further reduces the freezing point (Figure 2.3c). Lastly, dipole attraction causes water dipoles to orient their positive poles towards the negative surfaces of a clay particle (Figure 2.3d). Adsorbed cations are tightly held on surfaces of negatively charged clay particles. Due to their high concentration near the surfaces of particles, they tend to diffuse away into the pore water however, they are restricted by both the negative electric field on the particle surfaces and ion-surface interactions that are unique to specific cations (Mitchell and Soga, 2005). This leads to a uniform distribution of ions across the surfaces of a clay particle which further reduces the freezing point. The charged soil surface and the distributed charge in the adjacent phase are together termed the diffuse double layer (Mitchell and Soga, 2005).

\subsubsection{Water Movement in Permafrost and Active Layer}

Water movement from the thawed active layer to the top of the permafrost is well known. For example, seasonal water movement from the active layer into the top of permafrost has been measured directly by neutron probe (Cheng, 1983), and indirectly by heavemeter (Mackay, 1983; Smith 1985), and traced by the movement of tritium (Chizhov et al., 1983; Burn and Michel, 1988). Permafrost was for long considered as an impermeable barrier to water movement and hydrologically inactive (Williams and Smith, 1991), but a mobile liquid phase persists at temperatures significantly below $0{ }^{\circ} \mathrm{C}$ (Burt and Williams, 1976; Smith, 1985) and soils with high frost susceptibility, i.e. silts and some clays, have significant hydraulic conductivities well below $0{ }^{\circ} \mathrm{C}$. There are numerous forces that act upon the soil water to induce or prevent its movement. Adsorption, osmotic effects, 
and gravity constitute the total potential of soil water. The differences in potential give rise to movement of water, i.e. from high to low potential (Williams and Smith, 1991).

The movement of water through a porous medium, is governed by Darcy's Law:

$$
\text { (1) } q=k A \frac{\Delta h}{L}
$$

where $\mathrm{q}$ is the volumetric flow rate in $\mathrm{m}^{3} \mathrm{~s}^{-1}, \mathrm{k}$ is the hydraulic conductivity, $\mathrm{A}$ is the crosssectional area perpendicular to flow, and $\mathrm{L}$ is the flow path length. The fraction $\Delta \mathrm{h} \mathrm{L}^{-1}$ is the pressure gradient.

The hydraulic conductivity of a frozen soil is determined mainly by soil type and temperature (Burt and Williams, 1976). The porous and the particulate nature of the soil that primarily determine the amount of unfrozen water content at temperatures below $0{ }^{\circ} \mathrm{C}$. For example, silts have the highest frozen hydraulic conductivities at temperatures only a few degrees below $0{ }^{\circ} \mathrm{C}$ due to their permeable nature and larger capillaries (Figure 2.4). Clays on the other hand have high unfrozen water content, but lower hydraulic conductivity than silt due to the smaller pore sizes (Figure 2.4). Sands have the lowest unfrozen water content and very low hydraulic conductivities below $0{ }^{\circ} \mathrm{C}$.

A temperature gradient in the frozen soil establishes a gradient of water potential that induces water movement towards the area of lower temperatures (Burt and Williams, 1976). The pressure gradient in the frozen soil is proportional to change in the temperature, therefore, an imposed thermal gradient induces water movement along the direction of decreasing temperatures (Cheng, 1983). At high temperatures, the 'adsorbed layer' of water is thicker and under high pressure (lower tension) than at low temperatures where the layer is thinner and under low pressure (high tension). As a result, unfrozen water migrates from areas of high pressure to low pressure under an influence of thermally- 


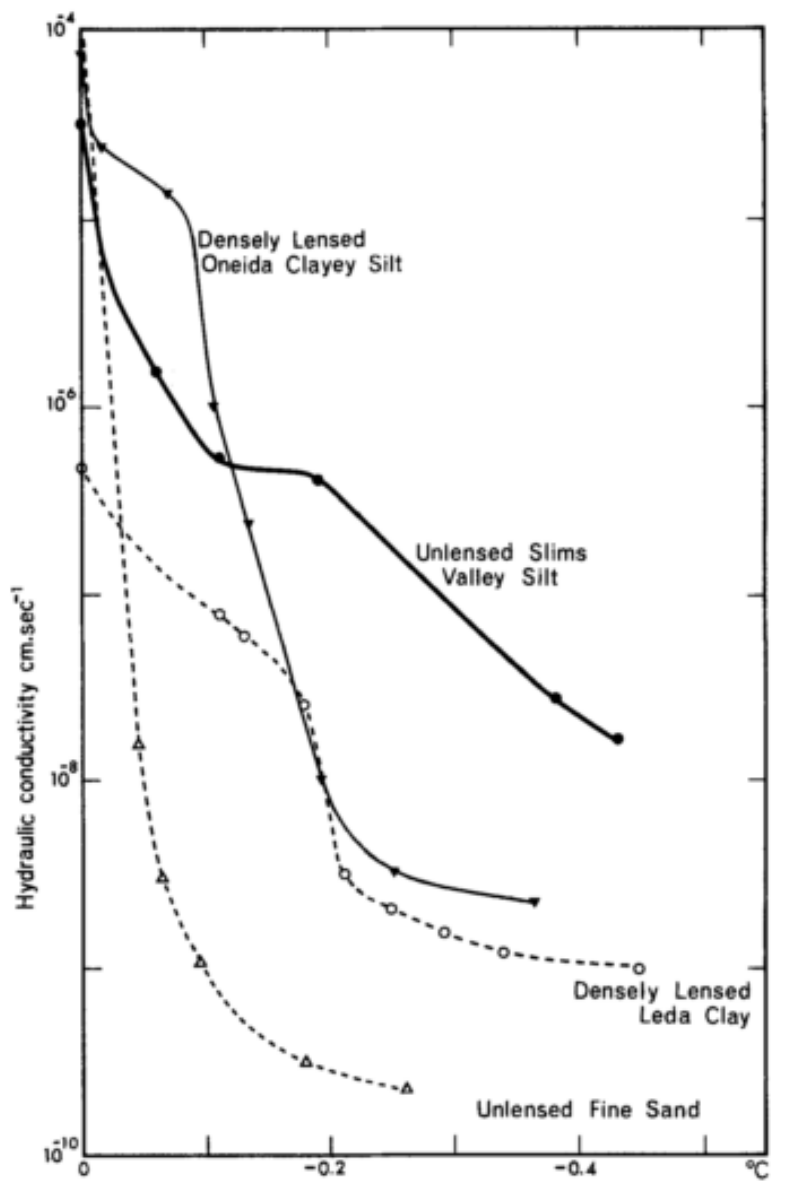

Figure 2.4 Hydraulic conductivities of different soil types below $0{ }^{\circ} \mathrm{C}$ (from Burt and Williams, 1976). 
induced pressure gradient (Cheng, 1983; Mackay, 1983).

\subsection{Solute and Organic Matter Content in Permafrost and Active Layer Soils}

\subsubsection{Ion Migration in Active Layer and Permafrost}

The migration of ions in the active layer and in permafrost is primarily influenced by the hydraulic conductivity, temperature gradients, and concentration gradients of ions in soils (Anderson and Morgenstern, 1973). Ion redistribution in the active layer is caused by freeze-thaw cycles of the seasonally frozen ground, which removes solutes by leaching (during summer thawing), and progressive removal and accumulation of ions (during

winter freezing). As a result, geochemical differences occur between the active layer and the subjacent permafrost (Kokelj et al., 2002). Entrapment of solutes by a rising permafrost table in conjunction with the downward migration of ions along thermally induced suction gradients suggest near-surface permafrost as a sink for soluble ion deposition (Kokelj and Burn, 2003).

Ion transfer in the frozen soil is linked with specific ground conditions such as salinity, and large gradients of temperature (Brouchkov, 2000). Ion transfers in the frozen soil occur through two different mechanisms. First, during soil freezing in permafrost, the films of water on particle surfaces have a tendency towards higher salinity due to longer residence time and sufficient dissolution with the adjacent soil particles (Lacelle and Vasil'chuk, 2013). Second, ions and solutes tend to be rejected from a growing ice lattice, where they are excluded and confined to the domains of the unfrozen interfacial water (Anderson and Morgenstern, 1973), they are then concentrated and mixed with other 
exchangeable ions to form a brine solution. Konrad and McCammon (1990) describe solute rejection as a function of the cooling rate.

\subsubsection{Hill-Slope Morphology and Geochemistry}

\subsubsection{Mass Movement Processes}

In periglacial environments, solifluction is regarded as the dominant mass wasting process on a year to year basis (Egginton and French, 1985). The term solifluction (slow flowing of soil masses from higher to lower ground) first used by J.G. Anderson (1906) is a general term used to represent both processes, i.e. gelifluction (flow) and frost creep (a rachetlike movement, Washburn, 1980). The resulting flow features have a lobate or terrace-like form (Figure 2.5a) with 'fronts' a few centimeters to meters high moving downslope a few centimeters per year (Washburn, 1980). According to McRoberts and Morgenstern (1974) freeze-thaw cycles in the active layer play an important role in solifluction movements. The importance of freeze-thaw cycles in solifluction movements is linked with the characteristic properties of the fine-grained soils common to solifluction slopes. During the autumn freeze-back period, fine-grained soils develop segregated ice lenses as water is attracted to the freezing front. This results in frost heave of the ground surface. Then, during the following thaw cycle, instability results because of the characteristic mechanical properties of low permeability and high compressibility of finegrained soil (McRoberts and Morgenstern, 1974). This instability can be further attributed to thawing of the active layer, which builds excess pore-water pressure at the base of the active layer, and thus decreases the friction and stability. Egginton and French (1985) found 
a)

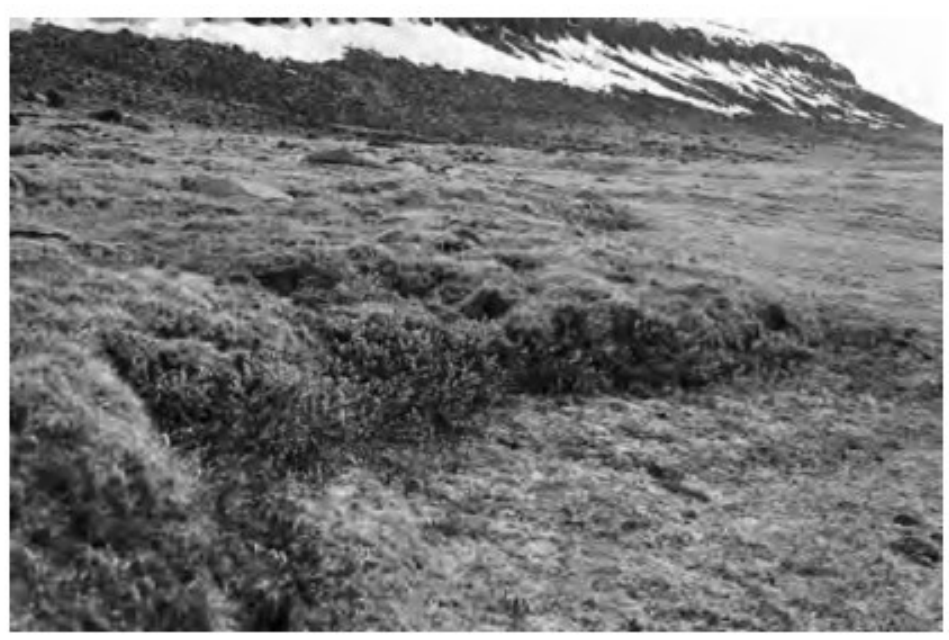

b)

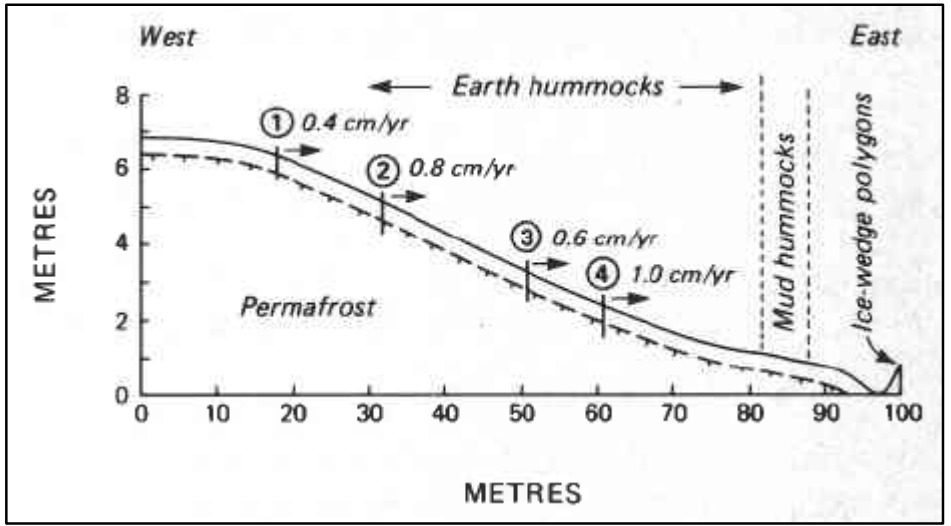

Figure 2.5 (a) A turf-banked solifluction terrace formed by the slow movement of soil downslope (near Holman, western Victoria Island, NWT, Canada) (from French, 2007), and (b) mean annual soil movement (cm/year) for the tops of plastic tubes inserted at Garry Island, N.W.T. for the (1964-1977) period (from Mackay, 1981). 
mean surface displacements with an average value of only $0.6 \mathrm{~cm} /$ year over the periods 1972-1983 on the hummocky moraine of eastern Banks Island. Mackay (1981) reported an average value of up to $1 \mathrm{~cm} /$ year in hummocky centres on Garry Island, N.W.T. (Figure 2.5b). Some rapid and more conspicuous soil movements have also been reported from Arctic and sub-arctic areas (Williams and Smith, 1991).

\subsubsection{Hill-Slope Geochemistry}

Mass movement processes such as solifluction and the subsurface flow of water have potential impacts on the geochemical characteristics of hill slopes. Seasonally frozen ground, (i.e. the active layer) undergoes a series of changes during its winter freezing and summer thawing. The influence of hill slope morphology on geochemistry could be explained using two endmember models related to: (a) solifluction, and (b) length of the flow path.

Solifluction transfers materials from a hilltop to the bottom of the hill (Figure 2.6). The hill top consists of relatively fresh materials which are recently exposed. The bottom of the hill contains the older material that has been subject to a long duration of downslope transport in the active layer and thus also to leaching. In addition, the leaching or leached material at the top is thinner due to dispersion of soil, while at bottom it is thicker due to the deposition of colluvium derived from further upslope. Mackay (1981) reported the slope movement to be plug-like in clayey hummocks at Garry Island, N.W.T., with burial of interhummock peat to form a widespread subsurface organic layer. This often leads to thicker colluvium associated with layers of organic materials near the base of hillslopes. According to Brown (1969) the distribution of soluble ions in soils, and perennially frozen 
ground is influenced by both the material and the present and past depositional and leaching environments. This suggests that on a hill slope, solifluction may play a significant role in generating contrasts in geochemical characteristics and soil organic carbon profiles. The fresh material at the hill top usually has a high soluble ion concentration while the material at the bottom of the hill is progressively depleted of ions along the pathway.

Second, geochemical contrasts between the points at a hill top and hill bottom also depend upon the nature and intensity of chemical and biogeochemical weathering, along the flow path. For example, excessive protons in soil can be produced through various processes, such as soil respiration (which increases the partial pressure of $\mathrm{CO}_{2}$ in the soil waters), and pyrite oxidation (which releases $\mathrm{H}^{+}$), which ultimately drives the carbonate dissolution (Woo and Marsh, 1977; Kling et al., 1992; Huh et al., 1998; and Slutter and Billet 2003). Similarly, Lacelle et al. (2008) discuss the importance of $p \mathrm{CO}_{2}$ to describe the difference in ion concentrations between the active layer and near the permafrost table. This study shows that in the active layer: 1) $p \mathrm{CO}_{2}$ of near-surface groundwater is lower than that of groundwater near the permafrost table; and 2) $p \mathrm{CO}_{2}$ of the groundwater near the permafrost table increases as we move downslope, because of the large volume of meltwaters passing through the sediments. This affects the ion concentrations, being higher at the bottom of the hill due to higher acidity along a longer flow path, while lower at the top of a hill due to lower acidity and shorter flow paths (Figure 2.7).

It is expected that both of these processes, i.e. solifluction and water movement, may occur on hill slopes in periglacial regions on different time scales. In this study, permafrost samples are collected from diverse locations on hillslopes to determine whether geochemical conditions vary between erosive and depositional permafrost environments. 


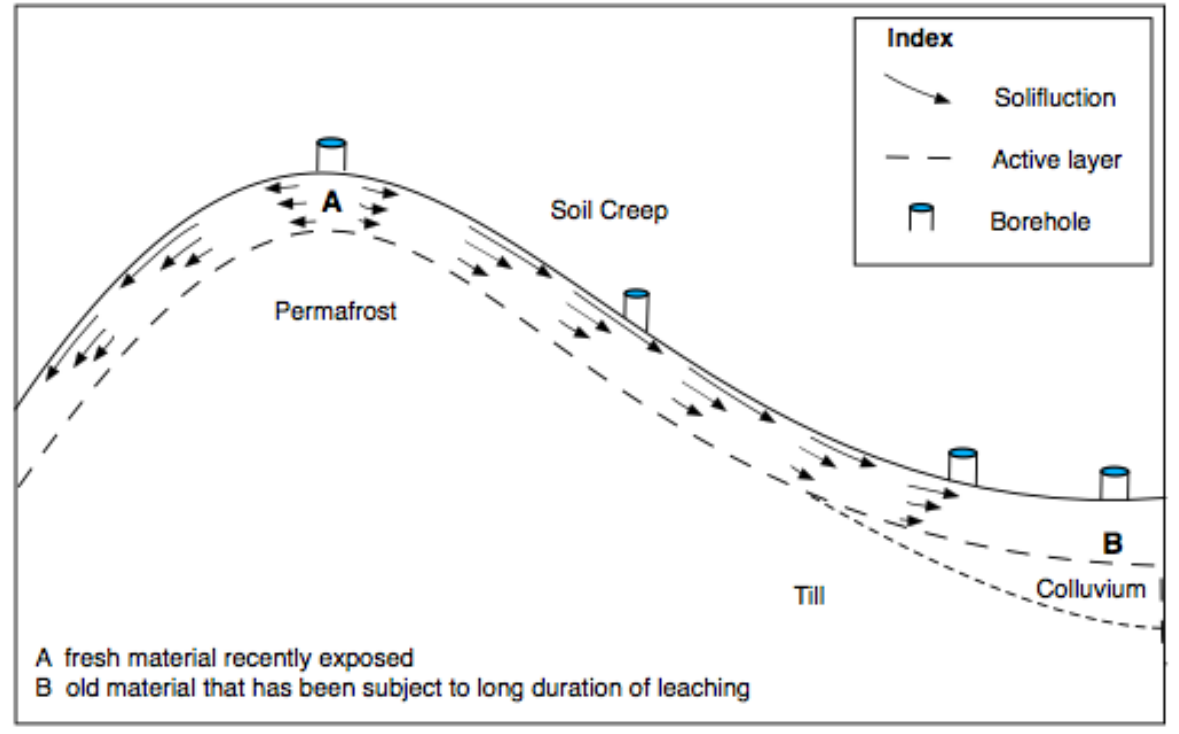

Figure 2.6 The possible relation between hill slope morphology and geochemistry as explained by mass movement process (solifluction).

Length of the Flow Path Through Soil

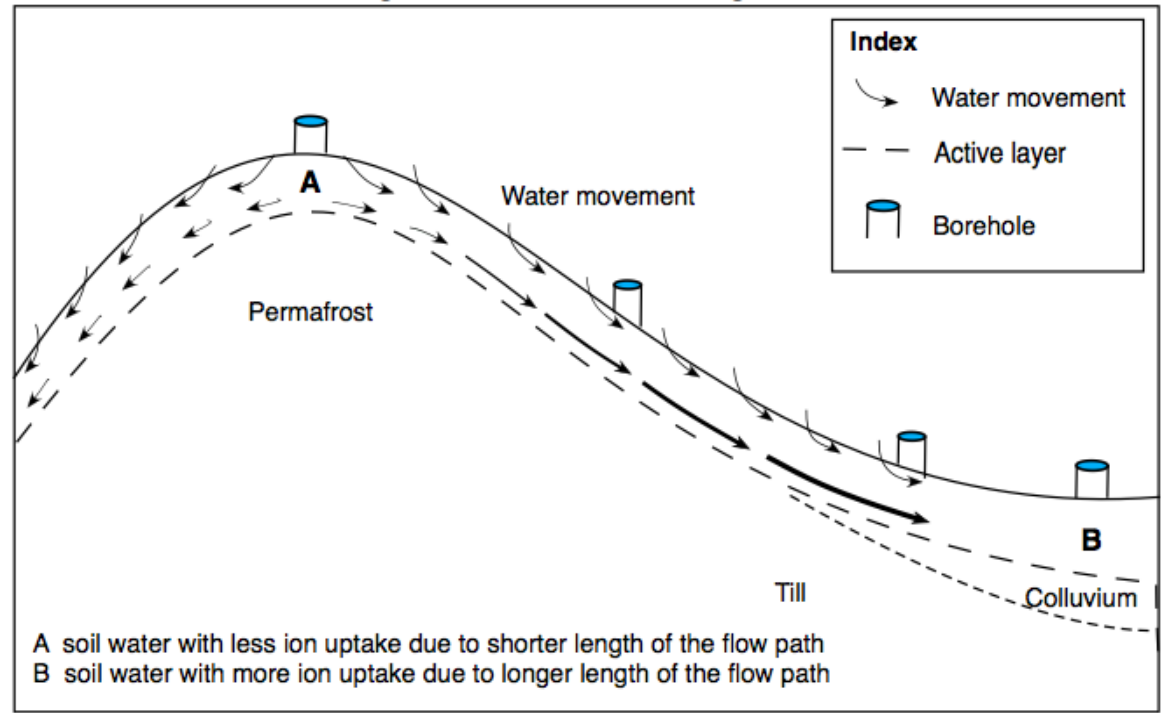

Figure 2.7 The possible relation between hill slope morphology and geochemistry as explained by water movement along the flow path. The darker longer arrows towards the slope and near the bottom of the hill represent increasing water content due to increase in the catchment area, and hence the potential for more leaching due to higher acidity. 


\subsubsection{Organic Matter in the Active Layer and in Permafrost}

Cryoturbation is an important process responsible for the transport and sequestration of organic materials into the active layer and near-surface permafrost (Bockheim, 2007). The influence of cryoturbation in sequestering organic materials in permafrost soils normally concerns shallow (1-3 m) depths (Tarnocai et. al., 2009). As the soil temperature falls below $0{ }^{\circ} \mathrm{C}$, pore water within the soil successively freezes and expands. This expansion as well as the formation of ice lenses by water migration to the freezing front leads to heaving and moves soil towards the surface (upwards). In some cases, this upward displacement of materials also results to form mound shaped features known as hummocks (Mackay, 1980). When the ice melts, this results in the subsidence of the previously frozen soil mass, and materials are transported downwards (Diochon et al., 2013). This repeated and laterally heterogeneous process of heaving and subsidence transfers and mixes organic-rich materials from the surface to the bottom of the active layer, and in some cases to the surface (Diochon et al., 2013). This gives rise to the characteristically broken or irregular soil horizons commonly associated with cryoturbation. Large quantities of organic materials can be transported by cryoturbation into the active layer and from there be incorporated into near-surface permafrost where conditions are not conducive for decomposition (Kaiser et al., 2007). Other possible

mechanisms include the burial of surface organic matter followed by permafrost aggradation which transfers organic matter content into the deeper horizons (e.g. Kokelj et al., 2009; O'Donnell et al., 2011).

There is relatively good understanding of the vertical (soil horizon) partitioning of the permafrost carbon pool in the upper $3 \mathrm{~m}$ of soils. However, deeper carbon pools in 
unconsolidated Quaternary deposits need to be better constrained (Kuhry et al., 2013). For example, deltaic, alluvial and yedoma deposits, are predicted to contain large amounts of organic carbon below $3 \mathrm{~m}$ depth (Tarnocai et al., 2009) which are at potential risk of thawing (Schuur et al., 2008). Several other deposits in permafrost have been reported from northern Siberia which are predicted to contain large SOC mass (Schirrmeister et al., 2002). These include the typical ice-rich, fine-grained 'Yedoma Ice Complex' of the late Pleistocene mammoth tundra-steppe, Holocene and Weichselian peat and fluvial deposits, lacustrine deposits in (former) thermokarst depressions and older Ice Complex deposits. These deposits vary greatly in carbon contents $(0.5-10 \%$ of dry weight). 


\section{CHAPTER 3. STUDY AREA AND METHODS}

\subsection{Study Area}

\subsubsection{Location and General Characteristics}

The study area is located in the Lac de Gras region of the Slave Geological Province, Northwest Territories. It is situated north of tree line, approximately $320 \mathrm{~km}$ northeast of Yellowknife and $200 \mathrm{~km}$ south of the Arctic Circle. The study area is in the continuous permafrost zone (Figure 1.1). Permafrost in this region is estimated to be more than $460 \mathrm{~m}$ thick (Canamera Geological, 1996).

The Lac de Gras area lies in the Bear Slave Upland physiographic region of the Canadian Shield, and is characterized generally by low relief (Hu et al., 2003). The area was covered by the Laurentide ice sheet and now glacial deposits form the most prevalent surface materials (Dredge et al., 1999). The region includes a wide range of terrain units (Figure 3.1). Most of the area is overlain by till often differentiated as till veneer $(<2 \mathrm{~m}$ thick), till blanket (2 to $10 \mathrm{~m}$ ), and hummocky till (5 to $30 \mathrm{~m}$ ) (Wilkinson et al., 2001). Similarly, bedrock with a thin, patchy veneer of glacially derived surficial soils is exposed over a considerable area, and irregular bedrock knobs and cuestas form hills up to $50 \mathrm{~m}$ high (Dredge et al., 1999). Numerous, eskers and outwash complexes are found in the Lac de Gras area (Dredge et al., 1994). Other terrain types in the region include organic deposits, peatlands, as well as earth hummocks in valleys. The area also contains some of the oldest rocks on earth and is well known for a long history related to mining and development (Karunaratne, 2011). The area is characterized by three main lithological units, namely: 1) greywacke-mudstone metaturbidites (metasedimentary rocks), 2) biotitehornblende tonalite to quartz diorite (diorite), and 3) 2-mica granite and suite (granite to 


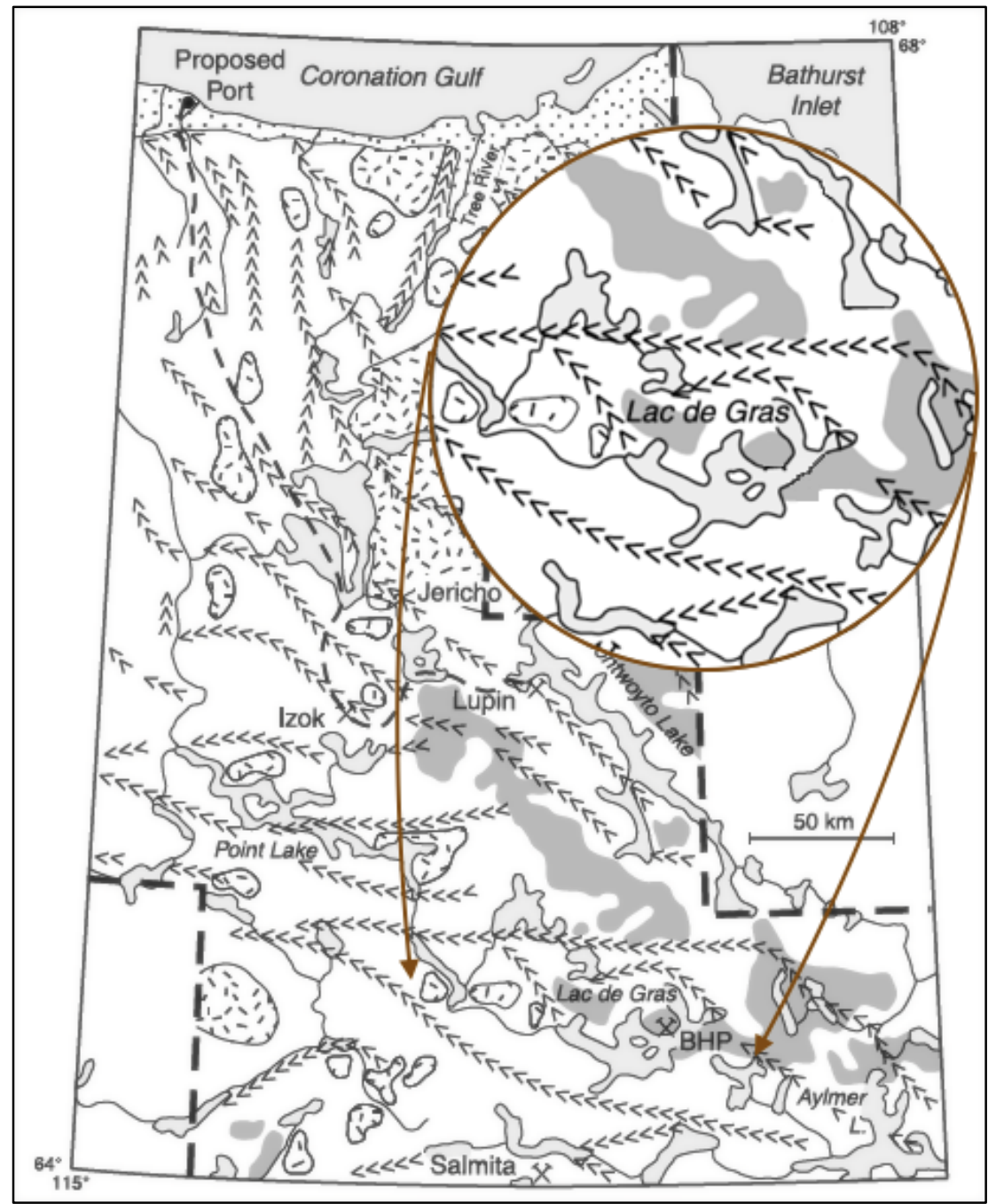

\section{TERRAIN UNITS}

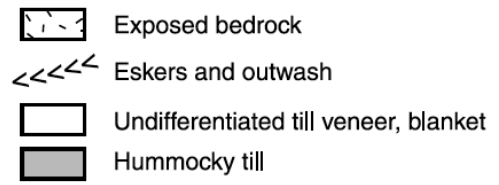

Figure 3.1 Surficial sediments and terrain units in the Lac de Gras area (circle). Modified from Dredge et al. (1999). 
granodiorite) (Hu et al., 2003). The metasedimentary rocks in the area belongs to the Yellowknife Supergroup and are comprised of thinly-bedded metagreywacke to locally thick-bedded porphyroblastic schists (Kjarsgaard and Wyllie 1994). At the surface, weathered materials from porphyroblastic schists with a dark grey to green-brown or rusty brown colour are typically avalable. The granitic rocks are usually light grey, fine to pegmatitic and are comprised of biotire, muscovite and portions of quartz, plagioclase and potassium feldspar. Some accessory minerals include apatitite, tourmaline and garnet $(\mathrm{Hu}$ et al., 2003).

\subsubsection{Surficial Geology}

All glacial features in the Lac de Gras area were conditioned by the Late Wisconsinan Laurentide ice sheet, which retreated about 9000 years ago (Kerr et al., 1997). The surficial soils consist predominantly of ablation till or glaciofluvial sediments. The northern half of the region is dominated by silty sand till deposits while the southern half consists of granitic bedrock with minor till deposits (Hu et al., 2003). Generally, however, the till is characterized by a silty sand to sand matrix with low percentages of clay, and contains 5 to $40 \%$ gravel (Wilkinson et al., 2001). Till derived from granitic and gneissic terrain has a slightly silty, sandy matrix, whereas, till derived from metasedimentary rocks contains a higher silt-clay content (Dredge et al., 1999).

Solifluction, freeze-thaw cycles and low temperatures have led to a range of periglacial features such as boulder fields, frost mounds and patterned ground (Hu et al., 2003). These processes have contributed to the development of large solifluction lobes on some slopes, especially on the drumlin flanks in terrain underlain by sedimentary rock 
where the tills are slightly plastic (Dredge et al., 1999). Due to the large modification of upper 0.5 to $1 \mathrm{~m}$ of soil by cryoturbation, organic material has been sequestered at depths of up to $80 \mathrm{~cm}$ (Dredge et al., 1994).

\subsubsection{Climate}

The regional climate is continental, with summers cool and short, and winters cold and extremely long (Hu et al., 2003). However, there are differences in the mean annual air temperature (MAAT), and precipitation across the region. Yellowknife, located approximately $320 \mathrm{~km}$ southwest of Lac de Gras area has a MAAT of $-4.2^{\circ} \mathrm{C}(1981-2010)$, and daily mean temperatures above $0{ }^{\circ} \mathrm{C}$ from May to September (Environment Canada, 2016). July is usually the warmest month $\left(17^{\circ} \mathrm{C}\right)$, and January is typically coldest $\left(-26^{\circ} \mathrm{C}\right)$ (Figure 3.2). Total annual precipitation at Yellowknife is $293 \mathrm{~mm}$ and the majority falls in the summer and autumn (Figure 3.2). In contrast, Lupin, a gold mine in Nunavut approximately $100 \mathrm{~km}$ northwest of Lac de Gras (Figure 3.1), has a MAAT of $-10.9{ }^{\circ} \mathrm{C}$ (1982-2006), and daily mean temperatures above $0{ }^{\circ} \mathrm{C}$ from June to September (Environment Canada 2016). The warmest and coldest months at Lupin are also July and January however, with mean monthly air temperatures of $12{ }^{\circ} \mathrm{C}$ and, $-30{ }^{\circ} \mathrm{C}$ respectively (Figure 3.2). Annual precipitation at Lupin is slightly greater than at Yellowknife, with a total of $298 \mathrm{~mm}$ (Figure 3.2). Ekati has a MAAT of $-8.9^{\circ} \mathrm{C}(1998-2008)$ with a maximum monthly temperature of about $14{ }^{\circ} \mathrm{C}$ in July and a minimum monthly temperature of $-28{ }^{\circ} \mathrm{C}$ in January (Figure 3.2) (Environment Canada 2016). Total annual precipitation at Ekati is $275 \mathrm{~mm}$. 

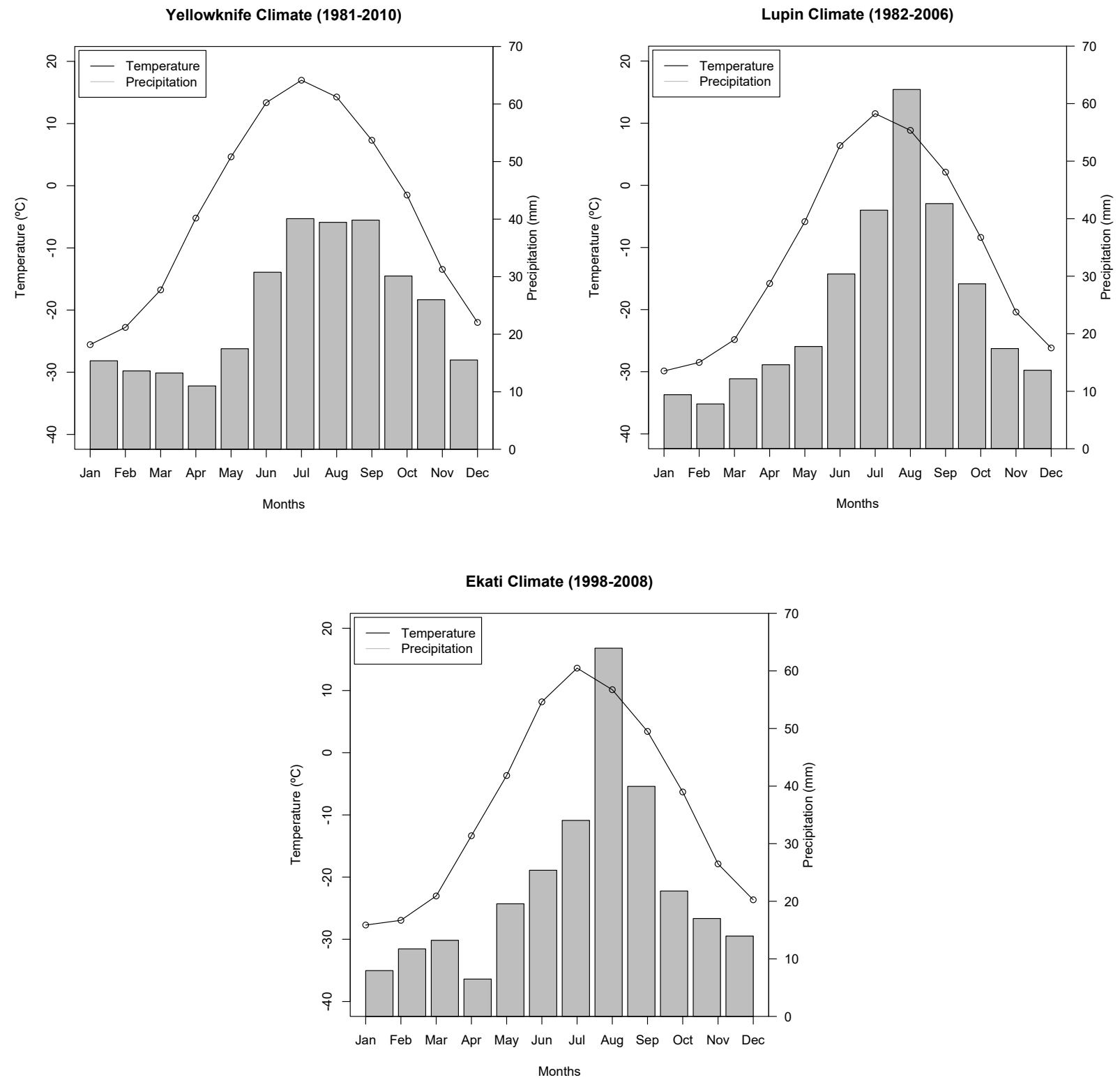

Figure 3.2 Mean monthly air temperature (circles), and mean monthly precipitation (bars) for Yellowknife Airport (1981-2010), Lupin Airport (1982-2006) and Ekati Airport (1998-2008) respectively (Environment Canada 2016). 


\subsubsection{Vegetation}

The project area is characterized mainly by continuous shrub tundra (Wiken et al., 1996). Common shrubs in the area include Northern Labrador Tea (Rhododendron tomentosum), and Dwarf Birch (Betula glandulosa), while Bog Cranberry (Vaccinium vitis-idaea) and Dwarf Bog Rosemary (Andromeda polifolia) are the dominant short shrubs (Karunaratne, 2011). The upland areas are often covered with a thin layer of lichens and mosses, due to well-drained soil conditions (Hu et al., 2003). Sphagnum spp. mosses also colonize many wetlands (Karunaratne, 2011). The most common species of lichens are Cladina spp. and Cladonia spp. while Aulacomnium turgidum and Rhacomitrium lanuginosum are the typical mosses (Karunaratne, 2011). Vegetation in valleys and low-lying areas consists mainly of coarse grasses, mosses, and peat, due to poorly-drained soil conditions ( $\mathrm{Hu}$ et al., 2003). The vegetation is lush along drainage courses, and in wet areas where willows (Salix spp) can be as tall as $2 \mathrm{~m}$ (Hu et al., 2003). In addition, lowlying depressions in this area also have thick deposits of peat associated with ice-wedge polygons and sedge meadows, underlain by fine-grained materials (Karunaratne, 2011).

\subsubsection{Permafrost}

In the Lac de Gras area, permafrost is estimated to be more than $460 \mathrm{~m}$ thick (Canamera Geological, 1996), however this varies considerably depending on local site conditions. Factors such as the mean annual ground temperature, thermal properties of earth materials, and proximity to water bodies contribute to this variability (Williams and Smith, 1991). The mean annual ground temperatures at a depth of $20 \mathrm{~m}$ range between -3 ${ }^{\circ} \mathrm{C}$ to $-6{ }^{\circ} \mathrm{C}$ (Hu et al., 2003). The depth of the active layer varies with vegetation cover, 
subsurface material type, and moisture conditions (Dredge et al., 1999). Active layer thicknesses range from a few tens of $\mathrm{cm}$ thickness in areas with a thick organic mat to over $2 \mathrm{~m}$ thickness in well drained granular deposits (Dredge et al, 1999; Hu et al., 2003). Thicknesses can exceed $5 \mathrm{~m}$ in bedrock (Hu et al., 2003).

\subsection{Study Design}

Lac de Gras is an ideal site for the study of permafrost geochemistry and organic carbon because the environmental conditions of this region distinguish it from other more intensively studied permafrost areas. The Lac de Gras region, characteristic of the broader Bear-Slave uplands is a bedrock dominated landscape veneered by glacial sediments. As most of the area is overlain by till, organic deposits and eskers (Dredge et al., 1999), this study uses these established surface types from the region, i.e., peatlands and wetlands, till blanket, till veneer and eskers as terrain units to investigate the spatial variability in permafrost geochemistry and organic carbon. The majority of studies in permafrost geochemistry compare water, soluble cations and organic carbon across only shallow depths, i.e., in the active layer and near-surface permafrost. However, in the present study permafrost cores have been obtained from depths up to $10 \mathrm{~m}$, and thus the vertical distribution of water, soluble cations and organic carbon are compared between three layers: the active layer, near-surface permafrost and permafrost at depth. In this regard, the study is different from most other studies related to permafrost geochemistry.

The results of cation and carbon contents derived from this study can be compared to those from other areas in northern Canada (e.g. Kokelj et al., 2002; Kokelj and Burn, 2003; Fontaine, 2016), including alluvial environments such as Mackenzie Delta (e.g. 
Smith, 1975; Kokelj and Burn, 2005), or regions with thick carbonate-derived tills (Kokelj and Burn, 2003; Lacelle et al., 2013). Therefore, patterns of geochemistry and organic carbon from the Lac de Gras region can be compared with these contrasting depositional environments.

\subsubsection{Site Selection}

The selection of sites was based on the LiDAR and imagery dataset provided by the Dominion Diamond Ekati Corporation. LiDAR data was collected in twelve flights between July $23^{\text {rd }}$ and August $11^{\text {th }} 2013$, and was made available at $1 \mathrm{~m}$ grid resolution. As the surficial conditions (relief, vegetation, drainage, snow, soil and rock characteristics) play a significant role in determining the conditions of permafrost, the collected data were interpreted in the context of the following attributes: slope-angle, potential direct solarradiation, and Topographic Wetness Index (TWI) computed from the LiDAR data. In addition, a Landsat-derived index outlining the location of late-lying snow drifts was available for the area. This helped in determining landscape variability and prioritizing areas representative of different environmental settings including a range of moisture, vegetation and soil conditions in peatlands, hilltops, hill slopes, hill bottoms, highly vegetated surfaces, and earth hummocks and depressions, which were then used for site selection and borehole placement. Twenty-four boreholes were selected using this approach in different terrain types such as peatlands and wetlands, till blankets, till veneer and eskers. The location of boreholes across various terrain types is shown in Figure 3.3. 


\subsubsection{Limitations of Site Selection}

There are several limitations associated with the site selection of this study. For example, no boreholes were drilled in block fields despite their importance in the landscape. Furthermore, problems arose when attempting to drill at many sites from Hill 2 and Hill 3 groups. At Hill 2 and Hill 3, there were some boreholes which got obstructed when drilled to a few centimeters because they were underlain by bedrock. As a result, they had to be abandoned. This affected the total number of boreholes available and the diversity of surface conditions that are sampled.

\subsubsection{Site Grouping Details}

Boreholes were grouped according to their proximity to each other and respective terrain types to provide an idea of the geographical location of boreholes. This was also carried out to facilitate the comparison of water content, soluble cations and organic carbon across sites within the same terrain type. For example, two different sites from till blanket terrain could be compared with each other between a hilltop and hill bottom. Table 3.1 shows seven site groups used for the current study. The Control group represents two boreholes that were drilled next to each other (within $5 \mathrm{~m}$ distance) in peatlands and wetlands. Peatland is a term used to encompass peat-covered terrain (Rydin et al., 2013). A wetland is defined as: land that is saturated with water long enough to promote wetland or aquatic processes as indicated by poorly drained soils, hydrophytic vegetation and various kinds of biological activity which are adapted to a wet environment (National Wetlands Working Group 1988). Hill 1 represents six boreholes drilled at various locations within a till blanket in hilly terrain near the Control group. Hill 3 represents two boreholes 


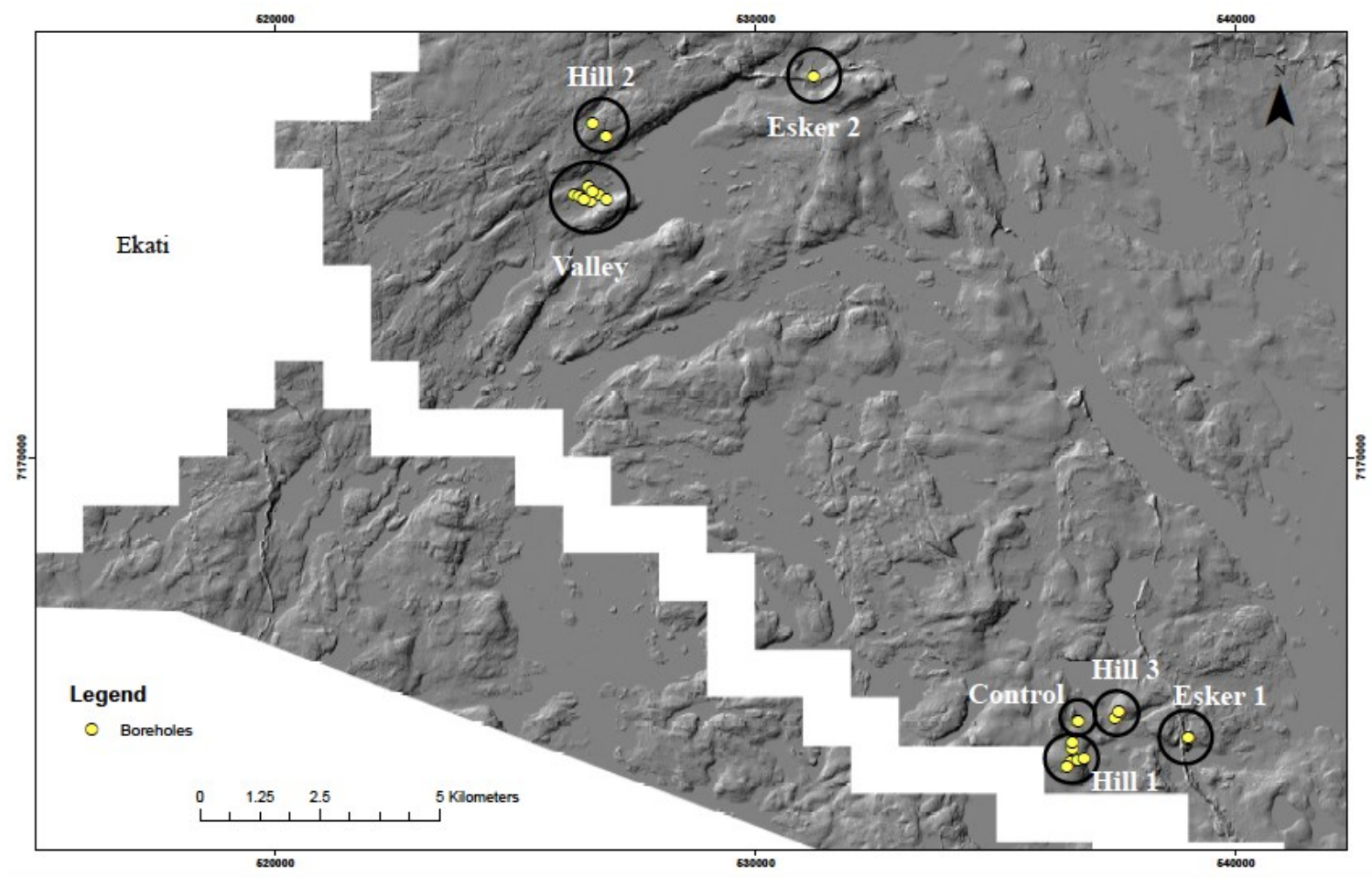

Figure 3.3 Locations of boreholes used for this study in the Lac de Gras area. The grey hillshade shows the area covered by the LiDAR DEM. The diamond mine (Ekati) infrastructure as well as areas not covered in the DEM acquisition are shown by white spaces. 
Table 3.1 Site groups representing boreholes located within proximity and similar regional setting

\begin{tabular}{|c|c|}
\hline Site Groups & Borehole ID (NGO-DD15- ) \\
\hline Control & 1006,1007 \\
\hline Hill 1 & 1014,2018 \\
\hline Hill 2 & 2009,2033 \\
\hline Hill 3 & 2016,2019 \\
\hline Valley & $2008,2028,2029$ \\
\hline Esker 1 & 2026 \\
\hline Esker 2 & \\
\hline
\end{tabular}


in a till blanket in hilly terrain to the east of the control group. Boreholes drilled at both hill sites reflected a range of surface conditions with respect to their slope, solar radiation, steepness, vegetation and wetness index. In addition, both Hill 1 and Hill 3 sites were characterized by frost boils and small solifluction lobes. Figure 3.4 shows the boreholes in the Control group, Hill 1 and Hill 3. Hill 2 represents two boreholes in a till veneer. The Valley group contains the largest number of boreholes drilled in two transects having varying slope, radiation, snow drift persistence and wetness conditions. Figure 3.5 shows the location of Hill 2 and the Valley. Finally, Esker 1 and Esker 2 represent four boreholes that are drilled in two different esker complexes. Figure 3.6 and Figure 3.7 show the location of the two esker sites.

\subsubsection{Site Classification}

Four different terrain types were compared, i.e., peatlands and wetlands, till blanket, till veneer and eskers. Previous studies related to geochemistry employed various formats to compare the sites of interest. For example, at Herschel Island sites were classified as disturbed vs. undisturbed terrain based on the range of surface conditions encountered on the island (Kokelj et al., 2002). In the Mackenzie Delta region, a range of forest-terrain types were considered as terrain types for site classification (Kokelj and Burn, 2005). In the present study, sites were classified on the basis of established terrain units that were local to Lac de Gras area (Figure 3.1, Table 3.2). This was done in order to represent a heterogeneous landscape, through sampling of different terrain types, to investigate the spatial variability that exists in water, organic carbon and soluble cations. 


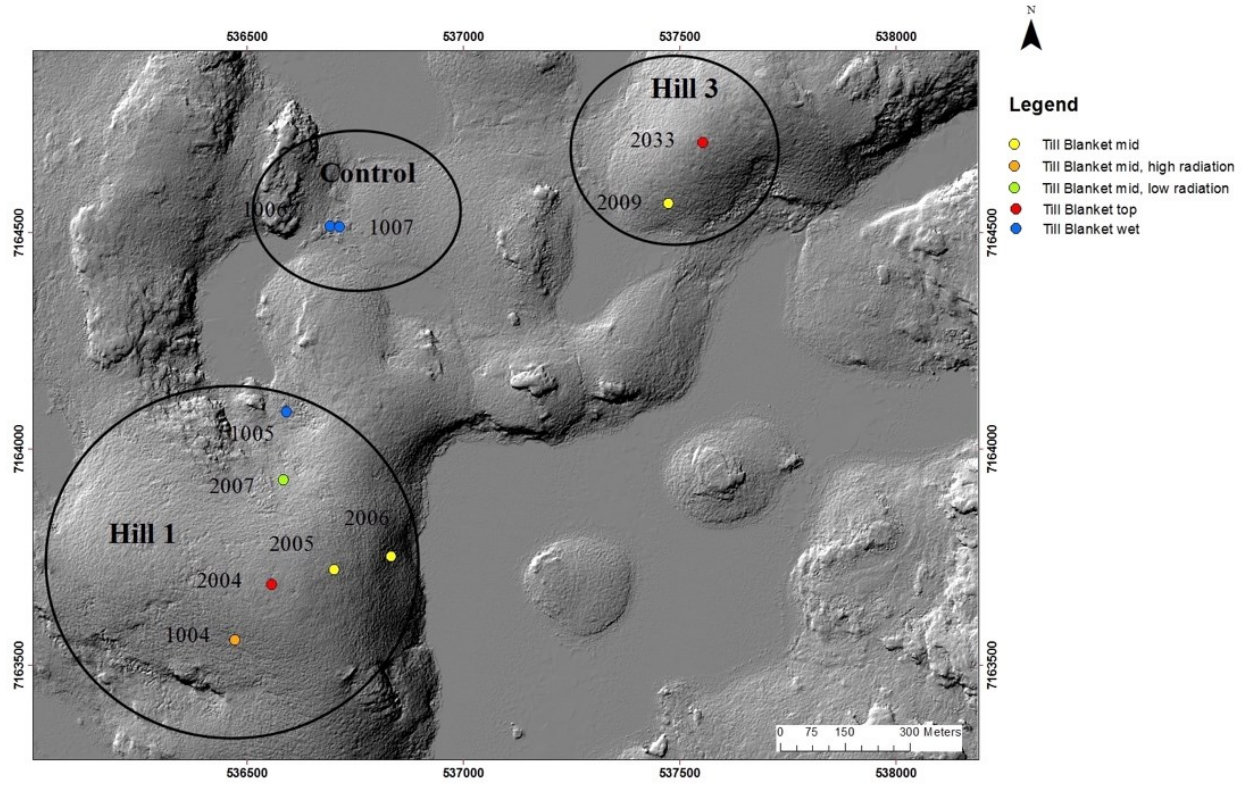

Figure 3.4 Borehole locations from the Control group, Hill 1 and Hill 3.

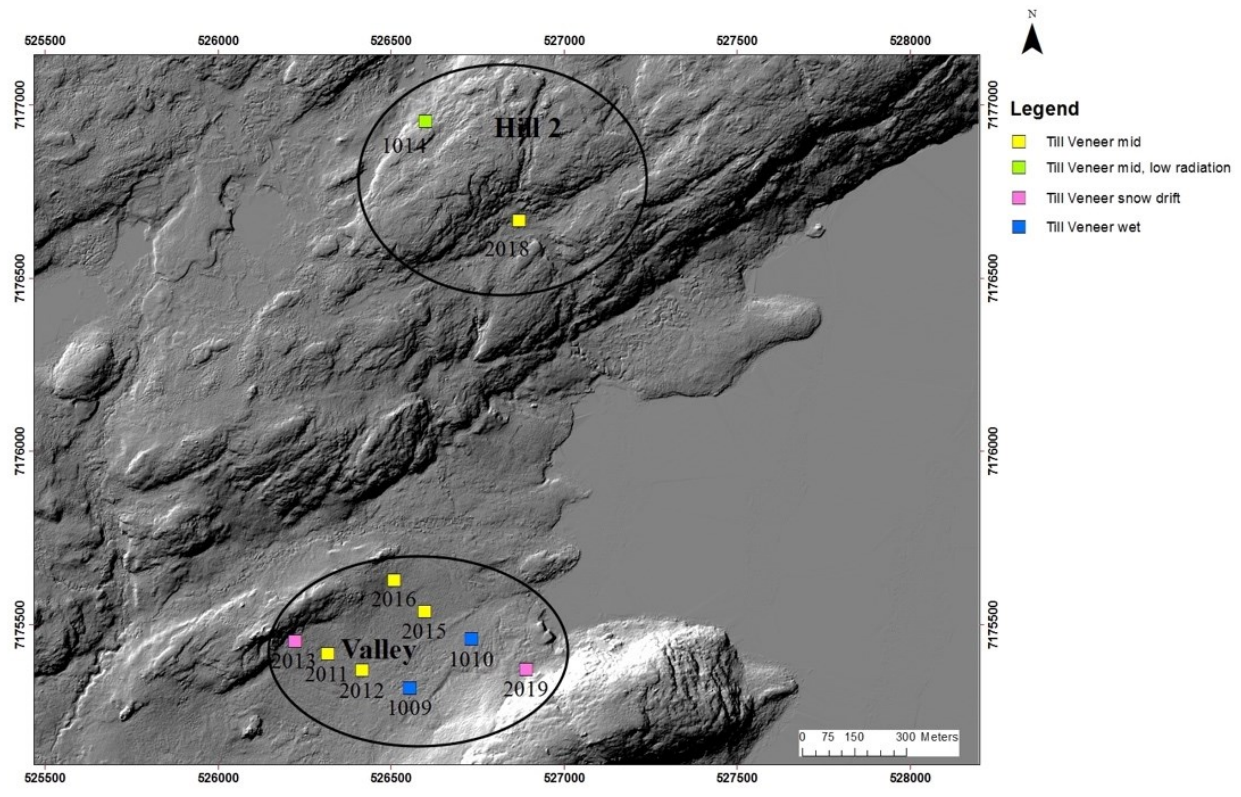

Figure 3.5 Borehole locations Hill 2 and Valley. The Valley group contains the largest number of boreholes drilled in two transects across various regional conditions. 


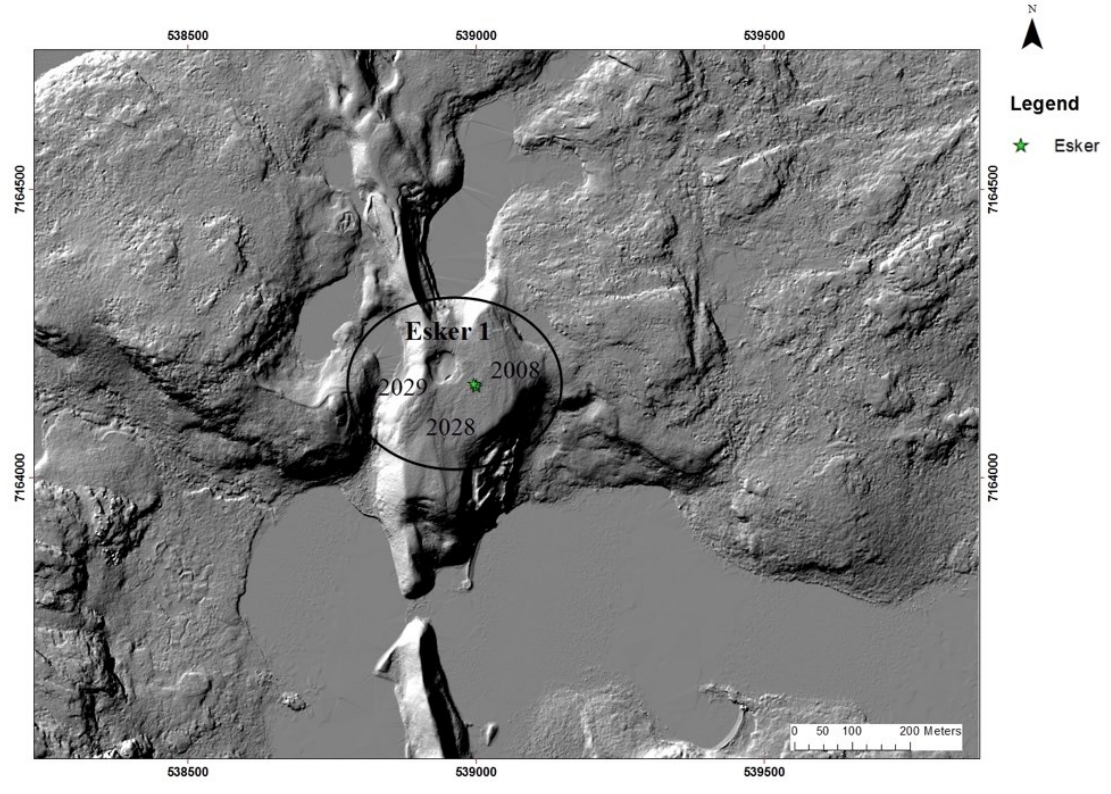

Figure 3.6 Esker 1, where 3 boreholes were drilled in proximity to compare the small-scale variability in geochemistry and organic carbon.

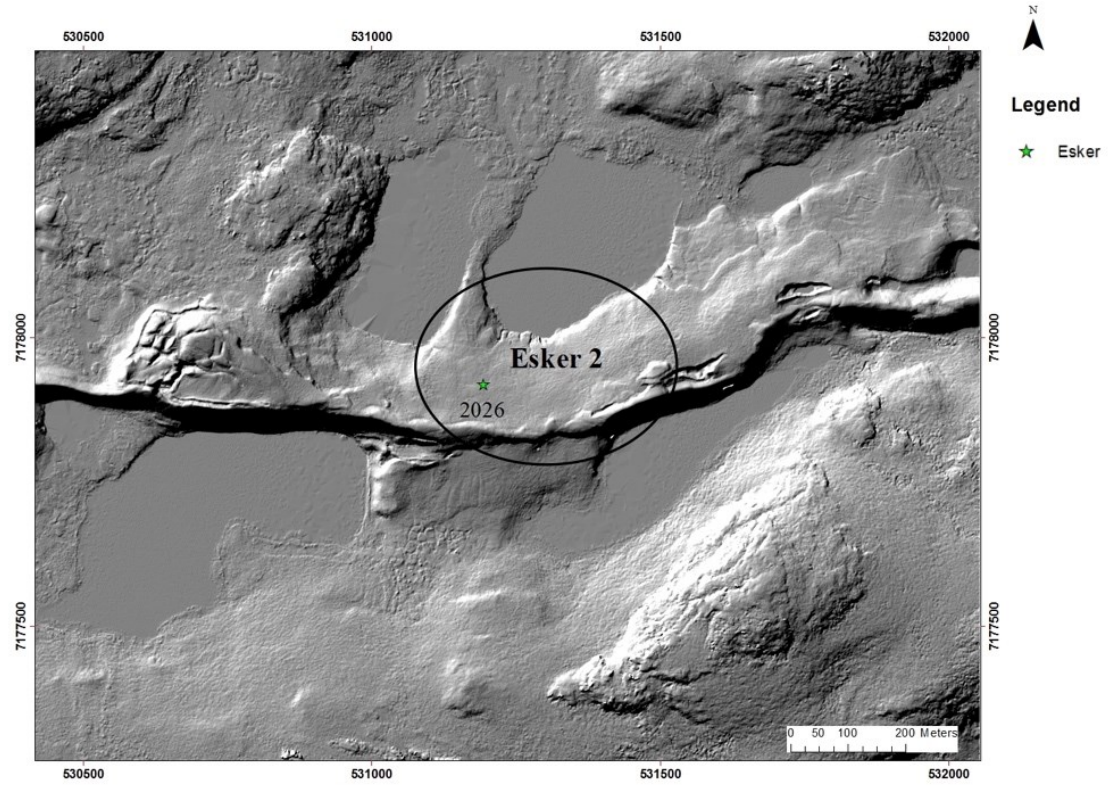

Figure 3.7 Location of Esker 2 containing a single borehole in its terrain. 
Table 3.2 Site classification of boreholes based on the terrain units

\begin{tabular}{|c|c|c|c|}
\hline Terrain Units & $\begin{array}{c}\text { Borehole ID (NGO- } \\
\text { DD15- ) }\end{array}$ & $\begin{array}{c}\text { Includes Site } \\
\text { Groups From }\end{array}$ & $\begin{array}{c}\text { Total Number of } \\
\text { Boreholes }\end{array}$ \\
\hline Till Blanket & $\begin{array}{c}1004,2004,2005,2006, \\
2007,2009,2033\end{array}$ & Hill 1 and Hill 3 & 7 \\
\hline Till Veneer & $1014,2013,2016,2018$, & Hill 2 and Valley & 5 \\
\hline Peatlands and & $1005,1006,1007,1009$, & Control group, Hill & 8 \\
\hline wetlands & $1010,2011,2012,2015$ & 1 and Valley & \\
\hline Eskers & $2008,2028,2029,2026$ & Esker 1 and Esker 2 & 4 \\
\hline
\end{tabular}




\subsection{Field Methods}

\subsubsection{Plot Design}

Upon arrival at the field site a $15 \mathrm{~m}$ by $15 \mathrm{~m}$ plot was centered around the borehole location and was delineated by wooden dowels placed in each corner. For each plot, observations of vegetation, topography, and surficial permafrost features were recorded. In addition, photographs were taken from all four sides of the plot facing towards the North, South, East, and West for reference. Following this, two soil pits were dug just outside the plot, aiming to sample similar surface conditions to those of the plot. A graphical representation of the plot design is shown in Figure 3.8. The idea behind selecting two extra soil pits was to carry out additional active layer measurements which would have been difficult to carry out at the drill site. A brief explanation of the measured variables from the exterior pit is given in Section 3.3.4.

\subsubsection{Borehole Core Extraction}

Borehole drilling was carried out using a diamond drilling rig (Kryotek Compact Diamond Sampler) operated by field drillers and an Aurora Geosciences geologist (Figure 3.9). This drilling machine extracts cores of $5 \mathrm{~cm}$ diameter. The length of the core segment was measured for every run using a measuring tape after it was removed from the barrel (Figure 3.9). Similarly, the depth of the borehole was measured after each run by sliding the measuring tape to the bottom of the borehole and taking the reading. When drilling to greater depths, the depth of the borehole was determined by first measuring the core segment of the barrel placed at the bottom of a run and adding the length of the barrel stacked on top. 
a)

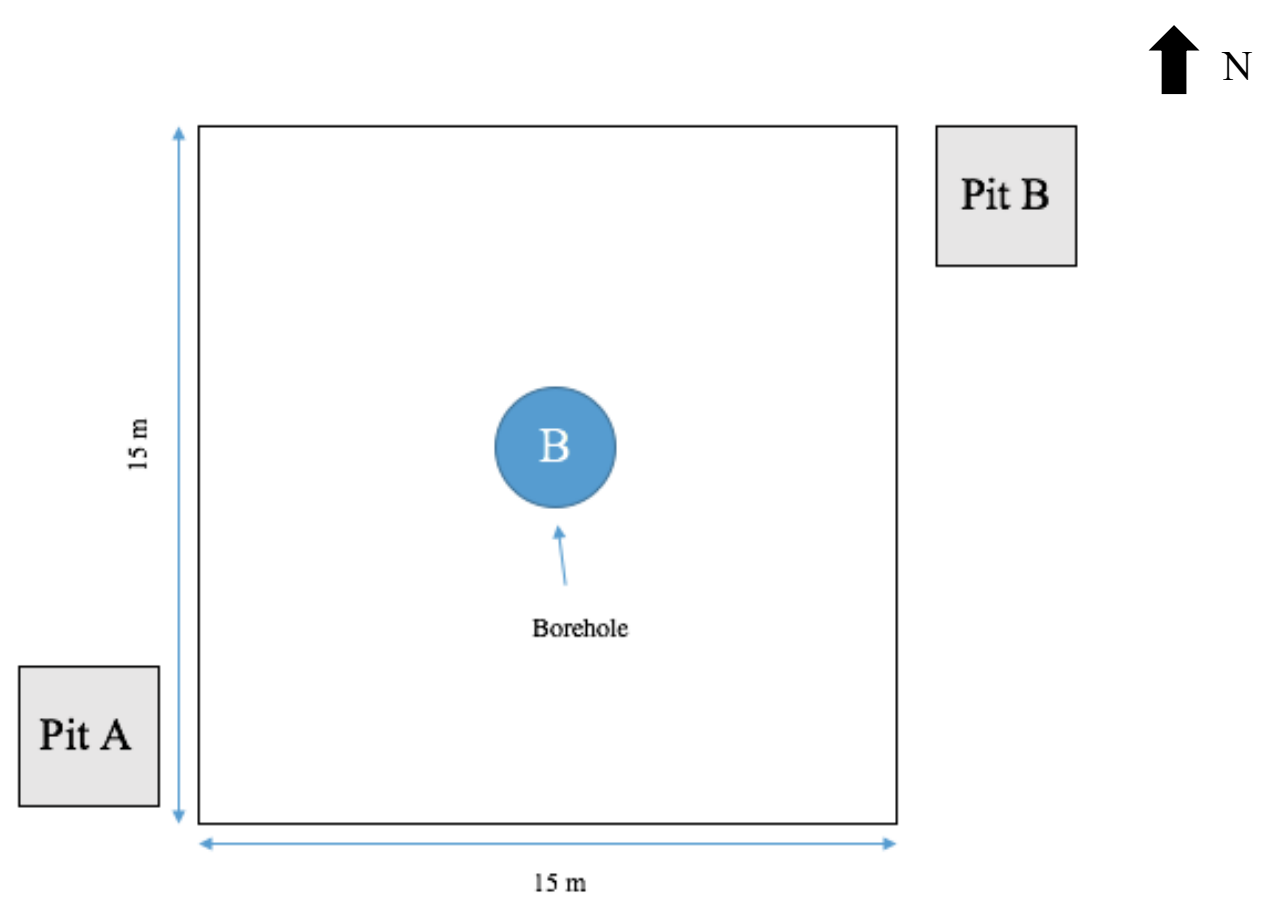

b)

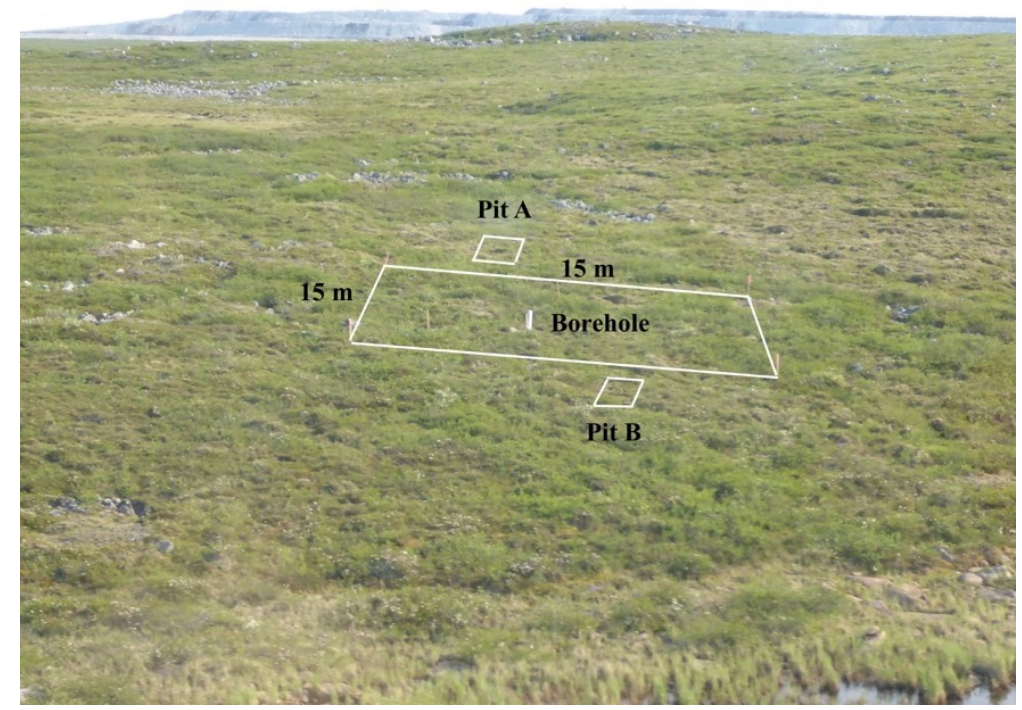

Figure 3.8 (a) Graphical representation of the plot design; (b) the position of the exterior pit varies at each site depending upon the surface conditions. 
a)

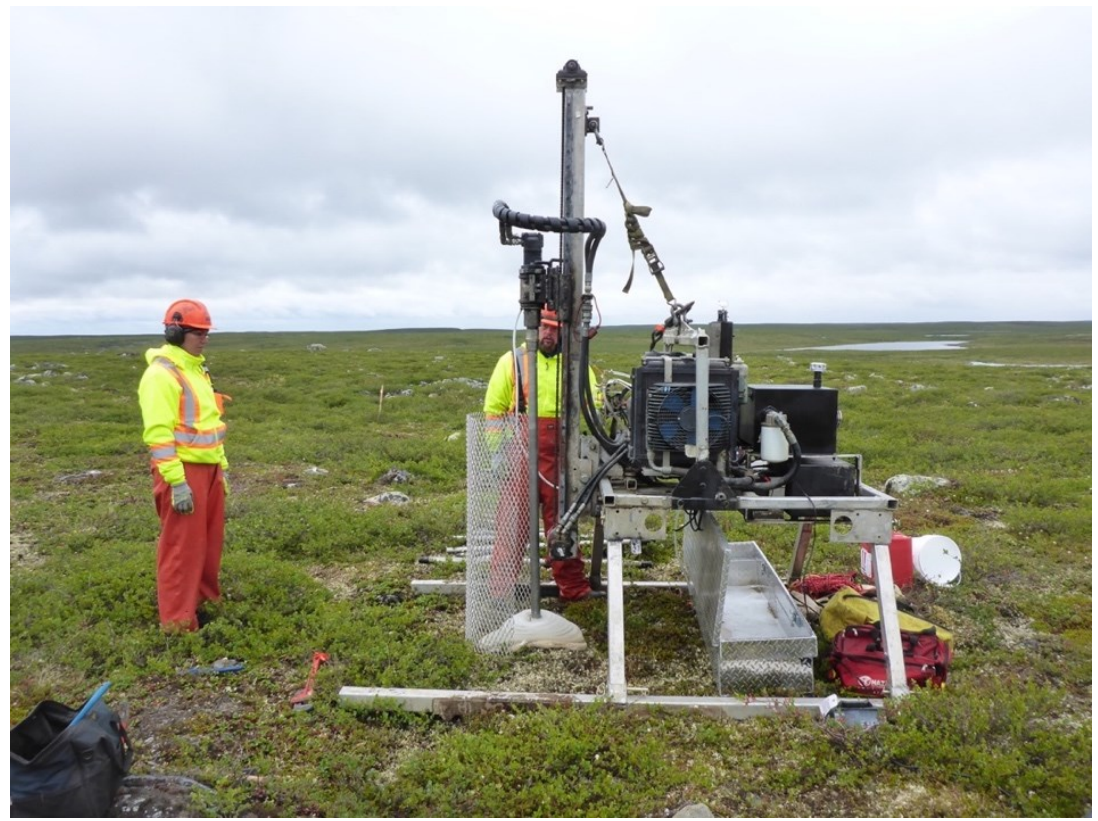

b)

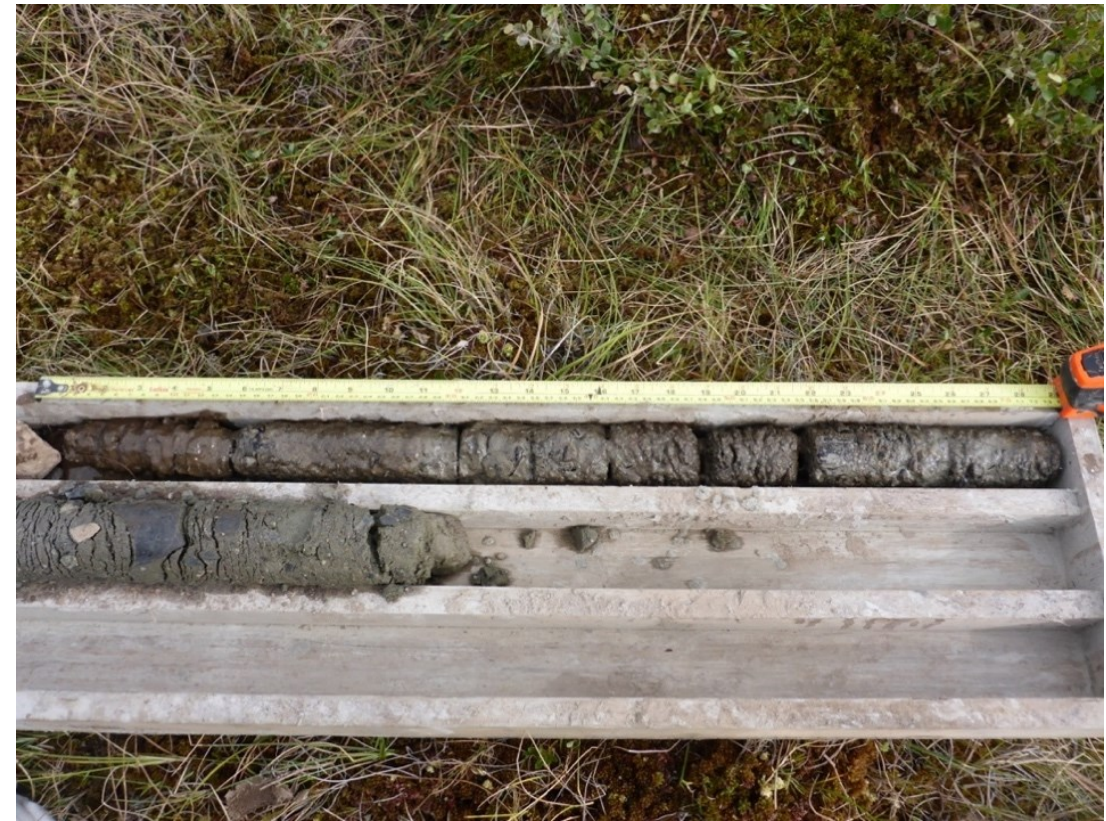

Figure 3.9 (a) Field use of diamond drilling rig (Kryotek Compact Diamond Sampler); (b) typical core segment. 
All core segments were sectioned into $20 \mathrm{~cm}$ intervals using a hammer and a chisel. The sectioned cores were examined carefully to record their general characteristics. This included soil type (texture), colour, ice content and visible organic matter. All records were maintained in a well-labelled drill $\log$ sheet. An example of a log sheet is attached in the Appendix A. After this, each section was kept in a well-labelled sample bag, which was doubled to avoid any leakage. Finally, the sample bags were made ready for transport to a laboratory in Yellowknife.

\subsubsection{Limitations of Field Measurements}

There are some uncertainties associated with field measurements in this study. Discrepancies existed between the total length of the core segments and the borehole depth. This was especially the case in lower parts of the boreholes. As core segments would stick to the bottom of the borehole, they had to be broken up into pieces to take them out. As a result, core segments would break, introducing a measurement error. Similarly, ice rich samples would often stick into the barrel so they had to be hammered many times before they could be taken out. Core segments were sometimes broken and accurate measurements could not be made. When there were discrepancies between the measurements, the borehole depth was used to determine the length of the core segment. Lastly, the depth of thaw at the time of sampling could not be measured accurately at the drilled locations. However, the sectioned cores were classified as being either frozen or unfrozen and the respective samples from permafrost and the overlying layers were distinguished. 


\subsubsection{Exterior Pits}

Two soil pits representative of plot conditions were excavated adjacent to each plot using a shovel. Pits were dug either to the maximum depth of thaw, or to a depth of $50 \mathrm{~cm}$ whichever was encountered first. A pre-labelled graduated scale bar was inserted into the pits to measure the depth of thaw at each site. An average was taken across two different pits and was considered as the active layer thickness of each site. Despite the fact that coring was undertaken in late July and early August, the depth of thaw at the time of coring was considered to be "active layer" thickness. As digging was carried out using a shovel, active layer thickness could be determined for only few sites.

A $\log$ sheet was maintained for each pit to record its general characteristics. This included soil type, colour, horizons and visible organic matter. In addition, pits were also examined to look for any visible signs of cryoturbation. An example of a log sheet used to record the information from the soil pit is attached in the Appendix B. Following this, three soil samples (and duplicate samples) were collected at each 0-10, 10-20 and 20-30 cm intervals. The samples were double bagged in the field and were returned to a laboratory in Yellowknife.

\subsubsection{Limitations of Field Methods}

There were some limitations associated with field methods. First, at some sites borehole drilling was accompanied by the use of a foaming agent (Halliburton Quik-Foam). This foam is used to improve the cutting capacity and prevent the drill barrel from freezing, and hence, was mostly used in boreholes that contained ice-rich samples. Approximately 100-250 ml of Quik Foam (diluted with 5 buckets of water with 19 liters each) were used 
for a $5 \mathrm{~m}$ borehole. Quik Foam is a proprietary blend of alcohol ethoxy sulphates (AES $\left.\mathrm{C}_{\mathrm{n}} \mathrm{H}_{2 \mathrm{n}}\left(\mathrm{C}_{2} \mathrm{H}_{4} \mathrm{O}\right)_{\mathrm{m}} \mathrm{SO}_{4} \mathrm{X}\right)$, where $\mathrm{n}=12-18, \mathrm{~m}=0-8$ and $\mathrm{X}=$ sodium, ammonium or triethanolamine. As the foam used in the current drilling belonged to a sodium salt grade, some boreholes were contaminated with some amount of sodium.

In order to determine the level of contamination on the samples, an analysis was conducted on Quik Foam, with concentrations of soluble cations measured at different dilution limits (Table 3.3). The contamination was evident at different dilution limits especially for $\mathrm{K}^{+}$and $\mathrm{Na}^{+}$ions. The concentration of $\mathrm{Ca}^{2+}$ and $\mathrm{Mg}^{2+}$ was negligible to almost $<0.1 \mathrm{mg} / 1$ at all three dilution limits. During field drilling, an average of $175 \mathrm{ml}$ of foam was diluted with 951 of water for each borehole. This implies about $542 \mathrm{ml}$ of water, per $\mathrm{ml}$ of foam, which is more than 500 times diluted. With the expected concentration at 500 times dilution, the contamination on the actual samples were predicted to be low due to the higher dilution (Table 3.3).

A separate lab experiment was carried out at Carleton University's Geocryology Laboratory in order to determine the amount of foam attached to a given volume of the frozen core segment after it is dipped in a foam mixture. This was done by weighing the frozen core, dipping it into a foam mixture and finally weighing it again to compare the weight gained. Table 3.4 reports the mass of frozen cores before and after dipping into the foam mixture. The experiment was performed two times with five and four replicates, respectively. A decrease in the mass of sample was observed at both trials after the samples were dipped into the foam mixture. This experiment shows that at least some of the foam which is attached to the outer surfaces of the frozen core flows away along with ice melt and causes a decrease in the total mass. Because the duration in the field is much 
longer from the time core segments are taken out from the barrel to examining their general characteristics and finally bagging, most of the foam attached to the outer surfaces of the cores likely runs off during the sample handling time.

The two different analyses on the foam showed that the concentration of $\mathrm{K}^{+}$and $\mathrm{Na}^{+}$in the actual sample should be relatively low due to higher dilution (nearly 500x), and running off of the foam during sample handling time.

Additional limitations of the field methods included irregular sampling intervals (core sectioning) for core segments of few boreholes. Occasionally, core segments would contain either bedrock, or boulders extending few $\mathrm{cm}$ in between soil samples and therefore, had to be discarded. Whenever, if this was the case, a note was made on a particular section. This included recording the material type and its length.

Finally, active layer depths could not be measured directly from the boreholes. This is because core barrels were longer than a meter length with only $5.5 \mathrm{~cm}$ diameter, making accurate measurements of the active layer impossible in the borehole itself. However, qualitative estimates of active layer depths were made when core segments were taken out from the barrel. This was done by examining the core segment and classifying it as being either frozen or unfrozen. The length of the unfrozen core segment obtained from the first run was considered as the thickness of the active layer. Lastly, the excess ice content reported in this study is a minimum estimate because at many instances, some ice was lost due to the drilling heat. This was mainly the case when drilling at sites from till blanket and till veneer terrains. 
Table 3.3 Measuring the concentration of major ions $(\mathrm{mg} / \mathrm{l})$ at different dilution limits

\begin{tabular}{|l|c|c|c|c|}
\hline Soluble Ions & $\mathbf{5 0 x}$ & $\mathbf{7 5 x}$ & $\mathbf{1 0 0 x}$ & Expected at 500x \\
\hline Calcium & $<0.1$ & $<0.1$ & $<0.1$ & $<0.1$ \\
\hline Magnesium & $<0.1$ & $<0.1$ & $<0.1$ & $<0.1$ \\
\hline Potassium & 143 & 135 & 125 & $14.3-25.0$ \\
\hline Sodium & 107 & 101 & 90.6 & $10.7-18.1$ \\
\hline
\end{tabular}

Table 3.4 Trial experiment reporting the mass of frozen cores before and after dipping in a foam mixture

$\underline{\text { First Trial }}$

\begin{tabular}{|l|l|}
\hline Initial Mass (g) & Final Mass (g) \\
\hline 729.91 & 728.84 \\
\hline 703.71 & 702.81 \\
\hline 690.35 & 689.38 \\
\hline 682.58 & 681.73 \\
\hline 675.88 & 674.74 \\
\hline
\end{tabular}

$\underline{\text { Second Trial }}$

\begin{tabular}{|l|l|}
\hline Initial Mass (g) & Final Mass (g) \\
\hline 900.55 & 900.44 \\
\hline 874.96 & 874.89 \\
\hline 825.64 & 825.60 \\
\hline 801.63 & 800.93 \\
\hline
\end{tabular}




\subsection{Laboratory and Analytical Methods}

\subsubsection{Soil Water Sampling}

A few samples collected from the field were first used in an experiment to compare three distinct soil water extraction techniques for geochemical analysis. Method 1 and Method 2 are commonly used methods in soil science for the extraction of soil water. Another method (Method 3) was also tested to compare cation concentrations obtained from all three methods. The experiment was performed using eight permafrost samples with sample numbers $(162-5,162-6,163-3,163-4,164-9,164-11,165-4$, and 165-17) at Carleton University’s Geocryology Laboratory.

In Method 1, permafrost samples were thawed and homogenized, poured into beakers, weighed, and allowed to settle for $12 \mathrm{~h}$. Supernatant water was extracted from thawed permafrost samples using a syringe and filtered through $0.45 \mu \mathrm{m}$ cellulose filter paper. Supernatant water was extracted from four samples (163-3, 164-9, 164-11, and 1654), which were vialed separately for analysis. One of the drawbacks of this method is that not all samples contain supernatant water and, therefore, some samples need to be processed with other methods such as Method 2 or Method 3 for soil-water extraction. In order to facilitate the comparison of solute concentrations obtained from the three water extraction techniques, gravimetric water content "at extraction" and the "field" moisture content were determined for samples that required deionized water.

In Method 2, all samples were oven dried and a known amount of deionized water was added to make a saturated paste ( 1:1 extraction ratio by mass; Janzen 1993). All samples were mixed thoroughly, and the samples were reweighed. The sediment was allowed to settle for $12 \mathrm{~h}$, and excess water was then collected with a syringe and filtered 
through $0.45 \mu \mathrm{m}$ cellulose filter paper for geochemical analysis. A drawback associated with this method is the likely possibility of reduced dissolution of ions into the soil-water after drying.

In Method 3, samples were subject to a direct addition of a known amount of deionized water ( 1:1 extraction ratio by mass; Janzen 1993). All samples were mixed thoroughly, and the samples were reweighed. The samples were allowed to settle for $12 \mathrm{~h}$, and excess water was extracted with the help of a syringe and finally, filtered through 0.45 $\mu \mathrm{m}$ cellulose filter paper. Four samples $(162-5,162-6,163-4$, and 165-17) underwent this method for the extraction of water which were kept in different vials. The extracted water from all three methods were sent to a lab for the analysis of soluble cations. A drawback associated with this method is a likely possibility of causing additional ion uptake due to reduced concentration after dilution.

The results obtained from this experiment indicate that concentrations of soluble cations obtained from Method 1 and Method 2 are relatively similar and distinct from Method 3 (Figure 3.10). Method 2 has the advantage of providing standardization for better comparability, but the disadvantage of possibly subduing high ion content present in soilwater. Method 1 is a desirable method, however, not practical as some samples do not contain supernatant water. Toner et al. (2013) describe that in the water extraction with Method 3 the resulting concentration of soluble ions changes with the extraction ratio chosen as samples are usually not fully leached out. Because this thesis aims to determine the pore water characteristics in active layer and permafrost samples (to infer the amount of solutes released into the environment, if the permafrost were to thaw), and not the potential to release ions during leaching over time, Methods 1 and 3 were considered 

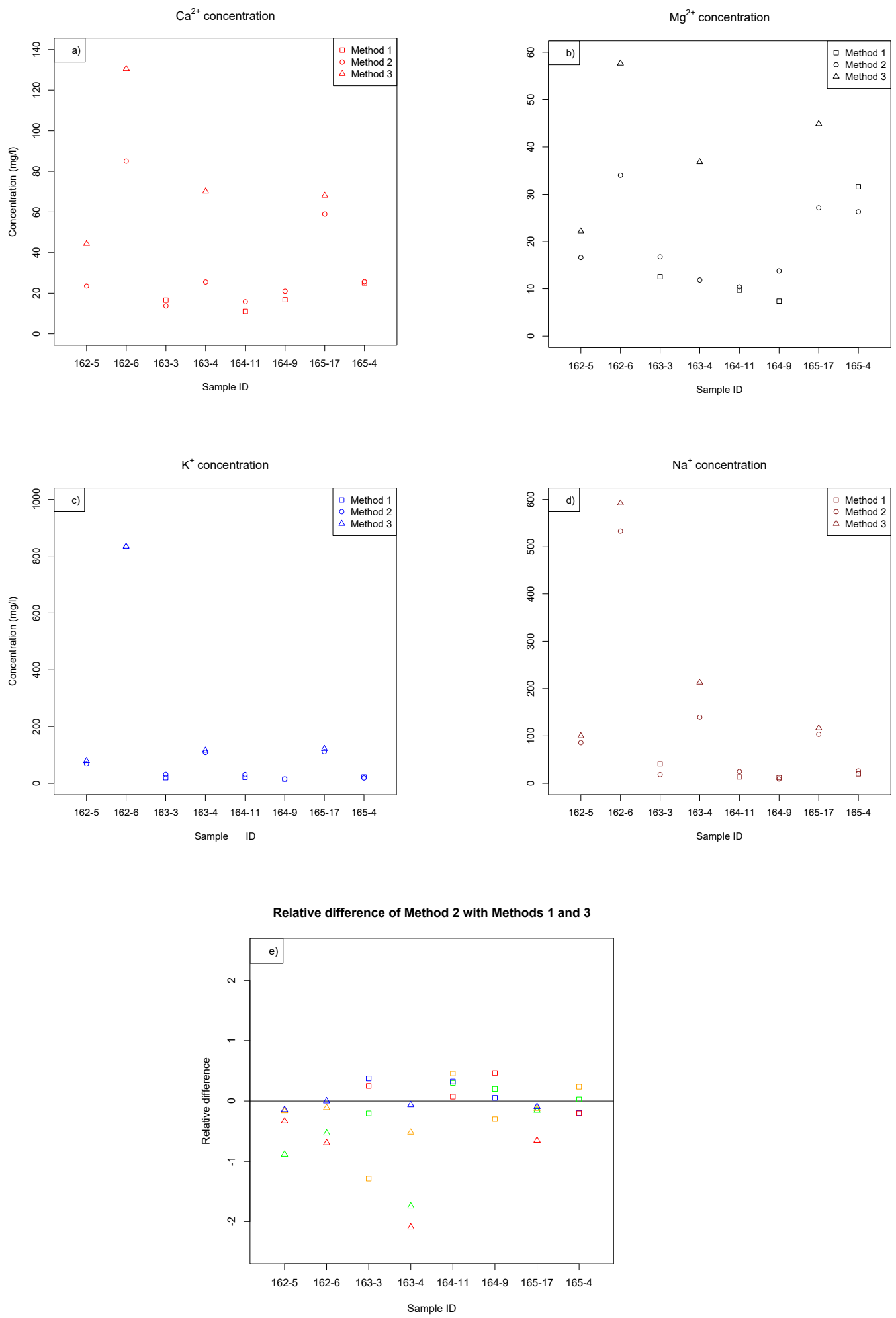

Figure 3.10 (a) Calcium concentration; (b) magnesium concentration; (c) potassium concentration; and (d) sodium concentration measured with three methods. (e) relative difference of Method 2 with Methods 1 and 3. Square represents 2 with 1 , while triangles represent 2 with 3 . Orange, green, blue and red denotes sodium, calcium, potassium and magnesium ions respectively. Concentrations obtained from Method 2 and Method 3 were corrected to original "field" water contents. 
appropriate for obtaining water for the determination of the concentration of soluble cations in cases with strongly differing soil-water contents.

\subsubsection{Core Samples (Boreholes + Exterior Pits)}

In the laboratory (EBA, Yellowknife), thawed permafrost samples were homogenized, poured into beakers, weighed, and allowed to settle for $12 \mathrm{~h}$ (e.g. Kokelj and Burn, 2003). A qualitative estimate of sediment texture and organic matter was also made and recorded. Following this, samples were processed to estimate the excess-ice content.

\subsubsection{Excess-Ice Content}

The excess-ice content was determined for each ice-rich sample from the boreholes. Volumes of sediment and supernatant water were recorded to estimate excess ice content Ic (\%) as follows (e.g. Kokelj and Burn, 2003):

$$
I c(\%)=(W v * 1.09) /(S v+(W v * 1.09)) * 100
$$

where $I c(\%)$ is the excess-ice content expressed on a volumetric basis, $\mathrm{Wv}$ is the volume of supernatant water, $\mathrm{Sv}$ is the volume of saturated sediment and 1.09 represents the density of water divided by that of ice.

\subsubsection{Soil Water Extraction}

After the comparison of results obtained from the Soil Water Sampling, Method 1 and Method 3 were considered as appropriate methods to obtain soil water for geochemical analysis. This section provides further details on the methods used to extract soil water from all core samples. Method 1 was used to extract supernatant water from thawed permafrost samples. A known amount of deionized water was added to active layer and 
permafrost samples that were not supersaturated ( 1:1 extraction ratio; Janzen 1993, Method 3). All samples were mixed thoroughly, and were allowed to settle for $12 \mathrm{~h}$. The excess water was then collected with a syringe and filtered through $0.45 \mu \mathrm{m}$ cellulose filter paper for geochemical analysis. Since, the "original" field moisture content and the water content "at extraction" were determined for each core sample, the concentration of soluble cations obtained from Method 3 were corrected to "field" water contents using the steps below:

$\underline{\text { Step } 1 \text { - Original water content in the sample }}$

$$
\text { Original water }=\left\{\left(G W B(\%) * m_{w s}\right) / 100\right\}
$$

where original water is the mass of water $(\mathrm{g})$ at field conditions, GWB $(\%)$ is the percentage gravimetric water content expressed on a wet-basis and $\mathrm{m}_{\mathrm{ws}}$ is the mass of field-moist soil (g).

$\underline{\text { Step } 2 \text { - Total water mass }}$

$$
\text { Total water }=\text { Original water }+ \text { Added water }
$$

Where total water is the mass of total water $(\mathrm{g})$ contained in a sample and added water is the mass of water $(\mathrm{g})$ that were added to samples which were not supersaturated.

$\underline{\text { Step } 3 \text { - Correction factor }}$

$$
\text { Correction factor }=\text { Total water } / \text { Original water }
$$

where correction factor is the correction for the original water in a sample depending upon total water contained. 


\subsubsection{Electrical Conductivity}

The electrical conductivity $(\mathrm{mS} / \mathrm{cm})$ was measured on all water extracts after filtering with a Yellow Springs Instruments Model 30 conductivity-salinity probe, calibrated daily against an $\mathrm{NaCl}$ reference solution. Since conductivity is proportional to the amount of electrolyte in solution, its measurement can be indicative of total soluble cations (sum of soluble $\mathrm{Ca}^{2+}, \mathrm{Mg}^{2+}, \mathrm{K}^{+}$and $\mathrm{Na}^{+}$) in soil-water extractions (Janzen, 1993). The values of conductivity $(\mathrm{mS} / \mathrm{cm})$ were corrected to the original water content in the samples:

$$
\text { Field conductivity }(\mathrm{mS} / \mathrm{cm})=\text { measured Conductivity * Correction factor }
$$

where correction factor is the correction for the original water in a sample depending upon total water contained.

\subsubsection{Gravimetric Water Content}

Gravimetric water content-dry basis $\left(\mathrm{GWC}_{\mathrm{D}}\right)$ was determined for each core sample using the oven drying method. Each sample was weighed in the lab, oven dried at $105^{\circ} \mathrm{C}$ for $24 \mathrm{~h}$ and reweighed to determine the $\mathrm{GWC}_{\mathrm{D}}$. The $\mathrm{GWC}_{\mathrm{D}}$ was obtained by dividing the mass of water $\left(\mathrm{m}_{\mathrm{w}}\right)$ given by difference between wet and dry masses by the mass of the dry soil.

(7) $\quad G W C_{D}=m_{W} / m_{d s}$

where $\mathrm{GWC}_{\mathrm{D}}$ is the gravimetric water content expressed on a dry-basis, $\mathrm{m}_{\mathrm{w}}$ is the mass of water $(\mathrm{g}), \mathrm{m}_{\mathrm{ds}}$ is the mass of oven-dried soil $(\mathrm{g})$.

In ice-rich soil, $\mathrm{GWC}_{\mathrm{D}}$ can produce values that greatly exceed $100 \%$, which are difficult to interpret (Phillips et al., 2015). Therefore, gravimetric water content was also 
expressed on a wet-basis, i.e., Gravimetric water content-wet basis (GWB). The water content GWB was obtained by dividing the mass of water by wet or field weight of the sample.

(8) $\quad G W B=m_{w} / m_{w s}$

where GWB is the gravimetric water content expressed on a wet-basis, $\mathrm{m}_{\mathrm{w}}$ is the mass of water $(\mathrm{g}), \mathrm{m}_{\mathrm{ws}}$ is the mass of field-moist soil $(\mathrm{g})$.

\subsubsection{Soluble Cation Concentrations}

The concentration of soluble cations (i.e. $\mathrm{Ca}^{2+}, \mathrm{Mg}^{2+}, \mathrm{Na}^{+}$and $\mathrm{K}^{+}$) was determined on all soil water extracts using an atomic adsorption spectrophotometer at the Taiga lab in Yellowknife. Since, the moisture content at extraction was determined for each core sample, the concentration of soluble cations obtained from Method 3 were corrected to original "field" water contents using the steps below:

$\underline{\text { Step } 4 \text { - Concentration of soluble cations with respect to "field" water contents }}$

$$
\text { CCFWC }=\text { Reported concentration }{ }^{*} \text { Correction factor }
$$

where CCFWC is the concentration of soluble cations in $(\mathrm{mg} / \mathrm{l})$ after correction to field water concentration. Reported concentration is the concentration of soluble cations in $(\mathrm{mg} / \mathrm{l})$ before correction and correction factor is the correction for the original water in a sample depending upon total water contained.

Soluble ion concentrations in soil-water extractions were also converted to milliequivalents per unit weight of dry soil (meq/ $100 \mathrm{~g}$ of dry soil). First, the reported concentration of soluble cations in $(\mathrm{mg} / \mathrm{l})$ were converted to $(\mathrm{meq} / \mathrm{l})$ by the equation:

(10) $C C E Q L=C C F W C / E q W t$. 
where CCEQL is the concentration of soluble cations in milli-equivalents per liter of water, CCFWC is the concentration of soluble cations in milli-grams per liter of water and EqWt. is the equivalent weight of ions in grams.

Finally, the results of ions from CCEQL were converted to $\mathrm{C}(\mathrm{meq} / 100 \mathrm{~g}$ of dry soil) by the equation:

$$
\text { (11) } C C E Q D S=W_{m} * C C E Q L
$$

where CCEQDS is the concentration of soluble cations expressed in milli-equivalents per unit weight of dry soil (meq/ $100 \mathrm{~g}$ of dry soil), $\mathrm{W}_{\mathrm{m}}$ is the mass of water per $100 \mathrm{~g}$ of dry soil and CCEQL is the concentration of soluble cations in milli-equivalents per liter of water. Presentation of soluble cation concentrations per unit weight of dry soil (meq/ 100g) facilitated comparison of solute concentration between core samples of varying moisture contents.

\subsubsection{Organic Matter Content}

Organic matter content was determined for all core samples using the sequential loss-on ignition method (Sheldrick, 1984) at Carleton University. A small amount (2-3) g of the oven dried sample $(<0.5 \mathrm{~mm}$ soil fraction) was placed in a crucible and heated to $550{ }^{\circ} \mathrm{C}$ in a high-temperature muffle-furnace for $6 \mathrm{~h}$ (Figure 3.11). However, some samples from the exterior pits were highly organic in nature and hence, in these cases crucibles were filled to only $1 / 4$. The crucible was allowed to cool in a desiccator and was then reweighed, and the organic matter content was determined according to (Sheldrick, 1984):

$$
L O I=\left(\left(S_{O D}-S_{i}\right) / S_{O D}\right) * 100
$$


a)

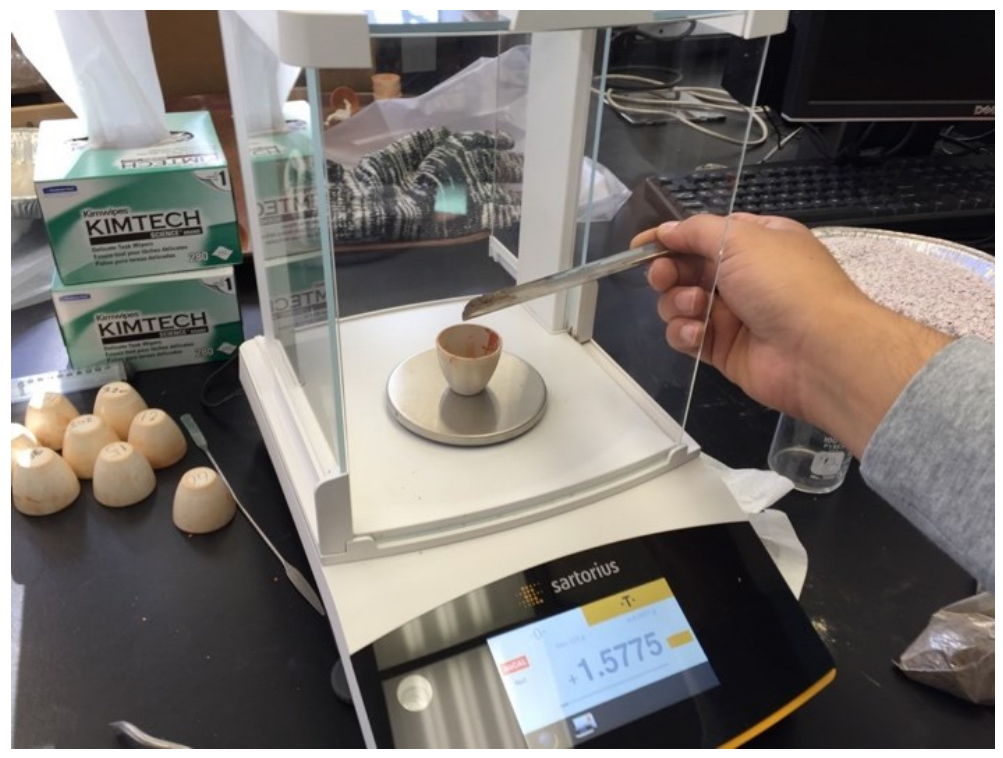

b)

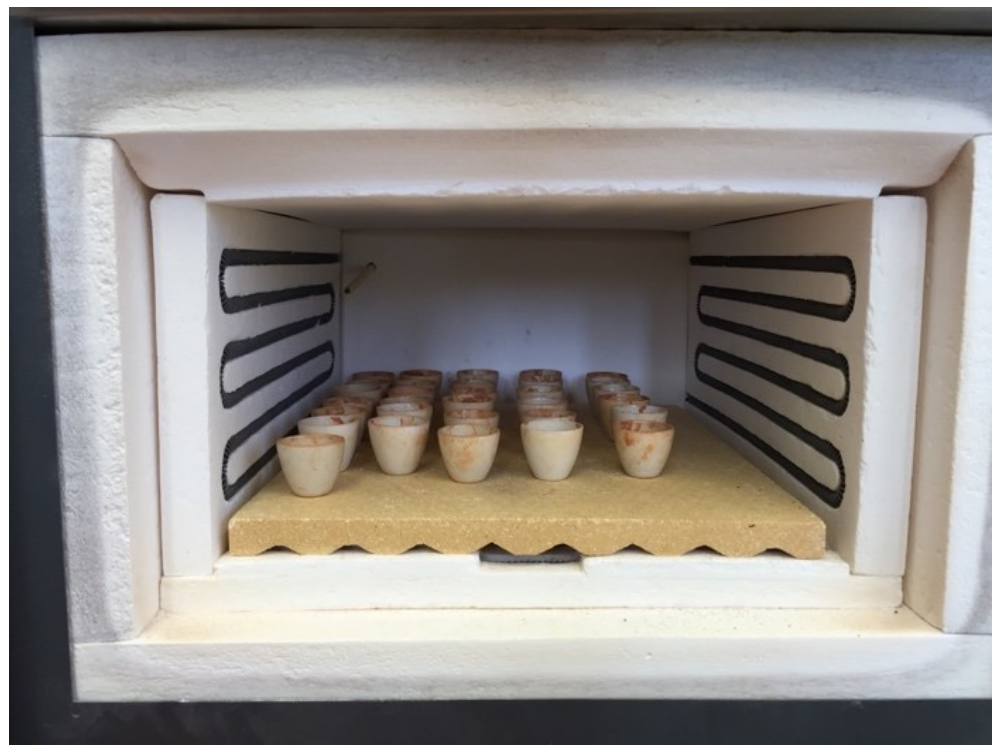

Figure 3.11 (a) Sample being weighed in a crucible; (b) crucibles inside a muffle furnace ready to undergo LOI 550. 
where LOI is the $\%$ Loss-on-ignition, $\mathrm{SOD}_{\mathrm{OD}}$ is the mass of sediment after oven drying at $105^{\circ}$ $\mathrm{C}$, and $\mathrm{S}_{\mathrm{i}}$ is the sediment mass after ignition at $550^{\circ} \mathrm{C}$.

\subsubsection{Soil Textural Analysis}

Soil type is an important control on hydraulic conductivity as it governs pore size distribution and water content below $0^{\circ} \mathrm{C}$, and therefore the potential for ice segregation and ground water movement. Finer-textured soils with moderate permeability and porosity (e.g. frost susceptible silts) allow unfrozen water to move towards a freezing front, and this process is responsible for the formation of segregation ice. In this study, selected samples from boreholes were analyzed for soil texture to examine whether water and excess ice contents at sites from various terrains were related to their soil textures. This provided the context for the present research, to examine the spatial variability of water content (including excess ice) between different terrain types based on their soil properties. The soil texture was analyzed using the laser diffraction (LD) method (e.g. Eshel et al., 2004).

Soil subsamples were taken from each borehole based on the total depth of the borehole, and spatial continuity of the sample distribution (sample types). To do this, samples were first identified from different depth intervals i.e. near-surface $(<2 \mathrm{~m})$, shallow (2-4 m), and deeper permafrost ( $>4 \mathrm{~m})$ depending upon the total depth of the borehole. Second, the spatial continuity of sample distribution was examined within each interval by looking at the drill logs that were prepared during the field measurements. A total of 59 samples were selected from 24 boreholes for the analysis of grain size which represented a range of soil types, and depth intervals found within each borehole. 
Each sample was first oven dried at $105^{\circ} \mathrm{C}$, and then crushed and homogenized in a mortar. The sample was then passed through a $2 \mathrm{~mm}$ sieve to remove any coarse particles. This was followed by the removal of organic matter using hydrogen peroxide. The samples were then mixed with calgon to prevent flocculation and passed through a Beckman Coulter LS 13320 Laser Diffraction-Particle Size Analyzer for the grain size analysis.

\subsection{Data}

\subsubsection{Quality Control}

Field sampling, analysis of samples, and processing of the data, followed established protocols. In the field, written protocols were used to maintain proper sampling and for recording of the information and sample bagging. Core samples were photographed, double-bagged and labelled properly to avoid any leakage or loss. Similarly, samples from each borehole were kept in a well-labelled pail until delivered to the laboratory.

Specific protocols were developed and handed to the EBA lab to assist sample preparation and analysis. This included step-wise instructions to prepare samples for the lab analysis of cations and soil organic matter. Gravimetric and volumetric measurements were used to derive the gravimetric water content and excess ice content in the samples. The protocol is presented in Appendix C. Test methods and data used by the Taiga lab are regularly validated by the Laboratory Quality Assurance Program. All the routine methods are based on recognized procedures from sources such as Standard Methods for the Examination of Water and Wastewater APHA (American Public Health Association), AWWA (American Water Works Association), WEF (Water Environment Federation), 
Environment Canada and USEPA (US Environmental Protection Agency). A regular correspondence was maintained with labs with the updated results and comments to ensure proper lab analysis at all times.

During the processing of the data, the original results (.xlsx files) from the Taiga lab were kept in a separate folder and renamed as "original results" to ensure no changes were made. Secondary files were created and renamed as "import sources" so that they could to be modified and read for data analysis using the software package $\mathrm{R}$. The changes were recorded in a separate file known as the "modification catalog".

\subsubsection{Presentation of the Data}

Data for this study is presented by site groups as described in Section 3.2.2, and is placed in the Appendix D. The first part of the data is the field data which is presented in tables. The field data includes site number, geographic location and elevation (from surveygrade GPS + PPP), terrain conditions, surface topography and vegetation conditions at each site. Next, field and laboratory data from each borehole are presented in plots. Each plot contains the information on the active layer depth (indicated by a dashed line), Unitcode (a visual description of permafrost samples as recorded by the field geologists in their drill $\operatorname{logs}$, total soluble cations (meq/100 g of dry soil), soil-water conductivity $(\mathrm{mS} / \mathrm{cm}$, standardized to the original water content in the samples), gravimetric water content $(\%$, expressed on a gravimetric wet basis) and excess ice content (\%, gravimetric basis), and organic matter content ( $\%$, expressed on a dry basis). The Unitcode provides an idea of the type of sample recovered, a rough estimate of soil texture, excess ice content and their types, and any organic materials recorded. Similarly, small symbols vs. larger symbols 
have been used in the plots to represent the samples from the exterior pits vs. boreholes. Gravimetric water content and excess ice content are plotted on the same graph for ease of understanding water and ice content in a sample. Only the recovered samples are plotted, and unrecovered drill intervals are left blank. 


\section{CHAPTER 4. RESULTS}

\subsection{Overview}

The results are organized into four sections. Following this introduction, the second section presents the results of the grain size analysis that was conducted on selected samples. The results of this analysis provide an idea of soil textures of samples from each site, and guides comparison of spatial variability in water and excess ice, organic matter and soluble cation content between terrain types. The third section reports the values of measured variables at sites to describe their vertical distribution, including the contrast between the active layer, near-surface permafrost and the permafrost at depth. Further, the section also incorporates the results of the statistical analyses conducted in order to compare the spatial variability of observed water, organic matter and ion contents between terrain types. Finally, the last section describes the observed correlations between the water content GWB, organic matter content and cation contents.

\subsection{Grain Size and Soil Texture}

The results of the grain size analyses are presented in Appendix E, classified according to the USDA textural classification system $(2 \mathrm{~mm}>$ sand $>53 \mu \mathrm{m}>$ silt $>2 \mu \mathrm{m}$ $>$ clay). The results indicate that on average, soils consist of poorly to very poorly sorted silt and sand. The mean grain size of samples from four different terrains was quite variable with highest of $212 \mu \mathrm{m}$ from eskers and the lowest of $83 \mu \mathrm{m}$ from peatlands and wetlands (Appendix E). The relative proportion of silt was quite high among peatlands and wetlands, and till veneer terrains. Clay percentage was $<18 \%$ among all four terrain types.

A textural ternary plot is presented in Figure 4.1. On average, the soil texture was classified to be "sandy loam" for peatlands and wetlands and till veneer, and "loamy sand" 


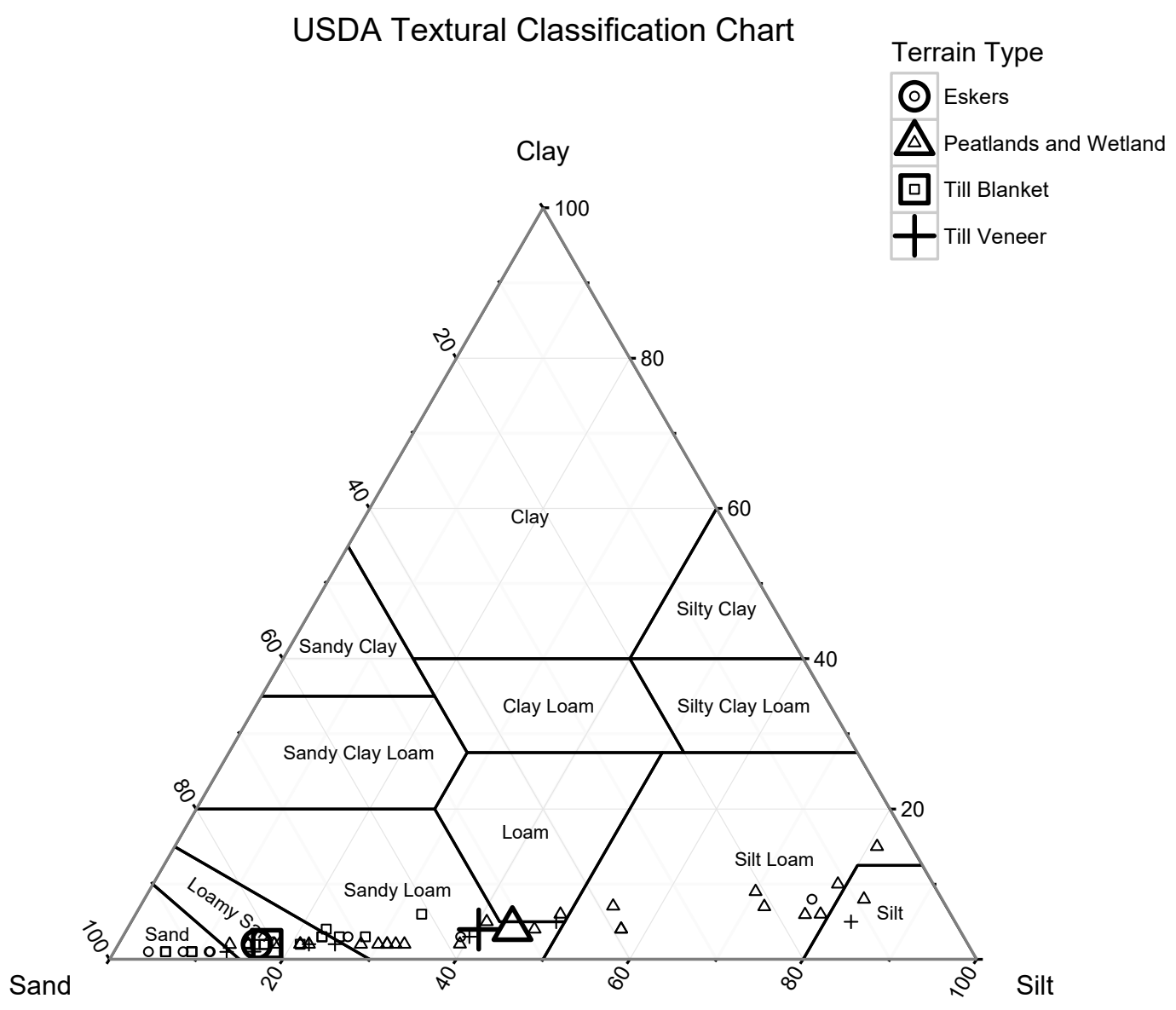

Figure 4.1 A textural ternary plot (from USDA soil classification system) indicating soil textures of various terrain types near Lac de Gras, N.W.T. Larger icons represent the mean soil texture of each terrain, while smaller icons denote soil textures of individual samples from each type. 
for till blanket and eskers.

\subsection{Depth Profiles: Moisture Content, Organic Matter and Soluble Cations}

\subsubsection{Moisture Content and Excess Ice Content}

In peatlands and wetlands, water content GWB was usually high in samples recorded as organics or ice-rich (Figure 4.2). "Till” samples generally had lower water content GWB, but some tills with increased excess-ice contents in the near-surface permafrost or at depth in permafrost had high water content GWB. The active layer at most sites had high water contents. Similarly, water content GWB was also high (between 50 and $90 \%$ ) in the near-surface permafrost. The zones with high water contents in the nearsurface permafrost were often associated with ice-lenses, several centimeters thick (Figure 4.2), but no excess ice was evident at the peatland sites (1005 and 1006), in the near-surface permafrost. This is due to a very high organic matter content, over $75 \%$, up to $1.5 \mathrm{~m}$ (Figure 4.2a and g). At most sites, water content GWB and excess ice contents at depth in permafrost declined with depth (e.g. Figure 4.2a, b, d, e, and g), however some sites from peatlands (1005 and 1009) were observed with increasing water content GWB and thick ice lenses at depth with excess ice contents more than 50\% (Figure 4.2c and f). These ice-rich intervals corresponded with their respective sample types from the Unicode information. 

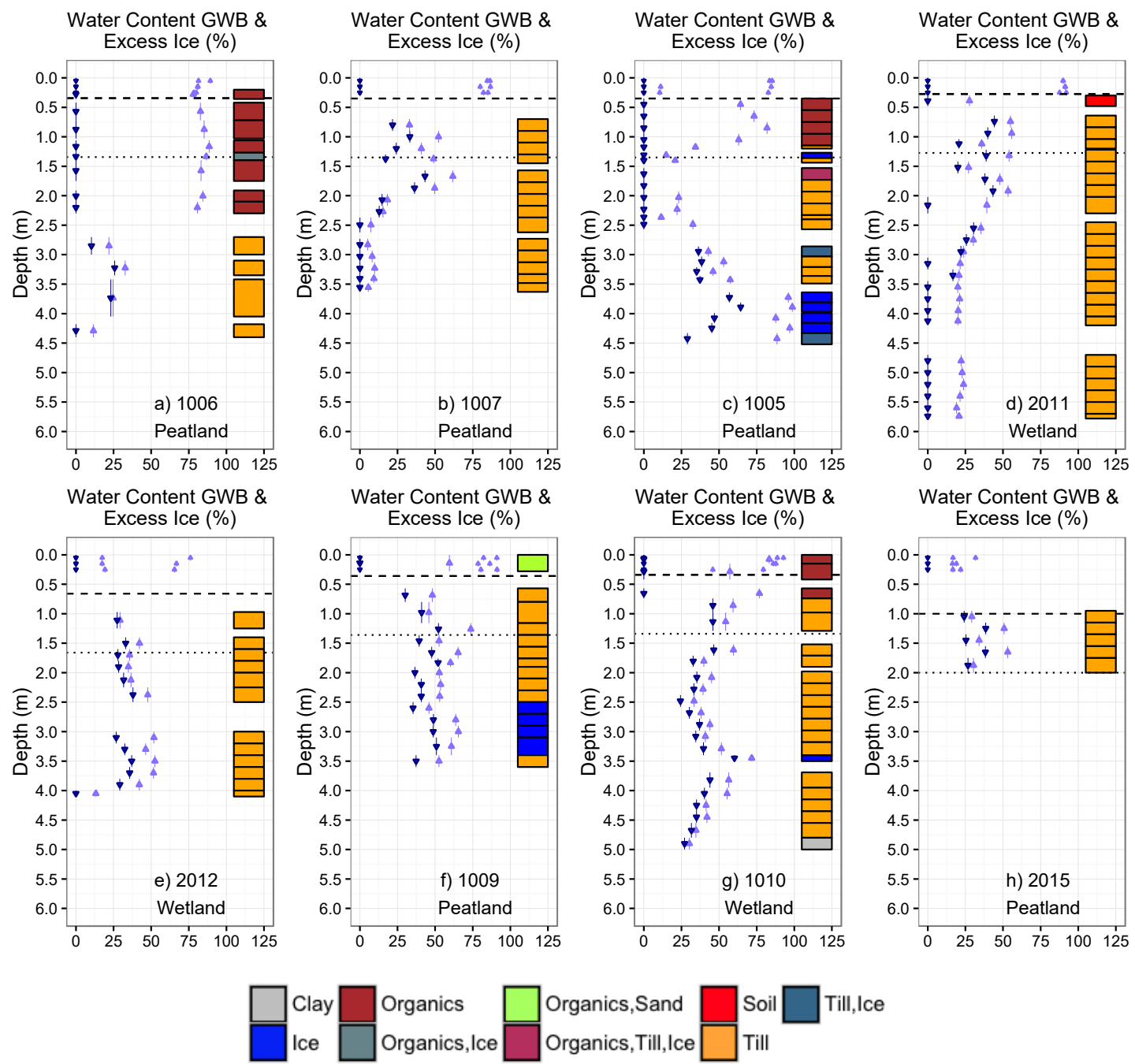

Figure 4.2 Gravimetric water content (GWB) and excess ice profiles from the active layer and permafrost at peatlands and wetlands sites, near Lac de Gras, N.W.T. Blue triangles represent water content GWB while dark blue upside down triangles represent excess ice content. The dashed line represents the thickness of the active layer at the time of sampling while the dotted line represents the lower boundary of the near-surface permafrost (See Figure 3.4 to 3.7 for location context). 
At a few sites discrepancies existed between the active layer moisture contents obtained between two exterior pits (Figure 4.2c and e), while some variations were also observed between the water content GWB of boreholes and exterior pits in the active layer (Figure 4.2f and g). Two sites in peatlands and wetlands terrain, i.e. 1009 and 1010, were ice-rich from the base of the active layer to permafrost at depth with distinct zones of ice lenses (Figure 4.2e, f, and g). These distinct zones of ice lenses had excess ice contents between 25 and $60 \%$.

In till blanket, a general correspondence in the water content profiles in the active layer was observed between various sites (Figure 4.3). However, water content profiles were different in the near-surface permafrost or at depth in permafrost depending upon the local positions of boreholes in a hillslope. Most sites indicated a water content GWB of $<$ $25 \%$ for the uppermost layer, with few exceptions at the hilltop and hillslope sites (2004, 2005 and 2007). Below this uppermost layer, lower moisture content extended to depths of about 1.75 to $2 \mathrm{~m}$ at all sites. Similarly, no excess ice content was recorded at any site except the hilltop site (2004) up to $2 \mathrm{~m}$ depth (Figure 4.3b). At this site (2004) two ice-rich layers, 12 to $17 \mathrm{~cm}$ thick, with water content GWB between 14 and 20\% were encountered at 1.0 and $1.7 \mathrm{~m}$ depths. Similarly, another interval between 1.75 and $4.00 \mathrm{~m}$ depth was underlain by three distinct ice-rich zones with water content GWB more than $60 \%$. Excess ice contents for all three intervals were more than $60 \%$.

Sites located on steep slopes and bottom of hills also had excess ice, however they were encountered much deeper in ground at the hill bottom site. Excess ice content was present at $2.5 \mathrm{~m}$ depth at the steep slope (site 2007), however was absent for the same depth interval at the bottom of the hill (site 2006) (Figure 4.3d and e). 

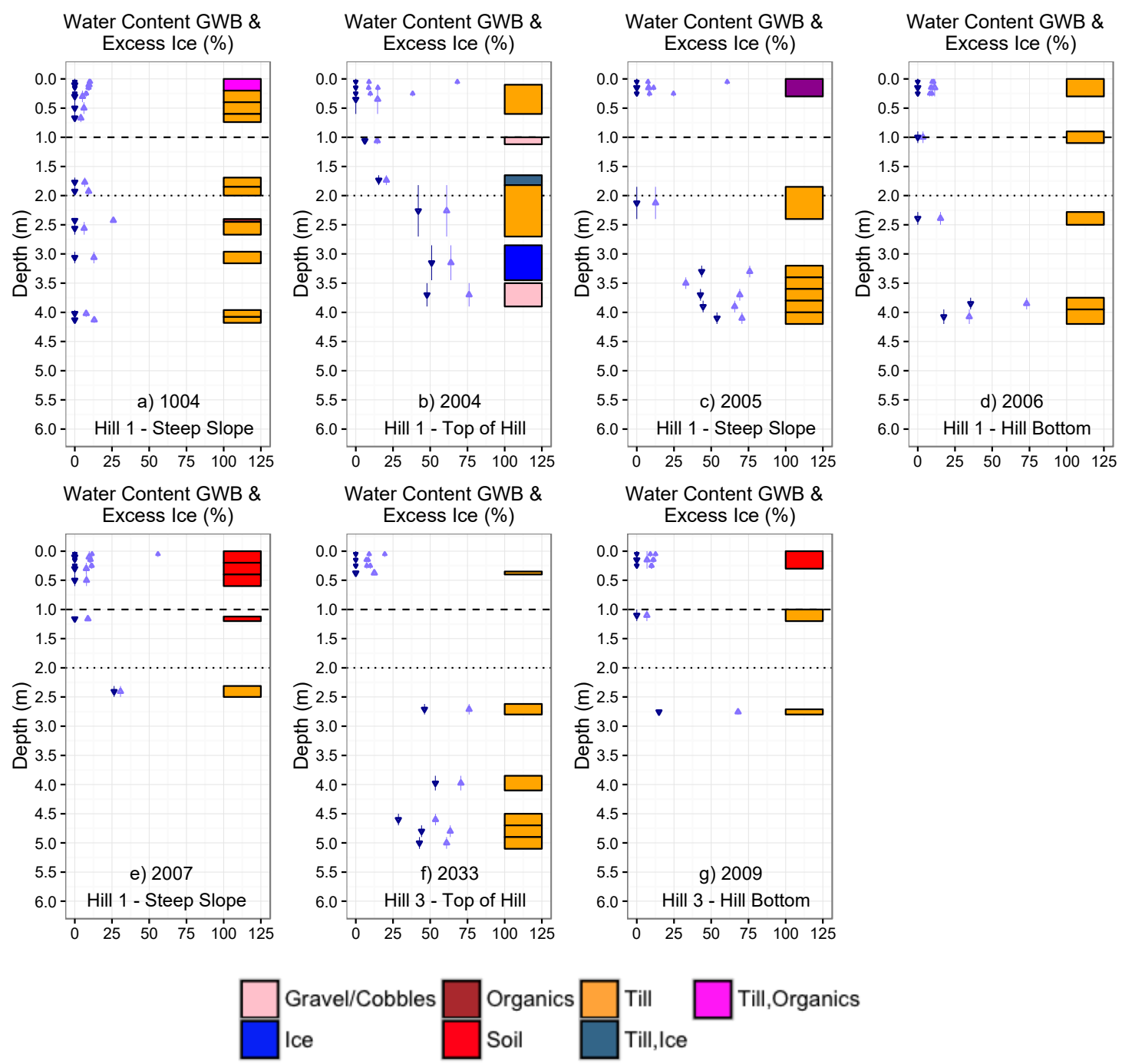

Figure 4.3 Gravimetric water content (GWB) and excess ice profiles from the till blanket sites, near Lac de Gras, N.W.T. Blue triangles represent water content GWB while dark blue upside down triangles represent excess ice content. The dashed line represents the thickness of the active layer at the time of sampling while the dotted line represents the lower boundary of the near-surface permafrost (See Figure 3.4 to 3.7 for location context). 
In till veneer, there was a high variation in the water content GWB of the active layer, between 10 and 90\% (Figure 4.4). The near-surface permafrost was observed with increased moisture content and some excess ice (Figure $4.4 \mathrm{~b}$ and c). By contrast, till samples at depth in permafrost generally contained high moisture and excess ice contents. For example, at the till hilltop site (1014), an ice-rich zone, several meters thick, extended from 4.0 to $9.5 \mathrm{~m}$, with increased moisture contents at $6.2 \mathrm{~m}$ and $8.3 \mathrm{~m}$ depths (Figure 4.4a). This ice-rich zone in "till" had excess ice contents up to $75 \%$. A similar profile was observed at depth in permafrost from the till hill bottom site (2019) (Figure 4.4e). A site located in a low-lying depression in till (2018) was observed with a zone of high water and excess ice content between 1 and $2 \mathrm{~m}$ depth. However, water contents were comparatively lower below and above this interval, and excess ice content was evident only below this interval (Figure 4.4b).

In general, water content GWB at the esker sites was very low. The top $30 \mathrm{~cm}$ at the esker sites had variable moisture contents between 0 and 30\% (Figure 4.5), however water content GWB below the base of the active layer was similar depending upon the sample types. For example, water content GWB below the base of the active layer at both sites, in 2028 and 2029 for the samples recorded as "sand" were below 25\% (Figure 4.5b and c). At site 2008, an increased moisture content was evident between 1.5-3 m and 3$6 \mathrm{~m}$ depths from 10 to $40 \%$ for the sample recorded as "till". 

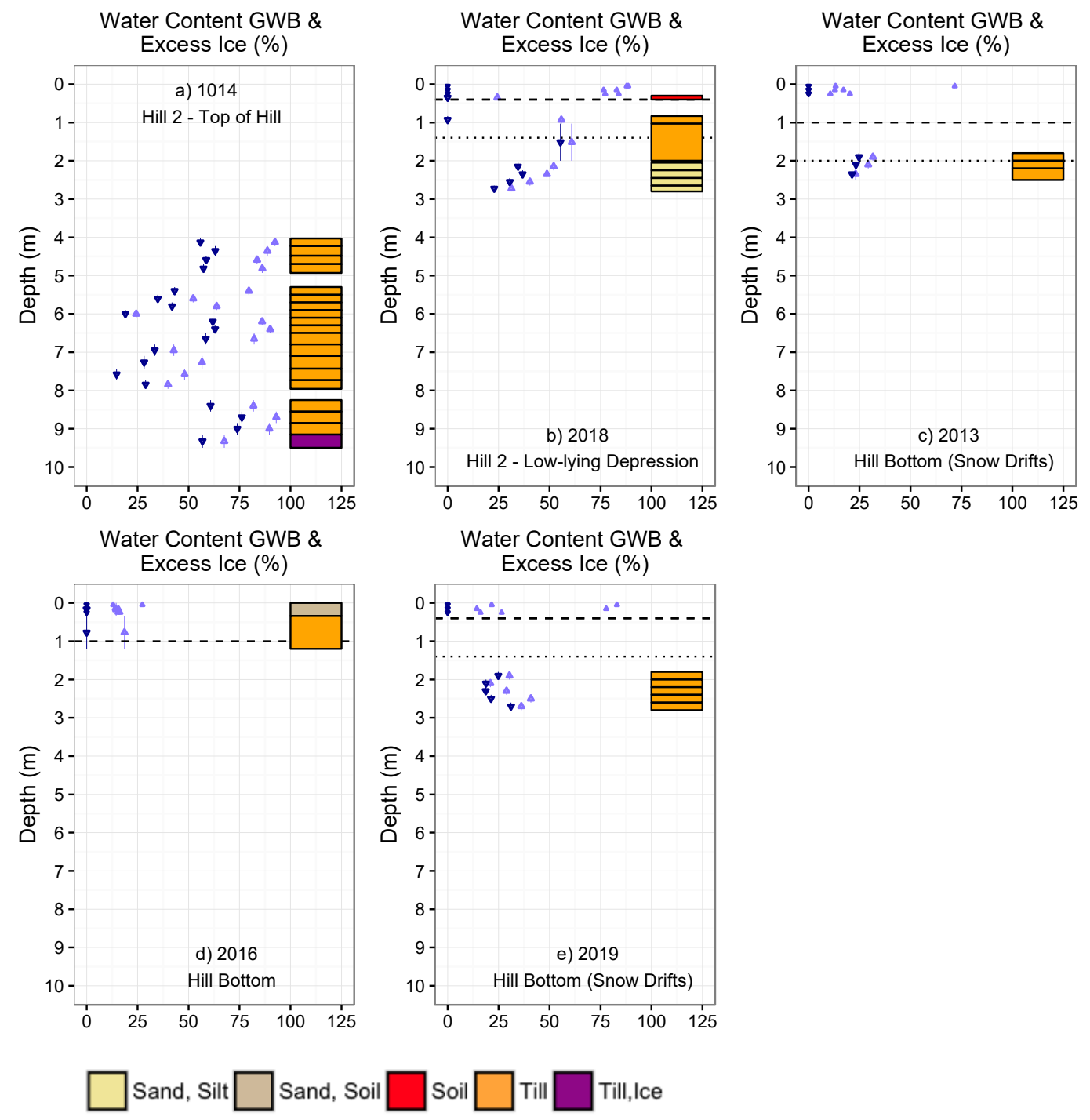

Figure 4.4 Gravimetric water content (GWB) and excess ice profiles from the active layer and permafrost, till veneer sites, near Lac de Gras, N.W.T. Blue triangles represent water content GWB while dark blue upside down triangles represent excess ice content. The dashed line represents the thickness of the active layer at the time of sampling while the dotted line represents the lower boundary of the near-surface permafrost (See Figure 3.4 to 3.7 for location context). 

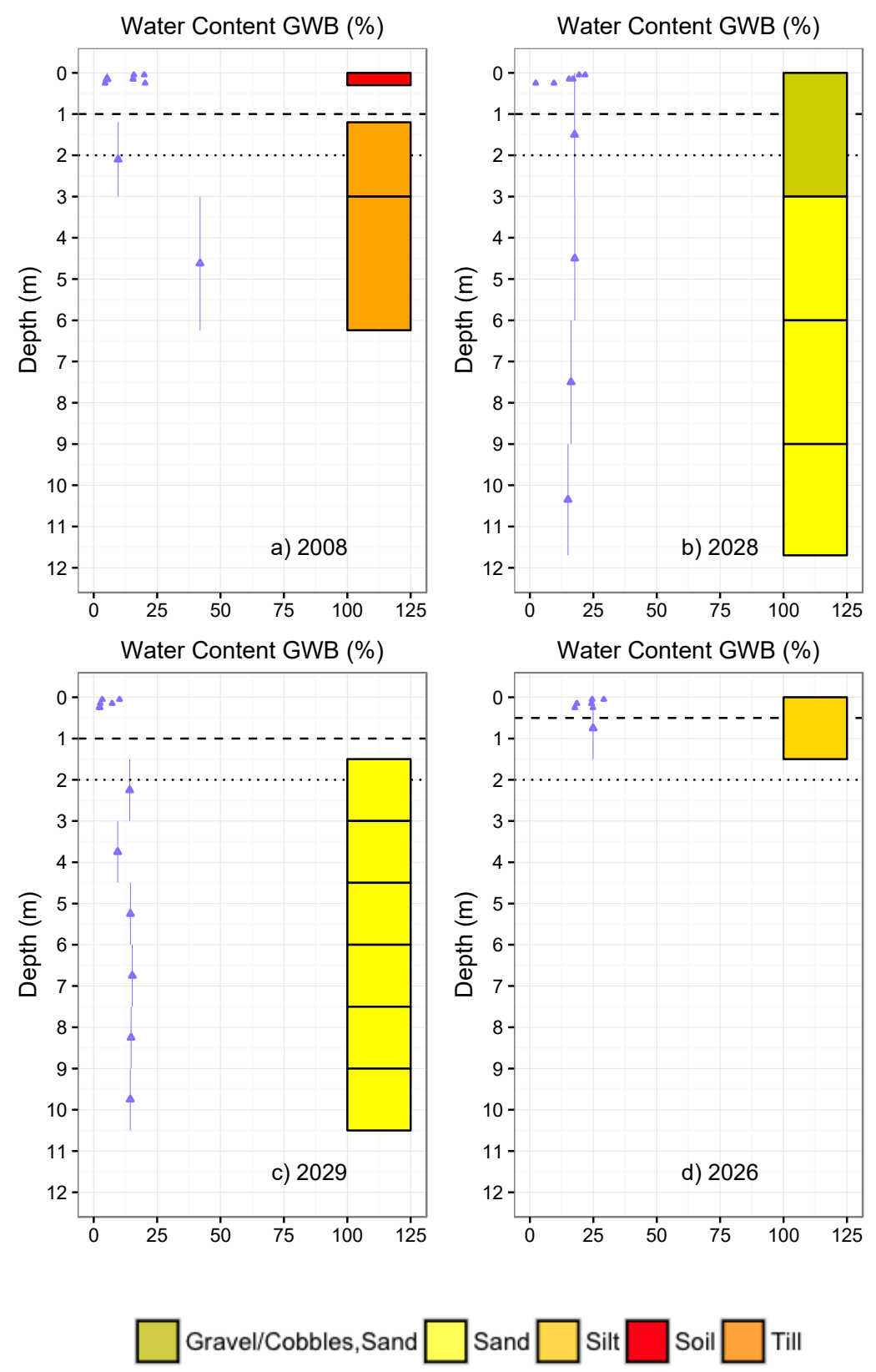

Figure 4.5 Gravimetric water content (GWB) profiles from the esker sites, near Lac de Gras, N.W.T. The dashed line represents the thickness of the active layer at the time of sampling while the dotted line represents the lower boundary of the near-surface permafrost (See Figure 3.4 to 3.7 for location context). 


\subsubsection{Organic Matter Content}

In peatlands and wetlands, the organic matter content in the active layer and in nearsurface permafrost of few sites was very high, up to $90 \%$ (Figure $4.6 \mathrm{a}$, c and g), and corresponded to their respective sample types. Organic matter contents normally declined with depth, and were the lowest at depth in permafrost. However, at one peatland site (1006) organic matter between $1.5 \mathrm{~m}$ and $2.5 \mathrm{~m}$ depth was very high, about $85 \%$ (Figure 4.6a). The majority of "till" samples in profiles were observed to have low organic matter contents (Figure 4.6c). By contrast, organic matter contents were also associated with icerich samples at depth in permafrost with some minor increments (Figure 4.6c and f), however the absolute percentage of this organic content at depth was very low.

In till blanket, the organic matter content of the top $50 \mathrm{~cm}$ depth was less than $5 \%$ at each site (Figure 4.7). In comparison to peatlands and wetlands terrain, this percentage of organic content in the active layer is low, which is likely due to the surface condition and vegetation. This is reflected in observed sample types of till blanket terrain in the uppermost layer, which were mostly classified as "till". Some minor increments in organic matter contents were noticed near the base of the active layer at the steep slope site (1004) and the hill bottom site (2006) (Figure 4.7a and d), however organics in the soil profile declined in cores at site from the top of the hill (2004) (Figure 4.7b). The near-surface permafrost in till blanket terrain contained only 2 to $5 \%$ of organic matter, and was quite comparable with the organic matter in the active layer. Organic matter content at depth in permafrost was generally low, less than $2.5 \%$, but some minor increments were observed at depth for sites located at the hilltop (2004) and the steep slope (2007) (Figure 4.7b and e). 

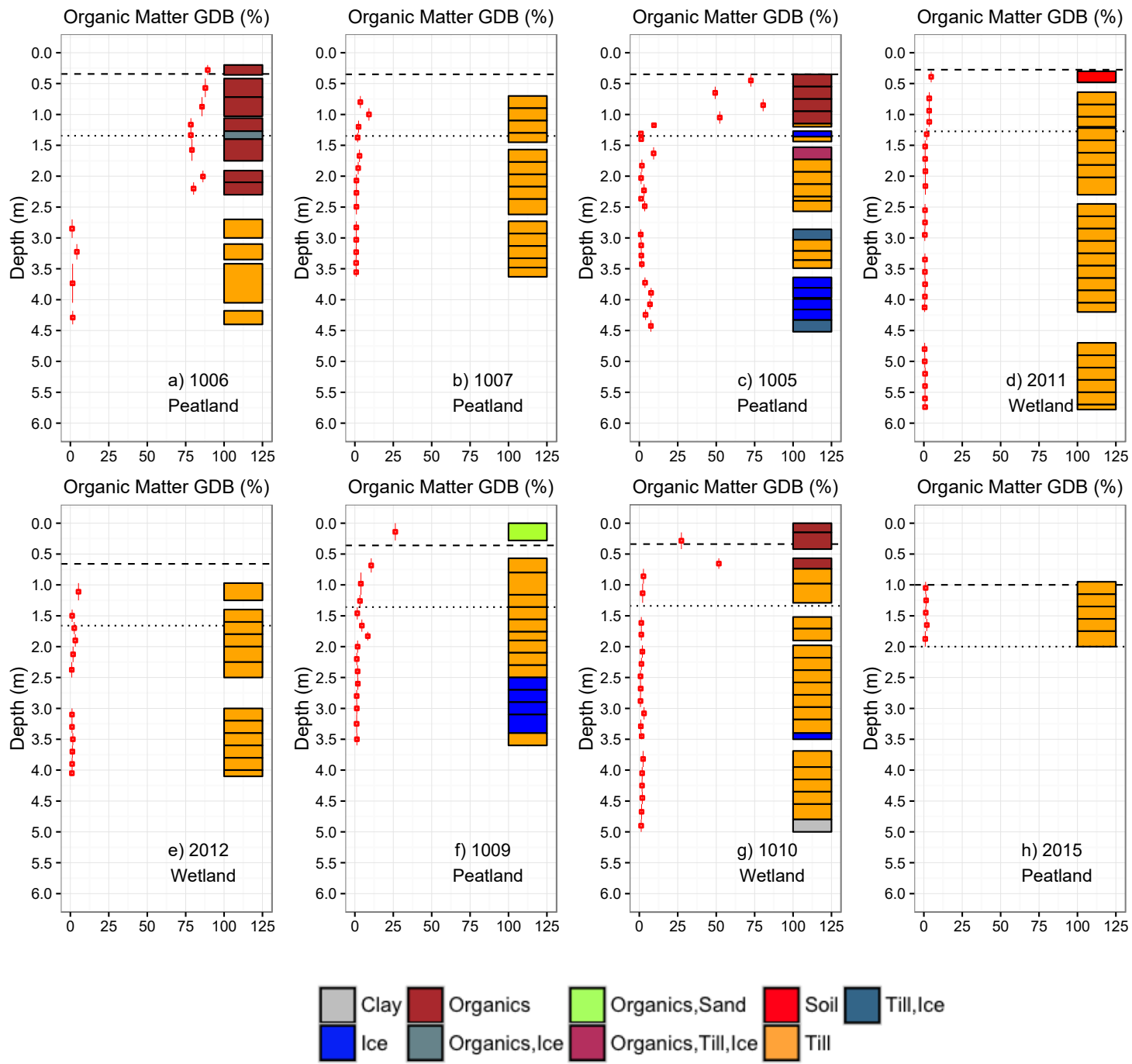

Figure 4.6 Soil Organic-matter contents in the active layer and permafrost, peatlands and wetlands site, near Lac de Gras, N.W.T. The dashed line represents the represents the thickness of the active layer at the time of sampling while the dotted line represents the lower boundary of the near-surface permafrost (See Figure 3.4 to 3.7 for location context). 


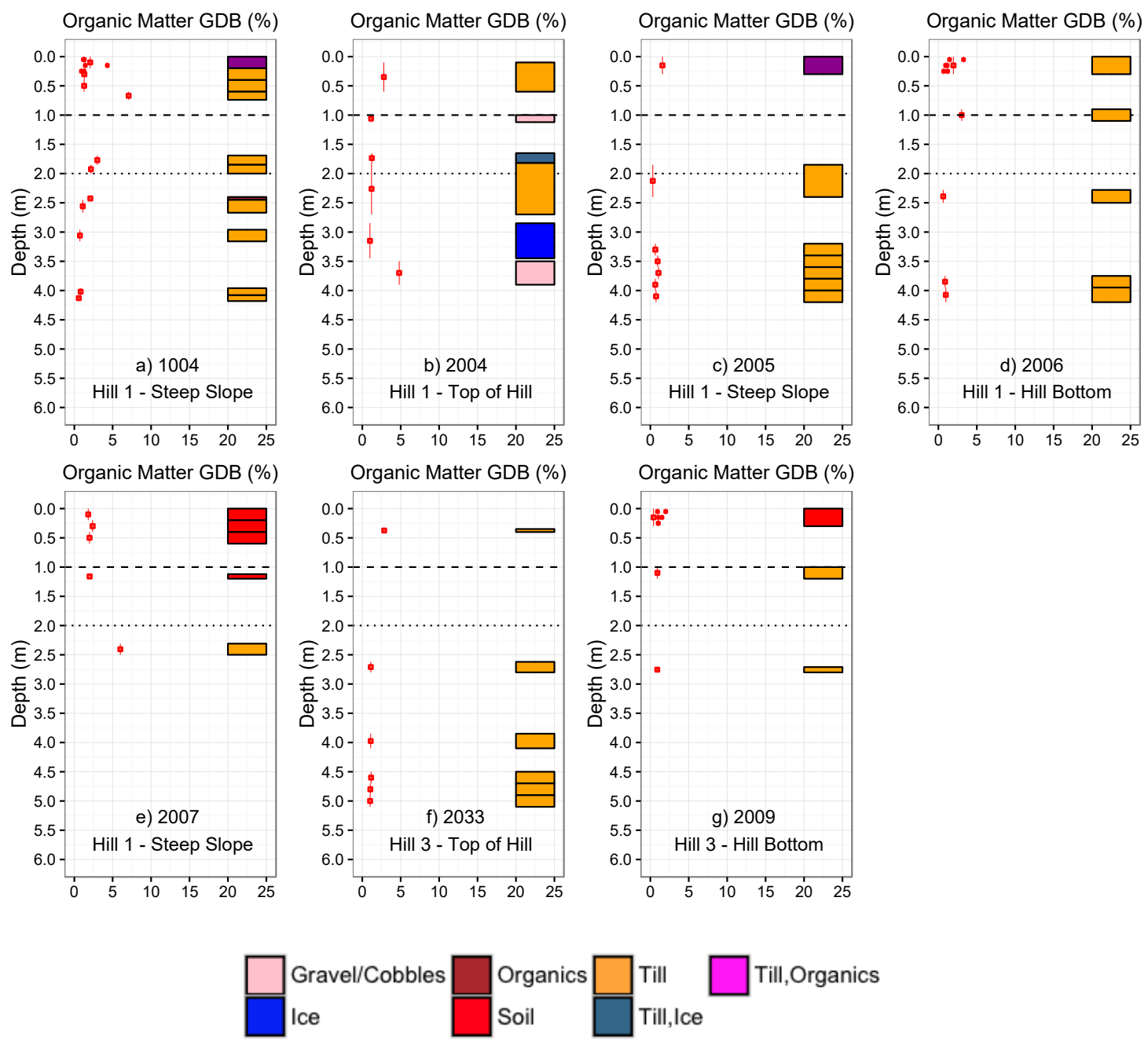

Figure 4.7 Soil Organic-matter content profiles from the till blanket sites, near Lac de Gras, N.W.T. The dashed line represents the thickness of the active layer at the time of sampling while the dotted line represents the lower boundary of the near-surface permafrost (See Figure 3.4 to 3.7 for location context). 
In till veneer, organic matter content at depth in permafrost was generally low, less than 1.5\% as observed at the till hilltop and hill bottom sites (1014, 2013 and 2019) (Figure 4.8a, c and e). The majority of samples at depth from this terrain were associated with "till" of varying excess ice contents. Similarly, organic matter content in the active layer was also low, between 2 and 6\%, however in the near-surface permafrost was high, about $65 \%$ (Figure $4.8 b$ and $d$ ).

At the esker sites, the top $50 \mathrm{~cm}$ depth was characterized with organic matter contents between 1 and 6\%, and was quite similar among most sites (Figure 4.9a, c and d). In the near-surface permafrost and at depth in permafrost, organic matter content was generally low and the profiles were relatively similar to each other. The observed relatively high percentage of organic matter in the active layer, and low percentage at depth corresponded with the sample nature belonging to those depths.

\subsubsection{Total Soluble Cations}

In peatlands and wetlands, total soluble cation concentration in the active layer had a wide variation, between 0.72 to $3.43 \mathrm{meq} / 100 \mathrm{~g}$ (Table 4.1 ). Similarly, the near-surface permafrost at some sites was observed with increased concentrations. The mean total soluble cation concentration in the active layer was at least 5 times greater than that present in the near-surface permafrost (Table 4.1). Permafrost at depth generally contained low soluble cation concentrations, however some minor peaks were evident in ice-rich samples.

The majority of "organic" samples in profiles from the active layer and nearsurface permafrost contained high soluble cation concentrations (Figure 4.10a, $\mathrm{c}$ and g). "Till" samples normally contained low soluble cations, but a few sites at depth were 

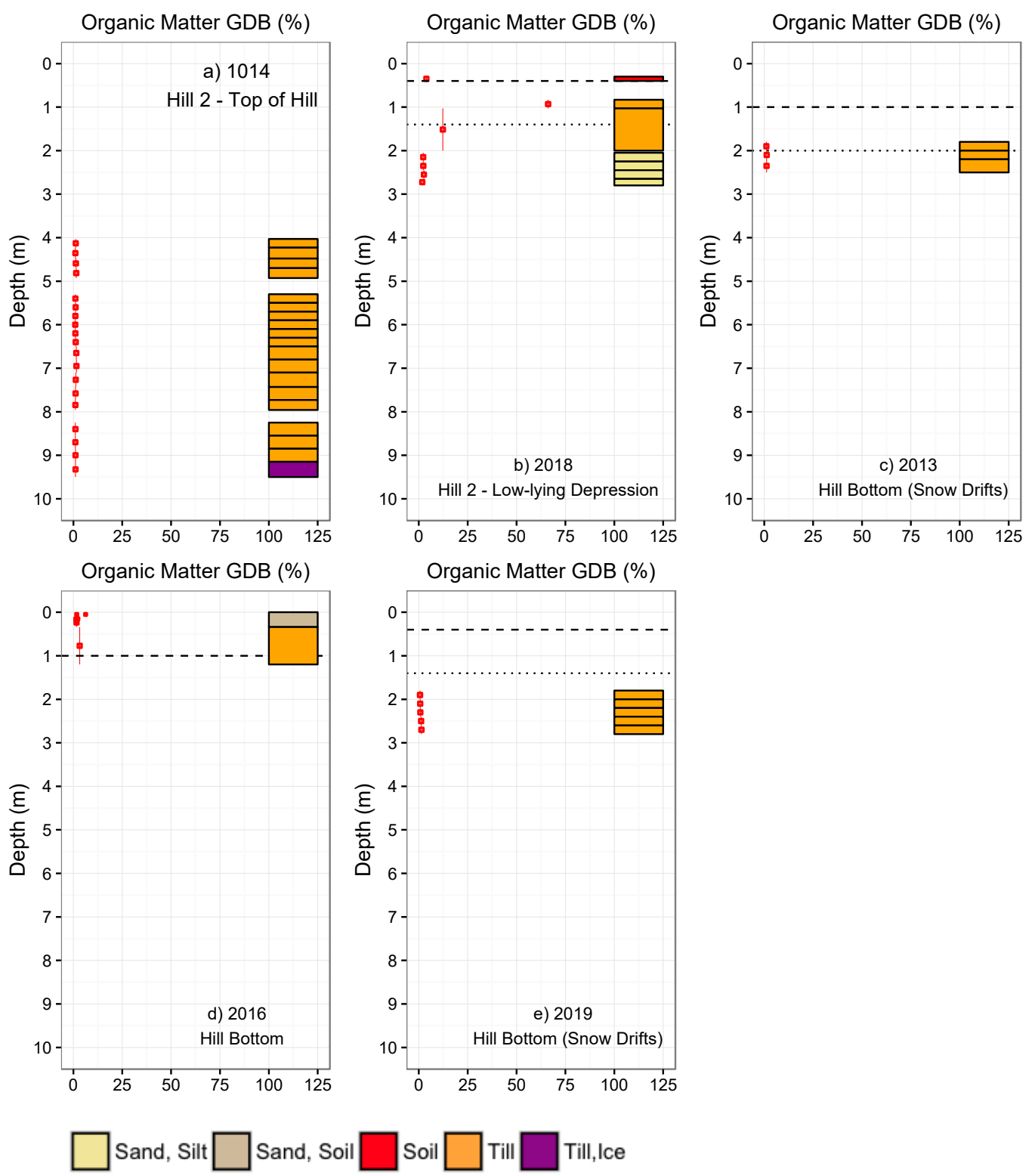

Figure 4.8 Soil Organic-matter contents in the active layer and permafrost, till veneer sites, near Lac de Gras, N.W.T. The dashed line represents the thickness of the active layer at the time of sampling while the dotted line represents the lower boundary of the near-surface permafrost (See Figure 3.4 to 3.7 for location context). 

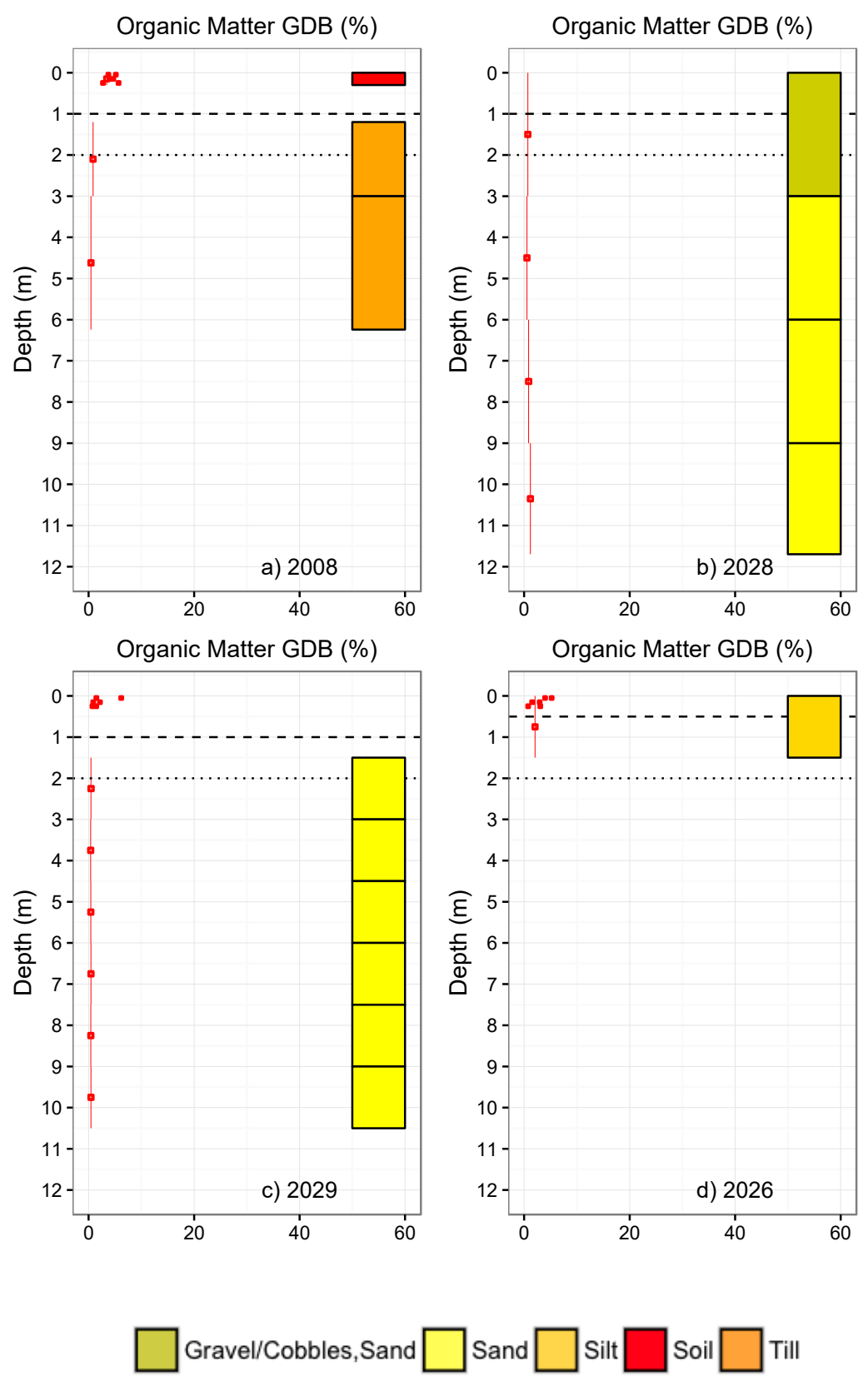

Figure 4.9 Soil Organic-matter content profiles from the esker sites, near Lac de Gras, N.W.T. The dashed line represents the thickness of the active layer at the time of sampling while the dotted line represents the lower boundary of the near-surface permafrost (See Figure 3.4 to 3.7 for location context). 
observed with increased concentrations, about $3 \mathrm{meq} / 100 \mathrm{~g}$ (Figure $4.10 \mathrm{~d}$ and f). The top of the permafrost at a few sites was observed with an increased soluble cation concentration compared to that at the base of the active layer. For example, at the peatland site (1006), total soluble cation concentration increased from $2.16 \mathrm{meq} / 100 \mathrm{~g}$ at the base of the active layer to $3.16 \mathrm{meq} / 100 \mathrm{~g}$ in a moisture enriched zone in near-surface permafrost (Figure 4.2a and 4.10a). Similar patterns were also observed at the peatland and wetland sites (1005 and 1010) (Figure 4.10c and g). All three sites had high organic matter content in the active layer and in the near-surface permafrost (Figure 4.6a, $\mathrm{c}$ and g). Soluble cation concentration also increased at depth in permafrost. For example, at one wetland site (2011) the depth interval between $2 \mathrm{~m}$ and $3 \mathrm{~m}$ depth was observed with an increased concentration of soluble cations up to $3 \mathrm{meq} / 100 \mathrm{~g}$ dry soil (Figure $4.10 \mathrm{~d}$ ).

The enriched zones in soluble cations at the majority of sites correspond with the ice-rich zones at that particular depth. Zones of low cation concentration also coincided with low ice contents in permafrost. For example, similar patterns in ice and soluble ion accumulation were observed at depth in profiles from the peatland and wetland sites (1005 and 1010) underlain by high-ice-content permafrost (Figure $4.2 \mathrm{c}$ and $4.10 \mathrm{c}$ ). However, at the wetland site (2011), the depth just below the base of the active layer was characterized by very low soluble cation concentration, and the zone of high cation concentration coincided with low ice content at the top of permafrost (Figure 4.10d and 4.2d).

In peatlands and wetlands, $\mathrm{Mg}^{2+}$ was the dominant cation reported from the active layer and permafrost at most sites except at the two peatland sites (1006 and 2015). At these two sites, the concentration of soluble $\mathrm{Mg}^{2+}$ in the active layer was slightly less than soluble $\mathrm{Ca}^{2+}$ (Table 4.1). The highest concentration of $\mathrm{Mg}^{2+}$ in the active layer was reported 


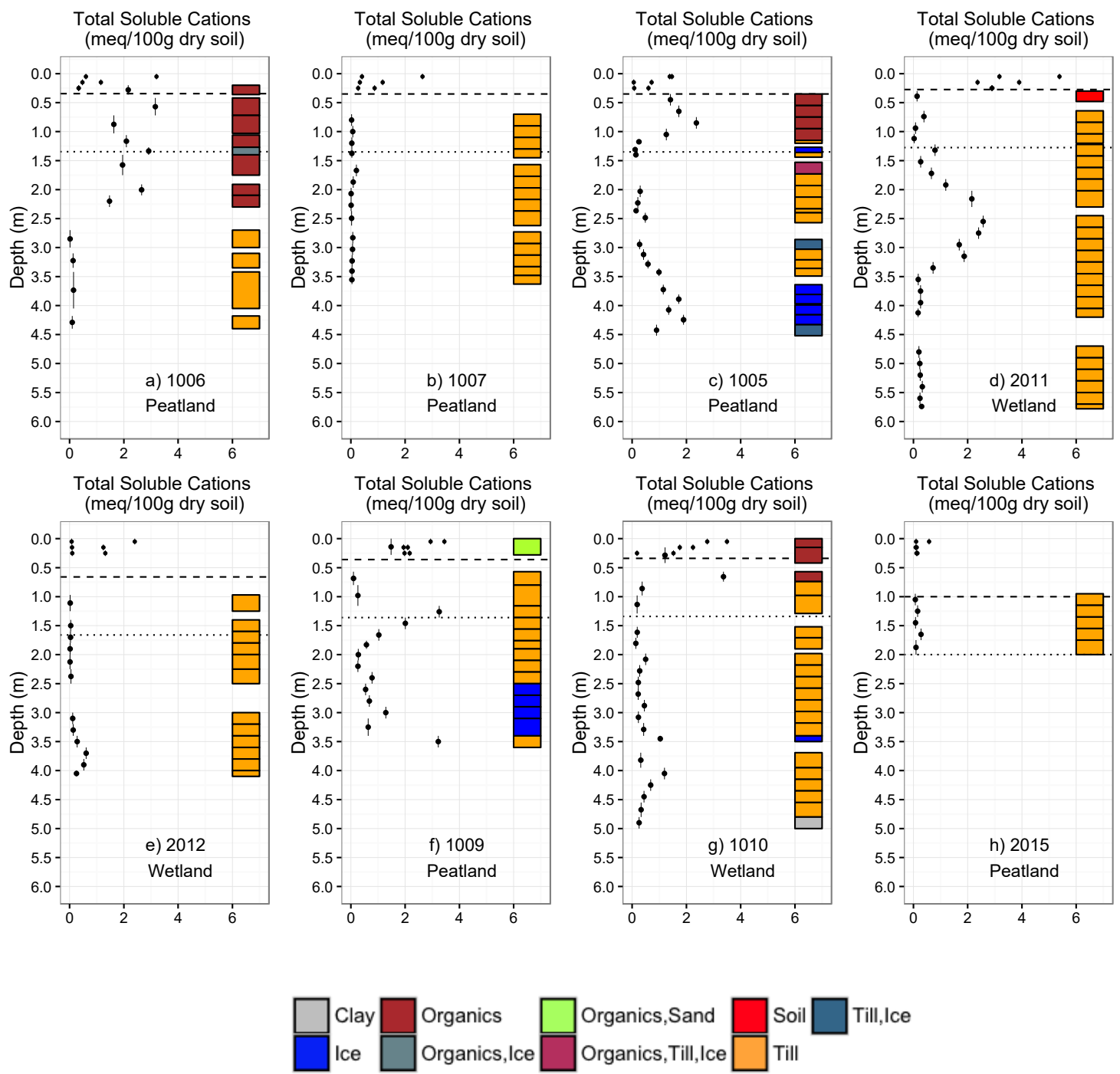

Figure 4.10 Profiles of total soluble cations in the active layer and permafrost, peatlands and wetlands sites, near Lac de Gras, N.W.T. The dashed line represents the thickness of the active layer at the time of sampling while the dotted line represents the inferred depth of the near-surface permafrost while the dotted line represents the lower boundary of the near-surface permafrost (See Figure 3.4 to 3.7 for location context). 
Table 4.1 Mean total soluble cation concentrations of various sites located within the peatlands and wetlands sites

\begin{tabular}{|c|c|c|c|c|c|c|c|c|c|c|}
\hline \multirow{3}{*}{$\begin{array}{l}\text { Borehole ID } \\
\text { (NGO-DD15- }\end{array}$} & \multicolumn{10}{|c|}{ Mean Total Soluble cations (meq/ 100g dry soil) } \\
\hline & \multicolumn{5}{|c|}{ Active Layer } & \multicolumn{5}{|c|}{ Permafrost } \\
\hline & $\mathrm{Ca}^{2+}$ & $\mathrm{Mg}^{2+}$ & $\mathrm{K}^{+}$ & $\mathrm{Na}^{+}$ & Total & $\mathrm{Ca}^{2+}$ & $\mathrm{Mg}^{2+}$ & $\mathrm{K}^{+}$ & $\mathrm{Na}^{+}$ & Total \\
\hline 1006 & 0.49 & 0.42 & 0.15 & 0.11 & 1.18 & 0.66 & 0.59 & 0.07 & 0.16 & 1.48 \\
\hline 1007 & 0.24 & 0.36 & 0.23 & 0.12 & 0.95 & 0.01 & 0.02 & 0.01 & 0.02 & 0.05 \\
\hline 1005 & 0.20 & 0.25 & 0.15 & 0.11 & 0.72 & 0.33 & 0.34 & 0.10 & 0.11 & 0.88 \\
\hline 2011 & 1.04 & 1.39 & 0.68 & 0.33 & 3.43 & 0.22 & 0.39 & 0.03 & 0.07 & 0.72 \\
\hline 2012 & 0.23 & 0.32 & 0.25 & 0.07 & 0.87 & 0.05 & 0.09 & 0.01 & 0.03 & 0.17 \\
\hline 1009 & 0.78 & 0.90 & 0.31 & 0.30 & 2.29 & 0.31 & 0.58 & 0.05 & 0.14 & 1.07 \\
\hline \multirow[t]{2}{*}{1010} & 0.82 & 0.97 & 0.64 & 0.24 & 2.67 & 0.17 & 0.30 & 0.03 & 0.07 & 0.57 \\
\hline & \multicolumn{5}{|c|}{ Top $1 \mathrm{~m}$ depth (unfrozen) } & \multicolumn{5}{|c|}{ Below $1 \mathrm{~m}$ depth (frozen) } \\
\hline 2015 & 0.08 & 0.07 & 0.01 & 0.03 & 0.19 & 0.03 & 0.04 & 0.00 & 0.06 & 0.14 \\
\hline
\end{tabular}


from the wetland site (2011) with $1.39 \mathrm{meq} / 100 \mathrm{~g}$, while in permafrost it was measured at the peatland site (1006) with $0.59 \mathrm{meq} / 100 \mathrm{~g}$ (Table 4.1). Similarly, $\mathrm{Ca}^{2+}$ was the other soluble cation whose relative abundance was quite high especially at the wetland sites (1010 and 2011), and one peatland site (1009) (Table 4.1). The concentrations of soluble $\mathrm{K}^{+}$and $\mathrm{Na}^{+}$were high in the active layer, but in permafrost they were relatively low (Table 4.1). In absolute terms, the concentration of soluble $\mathrm{Na}^{+}$was the lowest in the active layer at only two peatland sites, whereas in permafrost, soluble $\mathrm{K}^{+}$was recorded with their lowest concentrations at all sites (Table 4.1).

In till blanket, total soluble cation concentration of the active layer was generally low except at few sites from the top of the hill and steep slopes (2004, 2005 and 2007) (Figure 4.11b, c and e). At these three sites, soluble cation concentrations of the topmost layer between 0 and $10 \mathrm{~cm}$ depth were much higher, and declined with the elevation from the top of the hill down the steep slope, to the lowest at the bottom of the hill (Figure 4.11d). These variations in cation concentrations of the active layer along a hillslope correspond to the processes explained in Section 2.4.2.2 and Figure 2.6, on how geochemical conditions vary between depositional and erosive permafrost environments. The same phenomenon however could not be explained with the data obtained from Hill 3 as the active layer consisted of relatively low concentrations, both at the top of the hill as well as the hill bottom (Figure 4.11f and g).

Mean total soluble cation concentrations of the top $1 \mathrm{~m}$ and the ground below it indicated that four of seven sites were enriched with higher soluble cation concentrations in permafrost than in the active layer in till blanket terrain (Table 4.2). The mean concentration of cations in permafrost was very low, between 0.22 to $0.50 \mathrm{meq} / 100 \mathrm{~g}$. 


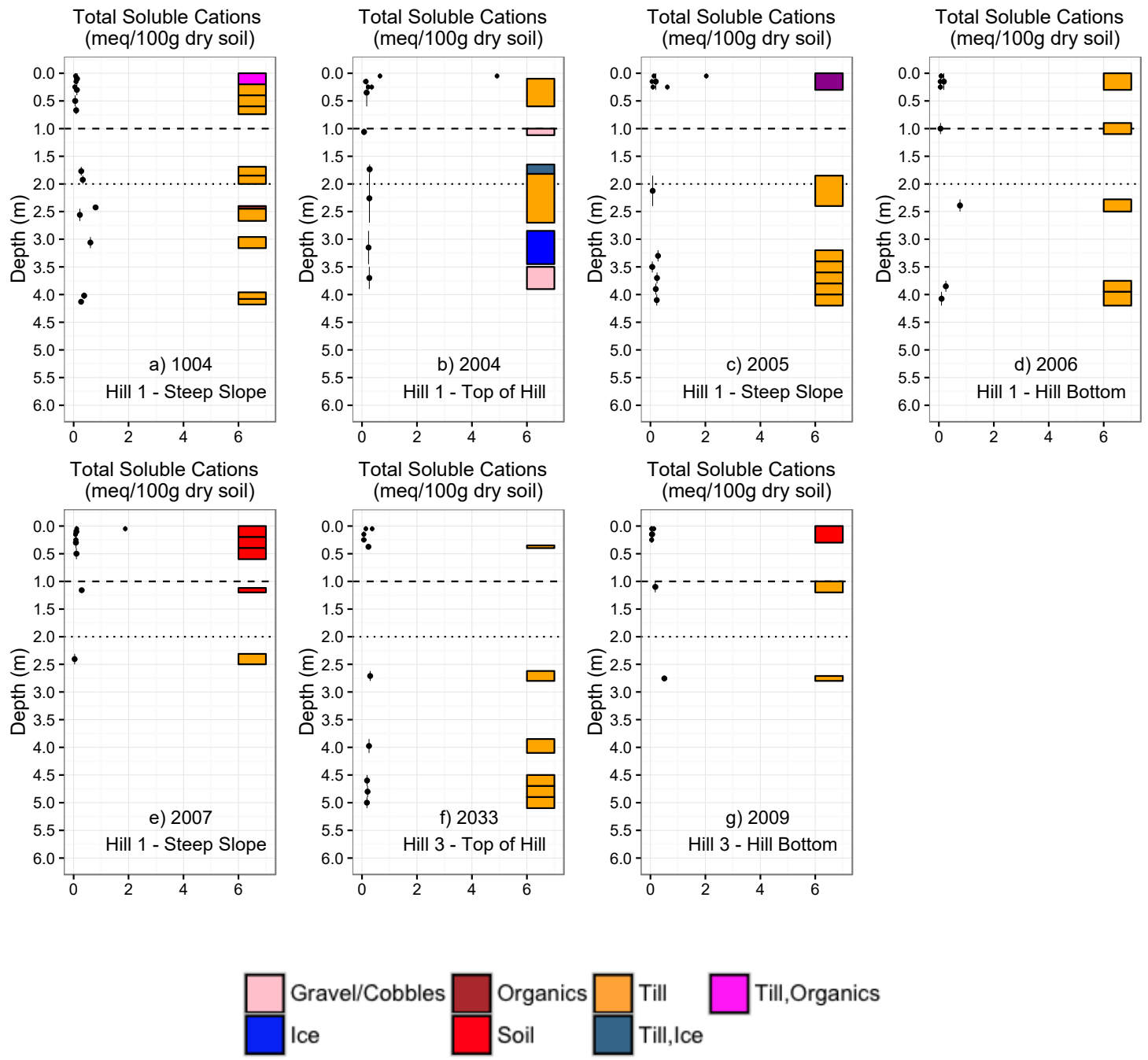

Figure 4.11 Profiles of total soluble cations from till blanket sites, near Lac de Gras, N.W.T. The dashed line represents the thickness of the active layer at the time of sampling while the dotted line represents the lower boundary of the near-surface permafrost (See Figure 3.4 to 3.7 for location context). 
Table 4.2 Mean total soluble cation concentrations of various sites located within the till blanket sites

\begin{tabular}{cccccccccccc}
\hline & \multicolumn{8}{c}{ Mean Total Soluble cations (meq/ 100g dry soil) } \\
$\begin{array}{c}\text { Borehole ID } \\
\text { (NGO-DD15- }\end{array}$ & \multicolumn{3}{c}{ Top 1 m depth (unfrozen) } & \multicolumn{5}{c}{ Below 1 m depth (frozen) } \\
\hline $\mathrm{Ca}^{2+}$ & $\mathrm{Mg}^{2+}$ & $\mathrm{K}^{+}$ & $\mathrm{Na}^{+}$ & Total & $\mathrm{Ca}^{2+}$ & $\mathrm{Mg}^{2+}$ & $\mathrm{K}^{+}$ & $\mathrm{Na}^{+}$ & Total \\
\hline 1004 & 0.03 & 0.02 & 0.01 & 0.03 & 0.08 & 0.10 & 0.12 & 0.07 & 0.08 & 0.37 \\
2004 & 0.27 & 0.45 & 0.20 & 0.03 & 0.94 & 0.06 & 0.11 & 0.03 & 0.02 & 0.23 \\
2005 & 0.16 & 0.19 & 0.09 & 0.03 & 0.47 & 0.06 & 0.07 & 0.04 & 0.03 & 0.18 \\
2006 & 0.03 & 0.03 & 0.01 & 0.02 & 0.08 & 0.11 & 0.13 & 0.03 & 0.03 & 0.30 \\
2033 & 0.05 & 0.06 & 0.01 & 0.02 & 0.14 & 0.06 & 0.09 & 0.04 & 0.03 & 0.22 \\
2007 & 0.09 & 0.10 & 0.06 & 0.03 & 0.29 & 0.01 & 0.01 & 0.01 & 0.01 & 0.04 \\
2009 & 0.02 & 0.03 & 0.01 & 0.02 & 0.08 & 0.15 & 0.24 & 0.07 & 0.04 & 0.50 \\
\hline
\end{tabular}


However, mean total soluble cation concentration in the top $1 \mathrm{~m}$ depth was recorded up to $0.94 \mathrm{meq} / 100 \mathrm{~g}$ at the hilltop site (2004) (Table 4.2).

In till blanket, soluble cation concentrations at depth in permafrost of few sites increased to more than double those present at the near-surface permafrost (Figure 4.11a, $\mathrm{d}$ and g). For example, at the till steep slope site (1004), an increase in the concentration from $0.33 \mathrm{meq} / 100 \mathrm{~g}$ to $0.80 \mathrm{meq} / 100 \mathrm{~g}$ was evident between the depths of 2.0 and 2.5 m. At the hill bottom sites (2006 and 2009), a similar increase in cation concentration was observed at depths of around $2.5 \mathrm{~m}$ where soluble cations reached up to $0.77 \mathrm{meq} / 100 \mathrm{~g}$ (Figure 4.11d and 4.11g).

In till blanket, $\mathrm{Mg}^{2+}$ was the dominant cation reported from the top $1 \mathrm{~m}$ and below $1 \mathrm{~m}$ depth at most sites (Table 4.2). Similarly, $\mathrm{Ca}^{2+}$ was also available in comparable amounts, but the absolute concentrations of both ions were low, not more than 0.45 meq/100 g (Table 4.2). Furthermore, soluble $\mathrm{K}^{+}$and $\mathrm{Na}^{+}$were also detected, and the relative abundances of these two ions were quite comparable with other cations, especially from the permafrost.

In till veneer, active layer soluble cation concentrations at the low-lying hill bottom sites (2018 and 2019) were comparatively higher than those at depths in permafrost (Figure 4.12b and e). At the low-lying depression site (2018), mean total soluble cation concentrations of the active layer reached up to $0.90 \mathrm{meq} / 100 \mathrm{~g}$, while in permafrost was only about $0.25 \mathrm{meq} / 100 \mathrm{~g}$ (Table 4.3 ). Similarly, at the hill bottom site (2019) mean total soluble cation concentrations in the active layer was nearly double those in permafrost (Table 4.3). The high concentrations of soluble cations at the topmost layers of these sites were mostly related to the organic samples. 

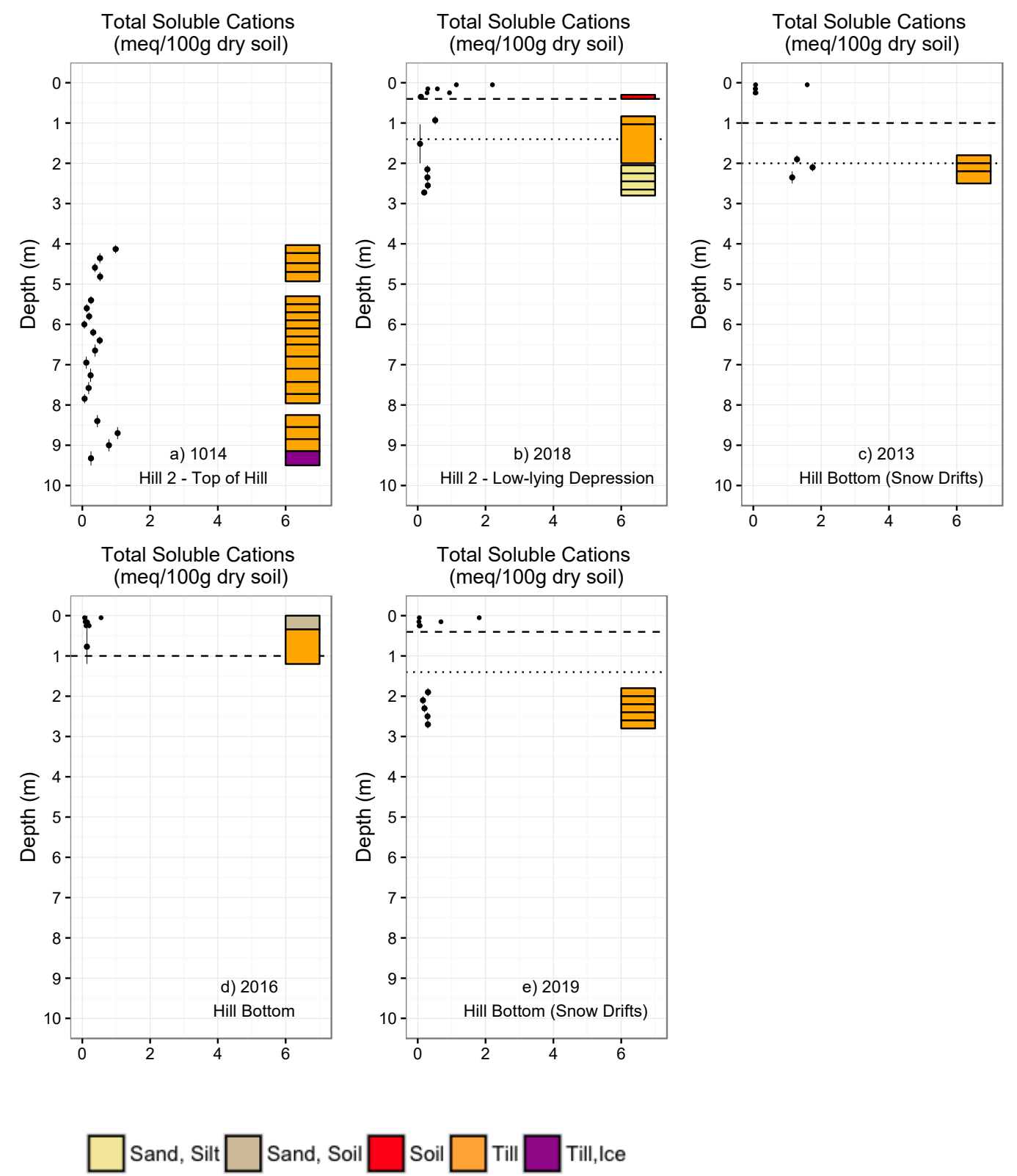

Figure 4.12 Profiles of total soluble cations in the active layer and permafrost, till veneer sites, near Lac de Gras, N.W.T. The dashed line represents the thickness of the active layer at the time of sampling while the dotted line represents the lower boundary of the near-surface permafrost (See Figure 3.4 to 3.7 for location context). 
Table 4.3 Mean total soluble cation concentrations of various sites located within the till veneer sites

\begin{tabular}{|c|c|c|c|c|c|c|c|c|c|c|}
\hline \multirow{3}{*}{$\begin{array}{l}\text { Borehole ID } \\
\text { (NGO-DD15- }\end{array}$} & \multicolumn{10}{|c|}{ Mean Total Soluble cations (meq/ 100g dry soil) } \\
\hline & \multicolumn{5}{|c|}{ Active Layer } & \multicolumn{5}{|c|}{$\underline{\text { Permafrost }}$} \\
\hline & $\mathrm{Ca}^{2+}$ & $\mathrm{Mg}^{2+}$ & $\mathrm{K}^{+}$ & $\mathrm{Na}^{+}$ & Total & $\mathrm{Ca}^{2+}$ & $\mathrm{Mg}^{2+}$ & $\mathrm{K}^{+}$ & $\mathrm{Na}^{+}$ & Total \\
\hline 2018 & 0.28 & 0.34 & 0.09 & 0.19 & 0.90 & 0.09 & 0.11 & 0.01 & 0.03 & 0.25 \\
\hline \multirow[t]{2}{*}{2019} & 0.15 & 0.14 & 0.11 & 0.05 & 0.45 & 0.06 & 0.13 & 0.01 & 0.05 & 0.25 \\
\hline & \multicolumn{5}{|c|}{ Top $1 \mathrm{~m}$ depth (unfrozen) } & \multicolumn{5}{|c|}{ Below $1 \mathrm{~m}$ depth (frozen) } \\
\hline 1014 & $\mathrm{~N} / \mathrm{A}$ & N/A & N/A & $\mathrm{N} / \mathrm{A}$ & N/A & 0.13 & 0.16 & 0.07 & 0.04 & 0.39 \\
\hline 2013 & 0.06 & 0.09 & 0.13 & 0.04 & 0.32 & 0.45 & 0.83 & 0.02 & 0.09 & 1.39 \\
\hline 2016 & 0.06 & 0.06 & 0.02 & 0.03 & 0.17 & 0 & 0 & 0 & 0 & 0 \\
\hline
\end{tabular}


Few sites also contained high soluble cation concentrations at depth in permafrost (Figure 4.12a and c). For example, at the hilltop site (1014), total soluble cation concentrations at depth between $4.0 \mathrm{~m}$ and $9.5 \mathrm{~m}$ ranged between 0.06 to $1.04 \mathrm{meq} / 100 \mathrm{~g}$, and fluctuations mostly followed the ice-rich intervals (Figure 4.12a and Figure 4.4a). However, this was not true at the hill bottom site (2013) (Figure 4.12c and Figure 4.4c). The depth interval between $2.0 \mathrm{~m}$ and $2.5 \mathrm{~m}$ contained high concentration of soluble cations, greater than $1.1 \mathrm{meq} / 100 \mathrm{~g}$, but the excess ice contents at this depth interval were much lower.

In till veneer, $\mathrm{Mg}^{2+}$ was the dominant cation reported from the permafrost at all sites. The concentration of soluble $\mathrm{Mg}^{2+}$ in permafrost ranged between 0.11 to 0.83 meq/100 $\mathrm{g}$ (Table 4.3). In the active layer, $\mathrm{Mg}^{2+}$ was a dominant cation at only two sites in 2018 and 2019 (Table 4.3). At other sites, active layer soluble cation concentration was either dominated by $\mathrm{Ca}^{2+}$ ions or the relative abundance of $\mathrm{Ca}^{2+}$ was comparable with soluble $\mathrm{Mg}^{2+}$ ions. Similarly, soluble $\mathrm{K}^{+}$and $\mathrm{Na}^{+}$were also present in considerable amounts within the active layer at till veneer sites, but the relative abundances of these ions in permafrost was comparatively low (Table 4.3).

At the esker sites, the relative and absolute concentrations of total soluble cations in the active layer and in permafrost were very low (Figure 4.13). A comparison of mean total soluble cation concentrations indicated that permafrost had higher soluble cation concentrations than the active layer (Table 4.4). Most sites in eskers indicated very low total soluble cation concentration of less than $0.25 \mathrm{meq} / 100 \mathrm{~g}$ except at 2028 . At this 

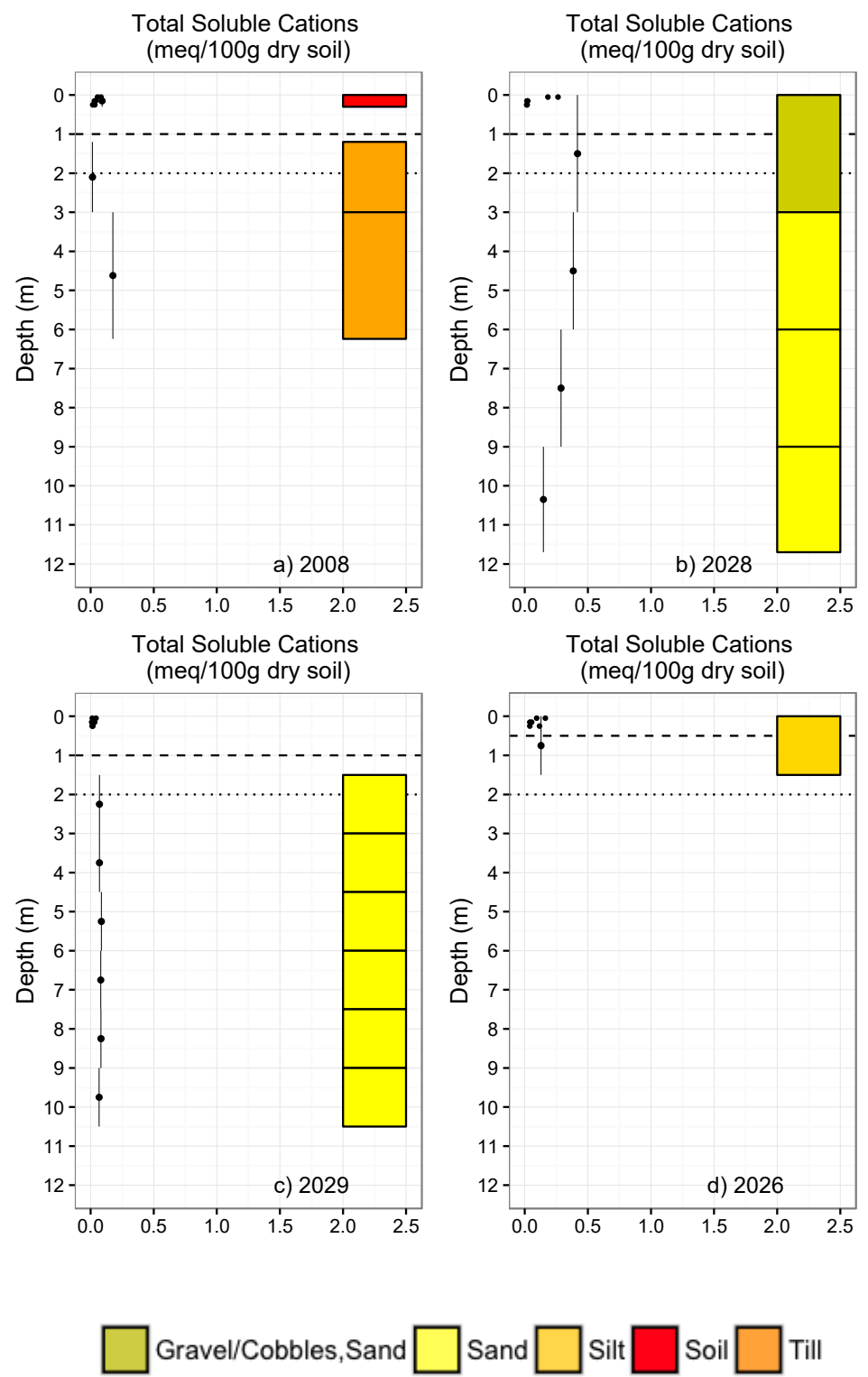

Figure 4.13 Profiles of total soluble cations from the esker sites, near Lac de Gras, N.W.T. The dashed line represents the thickness of the active layer at the time of sampling while the dotted line represents the lower boundary of the near-surface permafrost (See Figure 3.4 to 3.7 for location context). 
Table 4.4 Mean total soluble cation concentrations of various sites located within the esker sites

\begin{tabular}{|c|c|c|c|c|c|c|c|c|c|c|}
\hline \multirow{3}{*}{$\begin{array}{l}\text { Borehole ID } \\
\text { (NGO-DD15- }\end{array}$} & \multicolumn{10}{|c|}{ Mean Total Soluble cations (meq/ 100g dry soil) } \\
\hline & \multicolumn{5}{|c|}{ Top $50 \mathrm{~cm}$ depth (unfrozen) } & \multicolumn{5}{|c|}{ Below $50 \mathrm{~cm}$ depth (frozen) } \\
\hline & $\mathrm{Ca}^{2+}$ & $\mathrm{Mg}^{2+}$ & $\mathrm{K}^{+}$ & $\mathrm{Na}^{+}$ & Total & $\mathrm{Ca}^{2+}$ & $\mathrm{Mg}^{2+}$ & $\mathrm{K}^{+}$ & $\mathrm{Na}^{+}$ & Total \\
\hline \multirow[t]{2}{*}{2026} & 0.03 & 0.03 & 0.01 & 0.02 & 0.08 & 0.03 & 0.05 & 0.02 & 0.03 & 0.13 \\
\hline & \multicolumn{5}{|c|}{ Top $1 \mathrm{~m}$ depth (unfrozen) } & \multicolumn{5}{|c|}{ Below $1 \mathrm{~m}$ depth (frozen) } \\
\hline 2008 & 0.01 & 0.02 & 0.01 & 0.01 & 0.05 & 0.01 & 0.01 & 0.02 & 0.04 & 0.10 \\
\hline 2028 & 0.01 & 0.04 & 0.02 & 0.01 & 0.09 & 0.05 & 0.08 & 0.07 & 0.11 & 0.31 \\
\hline 2029 & 0.01 & 0.00 & 0.00 & 0.01 & 0.02 & 0.01 & 0.01 & 0.02 & 0.05 & 0.08 \\
\hline
\end{tabular}


particular site, soluble cation concentration in the near-surface permafrost was more than threefold greater than those in the overlying active layer, however the concentration declined gradually with the remaining depths (Figure 4.13b). A similar pattern was observed in the near-surface permafrost at site 2026, however the increment in cation concentration from the base of the active layer to this layer was very low. In contrast, the profiles of cation concentrations obtained from the esker sites were quite similar to their water content GWB profiles, indicating some relations between water content and soluble cations (Figure 4.13 and 4.5).

At the esker sites, the relative abundance of $\mathrm{K}^{+}$and $\mathrm{Na}^{+}$was quite high in permafrost, and comprised between $58 \%$ to $87 \%$ of the total cations (Table 4.4 ). In the active layer, soluble cation concentrations were relatively low and quite comparable with each other. $\mathrm{Mg}^{2+}$ was the dominant cation reported from the active layer at the esker sites, whereas permafrost was dominated by $\mathrm{Na}^{+}$ions.

\subsubsection{Summary}

Measurements were conducted across four different terrain types: peatlands and wetlands, till blanket, till veneer and eskers allowing the assessment of water content GWB, organic matter content and soluble cation content variations. They were highly variable within each terrain type and with depth. Unitcode was observed to have a major influence upon the measured variables within each terrain type. At all sites, water content GWB ranged from 2 to $99 \%$, excess ice content ranged from 0 to $98 \%$, organic matter content ranged from 0.5 to $89 \%$ and total soluble cations varied from less than 0.1 to 8 meq/100g dry. Summary statistics tables of the measured variables are presented in two 
different ways - (1) with respect to depth, integrating from the surface + the depths of 0.5 m, $1 \mathrm{~m}, 2 \mathrm{~m}, 4 \mathrm{~m}, 6 \mathrm{~m}$ and $10 \mathrm{~m}$ (Appendix F), and (2) with respect to strata, i.e., in the active layer, near-surface permafrost and at depth in permafrost (Tables 4.5, 4.6 and 4.7).

In comparing variations with respect to depth and sites statistically, the number of sample $(\mathrm{N})$ and actual percentage sampled (PS) were the limiting factors in the near-surface permafrost and also at depth in permafrost. PS is the actual interval sampled from the active layer, near-surface permafrost or from the permafrost at depth expressed as a percentage of the total thickness of that layer. N and PS were extremely low in the active layer of some sites for the organic matter content. Thus, variations with respect to depth are presented graphically with plots for describing the absolute amounts of water, organic matter and soluble cations at different depths.

\subsubsection{Gravimetric Water Content (\%) Variations}

Gravimetric water content was highly variable between depths for all terrain types except the eskers (Figure 4.14A). Similarly, water content GWB also varied between terrain types, and was observed to be the lowest at the esker sites. The highest water content GWB values were associated with the active layers in peatlands and wetlands with the median of $83 \%$, which is due to wet conditions and high organic matter in the uppermost layers of those sites. Till blanket and till veneer contained lower water contents in the active layer. A few sites from peatlands and wetlands, and till veneer have high median water contents GWB in the near-surface permafrost (Figure 4.14A). Water content GWB at depth in permafrost was also high, and were quite similar between two terrains (peatlands and wetlands and till veneer) with median of about $40 \%$, whereas in till blanket it was much higher 
Table 4.5 and Table 4.6: Summary statistics of gravimetric water content GWB (\%) and organic matter content GDB (\%) in the active layer, near-surface permafrost and at depth in permafrost of 24 sites near Lac de Gras, N.W.T. N is the number of samples, PS (\%) is the percentage of total sampling that was considered and N/A values delineate depth intervals where no samples were recovered or core lengths that did not reach the specified depths.

\begin{tabular}{|c|c|c|c|c|c|c|c|c|c|c|c|c|c|c|c|c|c|c|c|c|c|}
\hline \multirow{2}{*}{$\begin{array}{l}\text { 4.5. GWB } \\
\text { Terrain }\end{array}$} & \multirow[b]{2}{*}{ Core ID } & \multicolumn{7}{|c|}{ Active Layer } & \multicolumn{7}{|c|}{ Near-Surface Permafrost } & \multicolumn{6}{|c|}{ Permafrost Depth } \\
\hline & & $\mathrm{N}$ & $\begin{array}{l}\text { PS } \\
(\%)\end{array}$ & Mean & Median & $\operatorname{Max}$ & Min & SD & $\mathrm{N}$ & $\begin{array}{l}\text { PS } \\
(\%)\end{array}$ & Mean & Median & $\operatorname{Max}$ & Min & SD & $\mathrm{N}$ & Mean & Median & $\operatorname{Max}$ & Min & SD \\
\hline \multirow{8}{*}{ Peatlands and wetlands } & 1006 & 7 & 100 & 81.3 & 80.9 & 89.3 & 78.0 & 3.8 & 4 & 90 & 85.8 & 85.9 & 88.6 & 82.8 & 2.5 & 7 & 48.5 & 32.7 & 84.4 & 11.6 & 32.7 \\
\hline & 1007 & 6 & 86 & 84.2 & 84.9 & 86.8 & 80.0 & 2.6 & 3 & 60 & 42.0 & 40.8 & 52.3 & 33.0 & 9.7 & 11 & 21.8 & 9.8 & 61.8 & 5.2 & 21.0 \\
\hline & 1005 & 6 & 86 & 59.7 & 83.2 & 85.3 & 10.6 & 37.8 & 6 & 93 & 55.3 & 63.7 & 81.9 & 14.9 & 25.5 & 14 & 55.5 & 49.5 & 98.7 & 11.6 & 32.1 \\
\hline & 2011 & 6 & 100 & 90.4 & 90.6 & 92.1 & 87.6 & 1.6 & 4 & 75 & 43.6 & 45.4 & 55.8 & 27.7 & 14.0 & 20 & 28.3 & 22.5 & 54.1 & 19.2 & 11.5 \\
\hline & 2012 & 6 & 55 & 43.8 & 42.4 & 76.1 & 17.4 & 28.4 & 2 & 48 & 35.8 & 35.8 & 42.2 & 29.3 & 9.2 & 10 & 41.2 & 44.2 & 52.5 & 13.2 & 12.0 \\
\hline & 1009 & 7 & 83 & 81.3 & 82.2 & 91.1 & 59.5 & 10.8 & 3 & 79 & 55.9 & 48.1 & 73.7 & 45.8 & 15.5 & 11 & 56.9 & 53.7 & 65.5 & 45.9 & 6.4 \\
\hline & 1010 & 8 & 100 & 77.7 & 84.7 & 92.8 & 45.9 & 16.9 & 3 & 72 & 63.5 & 59.3 & 76.8 & 54.4 & 11.8 & 16 & 45.2 & 41.7 & 71.7 & 30.3 & 11.0 \\
\hline & 2015 & 6 & 30 & 20.4 & 17.9 & 31.8 & 16.4 & 5.9 & 5 & 100 & 39.5 & 34.1 & 53.2 & 29.3 & 11.5 & 0 & $\mathrm{~N} / \mathrm{A}$ & N/A & N/A & N/A & N/A \\
\hline \multirow[t]{7}{*}{ Till Blanket } & 1004 & 10 & 74 & 7.9 & 8.4 & 10.5 & 4.1 & 2.2 & 2 & 31 & 8.0 & 8.0 & 9.3 & 6.7 & 1.9 & 5 & 13.2 & 12.9 & 25.9 & 6.3 & 7.8 \\
\hline & 2004 & 7 & 60 & 23.3 & 14.7 & 68.2 & 8.7 & 22.3 & 2 & 29 & 17.5 & 17.5 & 20.6 & 14.4 & 4.3 & 3 & 67.0 & 63.9 & 76.1 & 61.0 & 8.0 \\
\hline & 2005 & 7 & 30 & 18.4 & 8.6 & 60.7 & 7.5 & 19.6 & 0 & 0 & $\mathrm{~N} / \mathrm{A}$ & N/A & N/A & N/A & N/A & 6 & 54.5 & 67.5 & 75.9 & 12.6 & 25.6 \\
\hline & 2006 & 8 & 40 & 8.9 & 9.5 & 11.4 & 3.5 & 2.4 & 0 & 0 & $\mathrm{~N} / \mathrm{A}$ & N/A & N/A & N/A & $\mathrm{N} / \mathrm{A}$ & 3 & 41.0 & 34.6 & 73.1 & 15.3 & 29.5 \\
\hline & 2033 & 7 & 35 & 10.5 & 9.0 & 19.5 & 7.1 & 4.3 & 0 & 0 & $\mathrm{~N} / \mathrm{A}$ & N/A & N/A & N/A & N/A & 5 & 64.9 & 63.5 & 76.1 & 53.5 & 8.7 \\
\hline & 2007 & 9 & 60 & 15.2 & 10.9 & 55.9 & 7.8 & 15.3 & 1 & 8 & 8.8 & 8.8 & 8.8 & 8.8 & N/A & 1 & 30.7 & 30.7 & 30.7 & 30.7 & N/A \\
\hline & 2009 & 7 & 30 & 10.1 & 10.2 & 12.6 & 6.9 & 1.8 & 1 & 20 & 6.8 & 6.8 & 6.8 & 6.8 & N/A & 1 & 68.0 & 68.0 & 68.0 & 68.0 & N/A \\
\hline \multirow[t]{5}{*}{ Till Veneer } & 2018 & 7 & 40 & 74.5 & 82.9 & 88.6 & 24.4 & 22.6 & 1 & 20 & 55.8 & 55.8 & 55.8 & 55.8 & N/A & 5 & 46.7 & 48.7 & 60.9 & 31.3 & 11.3 \\
\hline & 2019 & 6 & 75 & 39.9 & 24.0 & 83.1 & 14.4 & 31.7 & 0 & 0 & $\mathrm{~N} / \mathrm{A}$ & N/A & N/A & N/A & $\mathrm{N} / \mathrm{A}$ & 5 & 31.4 & 30.3 & 40.8 & 20.9 & 7.5 \\
\hline & 1014 & 0 & 0 & $\mathrm{~N} / \mathrm{A}$ & N/A & N/A & N/A & N/A & 0 & 0 & $\mathrm{~N} / \mathrm{A}$ & N/A & N/A & N/A & N/A & 19 & 71.0 & 81.8 & 93.0 & 24.3 & 21.1 \\
\hline & 2013 & 6 & 30 & 24.3 & 15.2 & 71.7 & 10.6 & 23.5 & 1 & 20 & 31.6 & 31.6 & 31.6 & 31.6 & $\mathrm{~N} / \mathrm{A}$ & 2 & 26.2 & 26.2 & 29.2 & 23.1 & 4.3 \\
\hline & 2016 & 8 & 100 & 16.8 & 15.4 & 27.3 & 13.0 & 4.6 & 0 & 0 & $\mathrm{~N} / \mathrm{A}$ & N/A & N/A & N/A & N/A & 0 & $\mathrm{~N} / \mathrm{A}$ & N/A & N/A & N/A & N/A \\
\hline \multirow{4}{*}{ Eskers } & 2026 & 6 & 60 & 23.2 & 24.4 & 29.1 & 17.7 & 4.3 & 0 & 0 & $\mathrm{~N} / \mathrm{A}$ & N/A & N/A & $\mathrm{N} / \mathrm{A}$ & N/A & 0 & $\mathrm{~N} / \mathrm{A}$ & $\mathrm{N} / \mathrm{A}$ & N/A & $\mathrm{N} / \mathrm{A}$ & $\mathrm{N} / \mathrm{A}$ \\
\hline & 2008 & 7 & 30 & 13.8 & 15.6 & 20.3 & 4.4 & 6.5 & 0 & 0 & $\mathrm{~N} / \mathrm{A}$ & N/A & N/A & N/A & $\mathrm{N} / \mathrm{A}$ & 2 & 25.8 & 25.8 & 41.9 & 9.6 & 22.8 \\
\hline & 2028 & 6 & 30 & 14.2 & 16.2 & 21.8 & 2.3 & 7.2 & 1 & 100 & 17.6 & 17.6 & 17.6 & 17.6 & N/A & 3 & 16.3 & 16.2 & 17.7 & 15.0 & 1.3 \\
\hline & 2029 & 6 & 30 & 4.7 & 3.0 & 10.2 & 2.1 & 3.3 & 0 & 0 & $\mathrm{~N} / \mathrm{A}$ & N/A & N/A & N/A & $\mathrm{N} / \mathrm{A}$ & 7 & 13.7 & 14.4 & 15.2 & 9.4 & 2.0 \\
\hline \multicolumn{2}{|l|}{ 4.6. Organic Matter } & \multicolumn{4}{|c|}{ Active Layer } & & & & \multicolumn{7}{|c|}{ Near-Surface Permafrost } & $\overline{\text { Per }}$ & afrost & epth & & & \\
\hline & & & PS & & & & & & & PS & & & & & & & & & & & \\
\hline Terrain & Core ID & $\mathrm{N}$ & $(\%)$ & Mean & Median & Max & Min & SD & $\mathrm{N}$ & (\%) & Mean & Median & Max & Min & $\mathrm{SD}$ & $\mathrm{N}$ & Mean & Median & Max & Min & SD \\
\hline Peatlands and wetlands & 1006 & 1 & 45 & 89.4 & 89.4 & 89.4 & 89.4 & $\mathrm{~N} / \mathrm{A}$ & 4 & 90 & 82.5 & 82.0 & 87.8 & 78.4 & 4.9 & 7 & 36.2 & 4.2 & 86.3 & 1.1 & 42.7 \\
\hline & 1007 & 0 & 0 & N/A & N/A & N/A & N/A & N/A & 3 & 60 & 5.0 & 3.5 & 9.2 & 2.4 & 3.6 & 11 & 1.3 & 1.0 & 3.0 & 0.8 & 0.7 \\
\hline & 1005 & 0 & 0 & N/A & N/A & N/A & N/A & N/A & 6 & 93 & 44.2 & 50.8 & 80.6 & 1.0 & 32.5 & 16 & 3.5 & 2.3 & 9.3 & 0.9 & 2.8 \\
\hline & 2011 & 0 & 0 & N/A & N/A & N/A & N/A & N/A & 4 & 75 & 3.8 & 3.5 & 4.8 & 3.5 & 0.6 & 19 & 0.8 & 0.8 & 1.9 & 0.5 & 0.3 \\
\hline & 2012 & 0 & 0 & N/A & $\mathrm{N} / \mathrm{A}$ & N/A & N/A & $\mathrm{N} / \mathrm{A}$ & 2 & 48 & 3.2 & 3.2 & 5.3 & 1.1 & 2.9 & 10 & 1.5 & 1.2 & 3.2 & 0.9 & 0.8 \\
\hline & 1009 & 1 & 78 & 26.3 & 26.3 & 26.3 & 26.3 & N/A & 3 & 79 & 6.0 & 3.9 & 10.6 & 3.3 & 4.1 & 11 & 2.4 & 1.6 & 8.4 & 1.1 & 2.2 \\
\hline & 1010 & 1 & 79 & 27.4 & 27.4 & 27.4 & 27.4 & N/A & 3 & 72 & 18.8 & 2.7 & 51.8 & 2.1 & 28.5 & 16 & 1.5 & 1.4 & 3.1 & 0.7 & 0.6 \\
\hline & 2015 & 0 & 0 & $\mathrm{~N} / \mathrm{A}$ & N/A & N/A & N/A & N/A & 5 & 100 & 1.4 & 1.2 & 1.9 & 1.0 & 0.4 & 0 & $\mathrm{~N} / \mathrm{A}$ & N/A & N/A & $\mathrm{N} / \mathrm{A}$ & N/A \\
\hline Till Blanket & 1004 & 10 & 74 & 2.2 & 1.3 & 7.1 & 0.9 & 2.0 & 2 & 31 & 2.6 & 2.6 & 3.0 & 2.2 & 0.6 & 5 & 1.1 & 0.8 & 2.1 & 0.6 & 0.6 \\
\hline & 2004 & 1 & 60 & 2.8 & 2.8 & 2.8 & 2.8 & N/A & 2 & 29 & 1.2 & 1.2 & 1.2 & 1.1 & 0.1 & 3 & 2.3 & 1.2 & 4.8 & 1.0 & 2.1 \\
\hline & 2005 & 1 & 30 & 1.6 & 1.6 & 1.6 & 1.6 & N/A & 0 & 0 & $\mathrm{~N} / \mathrm{A}$ & $\mathrm{N} / \mathrm{A}$ & N/A & N/A & $\mathrm{N} / \mathrm{A}$ & 6 & 0.7 & 0.7 & 1.1 & 0.3 & 0.3 \\
\hline & 2006 & 8 & 40 & 1.7 & 1.3 & 3.3 & 0.7 & 1.0 & 0 & 0 & N/A & N/A & N/A & N/A & N/A & 3 & 0.8 & 0.9 & 1.0 & 0.6 & 0.2 \\
\hline & 2033 & 1 & 5 & 2.9 & 2.9 & 2.9 & 2.9 & N/A & 0 & 0 & $\mathrm{~N} / \mathrm{A}$ & N/A & N/A & N/A & $\mathrm{N} / \mathrm{A}$ & 5 & 1.1 & 1.1 & 1.1 & 1.0 & 0.1 \\
\hline & 2007 & 3 & 60 & 2.1 & 2.0 & 2.4 & 1.8 & 0.3 & 1 & 8 & 2.0 & 2.0 & 2.0 & 2.0 & N/A & 1 & 6.0 & 6.0 & 6.0 & 6.0 & N/A \\
\hline & 2009 & 7 & 30 & 1.1 & 1.0 & 2.0 & 0.4 & 0.5 & 1 & 20 & 0.9 & 0.9 & 0.9 & 0.9 & $\mathrm{~N} / \mathrm{A}$ & 1 & 0.9 & 0.9 & 0.9 & 0.9 & N/A \\
\hline Till Veneer & 2018 & 1 & 10 & 3.9 & 3.9 & 3.9 & 3.9 & N/A & 1 & 20 & 66.1 & 66.1 & 66.1 & 66.1 & $\mathrm{~N} / \mathrm{A}$ & 5 & 4.3 & 2.3 & 12.3 & 1.8 & 4.5 \\
\hline & 2019 & 0 & 0 & $\mathrm{~N} / \mathrm{A}$ & N/A & N/A & N/A & N/A & 0 & 0 & $\mathrm{~N} / \mathrm{A}$ & N/A & N/A & N/A & N/A & 5 & 0.9 & 0.8 & 1.4 & 0.6 & 0.3 \\
\hline & 1014 & 0 & 0 & $\mathrm{~N} / \mathrm{A}$ & N/A & N/A & N/A & N/A & 0 & 0 & $\mathrm{~N} / \mathrm{A}$ & $\mathrm{N} / \mathrm{A}$ & N/A & N/A & N/A & 19 & 1.2 & 1.1 & 1.6 & 1.0 & 0.2 \\
\hline & 2013 & 0 & 0 & $\mathrm{~N} / \mathrm{A}$ & N/A & N/A & N/A & N/A & 1 & 20 & 1.1 & 1.1 & 1.1 & 1.1 & N/A & 2 & 1.2 & 1.2 & 1.3 & 1.2 & 0.0 \\
\hline & 2016 & 8 & 100 & 2.5 & 1.8 & 6.3 & 1.3 & 1.7 & 0 & 0 & $\mathrm{~N} / \mathrm{A}$ & N/A & N/A & N/A & N/A & 0 & $\mathrm{~N} / \mathrm{A}$ & N/A & N/A & N/A & N/A \\
\hline Eskers & 2026 & 6 & 60 & 2.9 & 3.0 & 5.2 & 0.8 & 1.6 & 0 & 0 & $\mathrm{~N} / \mathrm{A}$ & $\mathrm{N} / \mathrm{A}$ & $\mathrm{N} / \mathrm{A}$ & $\mathrm{N} / \mathrm{A}$ & $\mathrm{N} / \mathrm{A}$ & 0 & $\mathrm{~N} / \mathrm{A}$ & $\mathrm{N} / \mathrm{A}$ & $\mathrm{N} / \mathrm{A}$ & $\mathrm{N} / \mathrm{A}$ & $\mathrm{N} / \mathrm{A}$ \\
\hline & 2008 & 7 & 30 & 4.2 & 4.0 & 5.7 & 2.7 & 1.0 & 0 & 0 & $\mathrm{~N} / \mathrm{A}$ & N/A & N/A & N/A & N/A & 2 & 0.7 & 0.7 & 0.9 & 0.4 & 0.3 \\
\hline & 2028 & 0 & 0 & N/A & N/A & N/A & N/A & N/A & 1 & 100 & 0.7 & 0.7 & 0.7 & 0.7 & $\mathrm{~N} / \mathrm{A}$ & 3 & 0.9 & 0.9 & 1.2 & 0.5 & 0.3 \\
\hline & 2029 & 6 & 30 & 2.1 & 1.5 & 6.2 & 0.7 & 2.0 & 0 & 0 & $\mathrm{~N} / \mathrm{A}$ & N/A & N/A & N/A & N/A & 7 & 0.4 & 0.4 & 0.5 & 0.4 & 0.0 \\
\hline
\end{tabular}


Table 4.7 Summary statistics of total soluble cations (meq/100 g dry soil) in the active layer, near-surface permafrost and at depth in permafrost of 24 sites near Lac de Gras, N.W.T. N is the number of samples, PS (\%) is the percentage of total sampling that was considered and N/A values delineate depth intervals where no samples were recovered or core lengths that did not reach the specified depths.

\begin{tabular}{|c|c|c|c|c|c|c|c|c|c|c|c|c|c|c|c|c|c|c|c|c|c|}
\hline \multirow[b]{2}{*}{ Terrain } & \multirow[b]{2}{*}{ Core ID } & \multicolumn{7}{|c|}{ Active Layer } & \multicolumn{7}{|c|}{ Near-Surface Permafrost } & \multicolumn{6}{|c|}{ Permafrost Depth } \\
\hline & & $\mathrm{N}$ & $\begin{array}{c}\text { PS } \\
(\%)\end{array}$ & Mean & Median & Max & Min & SD & $\mathrm{N}$ & $\begin{array}{l}\text { PS } \\
(\%) \\
\end{array}$ & Mean & Median & Max & Min & SD & $\mathrm{N}$ & Mean & Median & $\operatorname{Max}$ & Min & SD \\
\hline \multirow[t]{8}{*}{ Peatlands and wetlands } & 1006 & 7 & 100 & 1.2 & 0.6 & 3.2 & 0.3 & 1.1 & 4 & 90 & 2.4 & 2.5 & 3.2 & 1.6 & 0.7 & 7 & 0.9 & 0.1 & 2.7 & 0.0 & 1.1 \\
\hline & 1007 & 6 & 86 & 0.9 & 0.6 & 2.6 & 0.3 & 0.9 & 3 & 60 & 0.0 & 0.0 & 0.1 & 0.0 & 0.0 & 11 & 0.1 & 0.0 & 0.2 & 0.0 & 0.1 \\
\hline & 1005 & 6 & 86 & 0.7 & 0.7 & 1.5 & 0.1 & 0.6 & 6 & 93 & 1.2 & 1.3 & 2.4 & 0.1 & 0.9 & 14 & 0.8 & 0.5 & 1.9 & 0.1 & 0.6 \\
\hline & 2011 & 6 & 100 & 3.4 & 3.0 & 5.4 & 2.4 & 1.1 & 4 & 75 & 0.2 & 0.1 & 0.4 & 0.0 & 0.2 & 20 & 0.8 & 0.3 & 2.6 & 0.2 & 0.8 \\
\hline & 2012 & 6 & 55 & 0.9 & 0.7 & 2.4 & 0.1 & 1.0 & 2 & 48 & 0.0 & 0.0 & 0.0 & 0.0 & 0.0 & 10 & 0.2 & 0.1 & 0.6 & 0.0 & 0.2 \\
\hline & 1009 & 7 & 83 & 2.3 & 2.1 & 3.4 & 1.5 & 0.7 & 3 & 79 & 1.2 & 0.3 & 3.3 & 0.1 & 1.8 & 11 & 1.0 & 0.7 & 3.2 & 0.3 & 0.9 \\
\hline & 1010 & 8 & 100 & 2.7 & 2.0 & 8.1 & 0.2 & 2.4 & 3 & 72 & 1.3 & 0.4 & 3.4 & 0.2 & 1.8 & 16 & 0.4 & 0.3 & 1.2 & 0.1 & 0.3 \\
\hline & 2015 & 6 & 30 & 0.2 & 0.1 & 0.6 & 0.1 & 0.2 & 5 & 100 & 0.1 & 0.1 & 0.3 & 0.1 & 0.1 & 0 & $\mathrm{~N} / \mathrm{A}$ & N/A & N/A & N/A & $\mathrm{N} / \mathrm{A}$ \\
\hline \multirow{7}{*}{ Till Blanket } & 1004 & 10 & 74 & 0.1 & 0.1 & 0.1 & 0.0 & 0.0 & 2 & 31 & 0.3 & 0.3 & 0.3 & 0.3 & 0.0 & 5 & 0.5 & 0.4 & 0.8 & 0.2 & 0.2 \\
\hline & 2004 & 7 & 60 & 0.9 & 0.2 & 4.9 & 0.1 & 1.8 & 2 & 29 & 0.2 & 0.2 & 0.3 & 0.1 & 0.1 & 3 & 0.3 & 0.3 & 0.3 & 0.2 & 0.0 \\
\hline & 2005 & 7 & 30 & 0.5 & 0.2 & 2.0 & 0.1 & 0.7 & 0 & 0 & N/A & N/A & N/A & N/A & N/A & 6 & 0.2 & 0.2 & 0.3 & 0.1 & 0.1 \\
\hline & 2006 & 8 & 40 & 0.1 & 0.1 & 0.2 & 0.0 & 0.0 & 0 & 0 & N/A & N/A & N/A & N/A & $\mathrm{N} / \mathrm{A}$ & 3 & 0.4 & 0.3 & 0.8 & 0.1 & 0.4 \\
\hline & 2033 & 7 & 35 & 0.1 & 0.1 & 0.4 & 0.0 & 0.1 & 0 & 0 & N/A & N/A & N/A & N/A & N/A & 5 & 0.2 & 0.2 & 0.3 & 0.2 & 0.1 \\
\hline & 2007 & 9 & 60 & 0.3 & 0.1 & 1.9 & 0.1 & 0.6 & 1 & 8 & 0.3 & 0.3 & 0.3 & 0.3 & N/A & 1 & 0.0 & 0.0 & 0.0 & 0.0 & $\mathrm{~N} / \mathrm{A}$ \\
\hline & 2009 & 7 & 30 & 0.1 & 0.1 & 0.1 & 0.0 & 0.0 & 1 & 20 & 0.2 & 0.2 & 0.2 & 0.2 & N/A & 1 & 0.5 & 0.5 & 0.5 & 0.5 & $\mathrm{~N} / \mathrm{A}$ \\
\hline \multirow[t]{5}{*}{ Till Veneer } & 2018 & 7 & 40 & 0.8 & 0.6 & 2.2 & 0.1 & 0.7 & 1 & 20 & 0.5 & 0.5 & 0.5 & 0.5 & $\mathrm{~N} / \mathrm{A}$ & 5 & 0.2 & 0.3 & 0.3 & 0.1 & 0.1 \\
\hline & 2019 & 6 & 75 & 0.4 & 0.1 & 1.8 & 0.0 & 0.7 & 0 & 0 & N/A & N/A & N/A & N/A & N/A & 5 & 0.2 & 0.3 & 0.3 & 0.2 & 0.1 \\
\hline & 1014 & 0 & 0 & N/A & $\mathrm{N} / \mathrm{A}$ & N/A & N/A & N/A & 0 & 0 & N/A & N/A & N/A & N/A & N/A & 19 & 0.4 & 0.3 & 1.0 & 0.1 & 0.3 \\
\hline & 2013 & 6 & 30 & 0.3 & 0.1 & 1.6 & 0.1 & 0.6 & 1 & 20 & 1.3 & 1.3 & 1.3 & 1.3 & N/A & 2 & 1.4 & 1.4 & 1.7 & 1.1 & 0.4 \\
\hline & 2016 & 8 & 100 & 0.2 & 0.1 & 0.6 & 0.1 & 0.2 & 0 & 0 & N/A & N/A & N/A & N/A & N/A & 0 & $\mathrm{~N} / \mathrm{A}$ & N/A & N/A & N/A & $\mathrm{N} / \mathrm{A}$ \\
\hline \multirow[t]{4}{*}{ Eskers } & 2026 & 6 & 60 & 0.1 & 0.1 & 0.2 & 0.0 & 0.0 & 0 & $\overline{0}$ & N/A & $\mathrm{N} / \mathrm{A}$ & N/A & $\mathrm{N} / \mathrm{A}$ & $\mathrm{N} / \mathrm{A}$ & 0 & $\mathrm{~N} / \mathrm{A}$ & $\mathrm{N} / \mathrm{A}$ & $\mathrm{N} / \mathrm{A}$ & $\mathrm{N} / \mathrm{A}$ & $\mathrm{N} / \mathrm{A}$ \\
\hline & 2008 & 7 & 30 & 0.0 & 0.0 & 0.1 & 0.0 & 0.0 & 0 & 0 & N/A & N/A & N/A & N/A & N/A & 2 & 0.1 & 0.1 & 0.2 & 0.0 & 0.1 \\
\hline & 2028 & 6 & 30 & 0.1 & 0.0 & 0.3 & 0.0 & 0.1 & 1 & 100 & 0.4 & 0.4 & 0.4 & 0.4 & N/A & 3 & 0.3 & 0.3 & 0.4 & 0.1 & 0.1 \\
\hline & 2029 & 6 & 30 & 0.0 & 0.0 & 0.0 & 0.0 & 0.0 & 0 & 0 & N/A & N/A & N/A & N/A & N/A & 7 & 0.1 & 0.1 & 0.1 & 0.1 & 0.0 \\
\hline
\end{tabular}


A

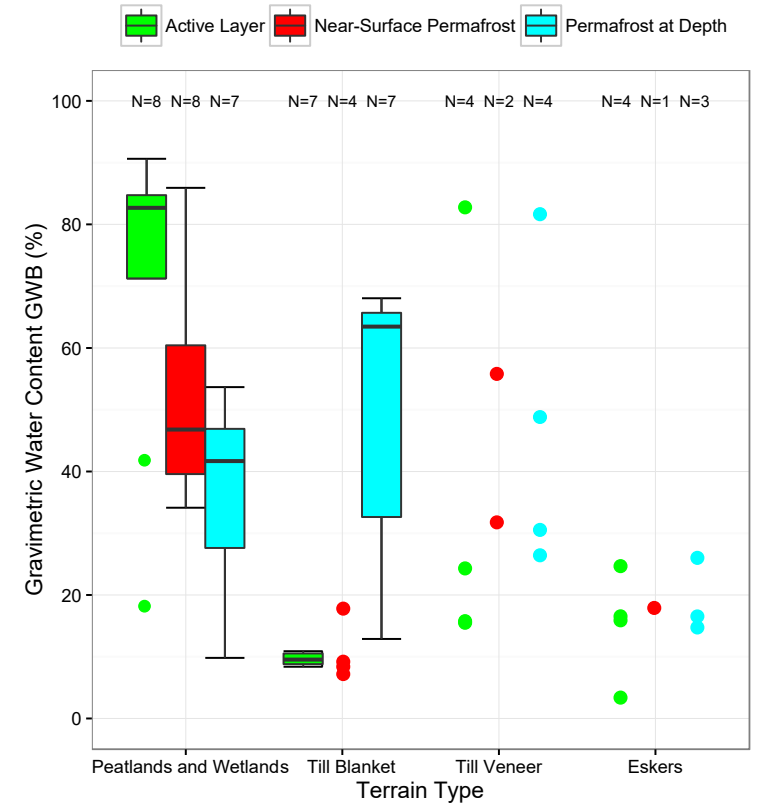

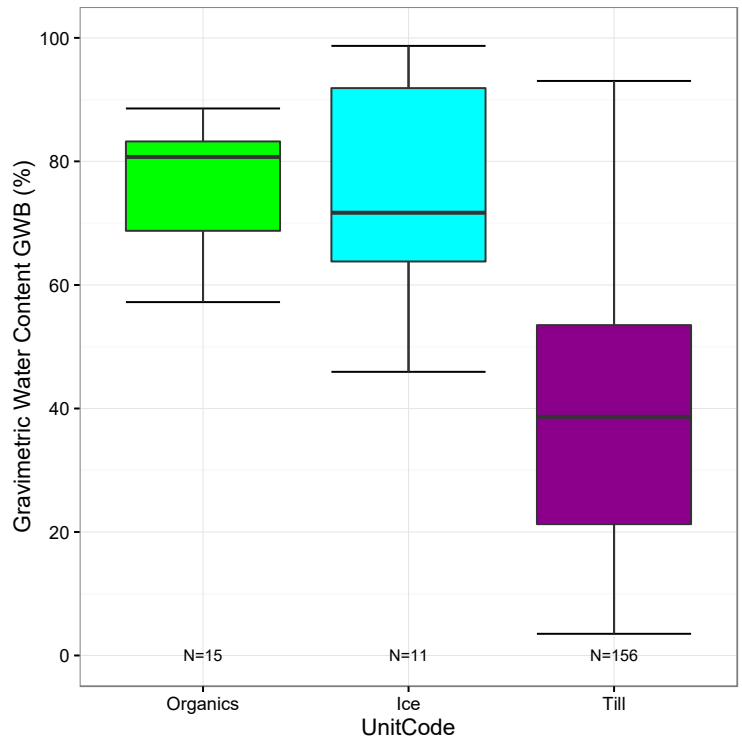

Figure 4.14 Gravimetric water content GWB (\%) variations (A) between the active layer, nearsurface permafrost and the permafrost at depth of four different surface types; and (B) between the Unitcodes. In cases where $\mathrm{N} \leq 5$ all data points have been represented using dots.

A

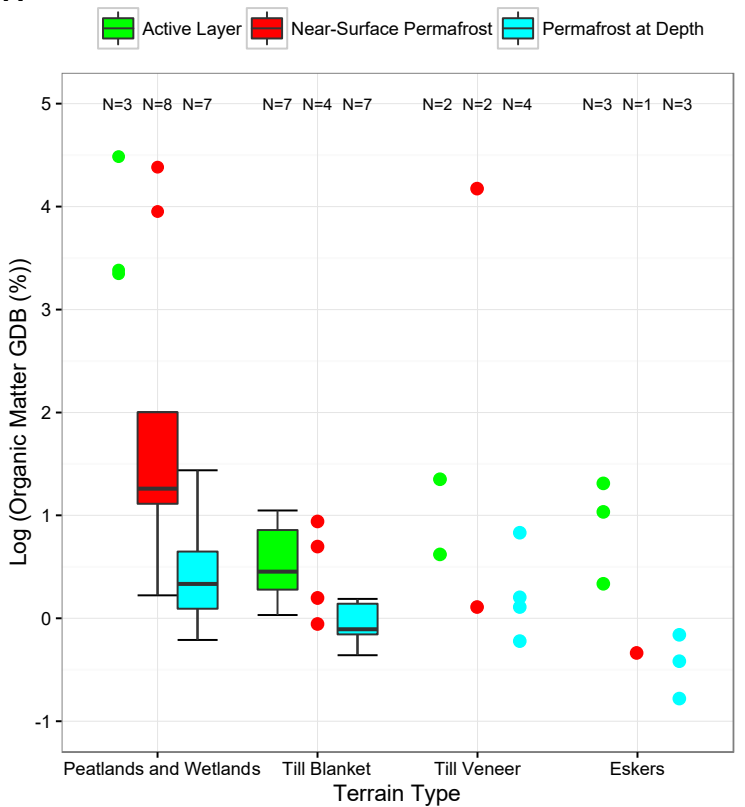

B

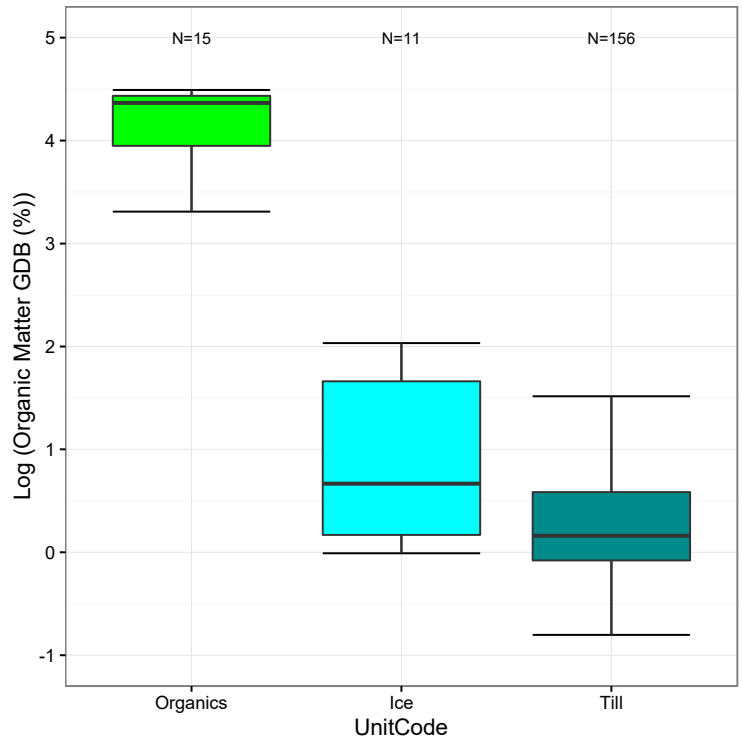

Figure 4.15 Organic matter content GDB (\%) variations (A) between the active layer, near-surface permafrost and the permafrost at depth of four different surface types; and (B) between the Unitcodes. Organic matter content (\%) values for Figure A and B are transformed logarithmically. In cases where $\mathrm{N} \leq 5$ all data points have been represented using dots. 
with the median of nearly $65 \%$.

Water content GWB was also compared between the Unitcodes (classification of sample types based on the information from the drill logs, Figure 4.14B). Water contents were found to be very high in "organic" and "ice" logged samples with medians of $81 \%$ and $72 \%$, but comparatively low in "till" samples with the median of about $39 \%$. The high water content GWB in the active layer of peatlands and wetlands, but low in till blanket and till veneer terrains is well explained by the organic nature of core samples from the former terrain.

\subsubsection{Organic Matter Content GDB (\%) Variations}

In peatlands and wetlands, organic matter content was very high in the active layer, followed by the near-surface permafrost and was comparatively low at depth in permafrost (Figure 4.15). Organic matter content of the active layer and near-surface permafrost were comparable in till blanket terrain, but varied more than threefold in the eskers. In till veneer, the near-surface permafrost was characterized with very high organic matter content, but was comparatively low in the active layer and especially at depth in permafrost. In summary, organic matter content was high in peatlands and wetlands and till veneer terrains, but was very low in till blanket and esker terrains.

Organic matter content between sample types was observed to be very high in samples logged as "organics" with median of about $80 \%$. Similarly, ice-rich samples were also observed to contain organic materials, however much less than the organic samples. Till samples contained the lowest organic matter contents between 0 and $1 \%$ (Figure 4.15B). As most samples from permafrost at depth were logged as "till", and from Figure $4.15 \mathrm{~A}$ it is clear that deep till or till with ice-rich materials at depth contains less organic 
carbon. In summary, organic matter content varied with depth for most terrains, and was very high in the active layer and in the near-surface permafrost at peatlands and wetlands terrain.

\subsubsection{Variations in Total Soluble Cation Concentration}

Soluble cation concentration in the near-surface permafrost was higher and more than double than that in the overlying active layer at the majority of sites from till blanket, and in few sites from peatlands and wetlands, till veneer and esker terrains (Figure 4.16A and B). Conversely, the majority of sites from peatlands and wetlands terrain contained higher soluble cation concentrations in the active layer than in the underlying permafrost. In peatlands and wetlands terrain, the median soluble cation concentration at depth in permafrost was higher than the median soluble cation in the near-surface permafrost. This is due to increased concentration of soluble cations below the depth of lower boundary of the near-surface permafrost at few sites (e.g. 2011 and 1009) (Figure 4.10c and f). In till blanket terrain, soluble cation concentration between the near-surface permafrost and the permafrost at depth were relatively similar, but in till veneer and eskers, soluble cations in the near-surface permafrost was higher than those at depth in permafrost.

Enrichment ratios were determined for the respective sites using data presented in Figure 4.16 by diving median total soluble cation concentration in the near-surface permafrost by the median total soluble cation concentration in samples obtained from the active layer. Permafrost enrichment ratios for specific sites ranged from less than 0.05 to 21, indicating several sites to be depleted or enriched in the active layer (Table 4.8, Figure 4.16A and B). 
A

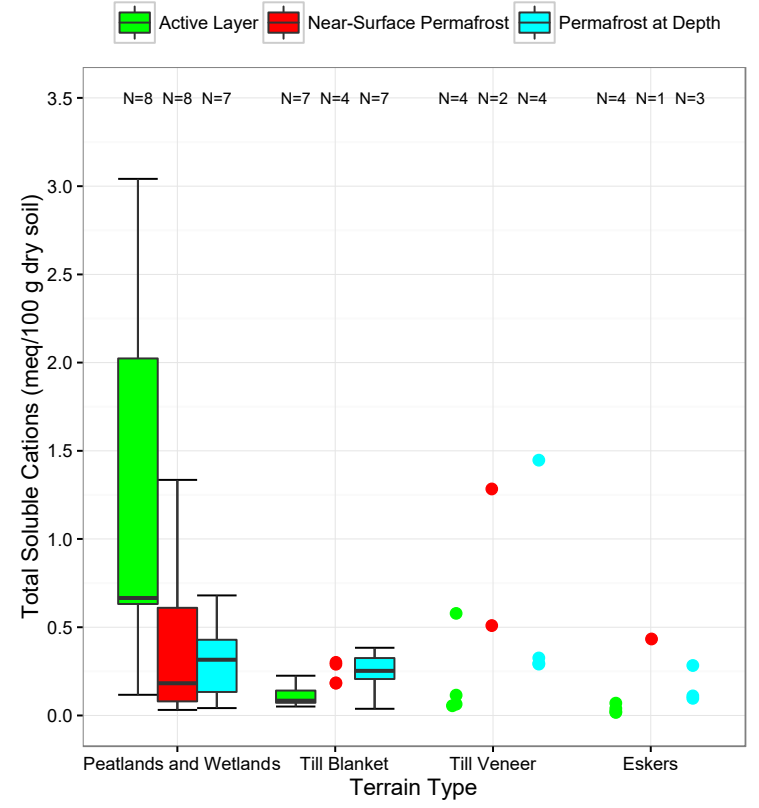

B

Terrain Type $\bullet$ Eskers $\boldsymbol{\Delta}$ Peatlands and Wetland $\square$ Till Blanket $\#$ Till Veneer

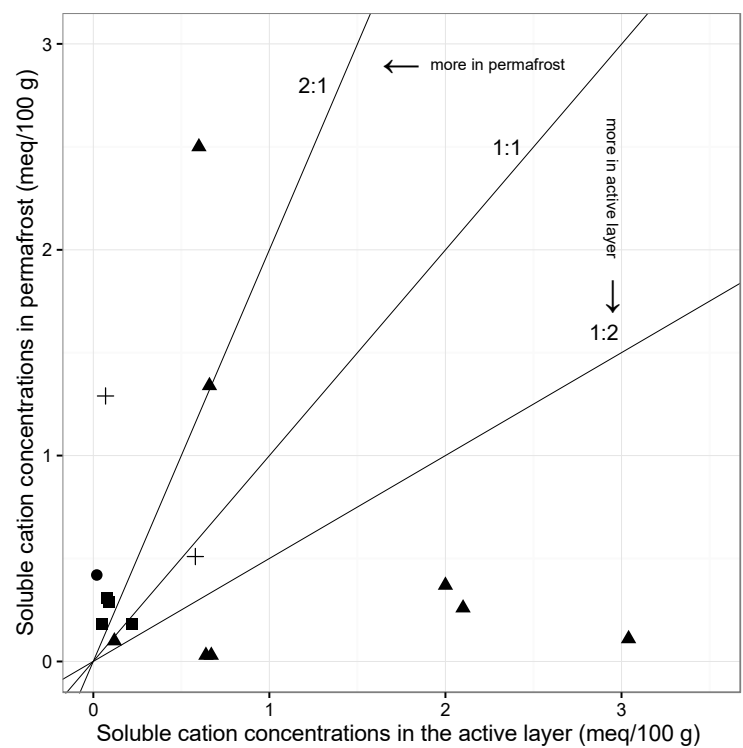

Figure 4.16 (A) Soluble cation concentration variations between the active layer, near-surface permafrost and the permafrost at depth; and (B) median total soluble cation concentrations in mineral soils of the active layer and in the top $1 \mathrm{~m}$ of underlying permafrost $(\mathrm{N}=15)$. In cases where $\mathrm{N} \leq 5$ all data points in Figure 4.16A have been represented using dots. 
Additionally, active layer soluble cation contents were compared between the low density "organic samples" vs. high density "mineral samples" to examine if organic soils sequester more solutes relative to mineral soils. The respective samples were identified based on their organic matter content. Four sites from peatlands and wetlands terrain with organic matter content greater than $17 \%$ in the active layer were considered as "organic soils". Similarly, seven sites from the till blanket terrain with organic matter content less than $17 \%$ in the active layer were considered as "mineral soils". Table 4.9 shows the classification of respective soil samples according to the Canadian System of Soil Classification (CSSC, 1978).

The comparison of solute concentrations between soil types shows that organic soils are enriched with solutes relative to the mineral soils in the active layer (Figure 4.17). By contrast, the median total soluble cation concentration in the organic soil is more than ten times higher than those in the mineral soils of the active layer. Therefore, the enrichment of the active layer presented in Figure 4.16B can be attributed to high organic matter content of the organic soils relative to mineral soils.

The data were distributed among two groups based on the ice content of nearsurface permafrost. It was found that 7 out of 8 sites underlain by medium- to high-icecontent permafrost (excess ice content $>10 \%$ ) were enriched with soluble cations in the active layer, while sites underlain by low-ice-content permafrost (excess ice content $<$ $10 \%$ ) were enriched in permafrost (6 out of 7 sites, Table 4.8). At sites underlain by medium- to high-ice-content permafrost, mean soluble cation enrichment was 2.6 (the median was 0.15 , and the sample standard deviation 6.4 ). However, at sites underlain by low-ice-content permafrost, mean soluble cation enrichment was 5.5 (the median was 3.6, 
Table 4.8 Enrichment ratio of soluble cation concentration of near-surface permafrost for several sites in various terrains, near Lac de Gras, N.W.T

\begin{tabular}{|c|c|c|c|c|c|}
\hline \multirow[b]{2}{*}{ Terrain-Type } & \multirow[b]{2}{*}{$\begin{array}{c}\text { Borehole } \\
\text { ID }\end{array}$} & \multirow[b]{2}{*}{ Excess Ice } & \multicolumn{2}{|c|}{$\begin{array}{l}\frac{\text { Median Total Soluble }}{\text { Cation Concentration }} \\
\underline{\text { (meq./100g dry soil) }}\end{array}$} & \multirow[t]{2}{*}{$\frac{\text { Enrichment Ratio of }}{\underline{\text { Near-Surface }}}$} \\
\hline & & & Active Layer & Permafrost & \\
\hline \multirow{8}{*}{$\begin{array}{c}\text { Peatlands and } \\
\text { Wetlands }\end{array}$} & 1006 & Low & 0.60 & 2.50 & 4.2 \\
\hline & 1007 & Medium To High & 0.64 & 0.03 & 0.05 \\
\hline & 2011 & Medium To High & 3.04 & 0.11 & 0.04 \\
\hline & 2012 & Medium To High & 0.67 & 0.03 & 0.04 \\
\hline & 1009 & Medium To High & 2.10 & 0.26 & 0.12 \\
\hline & 1010 & Medium To High & 2.00 & 0.37 & 0.19 \\
\hline & 2015 & Medium To High & 0.12 & 0.10 & 0.83 \\
\hline & 1005 & Low & 0.66 & 1.34 & 2.0 \\
\hline \multirow{4}{*}{ Till Blanket } & 2004 & Medium To High & 0.22 & 0.18 & 0.81 \\
\hline & 1004 & Low & 0.08 & 0.31 & 3.9 \\
\hline & 2007 & Low & 0.09 & 0.29 & 3.2 \\
\hline & 2009 & Low & 0.05 & 0.18 & 3.6 \\
\hline \multirow{2}{*}{ Till Veneer } & 2018 & Low & 0.58 & 0.51 & 0.88 \\
\hline & 2013 & Medium To High & 0.07 & 1.29 & 18.4 \\
\hline Eskers & 2028 & Low & 0.02 & 0.42 & 21 \\
\hline
\end{tabular}


Table 4.9 Classification of soil types with respect to organic matter content of the active layer according to the Canadian System of Soil Classification (CSSC, 1978).

\begin{tabular}{lccc}
\hline Terrain-Type & Borehole ID & $\begin{array}{c}\text { Median Active-Layer } \\
\text { Organic Matter } \\
\text { Content }(\%)\end{array}$ & Soil Type \\
\hline \multirow{3}{*}{ Peatlands and } & 1005 & $>17$ & Organic \\
Wetlands & 1006 & 89.4 & Organic \\
& 1009 & 26.3 & Organic \\
\cline { 2 - 4 } Till Blanket & 1010 & 27.4 & Organic \\
& 1004 & 1.31 & Mineral \\
& 2004 & 2.81 & Mineral \\
& 2005 & 1.57 & Mineral \\
& 2006 & 1.33 & Mineral \\
& 2007 & 1.98 & Mineral \\
& 2009 & 2.85 & Mineral \\
& & 1.03 & Mineral \\
\hline
\end{tabular}




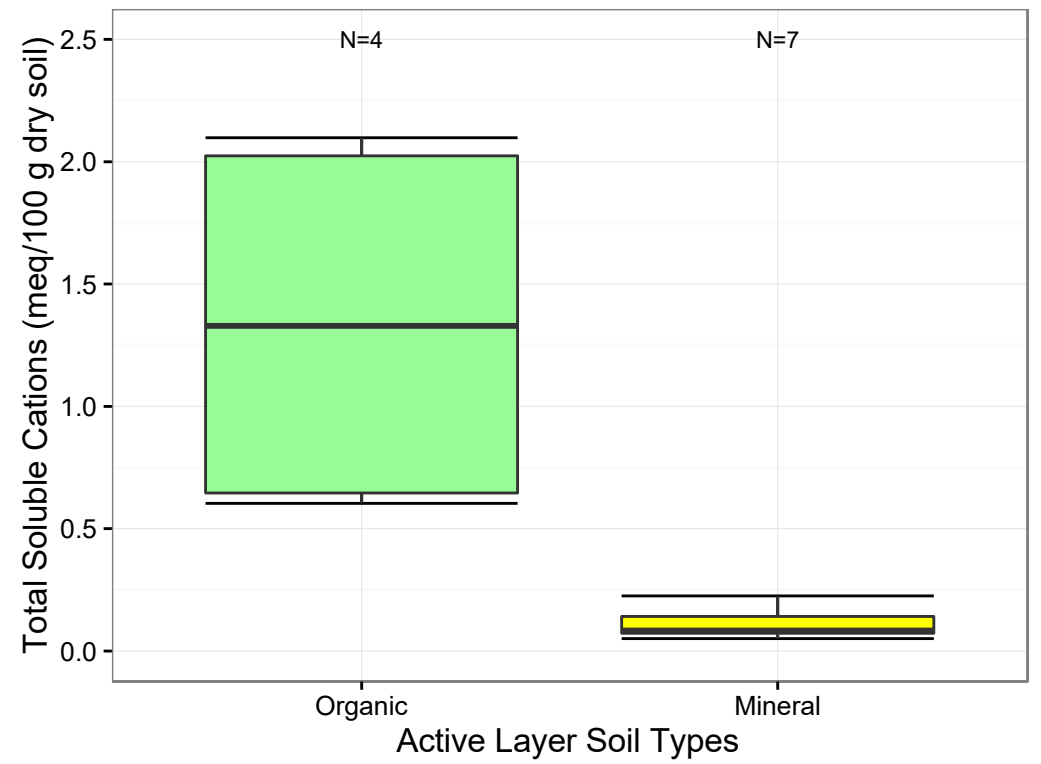

Figure 4.17 Active layer soluble cation contents compared between organic and mineral soils

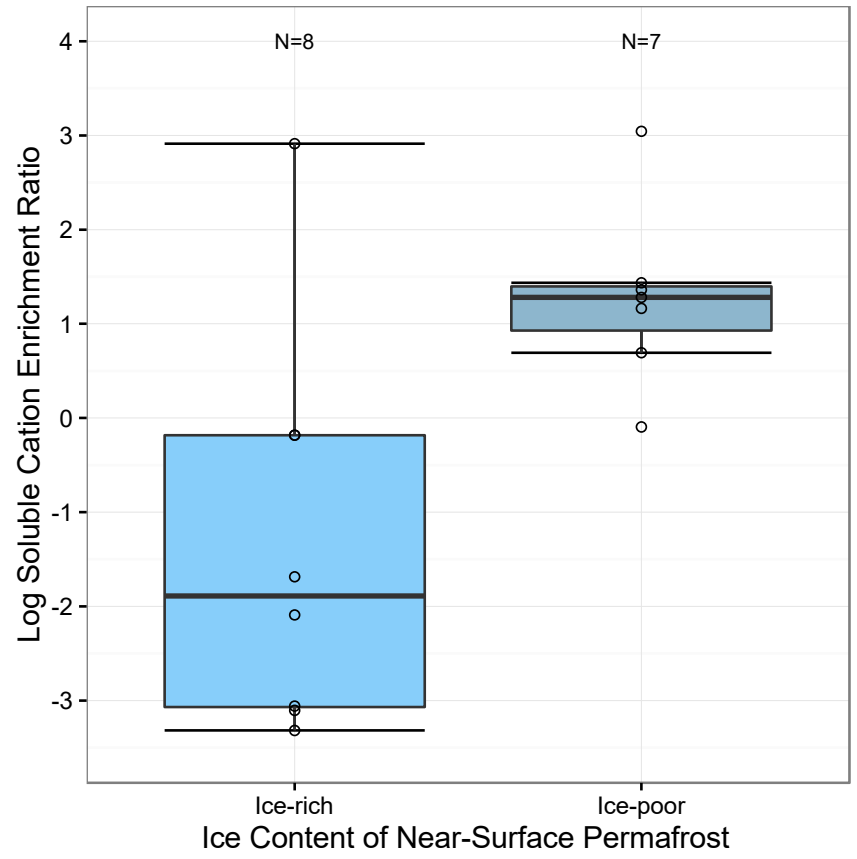

Figure 4.18 Comparison of logarithm soluble cation enrichment ratios between the ice-rich and ice-poor permafrost. A non-parametric (Mann-Whitney $U$ ) test showed the median enrichment ratios between ice-rich and ice-poor sites to be significantly different ( $p$-value $=0.009$ ). 
and sample standard deviation 6.9, Figure 4.18). A non-parametric (Mann-Whitney $U$ ) test showed that the median enrichment ratio between ice-rich and ice-poor sites was significantly different $(\mathrm{p}$-value $=0.009)$

Variations in soluble cation concentration were also compared between the Unitcodes (Figure 4.19). Soluble cations were much higher in samples logged as "organics" followed by the "ice" and the "till" samples. In organic samples, the mean cation concentration was $2.4 \mathrm{meq} / 100 \mathrm{~g}$ dry soil (the median was 2.0, and the sample standard deviation 1.8). In ice-rich samples, the mean cation concentration was $1.2 \mathrm{meq} / 100 \mathrm{~g}$ dry soil (the median was 1.1, and the sample standard deviation 0.8). In till samples, the mean was the lowest with $0.6 \mathrm{meq} / 100 \mathrm{~g}$ dry soil (the median was 0.4 , and the sample standard deviation 0.6).

\subsubsection{Relation Between Electrical Conductivity and Total Soluble Cations}

Electrical conductivity of water is a proxy for the concentration of dissolved ions and is therefore expected to correlate with the total soluble cations present in a solution. In this study, a large number of boreholes showed similar patterns between the electrical conductivity and total soluble cations (see Appendix D). To test the relationship between the two, the electrical conductivities in pore-water extracts were compared with the total soluble cations determined in the laboratory (i.e. $\mathrm{Ca}^{2+}, \mathrm{Mg}^{2+}, \mathrm{K}^{+}$and $\mathrm{Na}^{+}$). Figure 4.20 shows that the soil-water conductivity and total soluble cations were highly correlated $\left(\mathrm{R}^{2}=0.90, \mathrm{n}=313\right)$. 


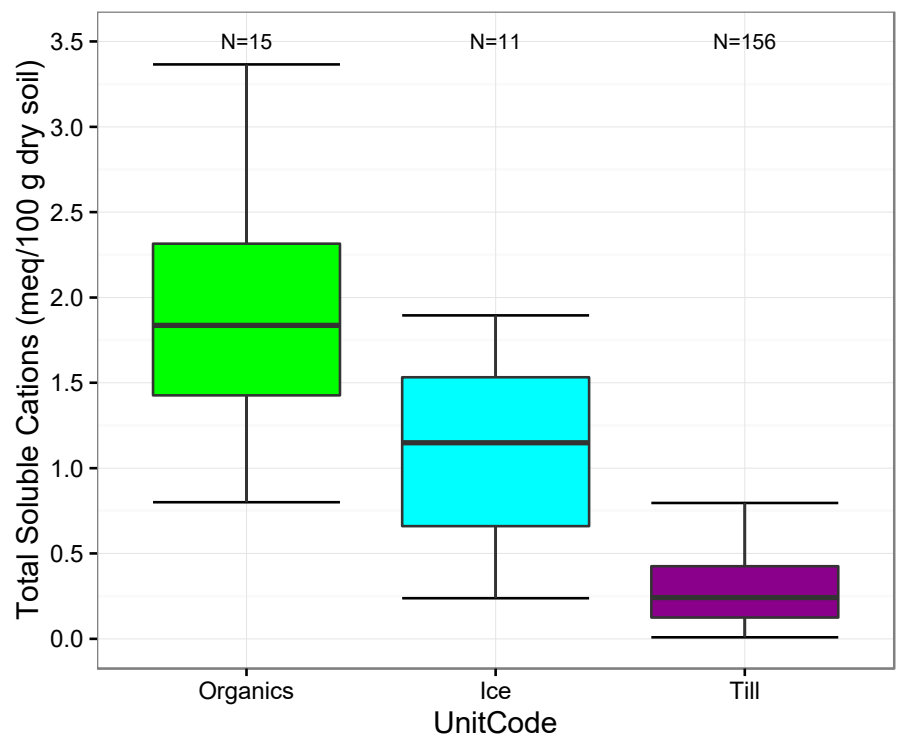

Figure 4.19 Soluble cation concentration variations between the Unitcodes, for the cores obtained near Lac de Gras, N.W.T.

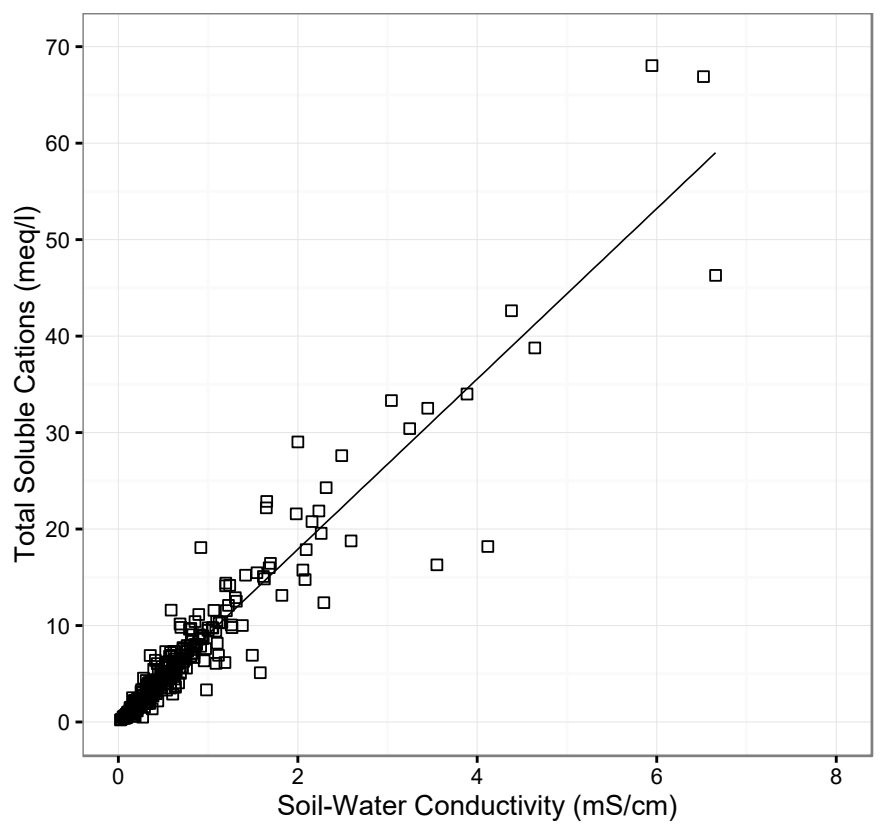

Figure 4.20 The relation between electrical conductivity $\left(\mathrm{C}_{\mathrm{pw}}\right)$ and total soluble cation concentrations $\left(\mathrm{S}_{\mathrm{pw}}\right.$ ) (sum of soluble $\mathrm{Ca}^{2+}, \mathrm{Mg}^{2+}, \mathrm{K}^{+}$and $\mathrm{Na}^{+}$) in pore-water extractions from the active layer and permafrost samples, near Lac de Gras, N.W.T. The relation between two variables is summarized by $\mathrm{S}_{\mathrm{pw}}=8.83 \mathrm{C}_{\mathrm{pw}}+0.253\left(\mathrm{R}^{2}=0.90, \mathrm{~N}=313\right)$. 


\subsubsection{Relation Between Water Content GWB and Total Soluble Cations}

Gravimetric water content GWB and soluble cation concentrations were compared with each other to see if any relation existed between these two variables. Figure 4.21 shows the regression analysis between water content GWB and soluble cations (A) with the data for the entire cores from every terrain; (B) with the data obtained from the active layer; and (C) with the data obtained from the near-surface permafrost near Lac de Gras, N.W.T. Regression analysis between water and cations yielded $\mathrm{R}^{2}$ values of $0.39,0.51$ and 0.53 , respectively, and p-values $<0.05$ (Figure 4.21) for the entire cores, in the active layer as well as in the near-surface permafrost. However, further examination of the linear fit between the two variables suggests that the residuals were not normally distributed. As such, the significance of this relationship could be tested statistically despite the low pvalue. Nonetheless, an increased $\mathrm{R}^{2}$ in the active layer and especially in the near-surface permafrost with most data from peatlands and wetlands indicates that some relationship exists between water and soluble cations (Figure 4.21B and C).

\subsubsection{Relation Between Organic Matter Content and Total Soluble Cations}

A comparison of organic matter content and total soluble cation concentration yielded an $\mathrm{R}^{2}$ value of 0.37 and a $\mathrm{p}$-value $<0.05$ (Figure 4.22A). However, further examination of the linear fit between the two variables indicated that residuals were heavy tailed, and hence non-normal. As such, the significance of this relationship could not be built from the statistical analysis, despite the low p-value. The two variables were also compared with data from the active layer and near-surface permafrost, however revealed similar results as in the previous analysis (Figure 4.22C and 4.22D). 

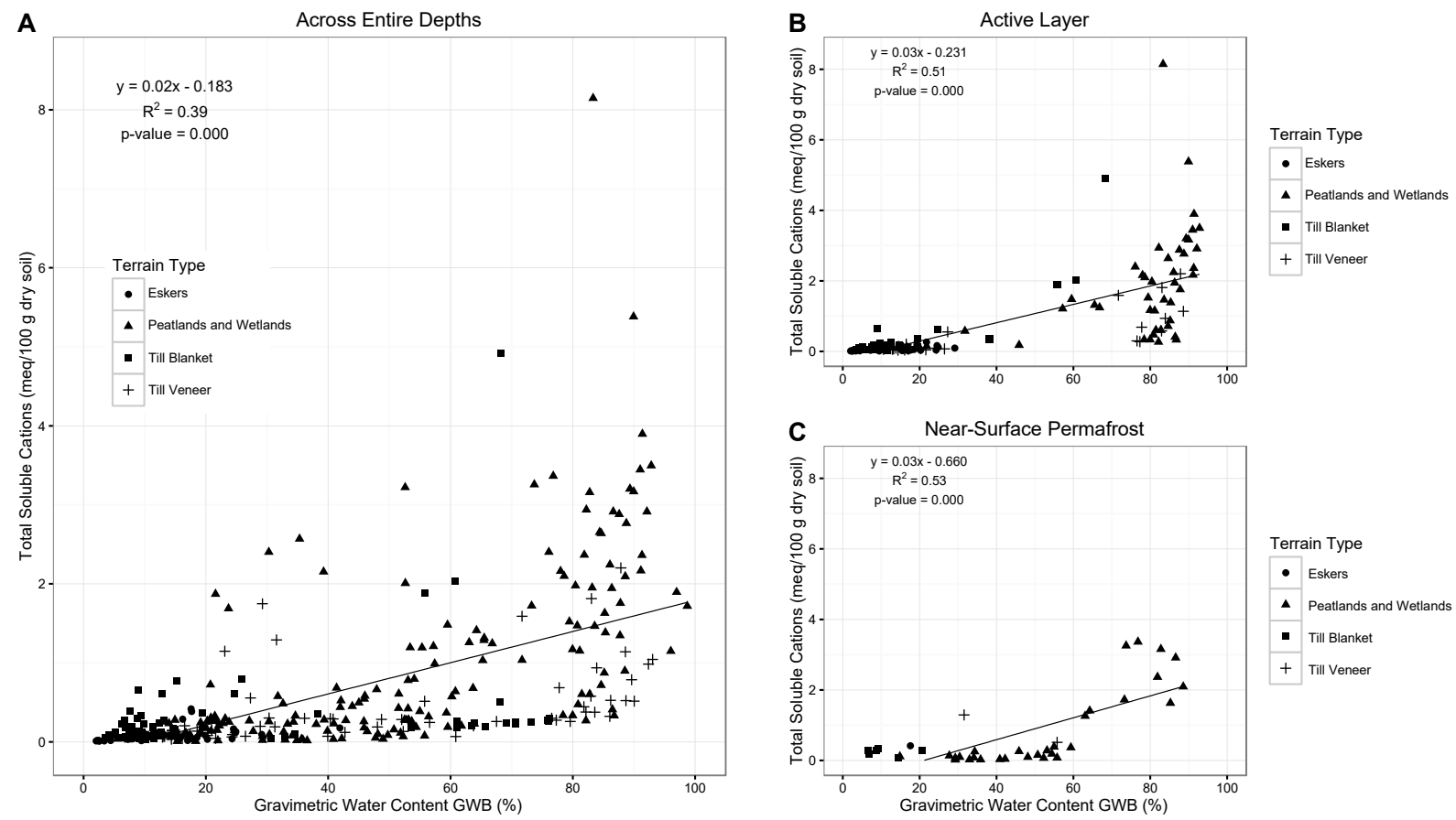

Figure 4.21 The relation between gravimetric water content GWB (\%) and total soluble cations meq/ $100 \mathrm{~g}$ dry soil (A) for the entire depths, i.e., in the active layer, near-surface permafrost and at depth in permafrost; (B) in the active layer; and (C) in the near-surface permafrost for the cores obtained from various terrain in near Lac de Gras, N.W.T. 
A further examination of the relationship between the organic matter content and total soluble cations based on the UnitCodes is presented in Figure 4.22B. Figure 4.22B suggests that other than "organic" samples there is no evidence to believe that any relationship exists between organic matter and soluble cations in gravel/cobbles, ice, sand, silt, soil and till samples. This is supported by an increased r-squared value, i.e., $\mathrm{R}^{2}=0.84$ and 0.53 in the active layer and near-surface permafrost, respectively with most organic data from the peatlands and wetlands terrain (Figure 4.22D), and a decreased $\mathrm{R}^{2}$ value 0.15 with few organic samples at depth in permafrost (Figure 4.22E). 

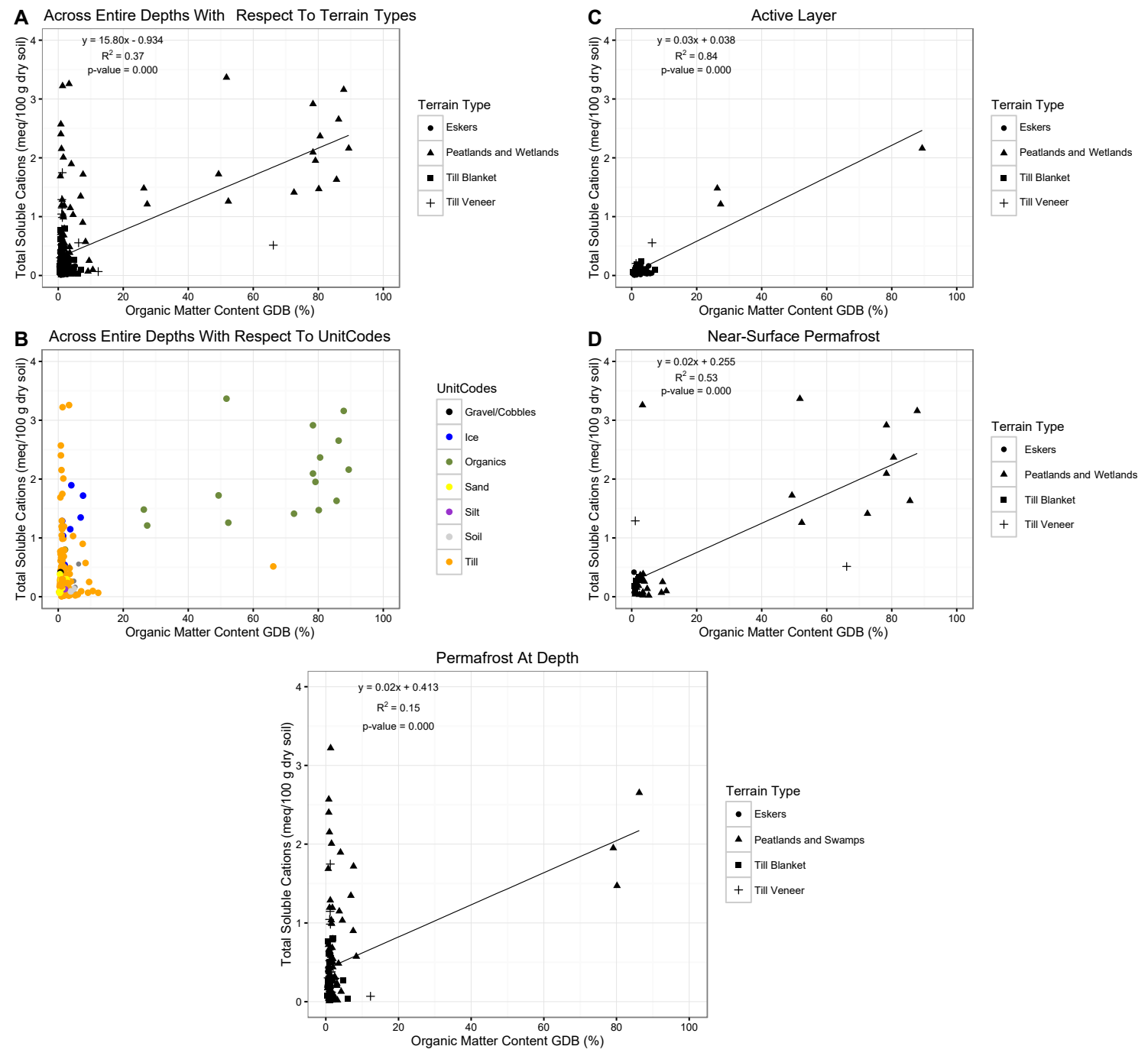

Figure 4.22 The relation between organic matter content (\%) and total soluble cations meq/ $100 \mathrm{~g}$ dry soil (A) with respect to terrain types for the entire cores in the active layer, near-surface permafrost and at depth in permafrost; (B) with respect to UnitCodes; (C) in the active layer; (D) in near-surface permafrost; and (E) in permafrost at depth for the cores obtained near Lac de Gras, N.W.T. 


\section{CHAPTER 5. DISCUSSION}

\subsection{Overview}

In Chapter 4, the vertical and spatial distribution of water content GWB, organic matter content and total soluble cations were examined between depths, and also between terrain types. Geochemical distinctions between the active layer, near-surface permafrost and the permafrost at depth were evident at sites in each terrain type. Differences were also observed between terrain types, and this was mainly attributed to type of sediment. This chapter discusses the observed profiles and patterns in more detail. First, in order to support the results of total soluble cations and provide rationale to the near-surface ionic enrichment of permafrost in this study, the results from three distinct water extraction techniques (Section 3.4.1) are discussed. The second section examines the relation between soil texture and water content GWB, to assess the relative importance of soil type on water and ground ice content variability. The third section discusses the factors associated with variation in water, organic matter and soluble cations between the active layer, near-surface permafrost and the permafrost at depth, and also between terrain types. This section also compares geochemical profiles of this study with previous studies from differing environments. The last section discusses the observed patterns of water, organic matter and soluble cations to infer the depth of thaw unconformity at one of the sites from till veneer terrain. 


\subsection{Effect of Soil-Water Extraction Method on the Concentration of Soluble}

\section{Cations}

This study used the pore water extraction technique, i.e., Method 1 and Method 3, to measure the concentration of soluble cations present in soil-water (e.g. Kokelj et al., 2002; Kokelj and Burn, 2003). Although most studies in permafrost geochemistry use the same method, some studies have also considered the leachate method, i.e., Method 2, in which permafrost samples are thawed and dried, and a pre-determined soil:water ratio, (extraction ratio) ranging from 1:1 to 1:25 by mass is used to extract the leachate water (e.g. Blum et al., 2002; Keller et al., 2007). Fontaine (2016) compared these two water extraction techniques and suggested that the use of Method 3 underestimates the concentration of total soluble cations by 2 to more than 20 times relative to Method 2 . Based on this study, the enrichment of soluble cations in the near-surface permafrost in studies from Kokelj et al. (2002) and Kokelj and Burn (2005) could have been biased as a result of using pore water extraction method.

The results obtained from soil-water sampling using Method 2 and Method 3 in this study however contradicts the aforementioned observation (Section 3.4.1). The concentration of soluble cations i.e. $\mathrm{Ca}^{2+}, \mathrm{Mg}^{2+}, \mathrm{K}^{+}$and $\mathrm{Na}^{+}$is much higher in pore water extracts obtained from Method 3, while those obtained from Method 2 are lower. A plot showing the relative difference of Method 3 with Method 2 is presented in Figure 5.1. The figure shows the concentration of $\mathrm{Ca}^{2+}$ and $\mathrm{Mg}^{2+}$ ions to vary the most, while $\mathrm{K}^{+}$and $\mathrm{Na}^{+}$ ions have smaller differences. Because a predetermined extraction ratio (1:1) was employed for both methods, while sufficient time was also given to undergo dissolution, the low concentration of soluble cations from Method 2 indicates possible effects of drying 


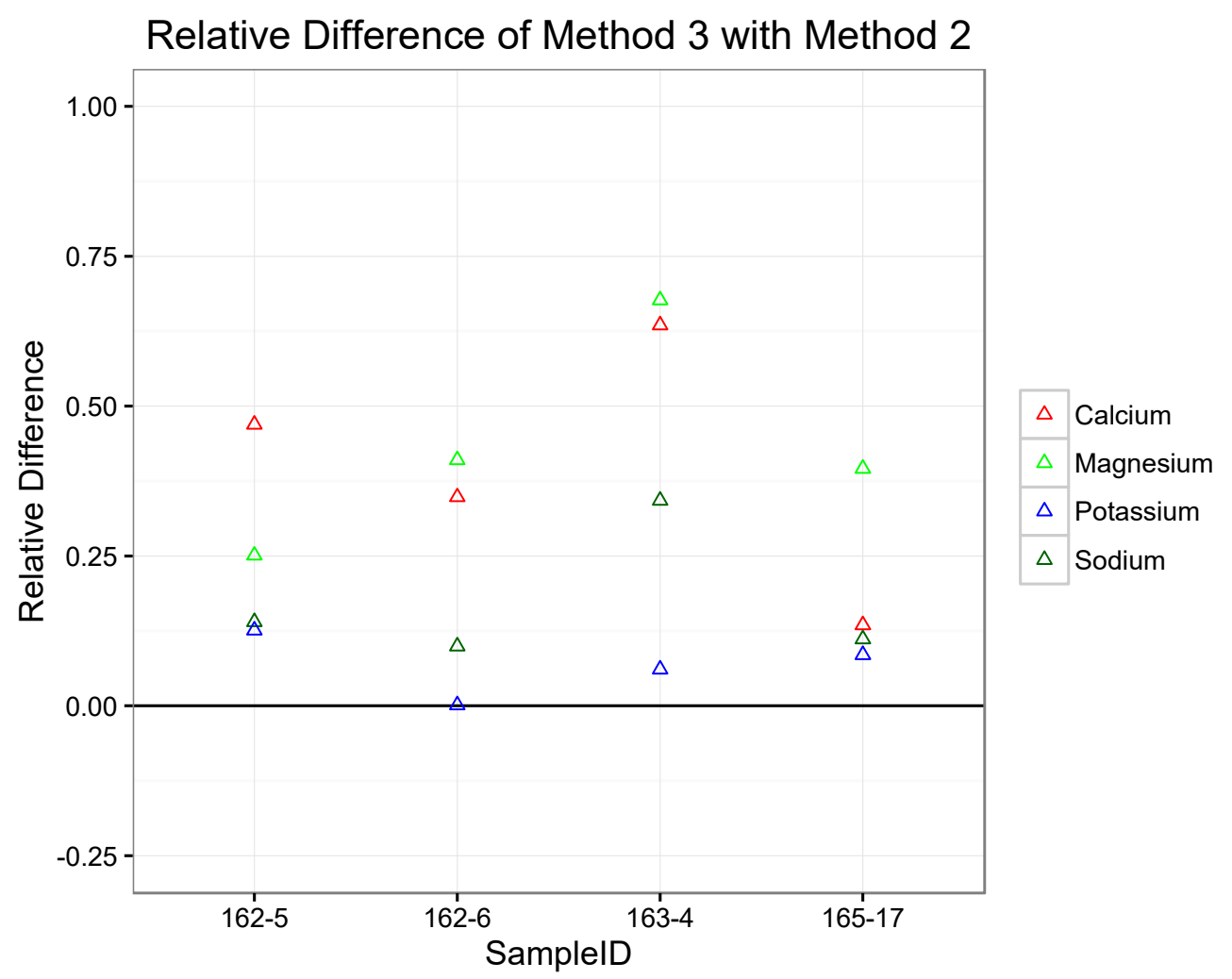

Figure 5.1 Relative difference of soluble cations obtained from Method 3 and Method 2. The relative difference is defined by subtracting the concentration of soluble cations obtained from Method 2 from the concentration of Method 3. 
on samples which subdues the high ion contents present in soil water. In addition, an extraction ratio greater than 1:1 allows an increase in the amount of soluble cations in the leachate water, because of higher dissolution rates. Thus, the high values of leachate conductivity in studies from Fontaine (2016) was likely simply a result of using a higher extraction ratio (1:10). Therefore, the results of the pore water geochemistry and the related near-surface ion enrichment of permafrost in studies from Kokelj et al. (2002) and Kokelj and Burn (2005) are likely not biased based on data presented here.

\subsection{Relation Between Gravimetric Water Content GWB and Soil Texture}

In order to assess the relative importance of soil type for water and ground ice content variability, the relation between water content GWB and soil texture was examined. Since, water and ground ice content in permafrost are closely related to soil porosity and pore geometry, finer-textured soils (e.g. "frost-suceptible" silts) are known to draw water towards a freezing front (French, 2007), leading to the development of segreated ice. In this study, the results of grain size analysis suggested higher silt contents in peatlands and wetlands and till veneer terrains in comparison to other terrains (Appendix E), thus indicating high potential for ground ice development in the former two terrain types. The depth profiles of gravimetric water content GWB presented in Section 4.3.1 and the comparison of water content GWB between terrain types (Figure 4.14) shows high water content GWB in peatlands and wetlands and till veneer terrains relative to till blanket and esker terrains. Thus, soil type represents a major influence on water and ground ice content variability in this study area. However, it is also important to note the influence of organic contents at a few sites from peatlands and wetlands terrain. For example, sites 
characterized by very high organic matter content in the active layer and near-surface permafrost $(1005,1006$ and 1010) have high water content GWB, but no excess ice contents (Figure 4.2). This is because organic soils have lower bulk density and high porosity compared with mineral soils. Thus, as Morse et al. (2009) suggest, it is important to handle gravimetric water content data carefully because high moisture content may be indicative of high organic matter content rather than high ice content.

In order to examine if a significant relationship exists between the water content GWB and soil texture in data obtained from various sites, a regression analysis was conducted. Figure 5.2 shows statistically significant results ( $p$-values $=<0.05$ ) between water content GWB vs. clay content (\%), silt content (\%) and sand content (\%) in permafrost samples with r-squared values of $(0.15,0.15$ and 0.16 , respectively). Water content GWB increased in fine-grained sediments (\%) (i.e. clay and silt), while it decreased in the coarser sediments (i.e. sand). These results support the observed high water content GWB values in the near-surface permafrost and in permafrost at depth for the peatlands and wetlands and till veneer terrains as till samples in those terrain types consisted of more fine-grained sediments than in till blanket or the esker terrains (Figure 5.2 A, B and C). In contrast, decreasing water content GWB was evident in the coarser sediments. However, points from the esker as well as till blanket sites which were expected to exemplify this relation are not too close to the line of best fit. Although the regression provides with some expected results, there is a significant amount of scatter in the plots indicating that other factors also influence these relations. One such factor may be the varying soil properties, such as bulk density, in samples from different terrain types. 

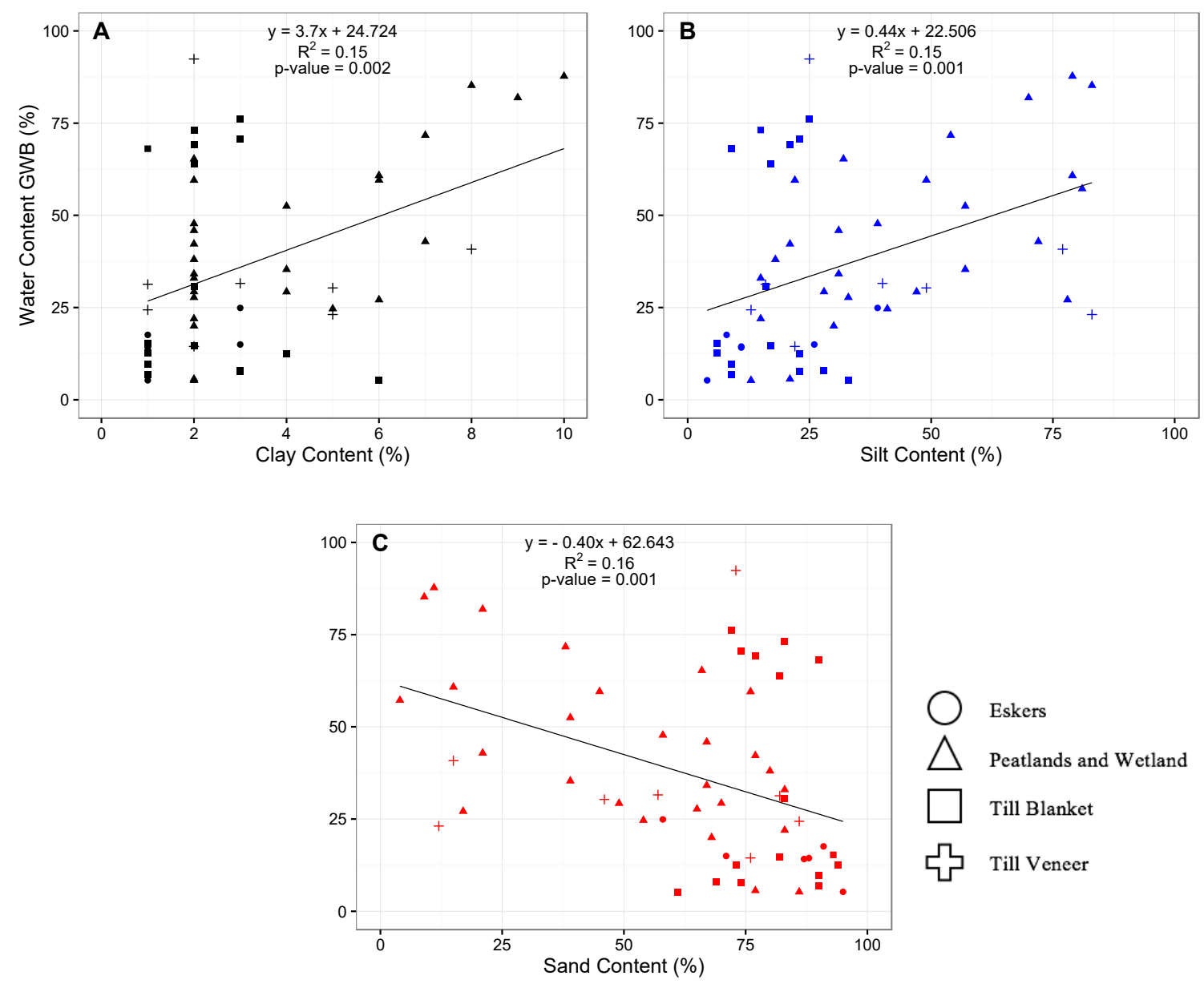

Figure 5.2 Comparison of water content GWB with Clay Content (\%), Silt Content (\%) and Sand Content $(\%)$ in samples obtained from various terrain types from Lac de Gras, N.W.T 
The results of the water content GWB and soil texture obtained here is quite comparable with the results from the western Arctic. For example, Kokelj and Burn (2005) documented an inverse association of sand content and the ice content of near-surface permafrost at a site in sandy silt alluvium, although in clayey silt alluvium excess ice contents increased due to high silt contents. Similarly, Morse et al. (2009) found that icerich permafrost in the outer Mackenzie Delta was associated with soils normally composed of at least $40 \%$ silt. In the Illisarvik drained lake basin, Mackay and Burn (2002) found aggradation ice development in frost-susceptible organic rich silts, while was very little in areas with sandy soils.

\subsection{Vertical and Spatial Distribution: Gravimetric Water Content GWB, Organic Matter Content and Total Soluble Cations}

\subsubsection{Gravimetric Water Content GWB (\%)}

The vertical and spatial distribution of water and excess ice contents from four terrain types indicated that near-surface permafrost at a majority of sites from peatlands and wetlands and till veneer terrains contained high water content GWB and excess ice (Figure 4.2 and 4.4). This zone of high excess ice content in the near-surface permafrost, also termed "transient layer" by Shur et al. (2005), is documented in many studies from the western Arctic (e.g. Kokelj et al., 2002; Kokelj and Burn, 2003; O' Neill and Burn, 2012). This zone of ice enrichment can be attributed to the annual flux divergence between the downward moisture migration from the active layer into frozen ground and upward out of permafrost, seasonally in summer and winter, respectively (Cheng, 1983). Mackay (1972) further introduced the term aggradational ice for the ice-rich zone, and emphasized that 
ice-lenses present at the base of the active layer may be trapped by an aggrading permafrost table due to climate cooling, vegetation change or sedimentation.

Cheng's (1983) hypothesis on segregated ice development is quite relevant for sites from peatlands and wetlands terrain. In peatlands and wetlands terrain, high ice content in the near-surface permafrost was often associated with frost-susceptible silts indicating high potential for segregated ice development (Appendix E). Photos of cores showing ice lenses from the near-surface permafrost of two different sites are given in Figure 5.3. Similarly, Mackay's (1972) hypothesis on near-surface aggradational ice is applicable at sites from the till veneer terrains. At this terrain, site (2018 and 2013) from Hill 2 and Valley groups, respectively were located either in low-lying depression or just at the bottom of the hill where permafrost aggradation likely coincided with sedimentation, which resulted in the development of near-surface ice-rich zone (Figure 3.5 and 4.4). In addition, the results of the grain size analysis also suggest high silt contents for this particular terrain, indicating high potential for ground ice development (Appendix E).

The active layer water content GWB at sites from peatlands and wetlands terrain was significantly higher (see Table 4.8) than in sites of any other terrains (Figure 4.14). This is due to the presence of high organic matter content in the uppermost layer of those terrains (Figure 4.15), which contain lower bulk density in comparison to the mineral soils. The comparison of water content GWB between the Unitcodes in Figure 4.14B also supports this assumption as water content GWB tended to be high in organic samples, with the median of about $80 \%$. However, other factors also need consideration. For example, conditions might have been favored by the lower relief at peatland and wetland sites, due to poor drainage or drainage convergence resulting in high moisture availability in the 

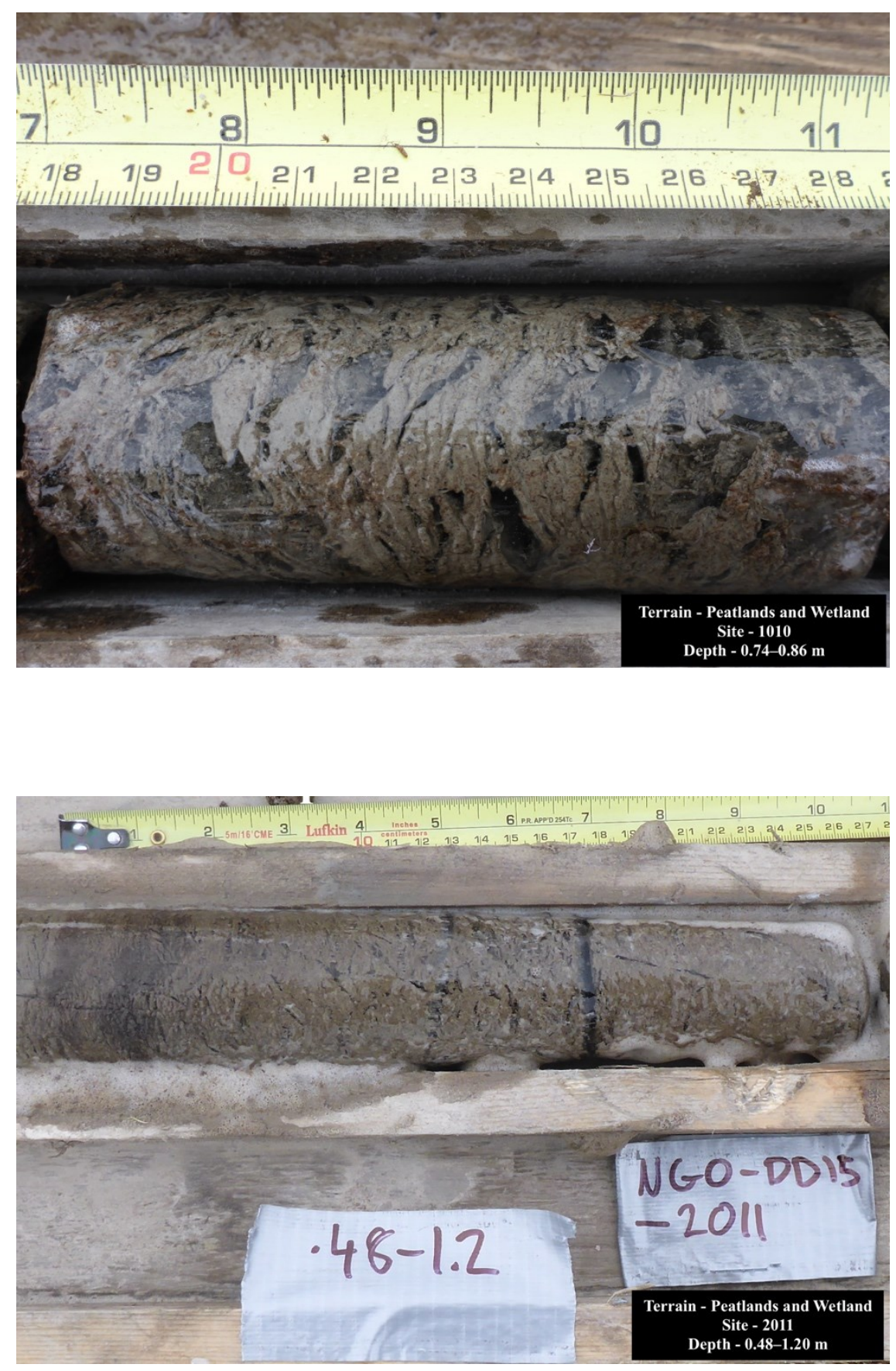

Figure 5.3 Core photos showing ice lenses present in the near-surface permafrost at two different sites from peatlands and wetlands terrain near Lac de Gras, N.W.T. 
active layer. By contrast, water content GWB of the active layer in till blanket and esker terrains were comparatively low, which is explained by the coarser grain size as well as the low organic matter content of the active layer in these terrains. Fontaine (2016) reported similar results from the western Canadian Arctic where a positive association between water and organic matter content described the uppermost $2 \mathrm{~m}$ of a sedge meadow site corresponding to an organic rich zone, whereas in sites from thaw slumps (characterized by low organic contents), gravimetric water content GWB was the lowest in the active layer $(<60 \%$ GDB). Several distinctions in the active layer water content GWB should be noted, especially from peatlands and wetlands, till veneer and esker terrains. Water content GWB of the active layer at sites from these terrains were quite variable for the data obtained between two exterior pits, or between pits and borehole. This variation corresponds to the small-scale variability at sites existing due to subtle differences in relief, drainage, soils and vegetation conditions over distances of $1-15 \mathrm{~m}$.

In peatlands and wetlands and till veneer terrains, water content GWB of permafrost normally declined with depth, but a few sites in those terrains were associated with extremely high water and excess ice contents of up to $98 \%$ and $75 \%$, respectively at depth (Figure 4.2c, 4.2e, 4.2f, 4.2g and 4.4a). This is due to the high ice-segregation at the bottom of the profiles, which were often associated with frost-susceptible tills of high silt contents. The depth profiles of water content GWB from Section 4.3.1 as well as the comparison of water content GWB between Unitcodes supports this argument as "till" samples contain water content GWB up to $95 \%$. The results of water content GWB and excess ice content presented here contrasts with previous studies from the western Arctic. For example, the deeper zones of increased moisture contents from Herschel Island are reported to be only 
20 to $30 \mathrm{~cm}$ thick with ice lenses of about $2 \mathrm{~cm}$ (Kokelj et al., 2002), but in the present study the zones of increased water content GWB at depth consisted between 50 to $100 \mathrm{~cm}$, and ice lenses at least $10 \mathrm{~cm}$ thick. Similarly, the deepest zones of ice accumulation on hummocky tops of Inuvik are reported to contain only 12\% excess-ice (Kokelj and Burn, 2003), whereas in this study, the average volumetric ice content in hummocky areas from the Valley group are reported to contain more than $50 \%$ excess-ice.

\subsubsection{Gravimetric Water Content GWB of the Hillslopes}

The observed distinctions in the water content GWB profiles of the hillslopes (especially from Hill 1 and Hill 3), depending upon the local positions of boreholes, indicate the influence of erosive as well as accumulative nature of the slope materials that are common at hill slope and hill bottom, respectively. For example, sites from Hill 1 and Hill 3 groups, in till blanket terrain show excess ice content much closer to the ground surface at the top of the hill, but as it approaches the slope and the hill bottom excess ice content is either absent at the same depth interval, or gets much deeper into the ground surface (Figure 4.3b, c, d, e and g). Core photos showing high excess ice contents in permafrost at depth from various sites in till blanket terrain are provided in Figure 5.4. Previous studies in western Arctic Canada have provided important evidence on buried glacial ice near the northwest limit of the Laurentide Ice Sheet (Mathews and Mackay, 1960; Mackay et al., 1972). In the western Arctic Canada, buried glacial ice from the Laurentide Ice sheet is supposed to have been preserved for more than $10 \mathrm{ka}$ within large moraine belts, hummocky till and glaciofluvial deposits (French and Harry, 1990). Given the long glacial history of this area 

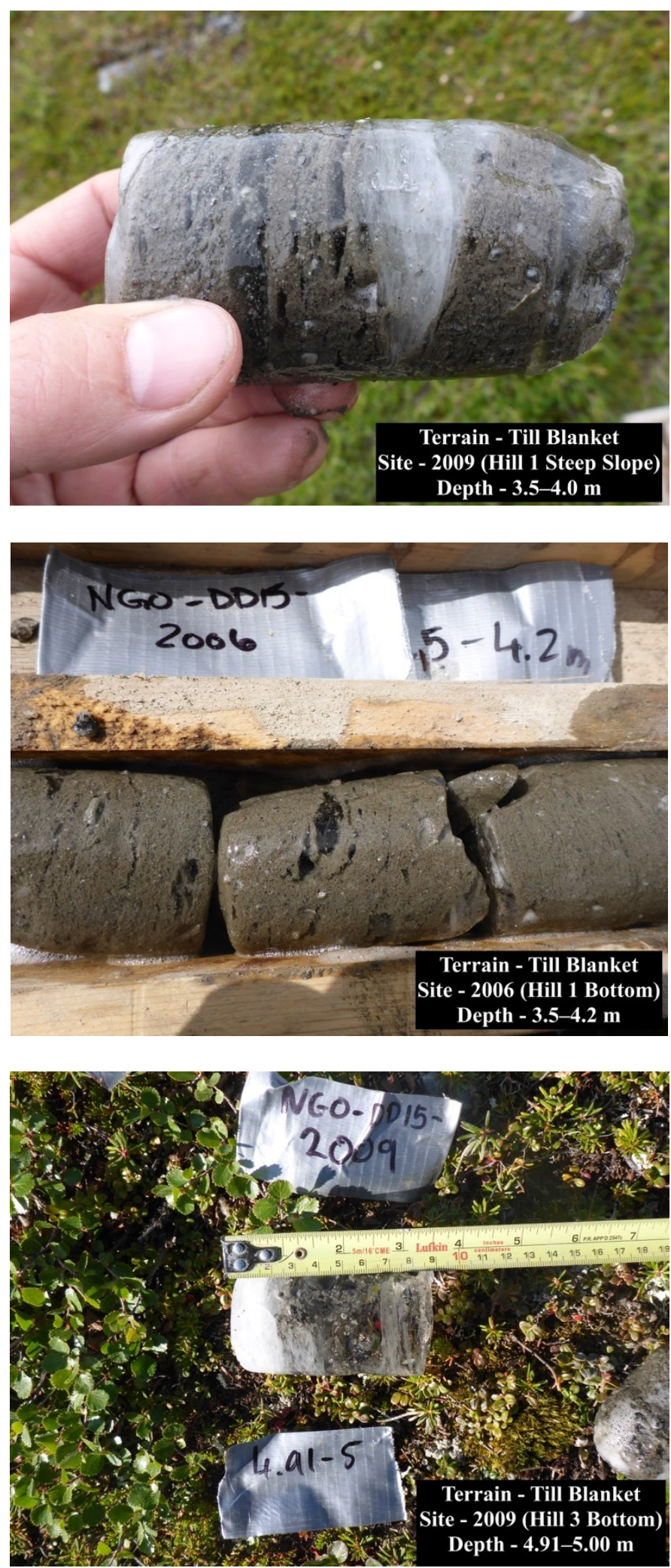

Figure 5.4 Core photos showing high excess ice contents in permafrost at depth for the till blanket terrain near Lac de Gras, N.W.T. 
attributed to the Late Wisconsinan Laurentide ice sheet, which retreated from the region approximately 9000 years ago (Kerr et al., 1997), it is possible that glacial thrusting and shearing emplaced unconsolidated frozen sediments into the ice, which in the present context is still buried underneath ablation till.

\subsubsection{Organic Matter Content GDB (\%)}

The active layer and near-surface permafrost from most sites contained high amounts of organic matter, while the permafrost at depth contained very little (Figure 4.15). Organic matter content was highly variable between terrain types, however a general similarity in profiles was observed in peatlands and wetlands, till blanket and eskers. In these terrain types, organic matter content usually declined with depth and was the lowest at depth in permafrost (Figure 4.15). By contrast, till veneer was observed with very high organic matter content in the near-surface permafrost, while in the active layer and at depth it was relatively low.

Organic matter content was highest in the active layer of peatlands and wetlands, with values of up to $90 \%$ (Table 4.6). This is due to the presence of thick layers of peat (up to $2.5 \mathrm{~m}$ thickness) near the surface (Figure 4.6). Similarly, active layers in other terrain types also contained organic matter, but the values were very low, less than $5 \%$. This is likely due to surface conditions as well as a harsher growing environment in unconsolidated tills which incorporate very little organic materials in the active layer. Similarly, the nearsurface permafrost also had some of the highest organic matter contents. This was mostly the case in peatlands and wetlands and till veneer terrains, but in other terrains were very low, less than 3\% (Table 4.6). In peatlands and wetlands, the thick layers of peat explain 
the high concentration of organic matter in the near-surface permafrost (Figure 4.6). Other possible mechanisms include cryoturbation (Dredge et al., 1994), and the burial of surface organic matter followed by permafrost aggradation which transfers organic matter content into the deeper horizons (e.g. Kokelj et al., 2009). The latter mechanism is relevant at sites from till veneer terrain because the majority of them were located in low-lying depressions or just at the bottom of the hills where permafrost aggradation likely coincided with sedimentation. Organic matter content was the lowest at depth in permafrost for all terrain types investigated. The absolute concentration of carbon in deeper unconsolidated Quaternary deposits had a range of $0.40-4.00 \%$ of dry weight.

\subsubsection{Total Soluble Cations (meq/100 g dry soil)}

Most studies from the western Arctic report distinct geochemical characteristics between the active layer and underlying permafrost, based on the increased concentrations of soluble cations in the near-surface permafrost (e.g. Kokelj and Lewkowicz, 1999; Kokelj et al., 2002; Kokelj and Burn, 2003; Kokelj and Burn, 2005). In this study, the near-surface permafrost in mineral soils is enriched with soluble cations similar to observations from other regions. For example, the median soluble cation concentration at the till steep slope and hill bottom sites $(1004,2007,2009$ and 2013) from till blanket and till veneer terrains, and at the esker site (2028) is higher in near-surface permafrost than the overlying active layer (Table 4.8 and Figure 4.16B). However, in this study, the result of soluble cations obtained from organic soils, contrasts with those obtained from mineral soils. In organic soils, the active layer soluble cation concentration is much higher than the underlying mineral soil permafrost. For example, the median soluble cation concentration of the active 
layer obtained from six peatland and wetland sites (1007, 2011, 2012, 1009, 1010 and 2015 ) is much higher in the organic active layer than the underlying mineral soil permafrost (Table 4.8 and Figure 4.16B). Further, the comparison of active layer soluble cations between organic soils and mineral soils revealed that organic soils contain more solutes than mineral soils (Figure 4.17). These results suggest that in the Lac de Gras area, organic soils are enriched with solutes relative to tills and glaciofluvial deposits, and since the organics are primarily at the surface or within the active layer, the active layer is therefore solute rich with respect to underlying mineral soil permafrost.

A recent study conducted by Fontaine (2016) near the Mackenzie delta region found similar enrichment in the active layer. Three out of her 8 sites, associated with high organic matter content, contained significantly higher concentration of soluble cations in the active layer than the underlying permafrost. The active layer enrichment of this study is quite comparable with Fontaine (2016), because the enriched sites in peatlands and wetlands terrain were highly organic in nature. In addition, the comparison of solute concentration between sample types also supports this result as organic samples show highest concentrations of soluble cations (Figure 4.19). Few enrichments in the active layer are also reported from the disturbed sites, at Herschel Island, but the sites had little or no vegetation (Kokelj et al., 2002).

The near-surface cation enrichment of sites observed in this study is related to the geomorphic setting of each terrain type, and may be explained with processes that are documented in previous studies. In peatlands and wetlands terrain, high concentration of soluble cations in the near-surface permafrost at the peatland sites (1005 and 1006) is explained by high organic matter content, which extended up to $2.5 \mathrm{~m}$ depth in permafrost 
(Figure 4.16B and Figure 4.10). The high concentration of soluble cation in the uppermost surface of low-lying site 2018 can be attributed to high volume of organics present in the active layer.

In profiles, zones of increased cation concentrations corresponded with ice-rich intervals at depth in permafrost, indicating that soluble materials may be drawn with water along thermal gradients (Cary and Mayland 1972; Qui et al., 1988; Chuvilin et al., 1998; Brouchkov 2000). This was especially true for sites in peatlands and wetlands and till veneer terrains (Figure 4.10 and 4.12), as samples in these terrains consisted of high silt contents, so solute accumulation may have accompanied segregated ice development.

The absolute concentration of soluble cations obtained in this study is very low compared to previous studies from northwestern Canada. Other than the organic samples, where the mean total soluble cation concentrations reach up to $3.43 \mathrm{meq} / 100 \mathrm{~g}$ dry soil in the active layer, and $1.48 \mathrm{meq} / 100 \mathrm{~g}$ dry soil in permafrost (Table 4.1), due to their lower bulk density, mineral soils constitute very low soluble cation concentration in the active layer and underlying permafrost (Table 4.2). In mineral soils, the mean total soluble cation concentration of the active layer from various sites in till blanket terrain is often less than $0.50 \mathrm{meq} / 100 \mathrm{~g}$ dry soil, and in permafrost, less than $0.40 \mathrm{meq} / 100 \mathrm{~g}$ dry soil (Table 4.2 ). Previous studies from the Mackenzie Delta and Herschel Island report higher concentration of soluble cations from the active layer and permafrost of various terrain types (Table 5.1). In Mackenzie Delta, a range of forest-terrain types contained soluble cations up to threefold higher in the active layer, and five times higher in permafrost, than those observed in mineral soils of this study (Table 5.1). Even when active layers and permafrost soluble cation concentrations are compared with undisturbed terrain types of Herschel Island, the 
Table 5.1 Concentration of soluble cations reported from the mineral soils of active layer and permafrost from previous studies in northwestern Canada.

\begin{tabular}{|c|c|c|c|c|c|c|c|c|}
\hline \multicolumn{3}{|c|}{$\begin{array}{c}\text { Mackenzie Delta } \\
\text { (Kokelj and Burn, 2005) }\end{array}$} & \multicolumn{3}{|c|}{$\begin{array}{c}\text { Herschel Island } \\
\text { (Kokelj et al., 2002) }\end{array}$} & \multicolumn{3}{|c|}{$\begin{array}{l}\text { Lac de Gras Area } \\
\text { (This Study) }\end{array}$} \\
\hline \multirow[t]{2}{*}{$\begin{array}{l}\text { Terrain } \\
\text { Type }\end{array}$} & \multicolumn{2}{|c|}{$\begin{array}{c}\text { Total Soluble } \\
\text { Cations (meq/100 g } \\
\text { dry soil) }\end{array}$} & \multirow[t]{2}{*}{$\begin{array}{l}\text { Terrain } \\
\text { Type }\end{array}$} & \multicolumn{2}{|c|}{$\begin{array}{c}\text { Total Soluble } \\
\text { Cations (meq/100 g } \\
\text { dry soil) }\end{array}$} & \multirow[t]{2}{*}{$\begin{array}{c}\text { Terrain } \\
\text { Type }\end{array}$} & \multicolumn{2}{|c|}{$\begin{array}{c}\text { Total Soluble } \\
\text { Cations (meq/100 g } \\
\text { dry soil) }\end{array}$} \\
\hline & $\begin{array}{l}\text { Active } \\
\text { Layer }\end{array}$ & Permafrost & & $\begin{array}{l}\text { Active } \\
\text { Layer }\end{array}$ & Permafrost & & $\begin{array}{l}\text { Active } \\
\text { Layer }\end{array}$ & Permafrost \\
\hline $\begin{array}{l}\text { Point-Bar } \\
\text { Willow }\end{array}$ & 2.06 & 3.83 & $\begin{array}{l}\text { Undisturbed } \\
\text { Plateau }\end{array}$ & $\begin{array}{c}0.25- \\
1.5\end{array}$ & $12-14$ & $\begin{array}{l}\text { Till } \\
\text { Blanket }\end{array}$ & $\begin{array}{c}0.08- \\
0.94\end{array}$ & $0.04-0.50$ \\
\hline $\begin{array}{l}\text { Point-Bar } \\
\text { Alder }\end{array}$ & 1.54 & 2.15 & $\begin{array}{l}\text { Undisturbed } \\
\text { Plateau }\end{array}$ & $\begin{array}{c}0.25- \\
6 \\
\end{array}$ & $8-14$ & $\begin{array}{l}\text { Till } \\
\text { Veneer }\end{array}$ & $\begin{array}{c}0.17- \\
0.90 \\
\end{array}$ & $0.25-1.39$ \\
\hline $\begin{array}{l}\text { Spruce- } \\
\text { Alder- } \\
\text { Bearberry } \\
\end{array}$ & 0.64 & 2.09 & $\begin{array}{l}\text { Undisturbed } \\
\text { Stable } \\
\text { Slope } \\
\end{array}$ & $<0.25$ & 5 & Eskers & $0.02-$ & $0.08-0.31$ \\
\hline $\begin{array}{l}\text { Spruce- } \\
\text { Feathermoss }\end{array}$ & 0.49 & 1.24 & $\begin{array}{l}\text { Disturbed } \\
\text { AL } \\
\text { Detachment } \\
\text { Slides }\end{array}$ & $2-10$ & 12 & & 0.08 & \\
\hline $\begin{array}{l}\text { Spruce- } \\
\text { Crowberry- } \\
\text { Lichen }\end{array}$ & 0.38 & 1.62 & $\begin{array}{l}\text { Disturbed } \\
\text { AL } \\
\text { Detachment } \\
\text { Slides }\end{array}$ & $2-12$ & 12 & & & \\
\hline
\end{tabular}


absolute concentrations of soluble cations are very low in this study. This difference in soluble cation concentrations from previous studies might be associated with materials of different origins. Since, Lac de Gras area has a contrasting geomorphic and regional setting from other areas in the north, this difference might be a major contributing factor to the observed low concentration of soluble cations in mineral soils. 


\section{CHAPTER 6. CONCLUSIONS}

This thesis examined the vertical and spatial patterns of water content GWB, organic matter content (\%) and total soluble cations (meq./100 g dry soil) near Lac de Gras, N.W.T. The following conclusions can be drawn from this study.

1. In the Lac de Gras area, organic soils are enriched with solutes relative to tills and glaciofluvial deposits, and since the organics are primarily at the surface or within the active layer, the active layer is solute rich with respect to underlying permafrost.

2. Active layer and underlying permafrost are geochemically distinct, but unlike previous studies from other areas, this difference is attributed to organic soils, which sequester more solutes in the active layer, relative to underlying mineral soil permafrost.

3. Near-surface solute enrichment of permafrost, similar to most previous studies from northwestern Canada, is evident at some sites in each terrain type.

4. The concentration of soluble cations at depth in permafrost was generally low, but the zones of increased cation concentrations at depth corresponded with ice-rich intervals.

5. Organic matter content was highest in the active layer of peatlands and wetlands terrain, and in other terrains the uppermost layers were characterized by relatively low organic matter. Organic matter content also declined with depth, i.e., it was highest in the active layer, followed by the near-surface permafrost and was lowest at depth in permafrost for all terrain types. 
6. In comparison with previous studies from northwestern Canada, the absolute concentration of soluble cations in the active layer and near-surface permafrost of mineral soils is about one order of magnitude lower in the Lac de Gras area. 


\section{BIBLIOGRAPHY}

Andersson, J. G. (1906). Solifluction; a component of subaerial denudation. Journal of Geology, 14, 91-112.

Anderson, D. M., and Morgenstern, N. R. (1973). Physics, chemistry, and mechanics of frozen ground. A review. In Permafrost: The North American contribution to the 2nd International Conference on Permafrost, Yakutsk, 13-28 July. pp. 257-288.

Associate Committee on Geotechnical Research (ACGR). (1988). Canadian glossary of permafrost and related ground-ice terms, technical memorandum No. 142. National Research Council of Canada: Ottawa, ON; 156 pp.

Bakhman, V.I., and Efemiov, A.L. (1962). Chemical composition of water and bottom sediments in some thermokarst lakes of central Yakutia. Akad. Nauk SSSR Sibirskoe otd - ie Inst Merzlotovedeniia Mnogoletnemerzlye, p. 114-122.

Beuselinck, L., Govers, G., Poesen, J., Degraer, G., and Froyen, L. (1998). Grain-size analysis by laser diffractometry: comparison with the sieve-pipette method. Catena, 32(3-4), p. 193-208.

Blum J. D., Klaue A., Nezat C. A., Driscoll C. T., Johnson C. E., Siccama T. G., Eagar C., Fahey T. J., and Likens G. E. (2002). Mycorrhizal weathering of apatite as an important calcium source in base-poor forest ecosystems. Nature 417:729-731.

Bockheim J. G., Everett L. R., Hinkel K. M., Nelson F. E., and Brown J. (1999). Soil organic carbon storage and distribution in arctic tundra, Barrow, Alaska. Soil Science Society of America Journal 63: 934-940.

Bockheim, J. G. (2007). Importance of cryoturbation in redistributing organic carbon in permafrost-affected soils. Soil Science Society of America Journal, 71, 1335.

Bouchard M. (1974). Geologie de depots de L'Ile Herschel, Territoire du Yukon. (Thèse M.Sc. non publié). University de Montreal, Montreal, Canada.

Brouchkov, A. (2000). Salt and water transfer in frozen soils induced by gradients of temperature and salt content. Permafrost and Periglacial Processes, 11: 42-49.

Brown, R.J.E. (1967). Permafrost in Canada. Geological Survey of Canada Map 1246a. National Research Council of Canada, Ottawa, Ontario.

Brown, J., Gray, S., and Webster, W. (1967). Chemical and related properties of permafrost section from Fairbanks, Alaska. USA. CRREL Technical Note, 18 p. 
Brown, J. (1969). Ionic concentration gradients in permafrost, Barrow, Alaska. Cold Regions Research and Engineering Lab Hanover NH (No. CRREL-RR-272).

Burn C.R. (1997). Cryostratigraphy, paleogeography, and climate change during the Early Holocene warm interval, western Arctic coast, Canada. Canadian Journal of Earth Sciences, 34, 912-925.

Burn C. R. (2004). The thermal regime of cryosols. In Cryosols: Permafrost-affected Soils, Kimble JM (ed.). Springer-Verlag: Berlin, Germany; 391-413.

Burn C. R., and Michel FA. (1988). Evidence for recent temperature-induced water migration into permafrost from tritium content of ground ice near Mayo, Yukon Territory, Canada. Canadian Journal of Earth Sciences 25: 909-915.

Burt T. P., and Williams P. J. (1976). Hydraulic conductivity in frozen soils. Earth Surface Processes 1: 349-360.

Canada Soil Survey Committee. (1978). The Canadian system of soil classification. Research Branch, Canada Department of Agriculture.

Canamera Gelogical (1996). Lytton Minerals Limited Jericho Diamond Project: Bulk Sample Class A Land Use Application. Report submitted to Indian and Northern Affaira Canada, p. 46.

Cary, J. W., and Mayland, H. F. (1972). Salt and water movement in unsaturated frozen soil. Soil Science Society of America Journal, 36(4), p. 549-555.

Cheng, G. (1983). The mechanism of repeated-segregation for the formation of thick layered ground ice. Cold Regions Science and Technology, 8(1), p. 57-66.

Chin, K. S., Lento, J., Culp, J. M., Lacelle, D., and Kokelj, S. V. (2016). Permafrost thaw and intense thermokarst activity decreases abundance of stream benthic macroinvertebrates. Global Change Biology, 22, p. 2715-2728.

Chizhov A. B., Chizhova N. I., Morkovina I. K., and Romanov VV. (1983). Tritium in permafrost and ground ice. In Proceedings, 4th International Conference on Permafrost, Fairbanks, Alaska, July 17-22, 1983, Vol. 1. National Academy Press: Washington, DC; 1030-1035.

Chuvilin, E. M., Ershov, E. D., and Smirnova, O. G. (1998). Ionic migration in frozen soils and ice. In Proceedings of the $7^{\text {th }}$ International Permafrost Conference, Yellowknife, N.W.T., 23-27 June 1998. Edited by A.G. Lewkowicz and M. Allard. Centre d'études 
nordiques, Université Laval, Laval, Quebec. p. 167-171.

Diochon, A., Gregorich, E. G., and Tarnocai, C. (2013). Evaluating the quantity and biodegradability of soil organic matter in some Canadian Turbic Cryosols. Geoderma, 202-203, 82-87.

Dredge, L.A., Ward, B.C., and Kerr, D.E. (1994). Glacial geology and implications for drift prospecting in the Lac de Gras, Winter Lake, and Aylmer Lake map areas, central Slave Province. In Current Research 1994-C; Geological Survey of Canada, p. 3338.

Dredge, L. A., Kerr, D. E., and Wolfe, S. A. (1999). Surficial materials and related ground ice conditions, Slave Province, N.W.T., Canada. Canadian Journal of Earth Sciences, 36, p. 1227-1238.

Egginton, P. A., and French, H. M. (1985). Solifluction and related processes, eastern Banks Island, N.W.T. Canadian Journal of Earth Sciences, 22(11), 1671-1678.

Environment Canada (2016). National climate data and information archive, climate normals and averages, http://climate.weather.gc.ca/climate_normals/index_e.html. [accessed February 2016].

Eshel, G., Levy, G. J., Mingelgrin, U., and Singer, M. J. (2004). Critical evaluation of the use of laser diffraction for particle-size distribution analysis. Soil Science Society of America Journal, 68(3), p. 736.

Fontaine, M. (2016). Ground ice content and geochemistry of active layer and permafrost in northwestern Arctic Canada. (Master's thesis). University of Ottawa, Ottawa, Canada. Retrieved from www.ruor.uottawa.ca/handle/10393/33428.

French, H. M., and Harry, D. G. (1990). Observations on buried glacier ice and massive segregated ice, western Arctic coast, Canada. Permafrost and Periglacial Processes, $1(1), 31-43$.

French, H. M. (2007). The periglacial environment. $3^{\text {rd }}$ edition. Longman, London, UK.

Frey K.E. and McClelland J.W. (2009). Impacts of permafrost degradation on arctic river biogeochemistry. Hydrological Processes, 23(1), 169-182.

Gill, D. (1973). Ecological modifications caused by the removal of tree and shrub canopies in the Mackenzie Delta. Arctic, 26: 95-111.

Guodong, C. (1983). The mechanism of repeated-segregation for the formation of thick 
layered ground ice. Cold Regions Science and Technology, 8(1), 57-66.

Heginbottom, J.A., Dubreuil, M.A., and Harker, P.A. (1995). Canada-Permafrost. In National Atlas of Canada 5th Edition, National Atlas Information Service, Natural Resources Canada, Ottawa, Plate 2.1, MCR 4177.

Hinzman L.D., Deal C.J., McGuire A.D., Mernild S.H., Polyakov I.V. and Walsh J.E. (2013). Trajectory of the Arctic as an integrated system. Ecological Applications, 23, $1837-1868$.

Hugelius, G., Kuhry, P., Tarnocai, C., and Virtanen, T. (2010). Soil organic carbon pools in a periglacial landscape: A case study from the central Canadian Arctic. Permafrost and Periglacial Processes, 21(1), p. 16-29.

Hu, X., Holubec, I., Wonnacott, J., Lock, R., and Olive, R. (2003). Geomorphological, geotechnical and geothermal conditions at Diavik Mines. In 8th International Conference on Permafrost. Zurich, Switzerland. p. 18.

Huh, Y., Tsoi, M. Y., Zaitsev, A., and Edmond, J. M. (1998). The fluvial geochemistry of the rivers of Eastern Siberia: I. Tributaries of the Lena River draining the sedimentary platform of the Siberian Craton. Geochimica et Cosmochimica Acta, 62: 1657-1676.

Janzen, H.H. (1993). Soluble salts. In Soil sampling and methods of analysis. Lewis Publishers, Boca Raton, Fla., p. 161-166.

Jorgenson M. T., Shur Y. L., and Pullman E. R. (2006). Abrupt increase in permafrost degradation in Arctic Alaska. Geophysical Research Letters 33: L02503.

Kaiser, C., Meyer, H., Biasi, C., Rusalimova, O., Basukov, P., and Richter, A., (2007). Conservation of soil organic matter through cryoturbation in arctic soils in Siberia. Journal of Geophysical Research 112, G02017.

Karunaratne, K. C. (2011). A field examination of climate-permafrost relations in continuous and discontinuous permafrost of the Slave geological province. (Doctoral dissertation). Carleton University, Ottawa, Canada.

Keller, K., Blum, J. D., and Kling, G. W. (2007). Geochemistry of soils and streams on surfaces of varying ages in Arctic Alaska. Arctic, Antarctic, and Alpine Research, 39(1), p. 84-98.

Kerr, D.E., Wolfe, S.A., and Dredge, L.A. (1997). Surficial geology of the Contwoyto Lake map area (north half), District of Mackenzie, Northwest Territories. In Current 
Research 1997-C, Geological Survey of Canada, p. 51-59.

Kjarsgaard, B.A. and Wyllie, R.J.S. (1994). Geology of the Paul Lake Area, Lac de Gras, Lac de Sauvage Region of the Central Slave Province, District of Keewatin, N.W.T. In Current Research. 1994-C, Geological Survey of Canada . 23- 32.

Kokelj, S. V., and Lewkowicz, A. G. (1999). Salinization of permafrost terrain due to natural geomorphic disturbance, Fosheim Peninsula, Ellesmere Island. Arctic, 52(4), p. 372-385.

Kokelj, S. V., Smith, C. A. S., and Burn, C. R. (2002). Physical and chemical characteristics of the active layer and permafrost, Herschel Island, western Arctic Coast, Canada. Permafrost and Periglacial Processes, 13(2), p. 171-185.

Kokelj, S. V., and Burn, C. R. (2003). Ground ice and soluble cations in near-surface permafrost, Inuvik, Northwest Territories, Canada. Permafrost and Periglacial Processes, 14(3), p. 275-289.

Kokelj, S. V., and Burn, C. R. (2005). Geochemistry of the active layer and near-surface permafrost, Mackenzie delta region, Northwest Territories, Canada. Canadian Journal of Earth Sciences, 42(1), p. 37-48.

Kokelj S. V., Lantz T. C., Kanigan J., Smith S. L., and Coutts R. (2009). Origin and polycyclic behavior of tundra thaw slumps, Mackenzie Delta Region, Northwest Territories, Canada. Permafrost and Periglacial Processes, 20, 173-184.

Kokelj S.V., and Jorgenson M.T. (2013). Advances in thermokarst research. Permafrost and Periglacial Processes, 24(2), 108-119.

Kokelj, S. V., Lacelle, D., Lantz, T. C., Tunnicliffe, J., Malone, L., Clark, I. D. and Chin, K.S. (2013). Thawing of massive ground ice in mega slumps drives increases in stream sediment and solute flux across a range of watershed scales. Journal of Geophysical Research: Earth Surface, 118, 681-692.

Konrad, J. M., and McCammon, A. W. (1990). Solute partitioning in freezing soils. Canadian Geotechnical Journal, 27(6), 726-736.

Kling, G.W., O'Brien, J., Miller, M.C., and Hershey, A.E. (1992). The biogeochemistry and zoogeography of lakes and rivers in arctic Alaska. Hydrobiologia, 240: 1-14.

Kopecký, M., and Čížková, Š. (2010). Using topographic wetness index in vegetation ecology: does the algorithm matter. Applied Vegetation Science, 13(4), 450-459. 
Kuhry, P., Grosse, G., Harden, J. W., Hugelius, G., Koven, C. D., Ping, C.-L., Schirrmeister, L., and Tarnocai, C. (2013). Characterisation of the Permafrost Carbon Pool. Permafrost and Periglacial Processes, 24(2), p. 146-155.

Kudryavtsev, A., Dostovalov, B. N., and Garagulya, L. S. (1978). Radiation-heat balance of the soil surface as a factor in the formation and dynamics of seasonally frozen soils and permafrost. In Permafrost, Second International Conference, July 13-28, 1973: USSR contribution. p. 18.

Lacelle, D., Juneau, V., Pellerin, A., Lauriol, B., and Clark, I.D. (2008). Weathering regime and geochemical conditions in a polar desert environment, Haughton impact structure region, Devon Island, Canada. Canadian Journal of Earth Sciences, 45, 1139-1157.

Lacelle, D., and Vasil'chuk, Y. K. (2013). Recent progress (2007-2012) in permafrost isotope geochemistry. Permafrost and Periglacial Processes, 24(2), p. 138-145.

Lantz, T. C., Kokelj, S. V., Gergel, S. E., and Henry, G. H. (2009). Relative impacts of disturbance and temperature: persistent changes in microenvironment and vegetation in retrogressive thaw slumps. Global Change Biology, 15(7), p. 1664-1675.

Leibman, M. O., and Streletskaya, I. D. (1997). Land-slide induced changes in the chemical composition of active layer soils and surface-water run-off, Yamal Peninsula, Russia. In Proceedings of the International symposium on physics, chemistry, and ecology of seasonally frozen soils, Fairbanks, Alaska, 10-12 June 1997. Edited by I.K. Iskandar, E.A. Wright, J.K. Radke, B.S. Sharratt, P.H. Groenevelt, and L.D. Hinzman. CRREL Special Report 97-10, Cold Regions Research and Engineering Laboratory (CRREL), Hanover, N.H., p. 120-126.

Mackay, J. R. (1972). The world of underground ice. Annals of the Association of American Geographers. 63, 1-22.

Mackay, J. R., Rampton, V. N., and Fyles, J. G. (1972). Relic Pleistocene permafrost, western Arctic, Canada. Science, 176(4041), 1321-1323.

Mackay, J. R. (1980). The origin of hummocks, western Arctic coast, Canada. Canadian Journal of Earth Sciences, 17, 996-1006.

Mackay, J. R. (1981). Active layer slope movement in a continuous permafrost environment, Garry Island, Northwest Territories, Canada. Canadian Journal of Earth Sciences, 18(11), 1666-1680. 
Mackay, J. R. (1982). Active layer growth, Illisarvik experimental drained lake site, Richards Island, Norwest Territories; in Current Research, Part A, Geological Survey of Canada, Paper 82-1A, p. 123-126, 1982.

Mackay, J. R. (1983). Downward water movement into frozen ground, Western Arctic coast, Canada. Canadian Journal of Earth Sciences, 20(1), p. 120-134.

Mackay, J. R. (1995). Active layer changes (1968 to 1993) following the forest-tundra fire near Inuvik, N.W.T., Canada. Arctic and Alpine Research, 27(4), p. 323.

Mackay J. R., and Burn C. R., (2002). The first 20 years (1978-1979 to 1998-1999) of active-layer development, Illisarvik experimental drained lake site, western Arctic coast, Canada. Canadian Journal of Earth Sciences 39: 1657-1674.

Malone L., Lacelle D., Kokelj S.V. and Clark I.D. (2013). Impacts of hillslope thaw slumps on the geochemistry of permafrost catchments (Stony Creek watershed, NWT, Canada). Chemical Geology, 356, 38-49.

Mathews, W. H. and Mackay, J. R. (1960). Deformation of soils by glacier ice and the influence of pore pressure and permafrost. Royal Society of Canada Transactions, LIX, Series III, Section 4, 27-36.

McRoberts, E. C., and Morgenstern, N. R. (1974). The stability of thawing slopes. Canadian Geotechnical Journal, 11(4), 447-469.

Mitchell, JK., Soga, K. (2005). Fundamentals of soil behaviour. John Wiley \& Sons, Hoboken, New Jersey.

Morse, P. D., Burn, C. R., and Kokelj, S. V. (2009). Near-surface ground-ice distribution, Kendall Island Bird Sanctuary, Western Arctic coast, Canada. Permafrost and Periglacial Processes, 20, 155-171.

National Wetlands Working Group. (1988). Wetlands of Canada. Ecological land classification series, no. 24. Sustainable Development Branch, Environment Canada, Ottawa, Ontario, and Polyscience Publications Inc., Montreal, Quebec, 452.

O'Donnell, J. A., Harden, J. W., McGuire, A. D., Kanevskiy, M. Z., Jorgenson, M. T., and $\mathrm{Xu}, \mathrm{X}$. (2011). The effect of fire and permafrost interactions on soil carbon accumulation in an upland black spruce ecosystem of interior Alaska: implications for post-thaw carbon loss. Global Change Biology, 17(3), 1461-1474.

O’Neill, H. B. and Burn, C.R. (2012). Physical and temporal factors controlling the 
development of near-surface ground ice at Illisarvik, western Arctic coast, Canada. Canadian Journal of Earth Sciences, 49, 1096-1110.

O'Sullivan, J. B. (1966). Geochemistry of permafrost, Barrow, Alaska. In Proceedings, International Conference on Permafrost. National Academy of Sciences - National Research Council Publication 1287. p. 30-37.

Osterkamp, T. E., and Burn, C. R., (2002), Permafrost, in Holton, J.R., Pyle, J., and Curry, J.A., eds., Encyclopedia of Atmospheric Sciences: New York, Academic Press, p. 1717-1729.

Pewe, T. L., and Sellmann, P. V. (1973). Geochemistry of permafrost and Quaternary stratigraphy. In Permafrost: North American Contribution to the Second International Conference, Yakutsk, U.S.S.R. National Academy of Science Press, Washington, D.C., pp. 166-170.

Phillips, M. R., Burn, C. R., Wolfe, S. A., Morse, P. D., Gaanderse, A. J., O'Neill, H. B., Shugar, D.H. and Gruber, S. (2015). Improving water content description of ice-rich permafrost soils. In Proceedings of the GeoQuebec 2015 Conference, September 2123, Quebec, Canada. Canadian Geotechnical Society, Richmond, BC. 7 p.

Qui, G., Sheng, W., Huang, C., and Zheng, K. (1988). Direction of ion migration during cooling and freezing processes. In Proceedings, Fifth International Conference on Permafrost, 2-5 August, Trondheim, Norway. Trondheim, Norway: Tapir Publishers, vol. 1, p. $442-447$.

Rampton V. N. (1988). Quaternary geology of the Tuktoyaktuk Coastlands, Northwest Territories. Geological Survey of Canada Memoir 423.

Rempel, A. W. (2010). Frost heave. Journal of Glaciology, 56(200), 1122-1128.

Rydin, H., Jeglum, J. K., and Jeglum, J. K. (2013). The biology of peatlands, 2e. Oxford university press.

Schirrmeister, L., C. Siegert, T. Kuznetsova, S. Kuzmina, A. Andreev, F. Kienast, H. Meyer, and A. Bobrov (2002). Paleoenvironmental and paleoclimatic records from permafrost deposits in the Arctic region of northern Siberia, Quat. Int., 89, 97-118

Schuur, E. A. G., et al. (2008), Vulnerability of permafrost carbon to climate change: Implications for the global carbon cycle, BioScience, 58, 701-714.

Sheldrick BH. (ed.). (1984). Analytical methods manual 1984. Land Resource Research 
Institute, Agriculture Canada, Ottawa, Canada, LRRI Contribution No. 84-30.

Shur, Y., Hinkel, K. M., and Nelson, F. E. (2005). The transient layer: implications for geocryology and climate-change science. Permafrost and Periglacial Processes, 16(1), 5-17.

Stutter, M. I., and Billet, M. F. (2003). Biogeochemical controls on stream water and soil solution chemistry in a High Arctic environment. Geoderma, 113: 127-146.

Smith, M. W. (1975). Microclimatic influences on ground temperatures and permafrost distribution, Mackenzie Delta, Northwest Territories. Canadian Journal of Earth Sciences, 12(8), p. 1421-1438.

Smith, MW. (1985). Observations of soil freezing and frost heave at Inuvik, Northwest Territories, Canada. Canadian Journal of Earth Sciences, 22, 283-290.

Smith C. A. S.., Fox C. A., and Hargrave A. E. (1991). Development of soil structure in some Turbic Cryosols in the Canadian low Arctic. Canadian Journal of Soil Science 71: 11-29.

Smith S. L., Romanovsky V. E., Lewkowicz A. G., Burn C. R., Allard M., Clow G. D., Yoshikawa K., and Throop J. (2010). Thermal state of permafrost in North America: a contribution to the International Polar Year. Permafrost and Periglacial Processes 21: $117-135$.

Tarnocai, C. (1999). The effect of climate warming on the carbon balance of Cryosols in Canada. Permafrost and Periglacial Processes, 10(3), p. 251-263.

Tarnocai, C., Canadell, J. G., Schuur, E. A. G., Kuhry, P., Mazhitova, G., and Zimov, S. (2009). Soil organic carbon pools in the northern circumpolar permafrost region. Global Biogeochemical Cycles, 23(2).

Thienpont, J. R., Johnson, D., Nesbitt, H., Kokelj, S. V., Pisaric, M. F., and Smol, J. P. (2012). Arctic coastal freshwater ecosystem responses to a major saltwater intrusion: A landscape-scale palaeolimnological analysis. The Holocene, 22(12), p. 1451-1460.

Toner, J. D., Sletten, R. S., and Prentice, M. L. (2013). Soluble salt accumulations in Taylor Valley, Antarctica: implications for paleolakes and Ross Sea Ice Sheet dynamics. Journal of Geophysical Research: Earth Surface, 118(1), 198-215.

Washburn A.L. (1980). Geocryology: a survey of periglacial processes and environments. John Wiley \& Sons, New York, NY, 406 p. 
Watanabe, K., Mizoguchi, M., (2002). Amount of unfrozen water in frozen porous media saturated with solution. Cold Regions Science and Technology. 34, 103-110.

Wiken, E. B., Gauthier, D., Marshall, I., Lawton, K., and Hirvonen, H. (1996). A perspective on Canada's ecosystems. Canadian Council on Ecological Areas, 14.

Wilkinson, L., Harris, J., Kjarsgaard, B., Mcclenaghan, B., and Kerr, D. (2001). Influence of till thickness and texture on till geochemistry in the Lac de Gras area, Northwest Territories, with applications for regional kimberlite exploration. Current research. Geological Survey of Canada, Report, C9.

Williams, P. J., and Smith, M. W. (1991). The Frozen Earth. Cambridge University Press. Wolfe S. A., Kotler E., and Nixon M. F. (2000). Recent warming impacts in the Mackenzie Delta, Northwest Territories, and northern Yukon Territory coastal areas. Current Research, Geological Survey of Canada Paper, 2000-B1.

Woo, M. K., and Marsh, P. (1977). Effect of vegetation on limestone solution in a small high Arctic basin. Canadian Journal of Earth Sciences, 14: 571-581. 


\section{APPENDIX A: Drill log sheet used for recording the core information}

HolelD:

Drill Log

Page $1 /$

Hole Location UTM NAD83 Zone 12

Date/Time

Easting:

Northing:

Elev: Start Date/Time:

End:

Crew

Drill Company: Kryotek

Driller:

Helper:

-Logistics

Move Notes:

Drilling Notes:

Downtime Length/Reason:

Site Evaluation (Circle Appropriately)

Terrain: $\{$ Shore, Swamp, Hills, Flat $\} \quad$ Trees: $\{$ None, Visible, Few, Many\} Frost Boil: $\{$ Active, Inactive, None, Unsure $\}$

Boulder Rounding: \{Low, Medium, High, Unsure $\}$ Boulder Abundance: \{Absent, Low, Medium, High\}

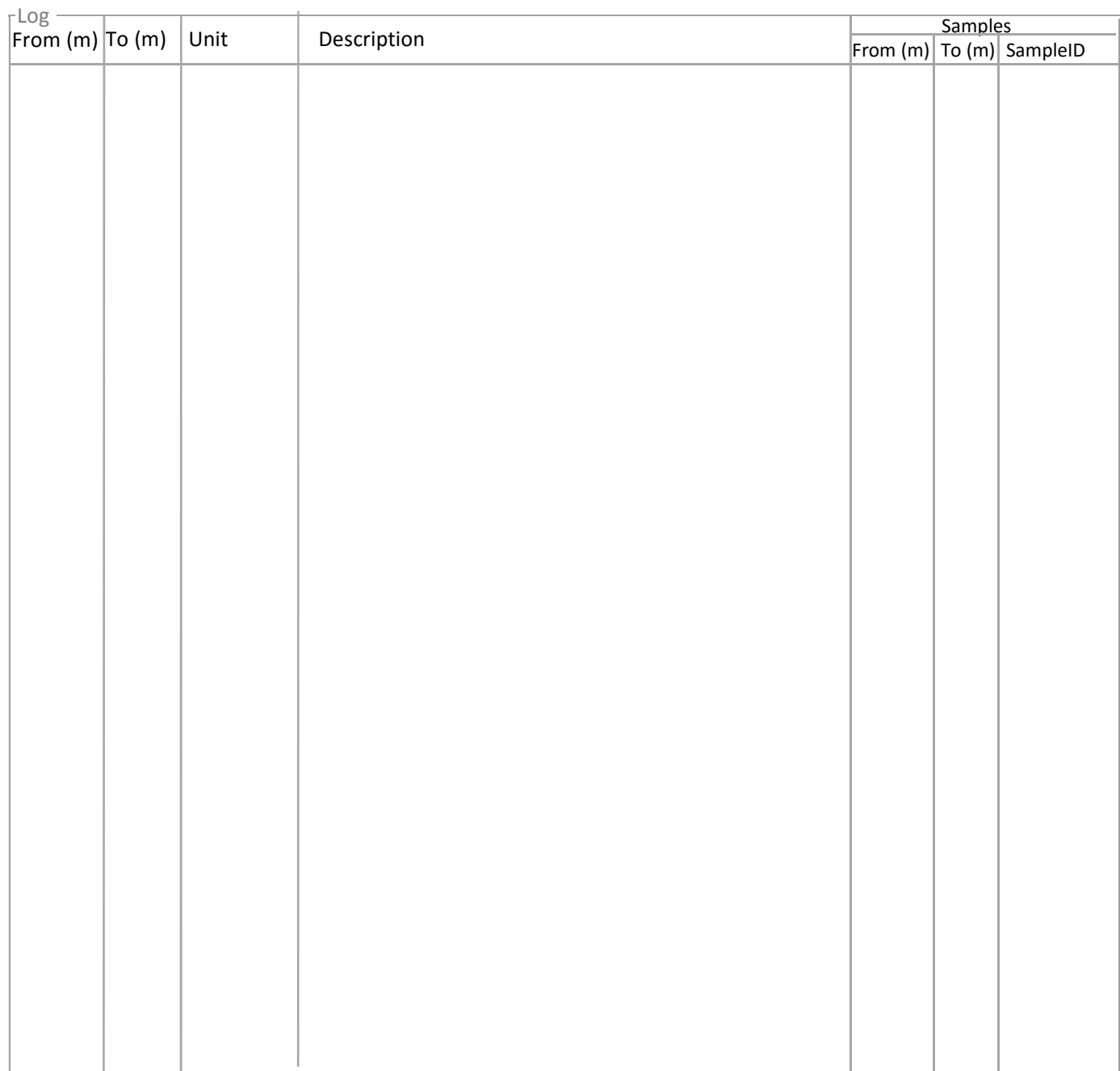




\section{APPENDIX B: Log sheet used for recording soil pit information}

Exterior pit form (One per pit)

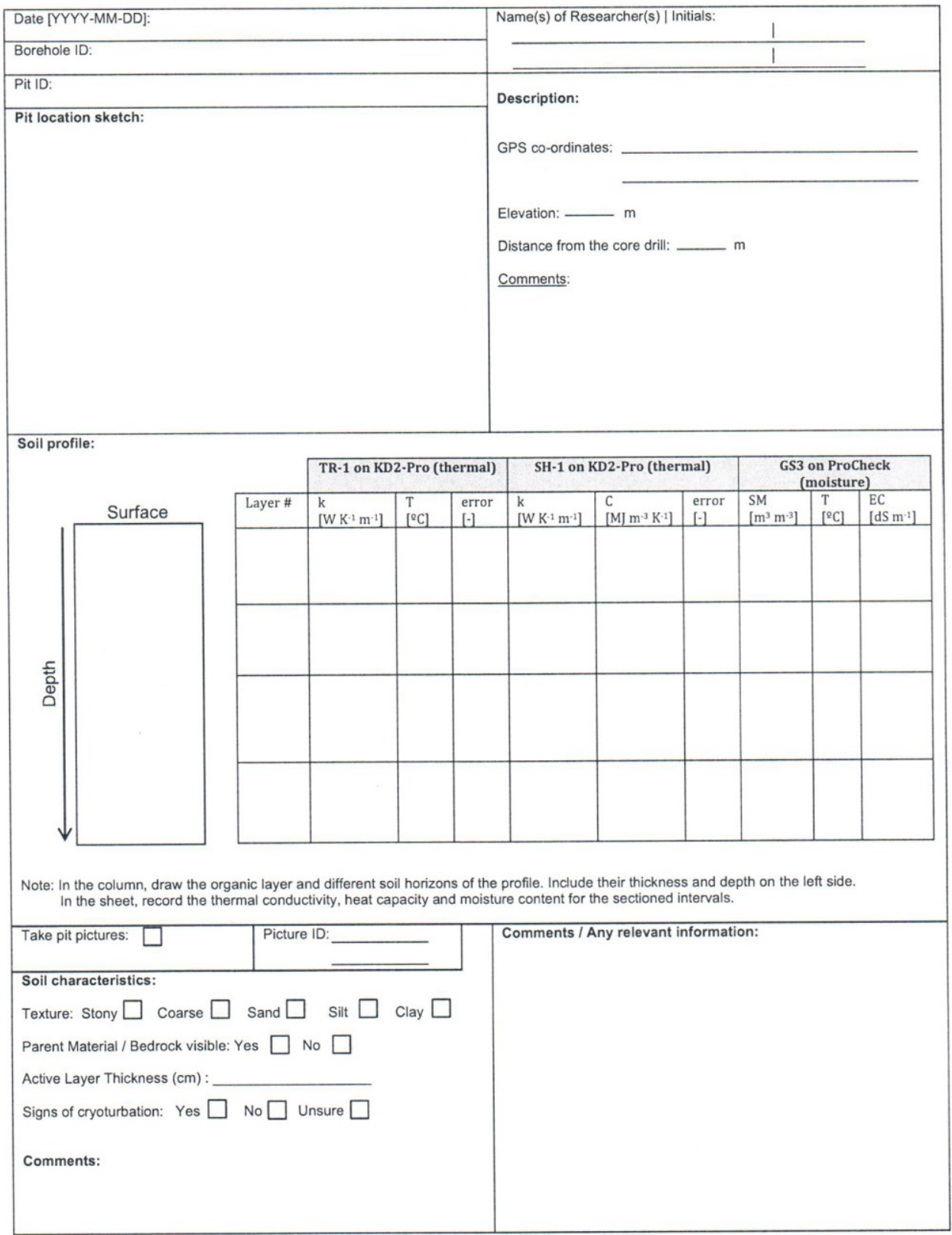




\section{APPENDIX C: Protocols for sample preparation and analysis}

\section{Processing Procedure for Permafrost Samples - Summer 2015}

1. Initial Mass - Weigh the sample in the plastic bag before untying knot and record the mass.

2. Beaker ID - Each sample will be processed in a separate clean glass beaker (probably 750 or $1000 \mathrm{ml}$ ) and the sample will be associated with a beaker ID which is recorded in the spreadsheet.

3. Beaker Mass - Weigh the clean and dry beaker and record the mass.

4. Sample in Beaker - Place the entire sample in the beaker including all of the water associated with the sample. This is probably melted ground ice and must be retained. Attention must be used to ensure that the sample doesn't spill or is not contaminated.

5. Gravel/Sand/Fines - Visually estimate percentage by volume of gravel (5 to $76 \mathrm{~mm})$, sand (0.074 to $5 \mathrm{~mm})$, and fines (silt/clay).

6. Wet Mass - Weigh the sample and the beaker and record this value in the column "Wet Mass of filled beaker (g)".

7. Added Supernatant Water - Some of the samples will have supernatant water overlying the sediment in the beaker, some will not. If there is less than $150 \mathrm{~mL}$ of supernatant water, add sufficient deionized water to produce at least $150 \mathrm{ml}$ of supernatant water overlying the sample. RECORD the amount of water added in the column "Added Deionized Water ( $\mathrm{ml})$ ". If there is at least $150 \mathrm{ml}$ of supernatant water in the sample, then do not add more water and enter ' 0 ' in the column "Added Deionized Water (ml)".

8. Homogenize Samples - Stir

9. Cover Samples - Cover all samples with plastic wrap to prevent evaporation.

10. Settle Sediment - Allow the sediment to settle for 12 hours.

11. Clarity of Supernatant Water - Describe the clarity of the supernatant water as either 'Clear', 'Slightly Cloudy', or 'Very Cloudy'.

12. Record "Volume of Supernatant Water (ml)".

13. Record "Volume of Sediment Below Supernatant Water (ml)"

14. Record "Total Volume of Sample Including Supernatant Water (ml)".

15. Water Samples - Remove $100 \mathrm{ml}$ supernatant water from all the samples using a syringe. The syringe must be clean and rinsed with deionized water. Place the $100 \mathrm{~mL}$ of supernatant water in vial provided, label vial.

16. Send water samples to Northwest Territories Geological Survey who will deliver to Taiga Environmental lab.

17. Dry the soil in the beakers at $105^{\circ} \mathrm{C}$ for 12 hours.

18. Weigh beaker with dry soil and record "Dry Weight + beaker".

19. Record "Volume of dry Sediment (ml)".

20. Remove dried sediment from the beaker

21. Subsample dried sediment by breaking off (like from a pizza or cake) around $50 \mathrm{~g}$. Crush and homogenize in a mortar and fill the resulting homogenized powder into three separate bags or vials of 10 to $20 \mathrm{~g}$ each. It is important that the subsamples contain representative amounts of fine and coarse material. 


\section{APPENDIX D: Data}

\section{Control Group}

Field data from the Control group representing the surface conditions

\begin{tabular}{|c|c|c|c|c|c|c|}
\hline $\begin{array}{c}\text { BoreholeID } \\
\text { (NGO- } \\
\text { DD15- }\end{array}$ & $\begin{array}{c}\text { Easting } \\
\text { (m) }\end{array}$ & $\begin{array}{l}\text { Northing } \\
\text { (m) }\end{array}$ & $\begin{array}{c}\text { Elevation } \\
\text { (m) }\end{array}$ & $\begin{array}{c}\text { Terrain } \\
\text { Type }\end{array}$ & $\begin{array}{c}\text { Surface } \\
\text { Topography }\end{array}$ & Vegetation \\
\hline 1006 & 536691 & 7164515 & 439 & Peatland & Hummocky & $\begin{array}{l}\text { Shrubs, } \\
\text { Grasses, } \\
\text { Sedges, } \\
\text { Mosses }\end{array}$ \\
\hline 1007 & 536712 & 7164515 & 439 & Peatland & Hummocky & $\begin{array}{c}\text { Shrubs, } \\
\text { Grasses, } \\
\text { Sedges, } \\
\text { Mosses }\end{array}$ \\
\hline
\end{tabular}




\section{Control: NGO-DD15-1006 (Peatlands and wetlands Terrain)}

A

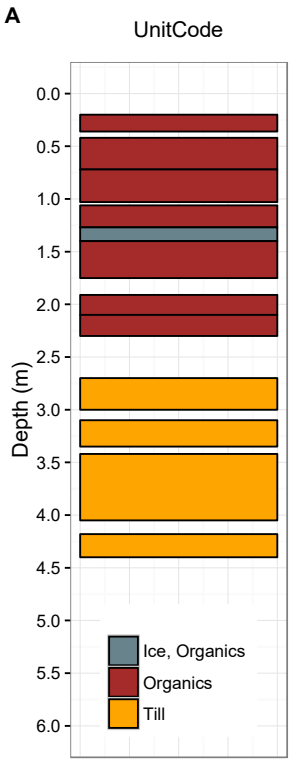

B Total Soluble Cations (meq/100g dry soil)

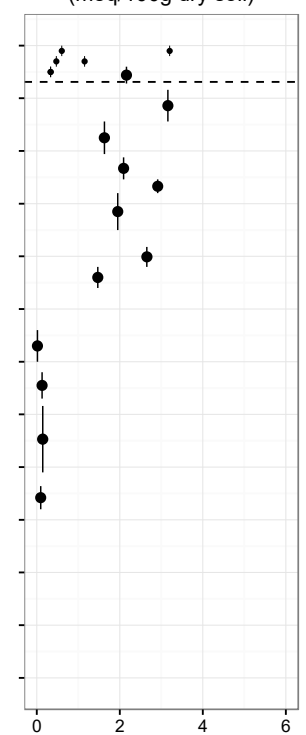

C Soil-Water Conductivity (mS/cm)

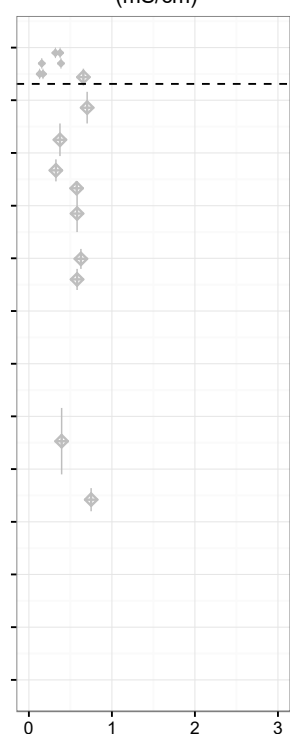

D Water Content GWB \& Excess Ice (\%)

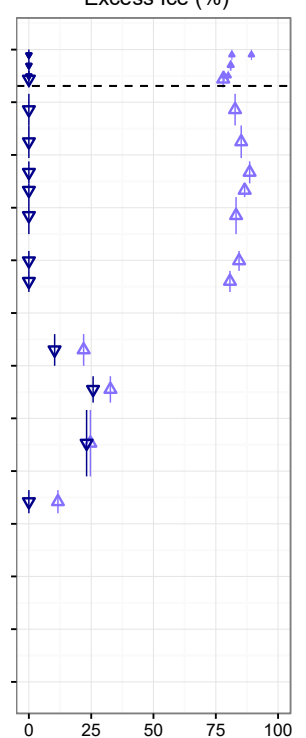

Organic Matter GDB (\%)

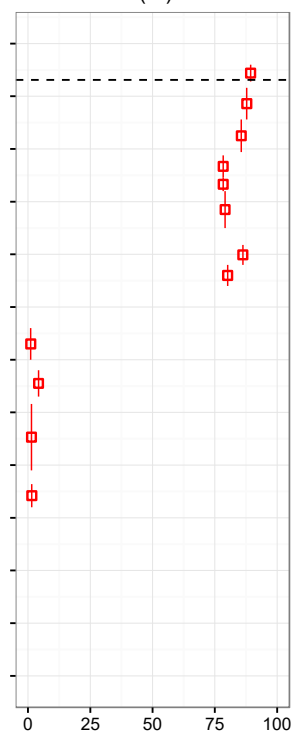

\section{Control: NGO-DD15-1007 (Peatlands and wetlands Terrain)}

A

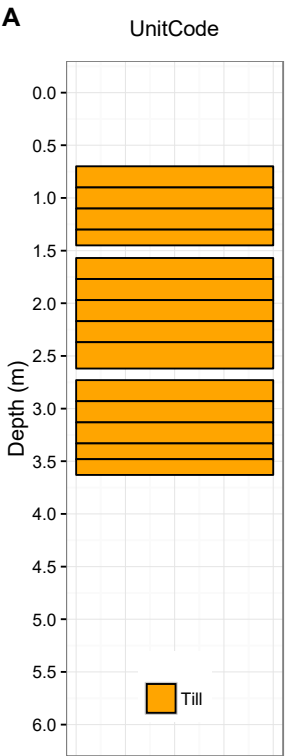

B Total Soluble Cations (meq/100g dry soil)

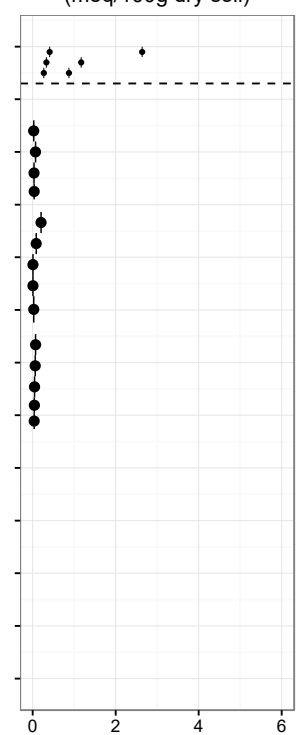

C Soil-Water Conductivity (mS/cm)

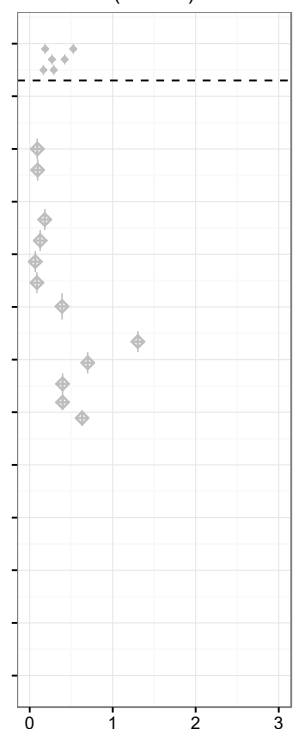

D Water Content GWB \& Excess Ice (\%)

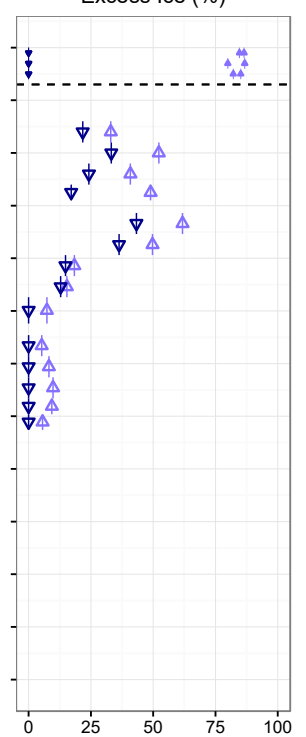

E Organic Matter GDB (\%)

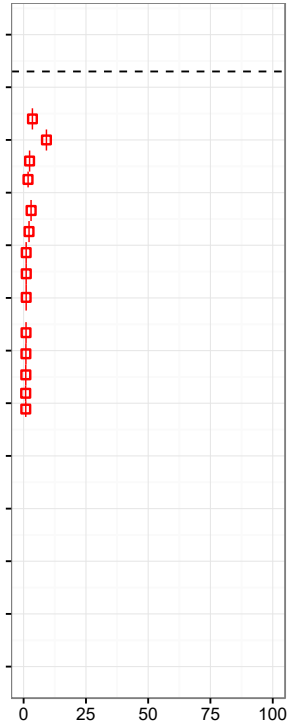

Graphical representation of A) UnitCode; B) Total Soluble Cations expressed in meq/ $100 \mathrm{~g}$ dry soil; C) Soil-Water Conductivity expressed in $\mathrm{mS} / \mathrm{cm}$; D) Gravimetric Water Content (\%) (represented by blue triangles) and Excess Ice Content (\%) (represented by a dark blue upside down triangles) both expressed on a gravimetric wet-basis; and E) Soil Organic Matter (\%) expressed on a dry-basis. The dashed line represents the thickness of the active layer at the time of sampling. The small symbols vs. larger symbols corresponds to samples from the exterior pits and borehole respectively. 


\section{Hill 1 Group}

Field data from Hill 1 group representing the surface conditions

\begin{tabular}{|c|c|c|c|c|c|c|}
\hline $\begin{array}{c}\text { BoreholeID } \\
\text { (NGO- } \\
\text { DD15- }\end{array}$ & $\begin{array}{c}\text { Easting } \\
\text { (m) }\end{array}$ & $\begin{array}{c}\text { Northing } \\
\text { (m) }\end{array}$ & $\begin{array}{l}\text { Elevation } \\
\text { (m) }\end{array}$ & $\begin{array}{c}\text { Terrain } \\
\text { Type }\end{array}$ & $\begin{array}{c}\text { Surface } \\
\text { Topography }\end{array}$ & Vegetation \\
\hline 1004 & 536470 & 7163553 & 471 & $\begin{array}{l}\text { Steep Slope } \\
\text { (SouthFace) }\end{array}$ & Hilly & $\begin{array}{l}\text { Shrubs, } \\
\text { Lichens, } \\
\text { Mosses }\end{array}$ \\
\hline 2004 & 536548 & 7163683 & 480 & Top of Hill & Hilly & $\begin{array}{l}\text { Shrubs, } \\
\text { Lichens, } \\
\text { Mosses }\end{array}$ \\
\hline 2005 & 536707 & 7163726 & 472 & $\begin{array}{c}\text { Steep Slope } \\
\text { (EastFace) }\end{array}$ & $\begin{array}{l}\text { Hilly (Gentle } \\
\text { slope) }\end{array}$ & $\begin{array}{l}\text { Shrubs, } \\
\text { Lichens, } \\
\text { Mosses }\end{array}$ \\
\hline 2006 & 536825 & 7163749 & 453 & $\begin{array}{l}\text { Hill Bottom } \\
\text { (EastFace) }\end{array}$ & $\begin{array}{c}\text { Hilly } \\
\text { (Steep slope) }\end{array}$ & $\begin{array}{l}\text { Shrubs, } \\
\text { Sedges, } \\
\text { Lichens, } \\
\text { Mosses }\end{array}$ \\
\hline 2007 & 536591 & 7163926 & 459 & $\begin{array}{l}\text { Steep Slope } \\
\text { (NorthFace) }\end{array}$ & Hilly & $\begin{array}{l}\text { Shrubs, } \\
\text { Lichens, } \\
\text { Mosses }\end{array}$ \\
\hline 1005 & 536587 & 7164081 & 440 & Peatland & Hummocky & $\begin{array}{l}\text { Shrubs, } \\
\text { Grasses, } \\
\text { Sedges, } \\
\text { Lichens }\end{array}$ \\
\hline
\end{tabular}


Hill 1: NGO-DD15-1004 (Till Blanket Terrain)

A

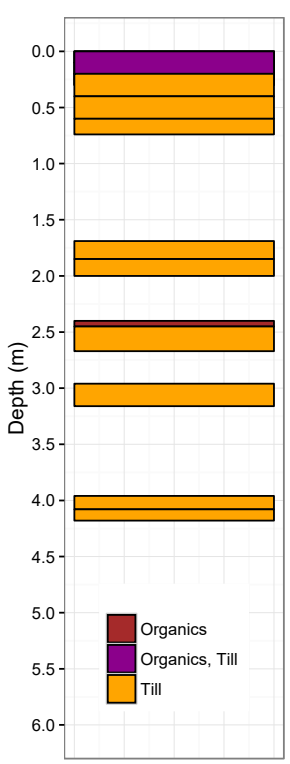

B Total Soluble Cations (meq/100g dry soil)

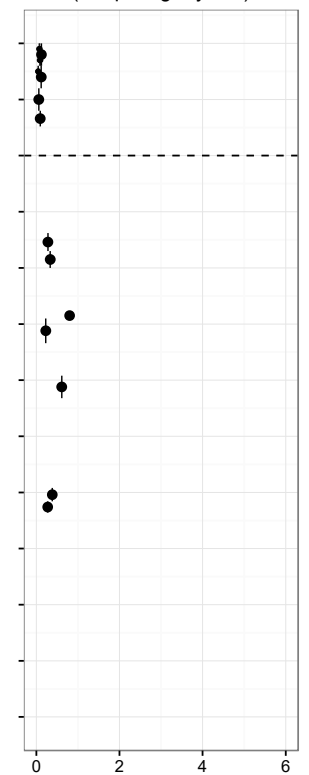

C Soil-Water Conductivity $(\mathrm{mS} / \mathrm{cm})$
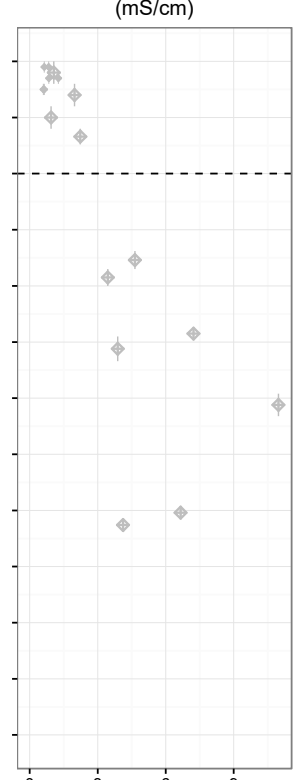

D Water Content GWB (\%)

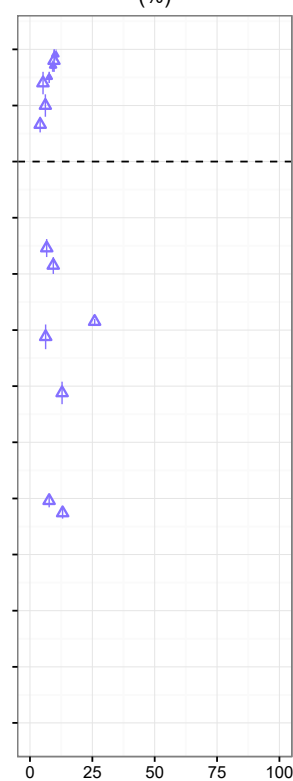

E Organic Matter GDB

(\%)

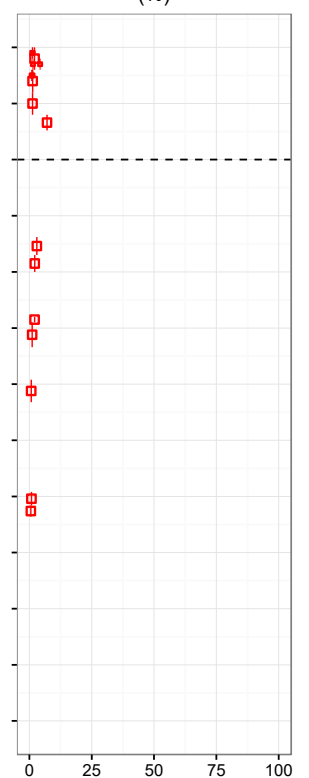

\section{Hill 1: NGO-DD15-2004 (Till Blanket Terrain)}

A

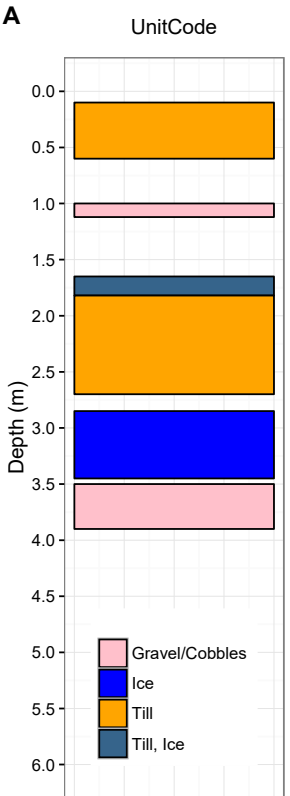

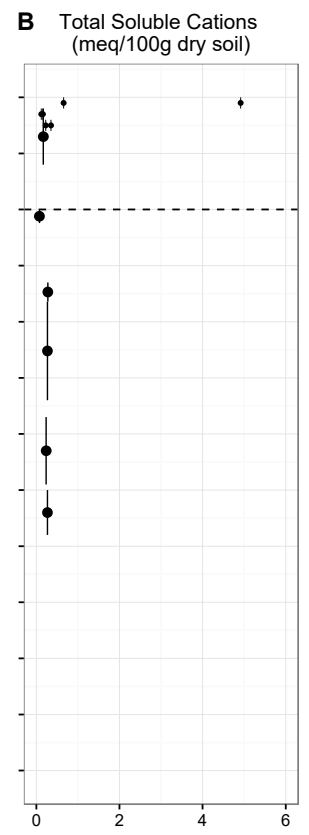

C Soil-Water Conductivity $(\mathrm{mS} / \mathrm{cm})$
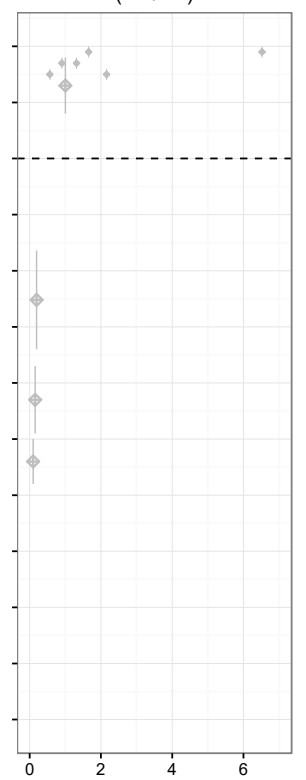

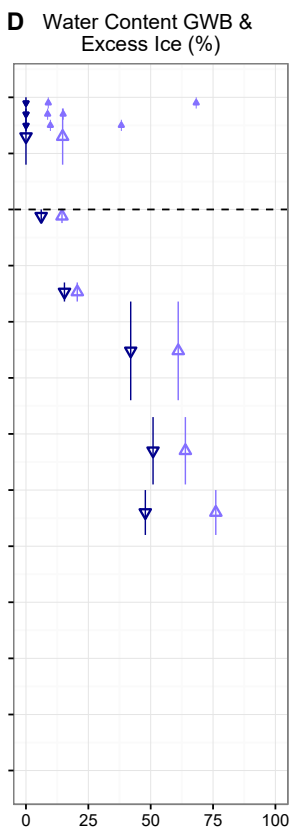

E Organic Matter GDB

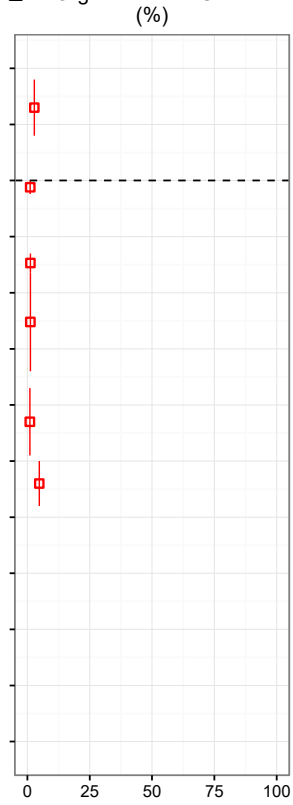

Graphical representation of A) UnitCode; B) Total Soluble Cations expressed in meq/ $100 \mathrm{~g}$ dry soil; C) Soil-Water Conductivity expressed in $\mathrm{mS} / \mathrm{cm}$; D) Gravimetric Water Content (\%) (represented by blue triangles) and Excess Ice Content (\%) (represented by a dark blue upside down triangles) both expressed on a gravimetric wet-basis; and E) Soil Organic Matter (\%) expressed on a dry-basis. The dashed line represents the thickness of the active layer at the time of sampling. The small symbols vs. larger symbols corresponds to samples from the exterior pits and borehole respectively. 


\section{Hill 1: NGO-DD15-2005 (Till Blanket Terrain)}
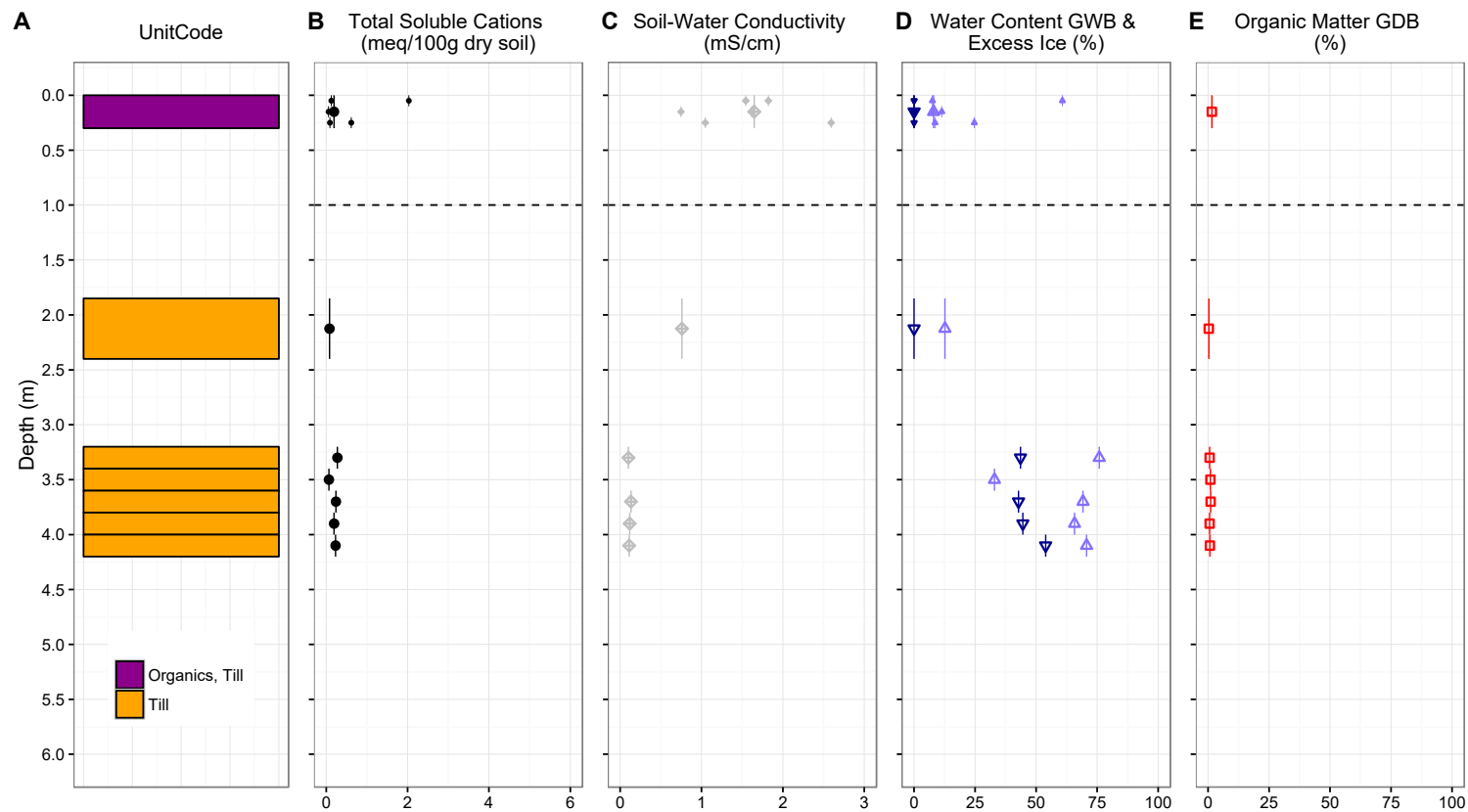

\section{Hill 1: NGO-DD15-2006 (Till Blanket Terrain)}

A

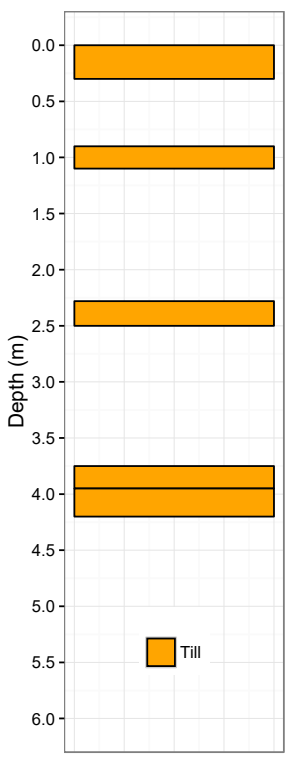

B Total Soluble Cations (meq/100g dry soil)

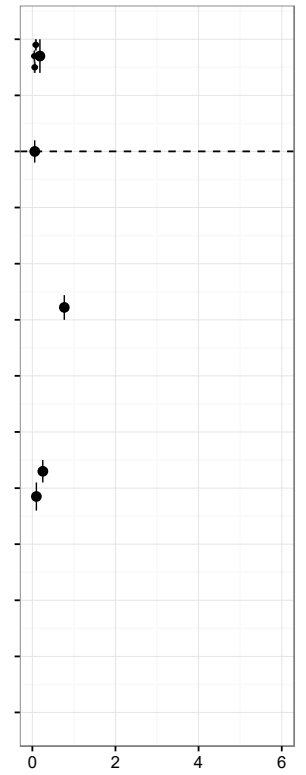

C Soil-Water Conductivity $(\mathrm{mS} / \mathrm{cm})$

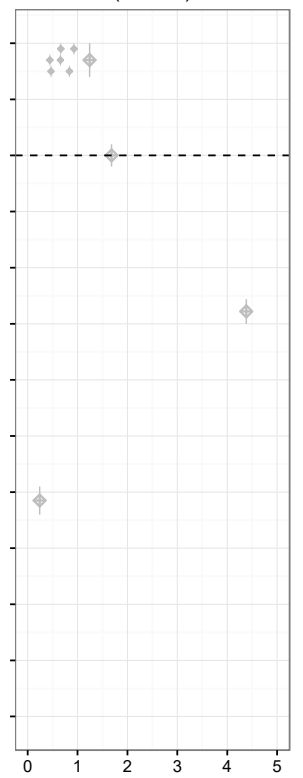

D Water Content GWB \& Excess Ice (\%)

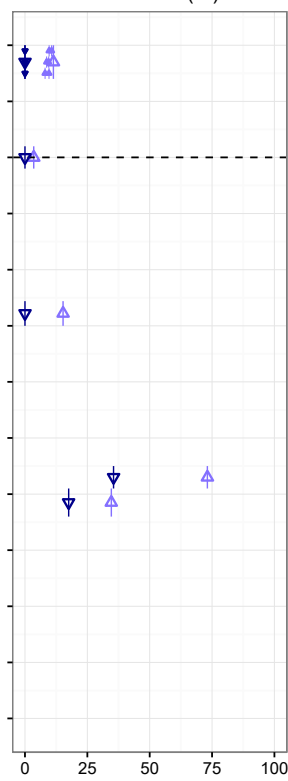

E Organic Matter GDB

(\%)

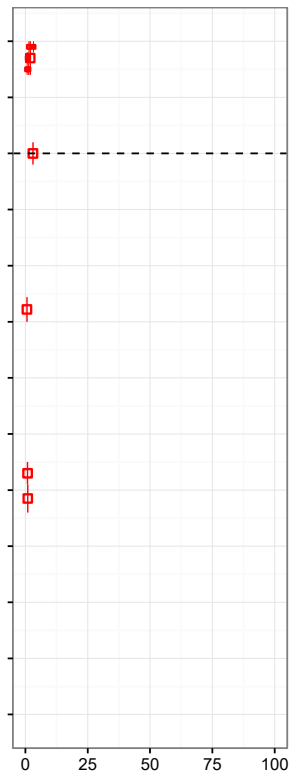

Graphical representation of A) UnitCode; B) Total Soluble Cations expressed in meq/ 100 g dry soil; C) Soil-Water Conductivity expressed in $\mathrm{mS} / \mathrm{cm}$; D) Gravimetric Water Content (\%) (represented by blue triangles) and Excess Ice Content (\%) (represented by a dark blue upside down triangles) both expressed on a gravimetric wet-basis; and E) Soil Organic Matter (\%) expressed on a dry-basis. The dashed line represents the thickness of the active layer at the time of sampling. The small symbols vs. larger symbols corresponds to samples from the exterior pits and borehole respectively. 
Hill 1: NGO-DD15-2007 (Till Blanket Terrain)
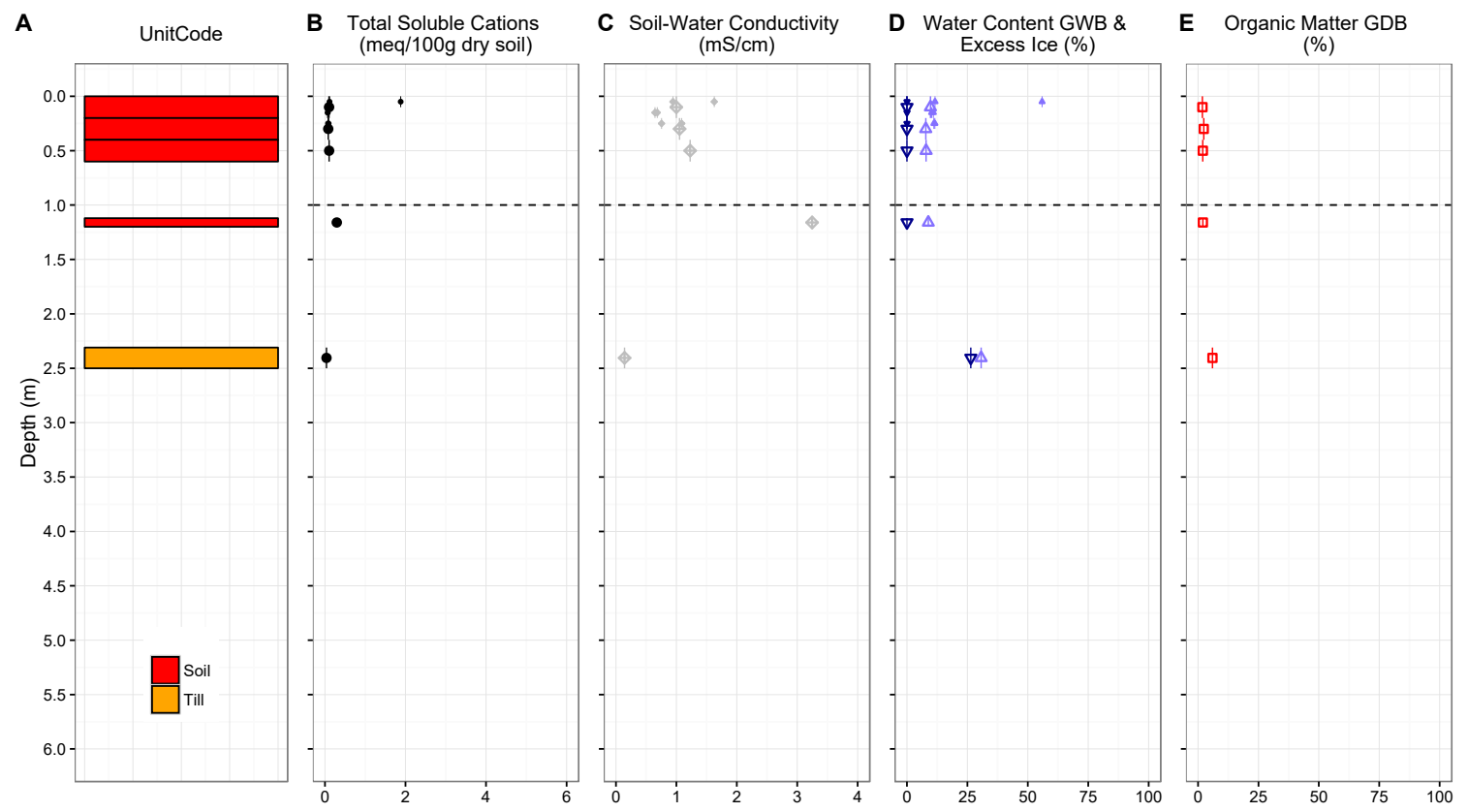

\section{Hill 1: NGO-DD15-1005 (Peatlands and wetlands Terrain)}

A

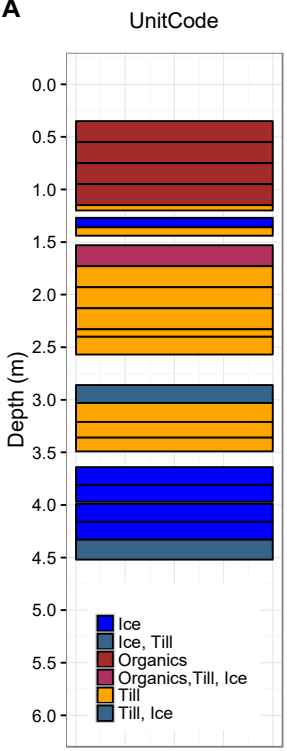

B Total Soluble Cations (meq/100g dry soil)

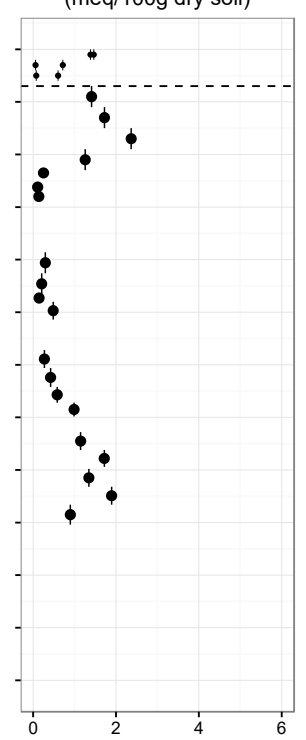

C Soil-Water Conductivity $(\mathrm{mS} / \mathrm{cm})$

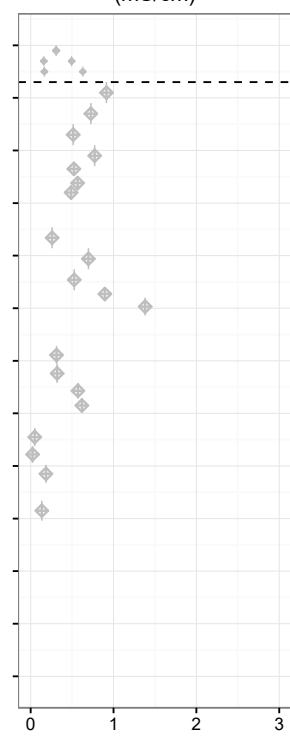

D Water Content GWB \& Excess Ice (\%)

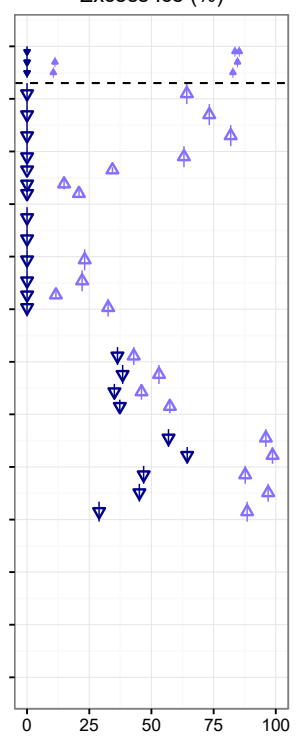

E Organic Matter GDB

(\%)

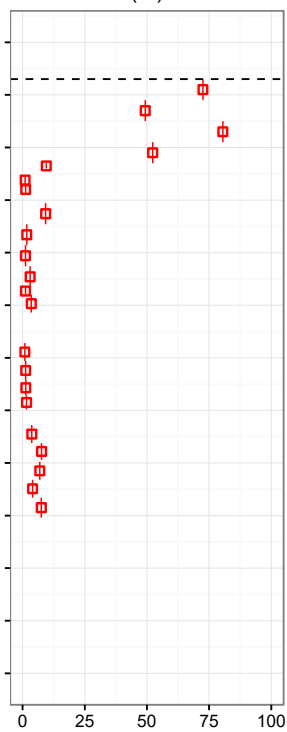

Graphical representation of A) UnitCode; B) Total Soluble Cations expressed in meq/ 100 g dry soil; C) Soil-Water Conductivity expressed in $\mathrm{mS} / \mathrm{cm}$; D) Gravimetric Water Content (\%) (represented by blue triangles) and Excess Ice Content (\%) (represented by a dark blue upside down triangles) both expressed on a gravimetric wet-basis; and E) Soil Organic Matter (\%) expressed on a dry-basis. The dashed line represents the thickness of the active layer at the time of sampling. The small symbols vs. larger symbols corresponds to samples from the exterior pits and borehole respectively. 
3. Hill 2 Group

Field data from Hill 2 group representing the surface conditions

\begin{tabular}{|c|c|c|c|c|c|c|}
\hline $\begin{array}{c}\text { BoreholeID } \\
\text { (NGO- } \\
\text { DD15- }\end{array}$ & $\begin{array}{c}\text { Easting } \\
\mathbf{( m )}\end{array}$ & $\begin{array}{c}\text { Northing } \\
(\mathbf{m})\end{array}$ & $\begin{array}{c}\text { Elevation } \\
\mathbf{( m )}\end{array}$ & $\begin{array}{c}\text { Terrain } \\
\text { Type }\end{array}$ & $\begin{array}{c}\text { Surface } \\
\text { Topography }\end{array}$ & Vegetation \\
\hline 1014 & 512651 & 7166738 & 489 & Top of Hill & Not Available & $\begin{array}{c}\text { Not } \\
\text { Available }\end{array}$ \\
\hline 2018 & 526886 & 7176651 & 461 & $\begin{array}{c}\text { Low-lying } \\
\text { Depression }\end{array}$ & Hummocky & $\begin{array}{c}\text { Shrubs, } \\
\text { Sedges, } \\
\text { Mosses }\end{array}$ \\
\hline
\end{tabular}




\section{Hill 2: NGO-DD15-1014 (Till Veneer Terrain)}

A

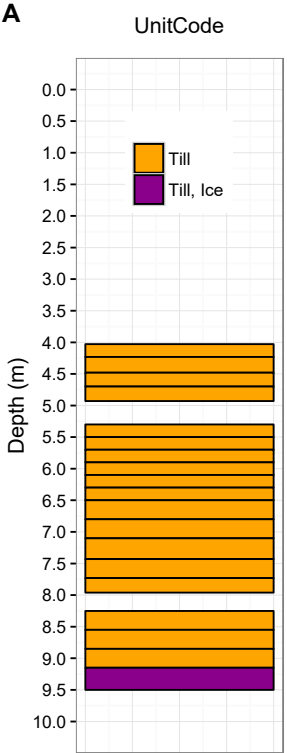

B Total Soluble Cations (meq/100g dry soil)

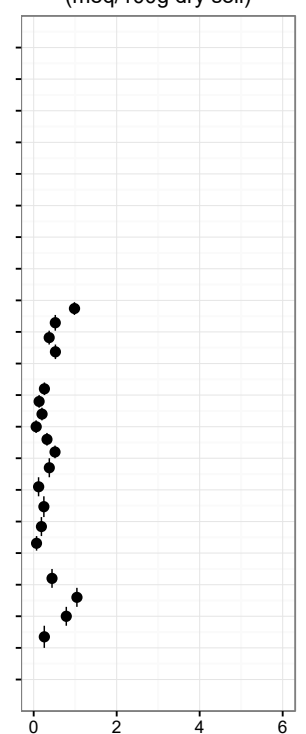

C Soil-Water Conductivity $(\mathrm{mS} / \mathrm{cm})$

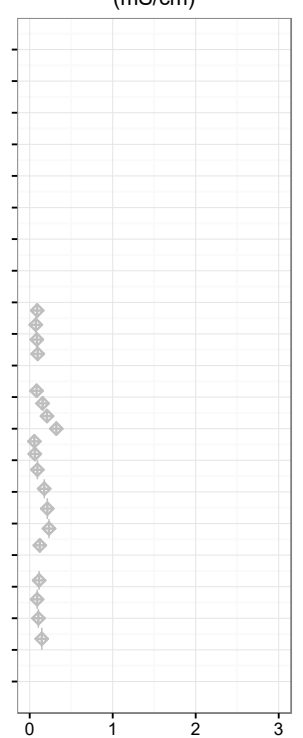

D Water Content GWB \& Excess Ice (\%)

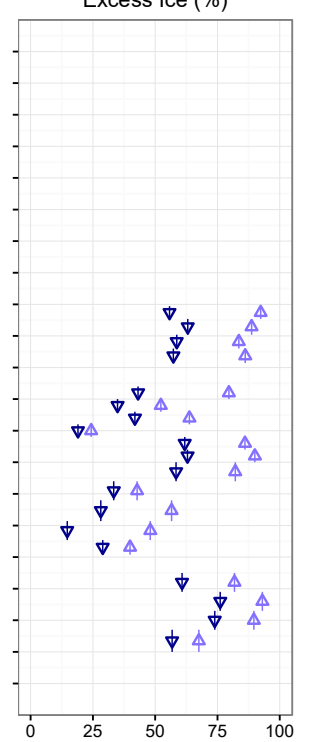

Organic Matter GDB (\%)

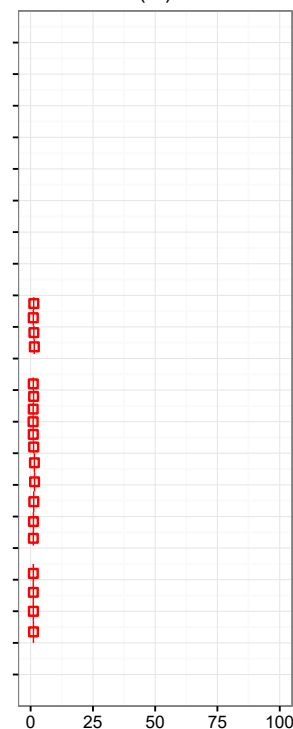

Hill 2: NGO-DD15-2018 (Till Veneer Terrain)

A

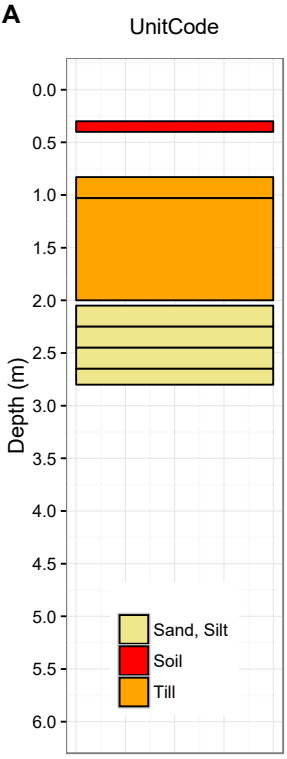

B Total Soluble Cations (meq/100g dry soil)

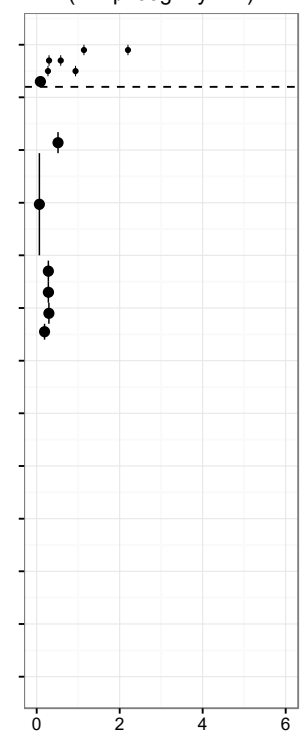

C Soil-Water Conductivity $(\mathrm{mS} / \mathrm{cm})$

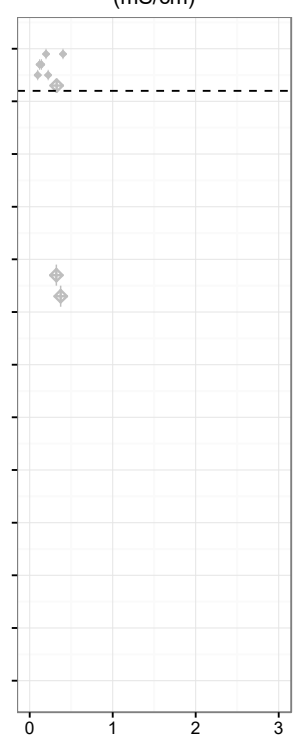

D Water Content GWB \& Excess Ice (\%)

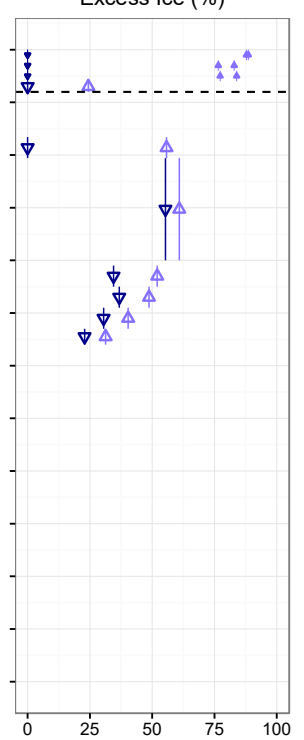

E Organic Matter GDB (\%)

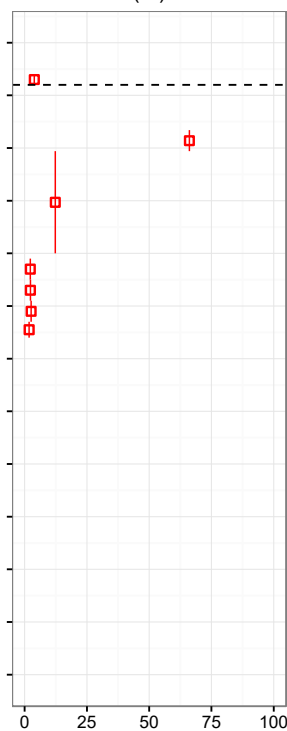

Graphical representation of A) UnitCode; B) Total Soluble Cations expressed in meq/ $100 \mathrm{~g}$ dry soil; C) Soil-Water Conductivity expressed in mS/cm; D) Gravimetric Water Content (\%) (represented by blue triangles) and Excess Ice Content (\%) (represented by a dark blue upside down triangles) both expressed on a gravimetric wet-basis; and E) Soil Organic Matter (\%) expressed on a dry-basis. The dashed line represents the thickness of the active layer at the time of sampling. The small symbols vs. larger symbols corresponds to samples from the exterior pits and borehole respectively. 
4. Hill 3 Group

Field data from Hill 3 group representing the surface conditions

\begin{tabular}{|c|c|c|c|c|c|c|}
\hline $\begin{array}{c}\text { BoreholeID } \\
\text { (NGO- } \\
\text { DD15- }\end{array}$ & $\begin{array}{c}\text { Easting } \\
(\mathbf{m})\end{array}$ & $\begin{array}{c}\text { Northing } \\
(\mathbf{m})\end{array}$ & $\begin{array}{c}\text { Elevation } \\
\mathbf{( m )}\end{array}$ & $\begin{array}{c}\text { Terrain } \\
\text { Type }\end{array}$ & $\begin{array}{c}\text { Surface } \\
\text { Topography }\end{array}$ & Vegetation \\
\hline 2033 & 537552 & 7164712 & 458 & Top of Hill & Hummocky & $\begin{array}{c}\text { Shrubs, } \\
\text { Grasses, } \\
\text { Mosses, } \\
\text { Lichens }\end{array}$ \\
\hline 2009 & 537477 & 7164566 & 446 & $\begin{array}{c}\text { Hill Bottom } \\
\text { (SouthFace) }\end{array}$ & Hummocky & $\begin{array}{c}\text { Shrubs, } \\
\text { Grasses, } \\
\text { Mosses, } \\
\text { Lichens }\end{array}$ \\
\hline
\end{tabular}




\section{Hill 3: NGO-DD15-2033 (Till Blanket Terrain)}

A UnitCode

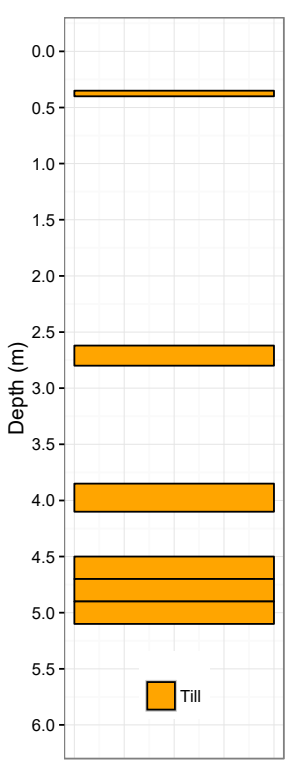

B Total Soluble Cations (meq/100g dry soil)
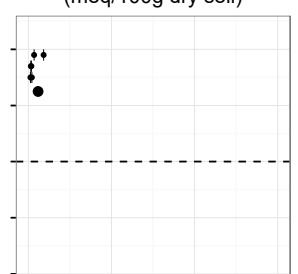

$-$

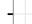

-

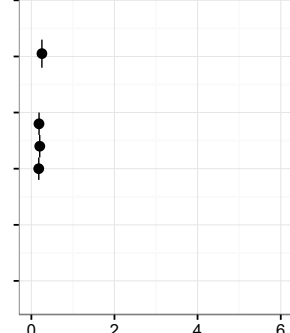

C Soil-Water Conductivity $(\mathrm{mS} / \mathrm{cm})$

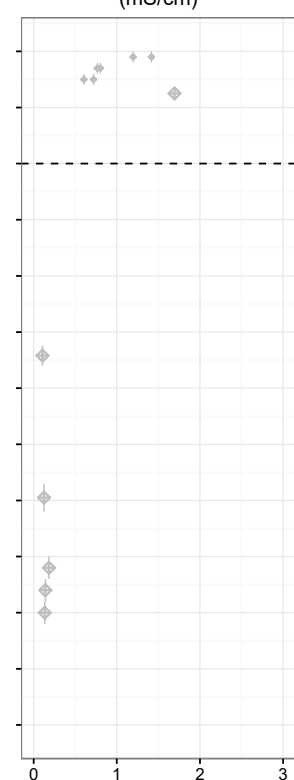

D Water Content GWB \& Excess Ice (\%)

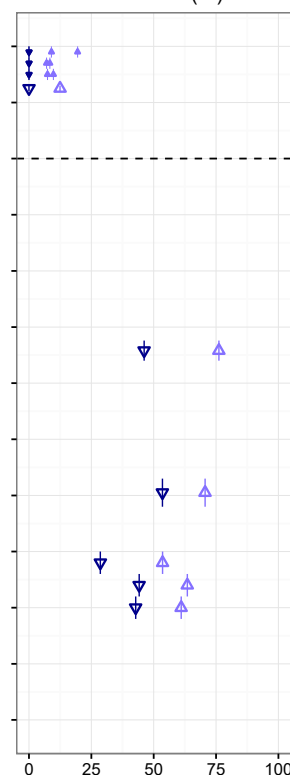

Organic Matter GDB

(\%)

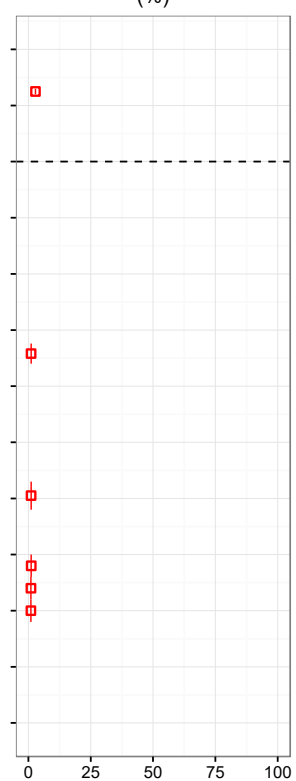

Hill 3: NGO-DD15-2009 (Till Blanket Terrain)

A

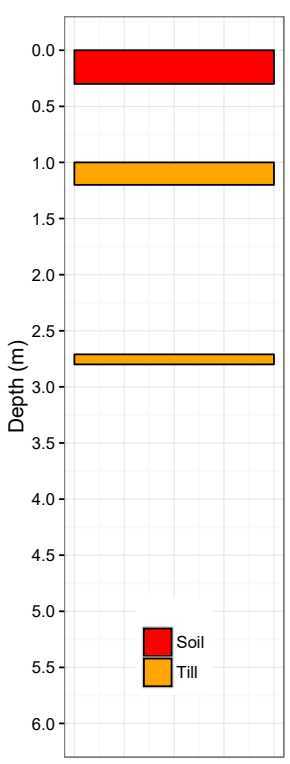

B Total Soluble Cations (meq/100g dry soil)

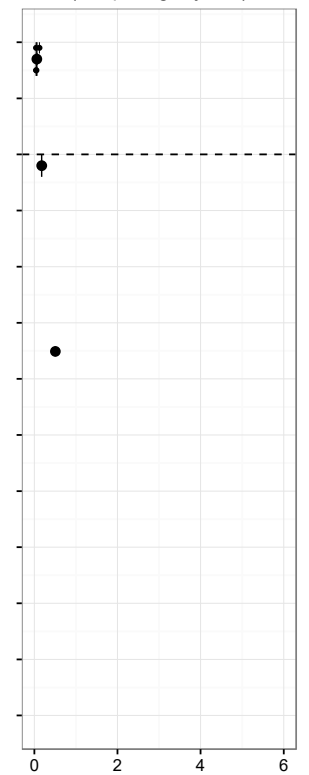

C Soil-Water Conductivity $(\mathrm{mS} / \mathrm{cm})$

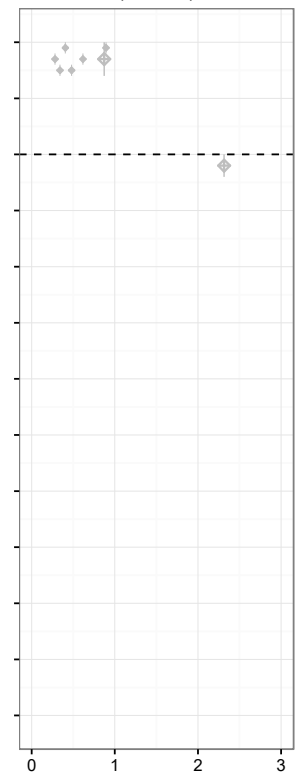

D Water Content GWB \& Excess Ice (\%)

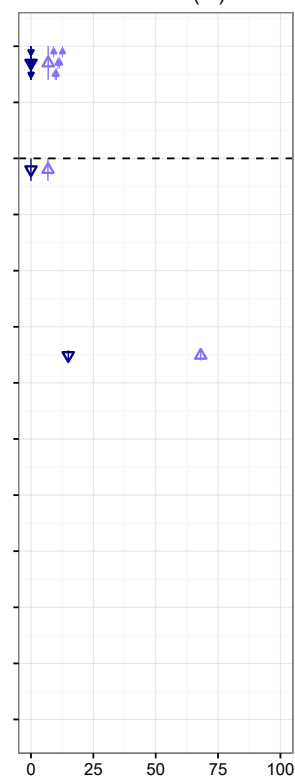

E Organic Matter GDB

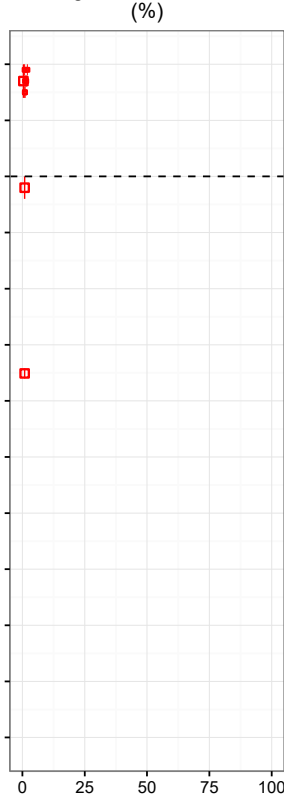

Graphical representation of A) UnitCode; B) Total Soluble Cations expressed in meq/ $100 \mathrm{~g}$ dry soil; C) Soil-Water Conductivity expressed in $\mathrm{mS} / \mathrm{cm}$; D) Gravimetric Water Content (\%) (represented by blue triangles) and Excess Ice Content (\%) (represented by a dark blue upside down triangles) both expressed on a gravimetric wet-basis; and E) Soil Organic Matter (\%) expressed on a dry-basis. The dashed line represents the thickness of the active layer at the time of sampling. The small symbols vs. larger symbols corresponds to samples from the exterior pits and borehole respectively. 


\section{Valley Group}

Field data from the Valley group representing the surface conditions

\begin{tabular}{|c|c|c|c|c|c|c|}
\hline $\begin{array}{c}\text { BoreholeID } \\
\text { (NGO- } \\
\text { DD15- }\end{array}$ & $\begin{array}{c}\text { Easting } \\
\text { (m) }\end{array}$ & $\begin{array}{l}\text { Northing } \\
\text { (m) }\end{array}$ & $\begin{array}{l}\text { Elevation } \\
\text { (m) }\end{array}$ & $\begin{array}{c}\text { Terrain } \\
\text { Type }\end{array}$ & $\begin{array}{c}\text { Surface } \\
\text { Topography }\end{array}$ & Vegetation \\
\hline 2013 & 525915 & 7175659 & 440 & $\begin{array}{l}\text { Hill Bottom, } \\
\text { Snow Drifts }\end{array}$ & Hummocky & $\begin{array}{l}\text { Shrubs, } \\
\text { Sedges, } \\
\text { Mosses, } \\
\text { Lichens }\end{array}$ \\
\hline 2011 & 526327 & 7175398 & 432 & Wetland & Hummocky & $\begin{array}{l}\text { Shrubs, } \\
\text { Sedges, } \\
\text { Mosses }\end{array}$ \\
\hline 2012 & 526341 & 7175331 & 433 & Wetland & Hummocky & $\begin{array}{l}\text { Shrubs, } \\
\text { Sedges, } \\
\text { Mosses, } \\
\text { Lichens }\end{array}$ \\
\hline 1009 & 526480 & 7175266 & 432 & Peatland & Hummocky & $\begin{array}{l}\text { Shrubs, } \\
\text { Sedges, } \\
\text { Lichens }\end{array}$ \\
\hline 2019 & 526910 & 7175377 & 428 & $\begin{array}{l}\text { Hill Bottom, } \\
\text { Snow Drifts }\end{array}$ & Hilly & $\begin{array}{l}\text { Shrubs, } \\
\text { Sedges, } \\
\text { Mosses }\end{array}$ \\
\hline 1010 & 526708 & 7175445 & 426 & Wetland & Hummocky & $\begin{array}{l}\text { Shrubs, } \\
\text { Sedges, } \\
\text { Mosses, } \\
\text { Lichens }\end{array}$ \\
\hline 2015 & 526747 & 7175566 & 425 & Peatland & Hummocky & $\begin{array}{l}\text { Shrubs, } \\
\text { Sedges, } \\
\text { Mosses, } \\
\text { Lichens }\end{array}$ \\
\hline 2016 & 526649 & 7175677 & 431 & Hill Bottom & Hummocky & $\begin{array}{l}\text { Shrubs, } \\
\text { Lichens }\end{array}$ \\
\hline
\end{tabular}


Valley: NGO-DD15-2013 (Till Veneer Terrain)
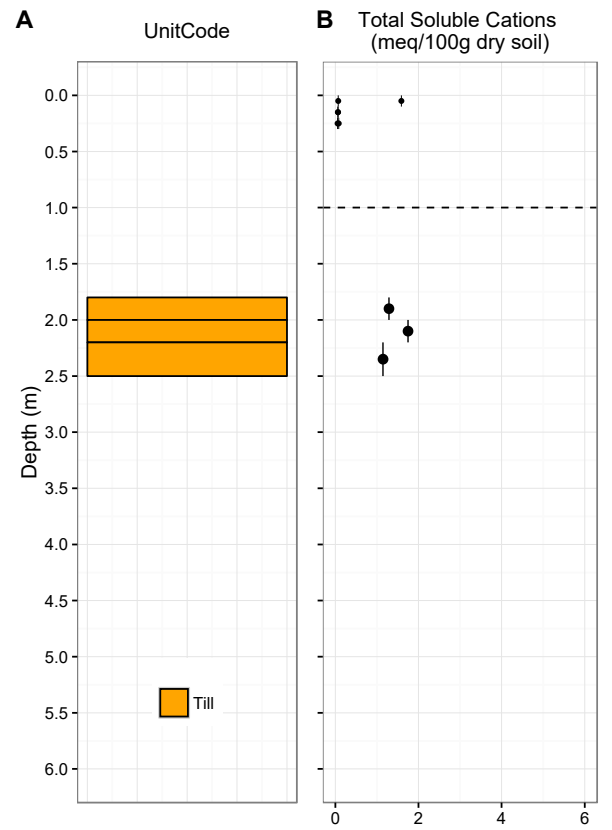

C Soil-Water Conductivity $(\mathrm{mS} / \mathrm{cm})$

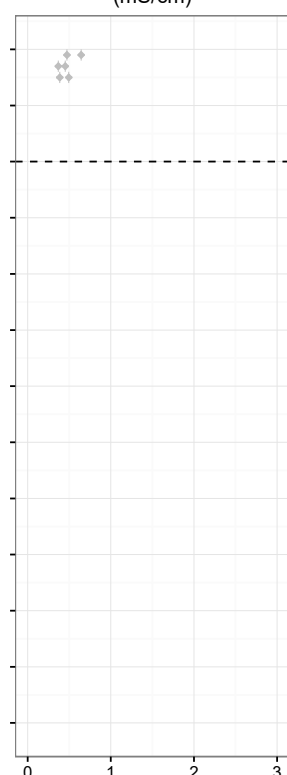

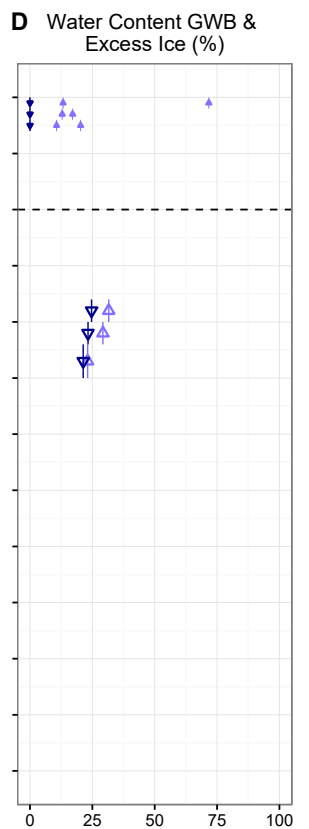

E Organic Matter GDB

(\%)

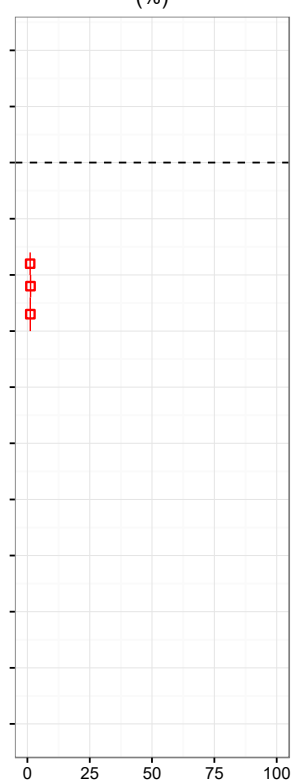

Valley: NGO-DD15-2011 (Peatlands and wetlands Terrain)

A

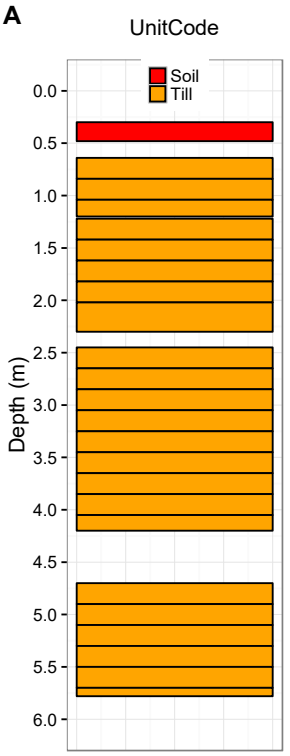

B Total Soluble Cations (meq/100g dry soil)

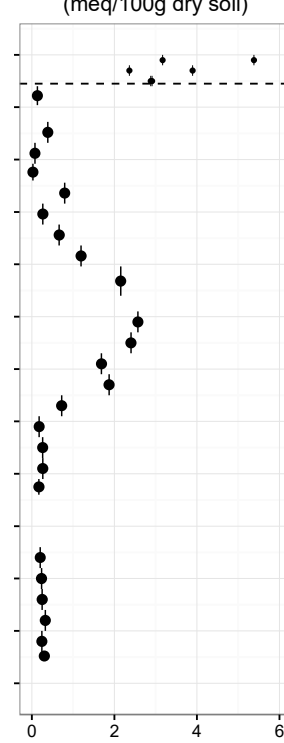

C Soil-Water Conductivity $(\mathrm{mS} / \mathrm{cm})$

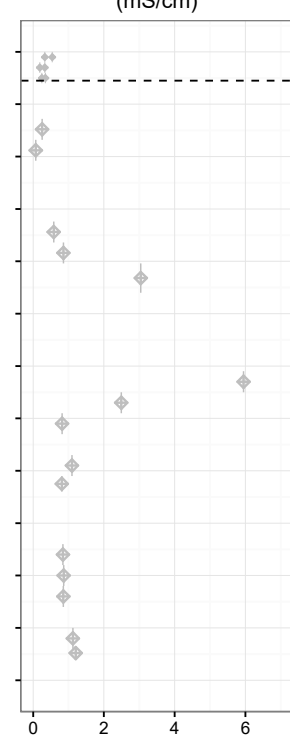

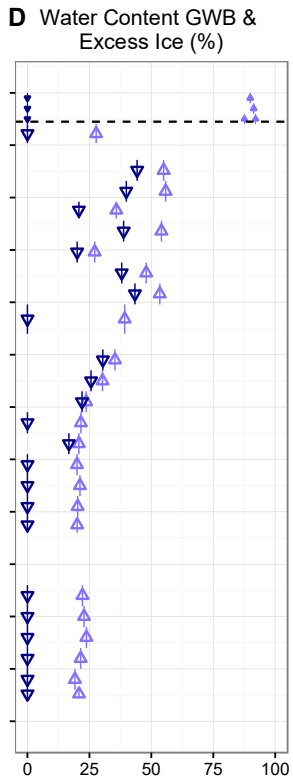

E Organic Matter GDB

$(\%)$

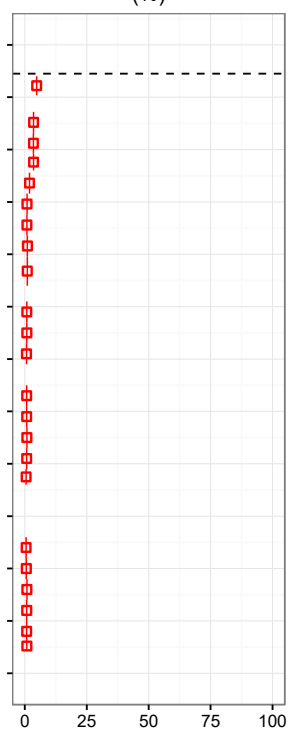

Graphical representation of A) UnitCode; B) Total Soluble Cations expressed in meq/ $100 \mathrm{~g}$ dry soil; C) Soil-Water Conductivity expressed in $\mathrm{mS} / \mathrm{cm}$; D) Gravimetric Water Content (\%) (represented by blue triangles) and Excess Ice Content (\%) (represented by a dark blue upside down triangles) both expressed on a gravimetric wet-basis; and E) Soil Organic Matter (\%) expressed on a dry-basis. The dashed line represents the thickness of the active layer at the time of sampling. The small symbols vs. larger symbols corresponds to samples from the exterior pits and borehole respectively. 
Valley: NGO-DD15-2012 (Peatlands and wetlands Terrain)
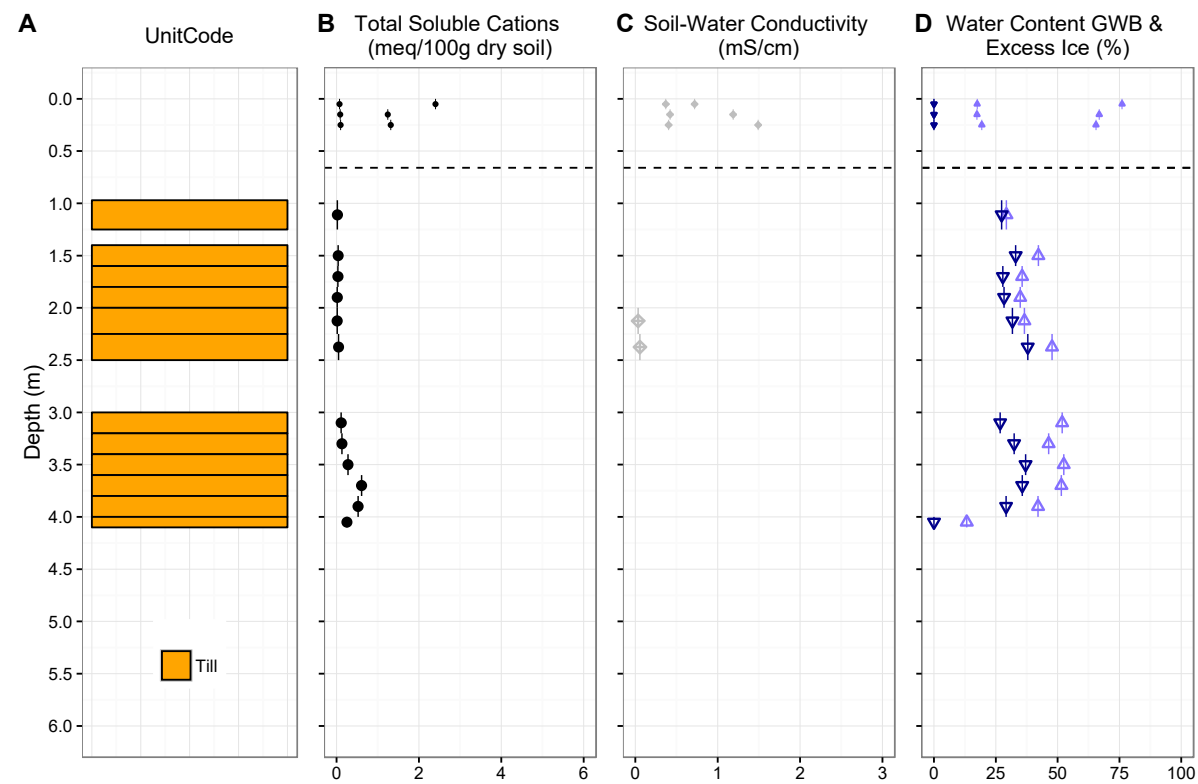

E Organic Matter GDB

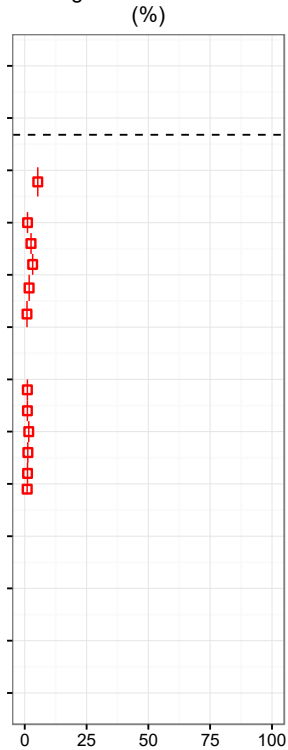

Valley: NGO-DD15-1009 (Peatlands and wetlands Terrain)

A

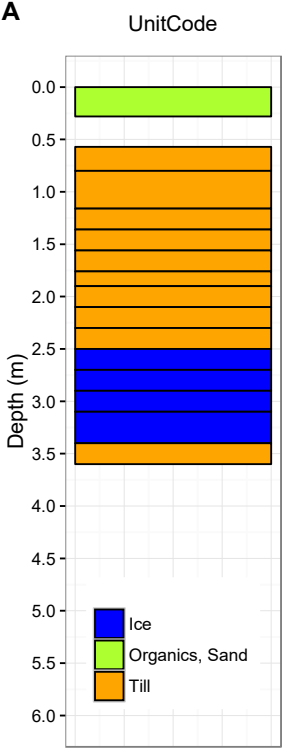

B Total Soluble Cations (meq/100g dry soil)

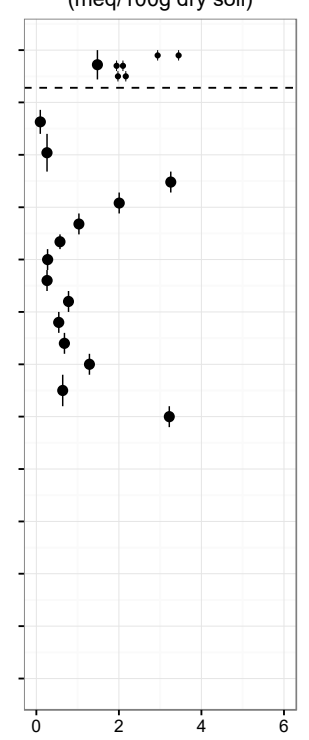

C Soil-Water Conductivity $(\mathrm{mS} / \mathrm{cm})$

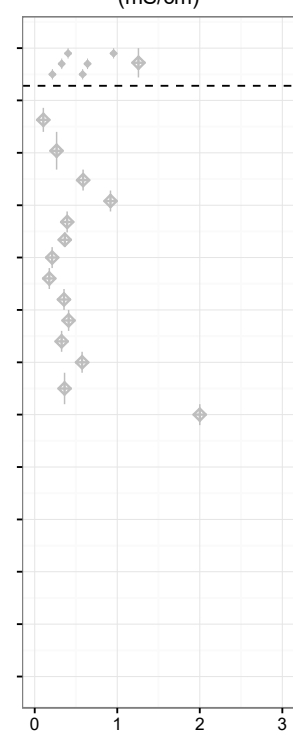

D Water Content GWB \& Excess Ice (\%)

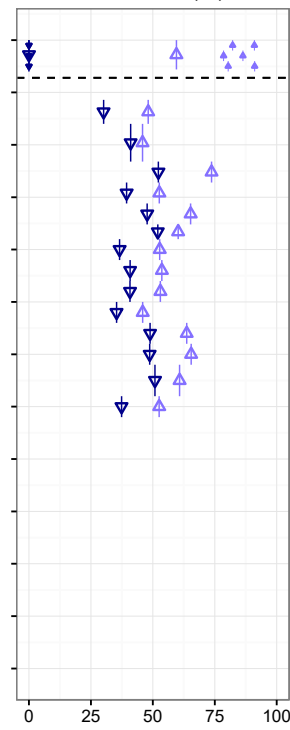

E Organic Matter GDB (\%)

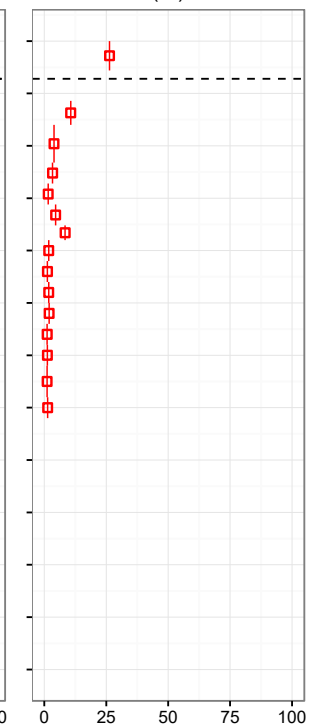

Graphical representation of A) UnitCode; B) Total Soluble Cations expressed in meq/ $100 \mathrm{~g}$ dry soil; C) Soil-Water Conductivity expressed in $\mathrm{mS} / \mathrm{cm}$; D) Gravimetric Water Content (\%) (represented by blue triangles) and Excess Ice Content (\%) (represented by a dark blue upside down triangles) both expressed on a gravimetric wet-basis; and E) Soil Organic Matter (\%) expressed on a dry-basis. The dashed line represents the thickness of the active layer at the time of sampling. The small symbols vs. larger symbols corresponds to samples from the exterior pits and borehole respectively. 
Valley: NGO-DD15-2019 (Till Veneer Terrain)
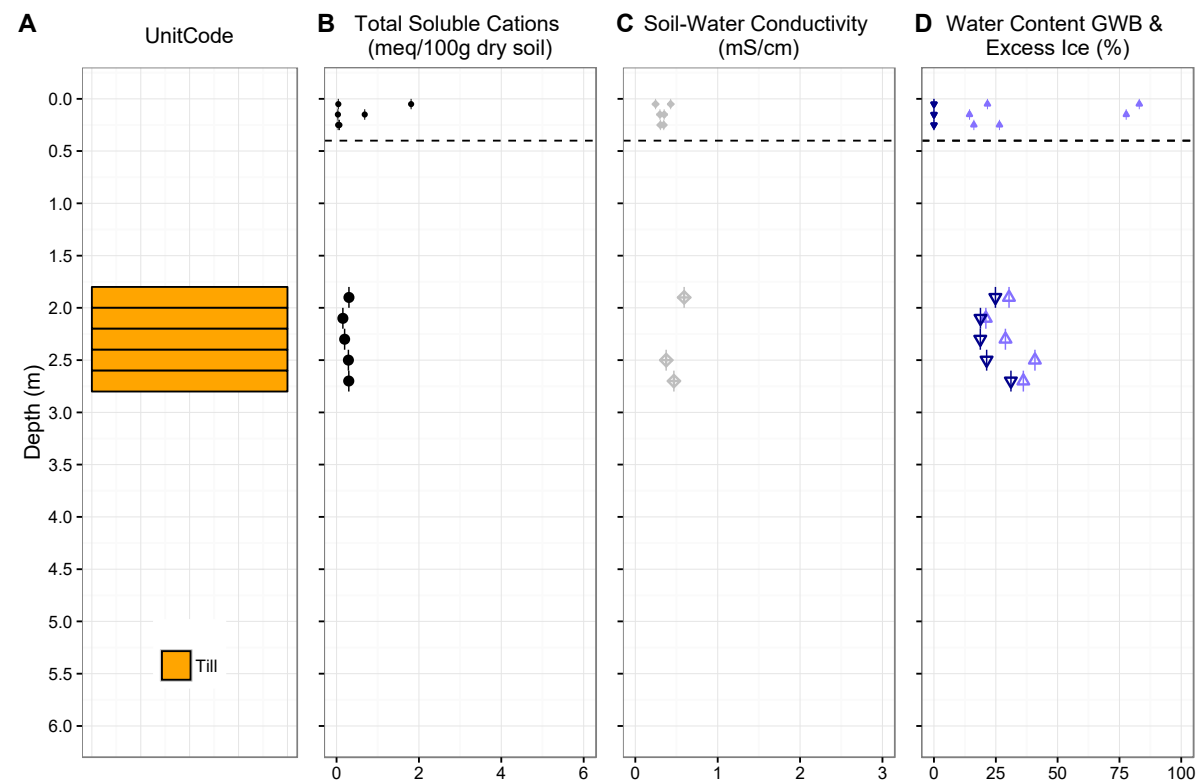

E Organic Matter GDB

$(\%)$

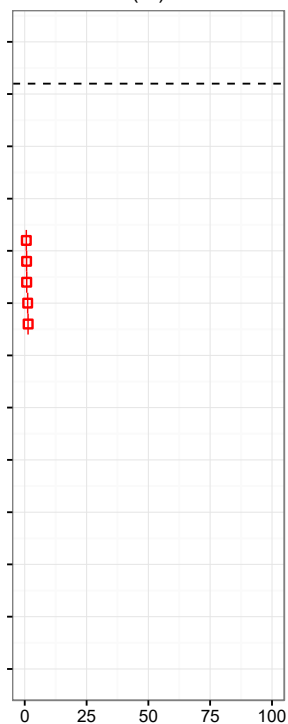

Valley: NGO-DD15-1010 (Peatlands and wetlands Terrain)

A

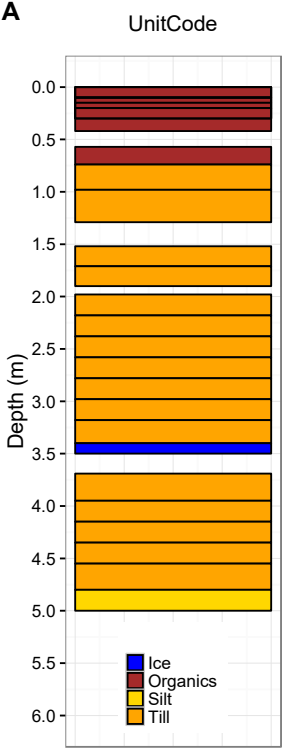

B Total Soluble Cations (meq/100g dry soil)

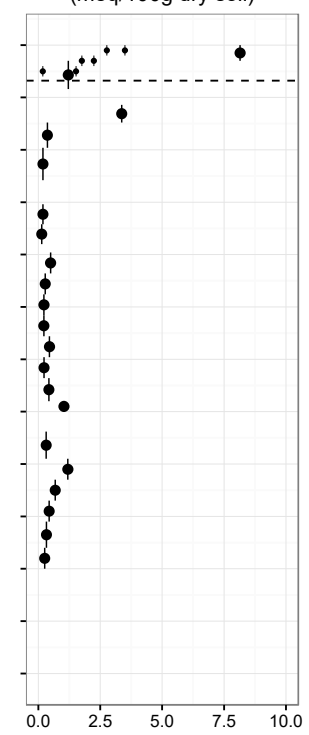

C Soil-Water Conductivity $(\mathrm{mS} / \mathrm{cm})$

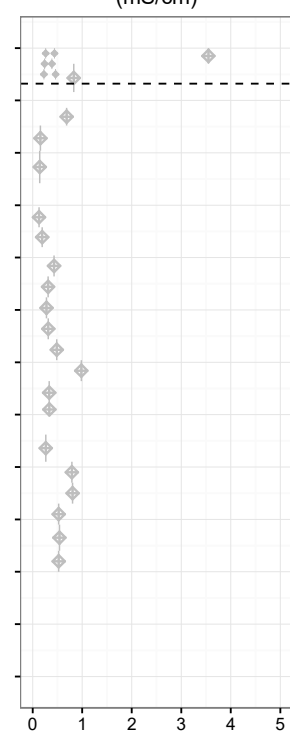

D Water Content GWB \& Excess Ice (\%)

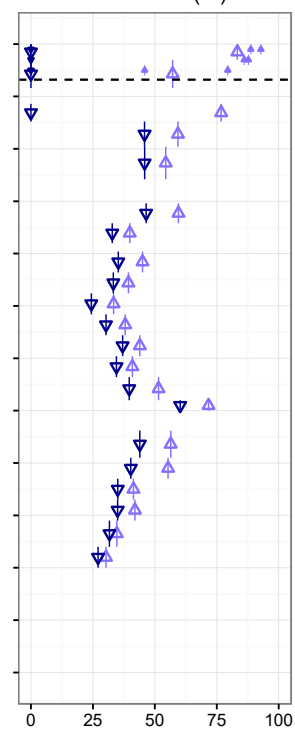

E Organic Matter GDB

(\%)

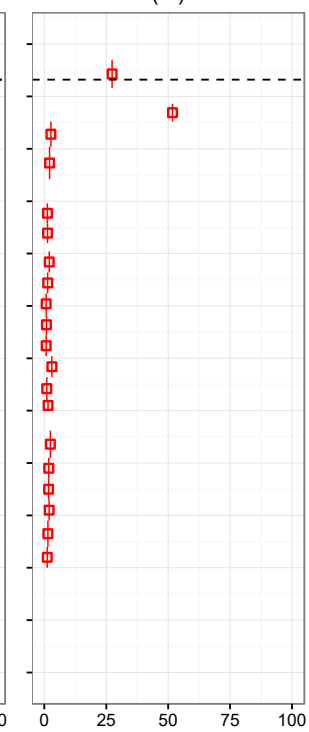

Graphical representation of A) UnitCode; B) Total Soluble Cations expressed in meq/ 100 g dry soil; C) Soil-Water Conductivity expressed in mS/cm; D) Gravimetric Water Content (\%) (represented by blue triangles) and Excess Ice Content (\%) (represented by a dark blue upside down triangles) both expressed on a gravimetric wet-basis; and E) Soil Organic Matter (\%) expressed on a dry-basis. The dashed line represents the thickness of the active layer at the time of sampling. The small symbols vs. larger symbols corresponds to samples from the exterior pits and borehole respectively. 
Valley: NGO-DD15-2015 (Peatlands and wetlands Terrain)
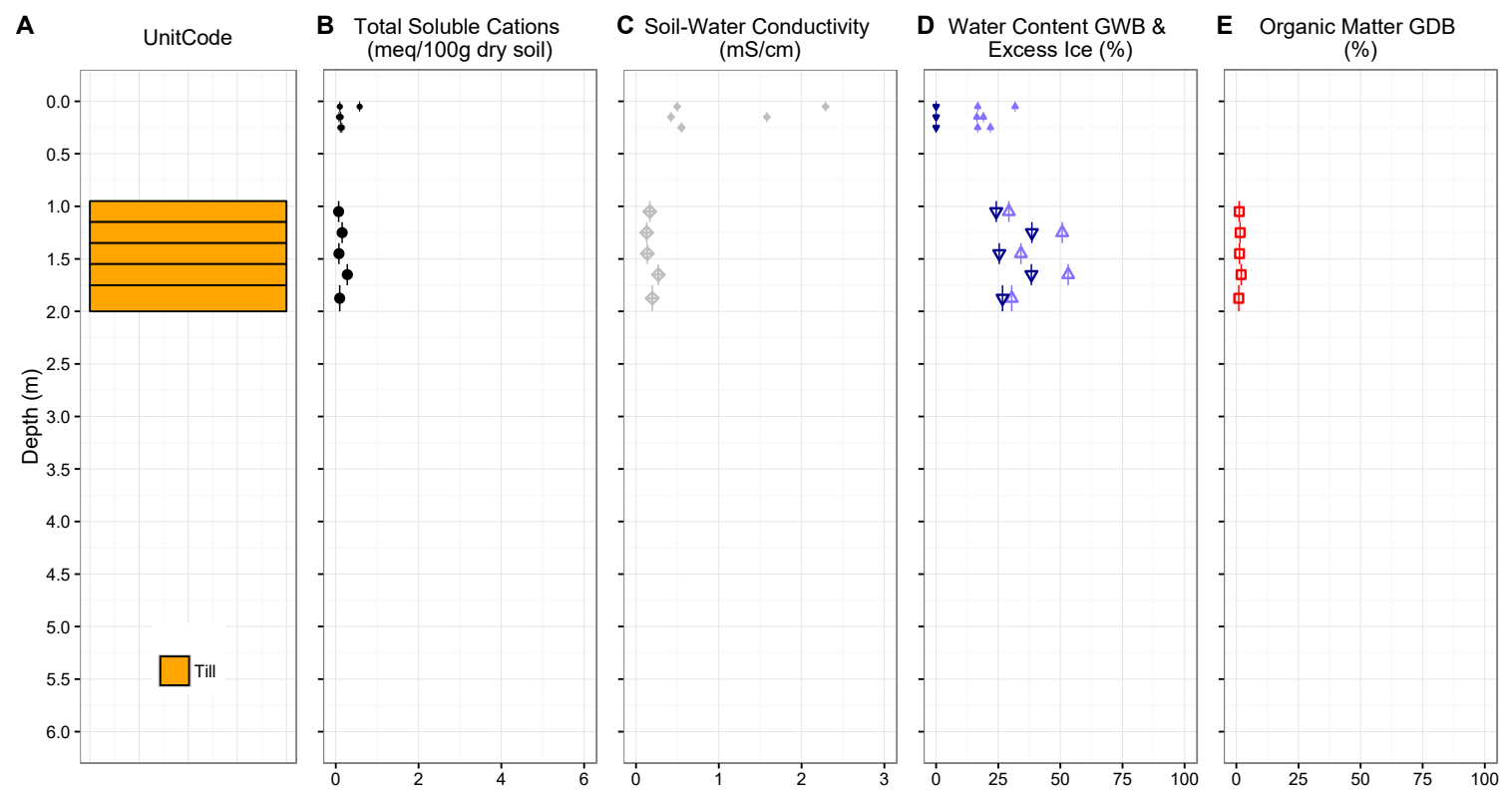

\section{Valley: NGO-DD15-2016 (Till Veneer Terrain)}

A

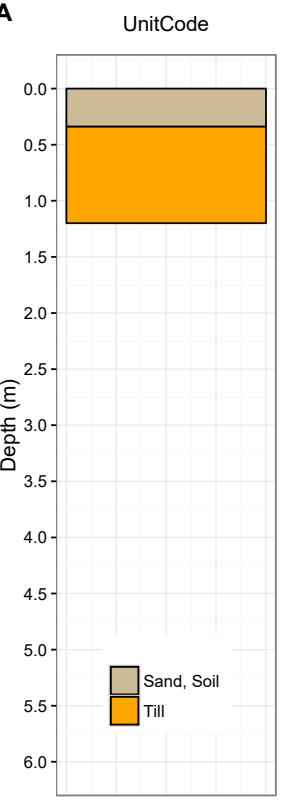

B Total Soluble Cations

C Soil-Water Conductivity

D Water Content GWB

E Organic Matter GDB (meq/100g dry soil)
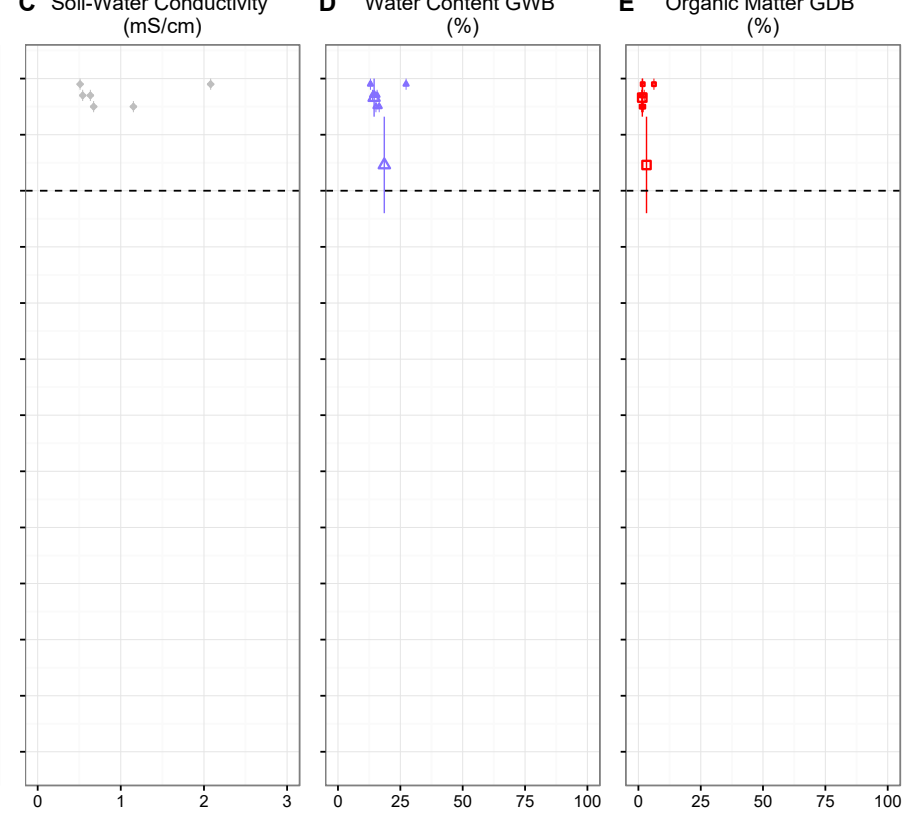

Graphical representation of A) UnitCode; B) Total Soluble Cations expressed in meq/ $100 \mathrm{~g}$ dry soil; C) Soil-Water Conductivity expressed in $\mathrm{mS} / \mathrm{cm}$; D) Gravimetric Water Content (\%) (represented by blue triangles) and Excess Ice Content (\%) (represented by a dark blue upside down triangles) both expressed on a gravimetric wet-basis; and E) Soil Organic Matter (\%) expressed on a dry-basis. The dashed line represents the thickness of the active layer at the time of sampling. The small symbols vs. larger symbols corresponds to samples from the exterior pits and borehole respectively. 


\section{Esker 1 Group}

Field data from the Esker 1 group representing the surface conditions

\begin{tabular}{|c|c|c|c|c|c|c|}
\hline $\begin{array}{c}\text { BoreholeID } \\
\text { (NGO- } \\
\text { DD15- }\end{array}$ & $\begin{array}{c}\text { Easting } \\
(\mathbf{m})\end{array}$ & $\begin{array}{c}\text { Northing } \\
(\mathbf{m})\end{array}$ & $\begin{array}{c}\text { Elevation } \\
\mathbf{( m )}\end{array}$ & $\begin{array}{c}\text { Terrain } \\
\text { Type }\end{array}$ & $\begin{array}{c}\text { Surface } \\
\text { Topography }\end{array}$ & Vegetation \\
\hline 2008 & 539002 & 7164161 & 458 & Esker & Hunmocky & $\begin{array}{c}\text { Shrubs, } \\
\text { Lichens }\end{array}$ \\
\hline 2028 & 539001 & 7164157 & 458 & Esker & Hummocky & $\begin{array}{c}\text { Shrubs, } \\
\text { Lichens }\end{array}$ \\
\hline 2029 & 539024 & 7164143 & 458 & Esker & Hummocky & $\begin{array}{c}\text { Shrubs, } \\
\text { Lichens }\end{array}$ \\
\hline
\end{tabular}




\section{Esker 1: NGO-DD15-2008 (Esker Terrain)}
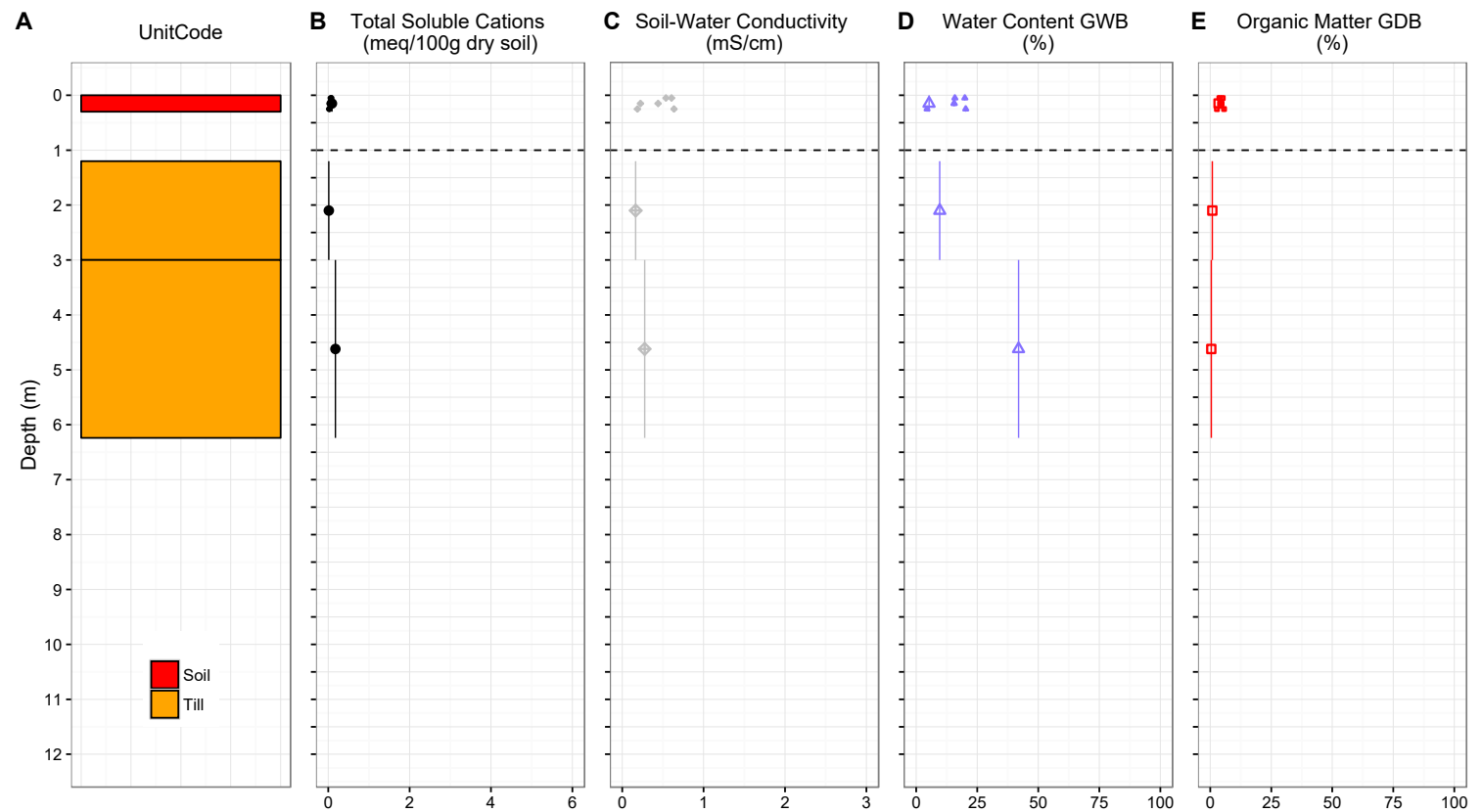

Esker 1: NGO-DD15-2028 (Esker Terrain)
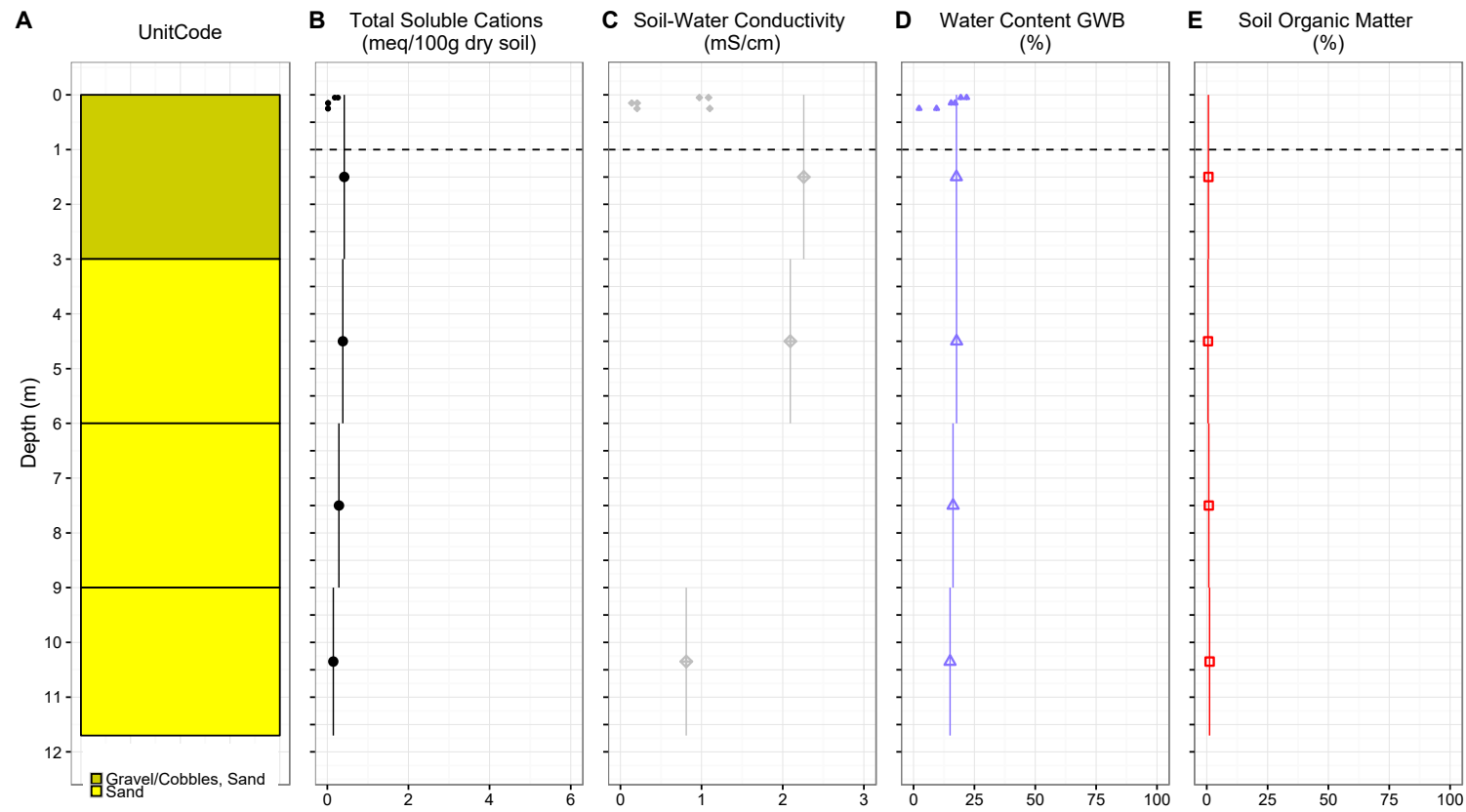

Graphical representation of A) UnitCode; B) Total Soluble Cations expressed in meq/ 100 g dry soil; C) Soil-Water Conductivity expressed in mS/cm; D) Gravimetric Water Content (\%) (represented by blue triangles) expressed on a wet-basis; and E) Soil Organic Matter (\%) expressed on a dry-basis. The small symbols vs. larger symbols corresponds to samples from the exterior pits and borehole respectively. 


\section{Esker 1: NGO-DD15-2029 (Esker Terrain)}

A

A UnitCode

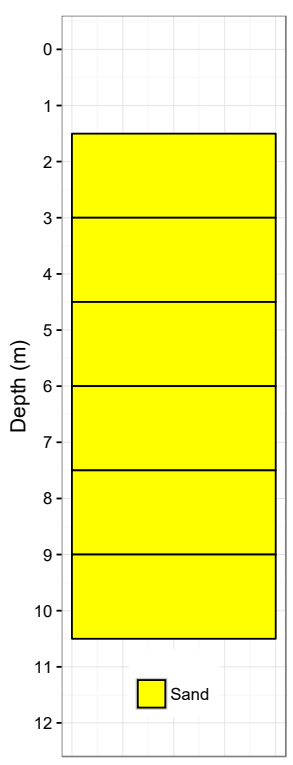

B Total Soluble Cations (meq/100g dry soil)

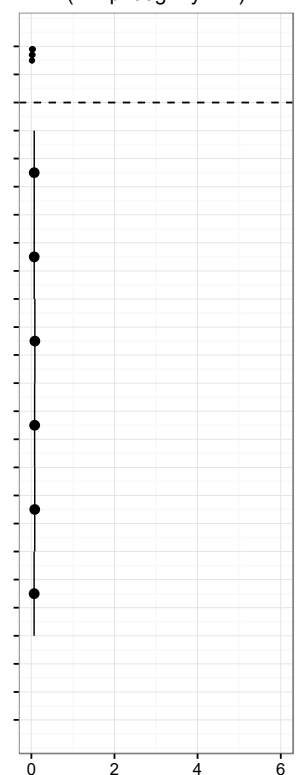

C Soil-Water Conductivity $(\mathrm{mS} / \mathrm{cm})$

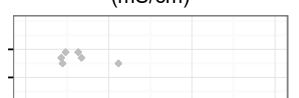

-

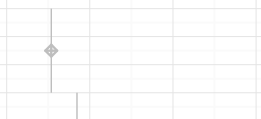

$-\rightarrow$

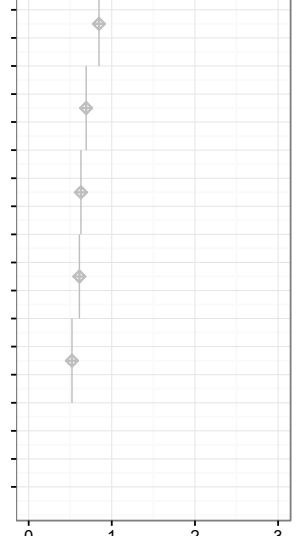

D Water Content GWB

(\%)

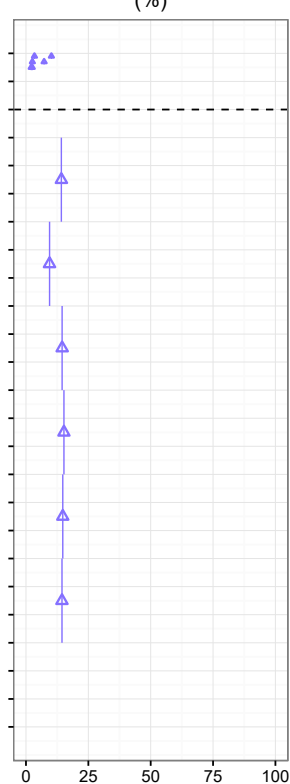

E Organic Matter GDB (\%)

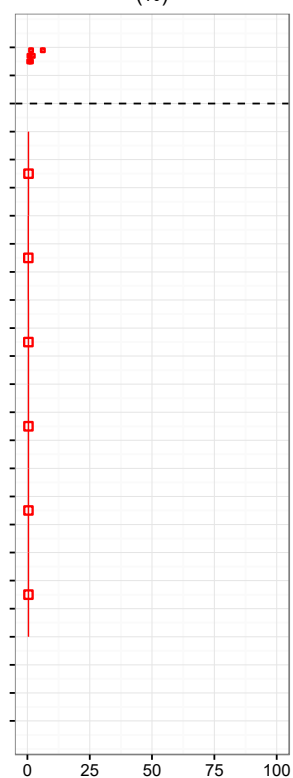

Graphical representation of A) UnitCode; B) Total Soluble Cations expressed in meq/ 100 g dry soil; C) Soil-Water Conductivity expressed in $\mathrm{mS} / \mathrm{cm}$; D) Gravimetric Water Content (\%) (represented by blue triangles) expressed on a wet-basis; and E) Soil Organic Matter (\%) expressed on a dry-basis. The small symbols vs. larger symbols corresponds to samples from the exterior pits and borehole respectively. 


\section{Esker 2 Group}

Field data from the Esker 2 group representing the surface conditions

\begin{tabular}{|c|c|c|c|c|c|c|}
\hline $\begin{array}{c}\text { BoreholeID } \\
\text { (NGO- } \\
\text { DD15- }\end{array}$ & $\begin{array}{c}\text { Easting } \\
(\mathbf{m})\end{array}$ & $\begin{array}{c}\text { Northing } \\
(\mathbf{m})\end{array}$ & $\begin{array}{c}\text { Elevation } \\
(\mathbf{m})\end{array}$ & $\begin{array}{c}\text { Terrain } \\
\text { Type }\end{array}$ & $\begin{array}{c}\text { Surface } \\
\text { Topography }\end{array}$ & Vegetation \\
\hline 2026 & 531203 & 7177920 & 437 & Esker & Hilly & $\begin{array}{c}\text { Shrubs, } \\
\text { Grasses, } \\
\end{array}$ \\
& & & & & & $\begin{array}{c}\text { Sedges, } \\
\text { Mosses }\end{array}$ \\
\hline
\end{tabular}




\section{Esker 2: NGO-DD16-2026 (Esker Terrain)}

A

AnitCode

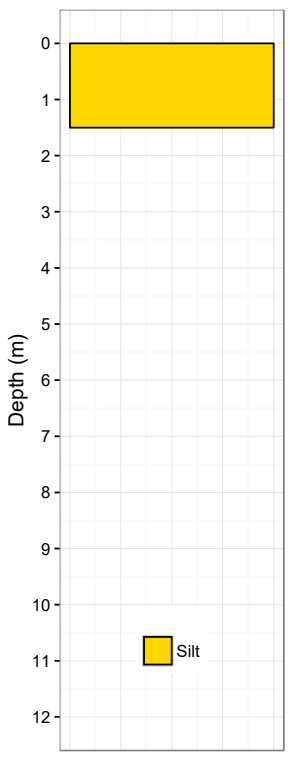

B Total Soluble Cations (meq/100g dry soil)

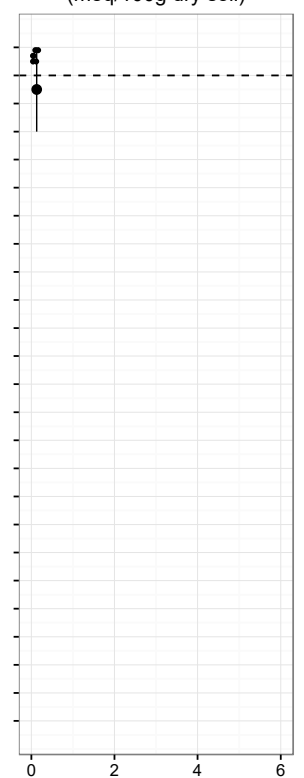

C Soil-Water Conductivity $(\mathrm{mS} / \mathrm{cm})$

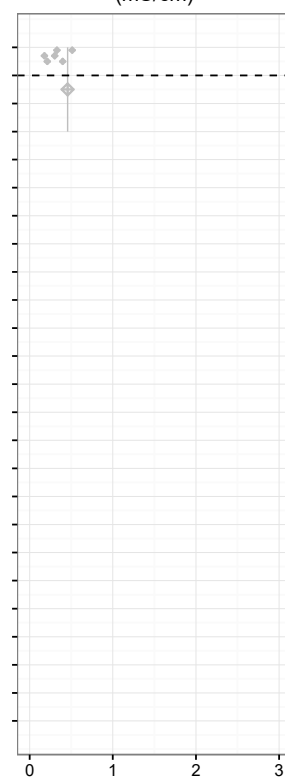

D Water Content GWB (\%)

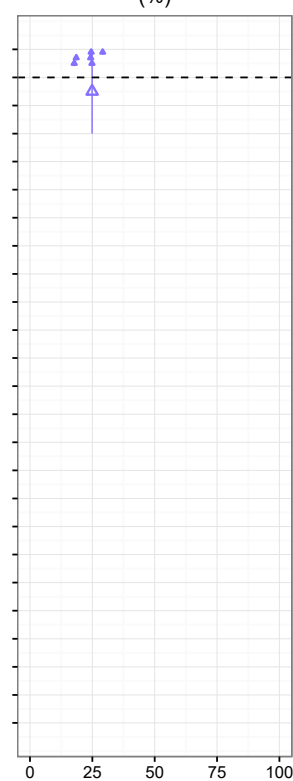

E Organic Matter GDB (\%)

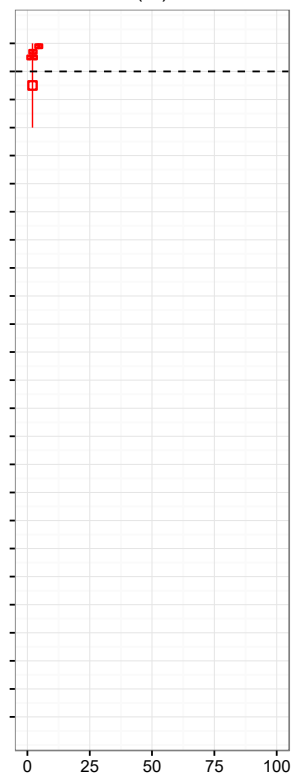

Graphical representation of A) UnitCode; B) Total Soluble Cations expressed in meq/ 100 g dry soil; C) Soil-Water Conductivity expressed in $\mathrm{mS} / \mathrm{cm}$; D) Gravimetric Water Content (\%) (represented by blue triangles) expressed on a wet-basis; and E) Soil Organic Matter (\%) expressed on a dry-basis. The small symbols vs. larger symbols corresponds to samples from the exterior pits and borehole respectively. 
APPENDIX E: Grain size analysis of active layer and permafrost samples from various terrain types near Lac de Gras, N.W.T.

\begin{tabular}{|c|c|c|c|c|c|c|}
\hline Terrain Type & Sample ID & Depth (m) & Mean Grain Size $(\mu \mathrm{m})$ & Sand (\%) & Silt (\%) & Clay (\%) \\
\hline \multirow[t]{27}{*}{ Peatlands and wetlands } & $1006-03$ & $0.72-1.03$ & 12 & 9 & 83 & 8 \\
\hline & 1006-09 & $2.70-3.00$ & 207 & 83 & 15 & 2 \\
\hline & $1006-11$ & $3.42-4.05$ & 64 & 54 & 41 & 5 \\
\hline & $1007-01$ & $0.70-0.90$ & 210 & 83 & 15 & 2 \\
\hline & $1007-10$ & $2.73-2.93$ & 269 & 86 & 13 & 2 \\
\hline & $1007-14$ & $3.48-3.63$ & 142 & 77 & 21 & 2 \\
\hline & $1005-03$ & $0.75-0.95$ & 16 & 21 & 70 & 9 \\
\hline & $1005-17$ & $2.86-3.03$ & 19 & 21 & 72 & 7 \\
\hline & $1005-24$ & $3.99-4.16$ & 11 & 11 & 79 & 10 \\
\hline & $2011-01$ & $0.30-0.48$ & 75 & 65 & 33 & 2 \\
\hline & 2011-06 & $1.42-1.62$ & 21 & 17 & 78 & 6 \\
\hline & 2011-10 & $2.45-2.65$ & 40 & 39 & 57 & 4 \\
\hline & $2011-15$ & $3.45-3.65$ & 80 & 68 & 30 & 2 \\
\hline & $2012-01$ & $0.97-1.25$ & 111 & 70 & 28 & 2 \\
\hline & 2012-02 & $1.40-1.60$ & 132 & 77 & 21 & 2 \\
\hline & $2012-06$ & $2.25-2.50$ & 63 & 58 & 39 & 2 \\
\hline & 2012-09 & $3.40-3.60$ & 45 & 39 & 57 & 4 \\
\hline & $1009-01$ & $0.00-0.28$ & 142 & 76 & 22 & 2 \\
\hline & $1009-06$ & $1.56-1.76$ & 108 & 66 & 32 & 2 \\
\hline & $1009-11$ & $2.50-2.70$ & 88 & 67 & 31 & 2 \\
\hline & 1009-14 & $3.10-3.40$ & 20 & 15 & 79 & 6 \\
\hline & $1010-02$ & $0.15-0.42$ & 6 & 4 & 81 & 15 \\
\hline & $1010-06$ & $1.52-1.71$ & 38 & 45 & 49 & 6 \\
\hline & $1010-11$ & $2.58-2.78$ & 165 & 80 & 18 & 2 \\
\hline & $1010-15$ & $3.40-3.50$ & 27 & 38 & 54 & 7 \\
\hline & $2015-01$ & $0.95-1.15$ & 52 & 49 & 47 & 4 \\
\hline & 2015-03 & $1.35-1.55$ & 89 & 67 & 31 & 2 \\
\hline \multirow{2}{*}{$\begin{array}{c}\text { Mean } \\
\text { SD }\end{array}$} & & & 83 & 51 & 44 & 4 \\
\hline & & & 68 & 26 & 23 & 3 \\
\hline \multirow[t]{16}{*}{ Till Blanket } & 1004-02 & $0.20-0.40$ & 84 & 61 & 33 & 6 \\
\hline & 1004-10 & $3.96-4.08$ & 135 & 74 & 23 & 3 \\
\hline & 2004-01 & $0.10-0.60$ & 188 & 82 & 17 & 2 \\
\hline & 2004-05 & $1.82-2.70$ & 172 & 82 & 17 & 2 \\
\hline & 2004-06 & $3.45-3.95$ & 124 & 72 & 25 & 3 \\
\hline & $2005-01$ & $0.00-0.30$ & 107 & 69 & 28 & 3 \\
\hline & 2005-04 & $1.85-2.40$ & 285 & 94 & 6 & 1 \\
\hline & 2005-07 & $3.60-3.80$ & 152 & 77 & 21 & 2 \\
\hline & $2006-03$ & $2.28-2.50$ & 241 & 93 & 6 & 1 \\
\hline & 2006-04 & $3.75-3.95$ & 201 & 83 & 15 & 2 \\
\hline & $2007-01$ & $0.00-0.20$ & 247 & 90 & 9 & 1 \\
\hline & $2007-05$ & $2.31-2.50$ & 198 & 83 & 16 & 2 \\
\hline & $2033-01$ & $0.35-0.40$ & 87 & 73 & 23 & 4 \\
\hline & $2033-03$ & $3.85-4.10$ & 136 & 74 & 23 & 3 \\
\hline & 2009-01 & $0.00-0.30$ & 274 & 90 & 9 & 1 \\
\hline & 2009-03 & $2.80-3.90$ & 289 & 90 & 9 & 1 \\
\hline \multirow{2}{*}{$\begin{array}{c}\text { Mean } \\
\text { SD }\end{array}$} & & & 182 & 80 & 17 & 2 \\
\hline & & & 67 & 9 & 8 & 1 \\
\hline \multirow[t]{8}{*}{ Till Veneer } & 1014-01 & $4.03-4.23$ & 139 & 73 & 25 & 2 \\
\hline & $2018-02$ & $0.30-0.40$ & 217 & 86 & 13 & 1 \\
\hline & 2018-08 & $2.65-2.80$ & 168 & 82 & 16 & 1 \\
\hline & 2013-01 & $1.80-2.00$ & 98 & 57 & 40 & 3 \\
\hline & 2013-03 & $2.20-2.50$ & 17 & 12 & 83 & 5 \\
\hline & 2016-01 & $0.00-0.34$ & 100 & 76 & 22 & 2 \\
\hline & 2019-01 & $1.80-2.00$ & 43 & 46 & 49 & 5 \\
\hline & 2019-04 & $2.40-2.60$ & 15 & 15 & 77 & 8 \\
\hline \multirow{2}{*}{$\begin{array}{c}\text { Mean } \\
\text { SD }\end{array}$} & & & 100 & 56 & 41 & 4 \\
\hline & & & 68 & 27 & 25 & 2 \\
\hline \multirow[t]{6}{*}{ Eskers } & $2008-01$ & $0.00-0.30$ & 238 & 95 & 4 & 1 \\
\hline & $2028-01$ & $0.00-0.30$ & 238 & 91 & 8 & 1 \\
\hline & 2028-04 & $9.00-11.7$ & 132 & 71 & 26 & 3 \\
\hline & 2029-01 & $1.50-3.00$ & 238 & 87 & 11 & 1 \\
\hline & 2029-06 & $9.00-10.5$ & 214 & 88 & 11 & 1 \\
\hline & 2026-01 & $0.00-1.50$ & 64 & 58 & 39 & 3 \\
\hline \multirow{2}{*}{$\begin{array}{c}\text { Mean } \\
\text { SD }\end{array}$} & & & 212 & 82 & 16 & 2 \\
\hline & & & 41 & 13 & 16 & 1 \\
\hline
\end{tabular}


APPENDIX F1: Summary statistics of gravimetric water content GWB (\%) in the top $0.5 \mathrm{~m}, 1 \mathrm{~m}, 2 \mathrm{~m}, 4 \mathrm{~m}, 6 \mathrm{~m}$ and $10 \mathrm{~m}$ of 24 sites near Lac de Gras, N.W.T. N is the number of samples, PS (\%) is the percentage of total sampling that was considered and N/A values delineate depth intervals where no samples were recovered or core lengths that did not reach the specified depths.

\begin{tabular}{|c|c|c|c|c|c|c|c|c|c|c|c|c|c|c|c|c|c|c|c|c|c|c|c|}
\hline \multirow{2}{*}{\multicolumn{3}{|c|}{ Terrain }} & \multirow[b]{2}{*}{ Core ID } & \multicolumn{6}{|l|}{ Top $0.5 \mathrm{~m}$} & \multicolumn{7}{|c|}{ Top $1 \mathrm{~m}$} & \multicolumn{7}{|c|}{ Top $2 \mathrm{~m}$} \\
\hline & & & & $\begin{array}{l}\text { PS } \\
(\%)\end{array}$ & Mean & Median & Max & Min & $\mathrm{SD}$ & $\mathrm{N}$ & $\begin{array}{l}\text { PS } \\
(\%)\end{array}$ & Mean & Median & Max & Min & SD & $\mathrm{N}$ & $\begin{array}{l}\text { PS } \\
(\%)\end{array}$ & Mean & Median & Max & Min & SD \\
\hline Peatlands & dd we & & 1006 & 72 & 81.3 & 80.9 & 89.3 & 78.0 & 3.8 & 9 & 100 & 81.9 & 81.1 & 89.3 & 78.0 & 3.5 & 12 & 83 & 83.0 & 82.1 & 89.3 & 78.0 & 3.8 \\
\hline & & & 1007 & 60 & 84.2 & 84.9 & 86.8 & 80.0 & 2.6 & 7 & 94 & 76.9 & 84.6 & 86.8 & 33.0 & 19.5 & 12 & 73 & 66.0 & 70.9 & 86.8 & 33.0 & 20.2 \\
\hline & & & 1005 & 90 & 60.3 & 82.8 & 85.3 & 10.6 & 34.6 & 9 & 90 & 64.2 & 81.9 & 85.3 & 10.6 & 31.0 & 13 & 86 & 54.7 & 64.3 & 85.3 & 10.6 & 31.2 \\
\hline & & & 2011 & 96 & 81.4 & 90.0 & 92.1 & 27.7 & 23.7 & 9 & 84 & 75.6 & 89.9 & 92.1 & 27.7 & 23.5 & 14 & 91 & 64.2 & 55.4 & 92.1 & 27.1 & 25.2 \\
\hline & & & 2012 & 60 & 43.8 & 42.4 & 76.1 & 17.4 & 28.4 & 0 & 0 & N/A & N/A & N/A & N/A & N/A & 10 & 59 & 40.5 & 35.3 & 76.1 & 17.4 & 21.8 \\
\hline & & & 1009 & 60 & 81.3 & 82.2 & 91.1 & 59.5 & 10.8 & 9 & 73 & 73.7 & 80.4 & 91.1 & 45.8 & 17.8 & 13 & 82 & 70.4 & 73.7 & 91.1 & 45.8 & 16.0 \\
\hline & & & 1010 & 84 & 77.7 & 84.7 & 92.8 & 45.9 & 16.9 & 10 & 83 & 75.7 & 81.4 & 92.8 & 45.9 & 15.9 & 13 & 76 & 70.1 & 76.8 & 92.8 & 39.9 & 18.0 \\
\hline & & & 2015 & 60 & 20.4 & 17.9 & 31.8 & 16.4 & 5.9 & 0 & 0 & N/A & N/A & N/A & N/A & N/A & 11 & 68 & 29.1 & 29.3 & 53.2 & 16.4 & 13.1 \\
\hline Till Blanl & & & 1004 & 80 & 8.6 & 9.2 & 10.5 & 5.2 & 1.7 & 10 & 74 & 7.9 & 8.4 & 10.5 & 4.1 & 2.2 & 12 & 53 & 7.9 & 8.4 & 10.5 & 4.1 & 2.0 \\
\hline & & & 2004 & 100 & 23.3 & 14.7 & 68.2 & 8.7 & 22.3 & 0 & 0 & N/A & N/A & N/A & N/A & N/A & 9 & 56 & 22.0 & 14.7 & 68.2 & 8.7 & 19.6 \\
\hline & & & 2005 & 60 & 18.4 & 8.6 & 60.7 & 7.5 & 19.6 & 0 & 0 & N/A & N/A & N/A & N/A & N/A & 0 & 0 & N/A & N/A & N/A & N/A & $\mathrm{N} / \mathrm{A}$ \\
\hline & & & 2006 & 60 & 9.6 & 9.6 & 11.4 & 8.0 & 1.1 & 0 & 0 & N/A & N/A & N/A & N/A & N/A & 8 & 25 & 8.9 & 9.5 & 11.4 & 3.5 & 2.4 \\
\hline & & & 2033 & 70 & 10.5 & 9.0 & 19.5 & 7.1 & 4.3 & 0 & 0 & N/A & N/A & N/A & N/A & N/A & 0 & 0 & N/A & N/A & N/A & N/A & $\mathrm{N} / \mathrm{A}$ \\
\hline & & & 2007 & 80 & 16.1 & 11.0 & 55.9 & 7.8 & 16.1 & 9 & 60 & 15.2 & 10.9 & 55.9 & 7.8 & 15.3 & 10 & 18 & 14.5 & 10.5 & 55.9 & 7.8 & 14.6 \\
\hline & & & 2009 & 60 & 10.1 & 10.2 & 12.6 & 6.9 & 1.8 & 0 & 0 & N/A & N/A & N/A & N/A & N/A & 8 & 25 & 9.7 & 9.9 & 12.6 & 6.8 & 2.1 \\
\hline Till Vene & & & 2018 & 80 & 74.5 & 82.9 & 88.6 & 24.4 & 22.6 & 8 & 57 & 72.2 & 80.1 & 88.6 & 24.4 & 21.9 & 9 & 79 & 70.9 & 77.3 & 88.6 & 24.4 & 20.9 \\
\hline & & & 2019 & 60 & 39.9 & 24.0 & 83.1 & 14.4 & 31.7 & 0 & 0 & N/A & N/A & N/A & N/A & N/A & 7 & 25 & 38.5 & 26.5 & 83.1 & 14.4 & 29.2 \\
\hline & & & 1014 & 0 & $\mathrm{~N} / \mathrm{A}$ & N/A & N/A & N/A & N/A & 0 & 0 & N/A & N/A & N/A & N/A & N/A & 0 & 0 & $\mathrm{~N} / \mathrm{A}$ & N/A & N/A & N/A & $\mathrm{N} / \mathrm{A}$ \\
\hline & & & 2013 & 60 & 24.3 & 15.2 & 71.7 & 10.6 & 23.5 & 0 & 0 & N/A & N/A & N/A & N/A & N/A & 7 & 25 & 25.3 & 17.1 & 71.7 & 10.6 & 21.6 \\
\hline & & & 2016 & 68 & 16.6 & 15.2 & 27.3 & 13.0 & 4.9 & 8 & 100 & 16.8 & 15.4 & 27.3 & 13.0 & 4.6 & 0 & 0 & N/A & N/A & N/A & N/A & $\mathrm{N} / \mathrm{A}$ \\
\hline Eskers & & & 2026 & 60 & 23.2 & 24.4 & 29.1 & 17.7 & 4.3 & 7 & 100 & 23.4 & 24.5 & 29.1 & 17.7 & 4.0 & $\overline{0}$ & 0 & N/A & N/A & N/A & N/A & $\mathrm{N} / \mathrm{A}$ \\
\hline & & & 2008 & 60 & 13.8 & 15.6 & 20.3 & 4.4 & 6.5 & 0 & 0 & N/A & N/A & N/A & N/A & N/A & 0 & 0 & N/A & N/A & N/A & N/A & N/A \\
\hline & & & 2028 & 60 & 14.2 & 16.2 & 21.8 & 2.3 & 7.2 & 0 & 0 & N/A & N/A & N/A & N/A & N/A & 7 & 100 & 14.7 & 17.0 & 21.8 & 2.3 & 6.7 \\
\hline & & & 2029 & 60 & 4.7 & 3.0 & 10.2 & 2.1 & 3.3 & 0 & 0 & N/A & N/A & N/A & N/A & N/A & 0 & 0 & N/A & N/A & N/A & N/A & N/A \\
\hline & Top & & & & & & & Top & & & & & & & & Top & & & & & & & \\
\hline Core ID & $\mathrm{N}$ & $\begin{array}{l}\text { PS } \\
(\%)\end{array}$ & Mean & Median & $\operatorname{Max}$ & Min & SD & $\mathrm{N}$ & $\begin{array}{l}\text { PS } \\
(\%)\end{array}$ & Mear & & Median & Max & Min & SD & $\mathrm{N}$ & $\begin{array}{l}\text { PS } \\
(\%)\end{array}$ & Mean & & Median & Max & Min & SD \\
\hline 1006 & 17 & 80 & 72.9 & 81.1 & 89.3 & 22.0 & 22.5 & 18 & 58 & 69.5 & & 81.0 & 89.3 & 11.6 & 26.2 & 18 & 0 & N/A & & $\mathrm{N} / \mathrm{A}$ & $\mathrm{N} / \mathrm{A}$ & N/A & $\mathrm{N} / \mathrm{A}$ \\
\hline 1007 & 20 & 75 & 43.5 & 44.9 & 86.8 & 5.2 & 32.2 & 0 & 0 & N/A & & N/A & N/A & N/A & $\mathrm{N} / \mathrm{A}$ & 20 & 0 & N/A & & N/A & N/A & N/A & $\mathrm{N} / \mathrm{A}$ \\
\hline 1005 & 23 & 83 & 51.9 & 53.1 & 98.7 & 10.6 & 30.0 & 0 & 0 & N/A & & N/A & N/A & N/A & $\mathrm{N} / \mathrm{A}$ & 26 & 0 & N/A & & N/A & N/A & N/A & N/A \\
\hline 2011 & 23 & 92 & 49.2 & 39.3 & 92.1 & 20.0 & 27.6 & 30 & 83 & 42.7 & & 29.0 & 92.1 & 19.2 & 26.9 & 30 & 0 & N/A & & N/A & N/A & N/A & $\mathrm{N} / \mathrm{A}$ \\
\hline 2012 & 17 & 65 & 43.1 & 42.2 & 76.1 & 17.4 & 17.1 & 18 & 46 & 41.5 & & 42.2 & 76.1 & 13.2 & 18.0 & 18 & 0 & N/A & & N/A & N/A & N/A & N/A \\
\hline 1009 & 21 & 83 & 64.9 & 60.8 & 91.1 & 45.8 & 14.9 & 0 & 0 & $\mathrm{~N} / \mathrm{A}$ & & N/A & N/A & N/A & $\mathrm{N} / \mathrm{A}$ & 21 & 0 & N/A & & N/A & N/A & N/A & $\mathrm{N} / \mathrm{A}$ \\
\hline 1010 & 22 & 83 & 60.5 & 56.8 & 92.8 & 33.4 & 19.4 & 27 & 74 & 56.9 & & 54.4 & 92.8 & 30.3 & 19.5 & 27 & 0 & N/A & & N/A & N/A & N/A & $\mathrm{N} / \mathrm{A}$ \\
\hline 2015 & 0 & 0 & N/A & N/A & $\mathrm{N} / \mathrm{A}$ & N/A & N/A & 0 & 0 & $\mathrm{~N} / \mathrm{A}$ & & N/A & N/A & N/A & $\mathrm{N} / \mathrm{A}$ & 11 & 0 & N/A & & N/A & N/A & $\mathrm{N} / \mathrm{A}$ & N/A \\
\hline 1004 & 15 & 38 & 9.4 & 9.0 & 25.9 & 4.1 & 5.1 & 17 & 29 & 9.5 & & 9.0 & 25.9 & 4.1 & 4.9 & 17 & 0 & $\mathrm{~N} / \mathrm{A}$ & & $\mathrm{N} / \mathrm{A}$ & $\mathrm{N} / \mathrm{A}$ & N/A & $\mathrm{N} / \mathrm{A}$ \\
\hline 2004 & 12 & 68 & 33.3 & 17.7 & 76.1 & 8.7 & 26.5 & 0 & 0 & N/A & & N/A & N/A & N/A & $\mathrm{N} / \mathrm{A}$ & 12 & 0 & N/A & & N/A & N/A & N/A & N/A \\
\hline 2005 & 12 & 41 & 32.1 & 18.6 & 75.9 & 7.5 & 27.7 & 13 & 26 & 35.1 & & 24.7 & 75.9 & 7.5 & 28.6 & 13 & 0 & $\mathrm{~N} / \mathrm{A}$ & & $\mathrm{N} / \mathrm{A}$ & N/A & N/A & $\mathrm{N} / \mathrm{A}$ \\
\hline 2006 & 10 & 24 & 15.9 & 9.6 & 73.1 & 3.5 & 20.3 & 11 & 80 & 17.6 & & 9.6 & 73.1 & 3.5 & 20.1 & 11 & 0 & N/A & & N/A & N/A & N/A & N/A \\
\hline 2033 & 9 & 17 & 24.5 & 9.8 & 76.1 & 7.1 & 28.0 & 0 & 0 & $\mathrm{~N} / \mathrm{A}$ & & N/A & N/A & $\mathrm{N} / \mathrm{A}$ & $\mathrm{N} / \mathrm{A}$ & 12 & 0 & N/A & & N/A & N/A & N/A & N/A \\
\hline 2007 & 11 & 22 & 16.0 & 10.9 & 55.9 & 7.8 & 14.7 & 0 & 0 & N/A & & N/A & N/A & N/A & $\mathrm{N} / \mathrm{A}$ & 11 & 0 & N/A & & N/A & N/A & N/A & $\mathrm{N} / \mathrm{A}$ \\
\hline 2009 & 9 & 40 & 16.2 & 10.2 & 68.0 & 6.8 & 19.5 & 0 & 0 & N/A & & $\mathrm{N} / \mathrm{A}$ & N/A & N/A & $\mathrm{N} / \mathrm{A}$ & 9 & 0 & N/A & & N/A & N/A & N/A & N/A \\
\hline 2018 & 13 & 83 & 62.4 & 60.9 & 88.6 & 24.4 & 22.1 & 0 & 0 & $\mathrm{~N} / \mathrm{A}$ & & $\mathrm{N} / \mathrm{A}$ & $\mathrm{N} / \mathrm{A}$ & $\mathrm{N} / \mathrm{A}$ & $\mathrm{N} / \mathrm{A}$ & 13 & 0 & $\mathrm{~N} / \mathrm{A}$ & & $\mathrm{N} / \mathrm{A}$ & $\mathrm{N} / \mathrm{A}$ & N/A & $\mathrm{N} / \mathrm{A}$ \\
\hline 2019 & 11 & 33 & 36.0 & 28.9 & 83.1 & 14.4 & 23.4 & 0 & 0 & $\mathrm{~N} / \mathrm{A}$ & & N/A & N/A & N/A & $\mathrm{N} / \mathrm{A}$ & 11 & 0 & N/A & & $\mathrm{N} / \mathrm{A}$ & N/A & N/A & N/A \\
\hline 1014 & 0 & 0 & N/A & N/A & N/A & N/A & $\mathrm{N} / \mathrm{A}$ & 7 & 25 & 78.1 & & 83.6 & 92.4 & 52.3 & 14.6 & 19 & 47 & 71.0 & & 81.8 & 93.0 & 24.3 & 21.1 \\
\hline 2013 & 9 & 25 & 25.5 & 20.3 & 71.7 & 10.6 & 18.8 & 0 & 0 & N/A & & N/A & N/A & N/A & $\mathrm{N} / \mathrm{A}$ & 9 & 0 & N/A & & N/A & N/A & N/A & N/A \\
\hline 2016 & 0 & 0 & N/A & N/A & N/A & N/A & $\mathrm{N} / \mathrm{A}$ & 0 & 0 & $\mathrm{~N} / \mathrm{A}$ & & N/A & N/A & N/A & $\mathrm{N} / \mathrm{A}$ & 8 & 0 & N/A & & $\mathrm{N} / \mathrm{A}$ & N/A & N/A & N/A \\
\hline 2026 & 0 & 0 & N/A & N/A & $\mathrm{N} / \mathrm{A}$ & N/A & $\mathrm{N} / \mathrm{A}$ & 0 & 0 & $\mathrm{~N} / \mathrm{A}$ & & $\mathrm{N} / \mathrm{A}$ & N/A & $\mathrm{N} / \mathrm{A}$ & $\mathrm{N} / \mathrm{A}$ & 7 & 0 & N/A & & N/A & $\mathrm{N} / \mathrm{A}$ & $\mathrm{N} / \mathrm{A}$ & $\mathrm{N} / \mathrm{A}$ \\
\hline 2008 & 8 & 53 & 13.3 & 15.5 & 20.3 & 4.4 & 6.2 & 9 & 85 & 16.5 & & 15.6 & 41.9 & 4.4 & 11.1 & 9 & 0 & N/A & & N/A & N/A & N/A & N/A \\
\hline 2028 & 7 & 25 & 14.7 & 17.0 & 21.8 & 2.3 & 6.7 & 8 & 100 & 15.1 & & 17.3 & 21.8 & 2.3 & 6.3 & 9 & 90 & 15.2 & & 17.0 & 21.8 & 2.3 & 5.9 \\
\hline 2029 & 8 & 70 & 6.4 & 5.3 & 14.2 & 2.1 & 4.5 & 9 & 88 & 7.3 & & 7.2 & 14.5 & 2.1 & 5.0 & 9 & 93 & 9.2 & & 9.8 & 15.2 & 2.1 & 5.4 \\
\hline
\end{tabular}


APPENDIX F2: Summary statistics of organic matter content (\%) in the top $0.5 \mathrm{~m}, 1 \mathrm{~m}, 2 \mathrm{~m}, 4 \mathrm{~m}, 6 \mathrm{~m}$ and $10 \mathrm{~m}$ of 24 sites near Lac de Gras, N.W.T. N is the number of samples, PS (\%) is the percentage of total sampling that was considered and N/A values delineate depth intervals where no samples were recovered or core lengths that did not reach the specified depths.

\begin{tabular}{|c|c|c|c|c|c|c|c|c|c|c|c|c|c|c|c|c|c|c|c|c|c|c|c|}
\hline \multirow{2}{*}{\multicolumn{3}{|c|}{ Terrain }} & \multirow[b]{2}{*}{ Core ID } & \multicolumn{6}{|l|}{ Top $0.5 \mathrm{~m}$} & \multicolumn{7}{|c|}{ Top $1 \mathrm{~m}$} & \multicolumn{7}{|c|}{ Top 2 m } \\
\hline & & & & $\begin{array}{l}\text { PS } \\
(\%)\end{array}$ & Mean & Median & Max & Min & $\mathrm{SD}$ & & $\begin{array}{l}\text { PS } \\
(\%)\end{array}$ & Mean & Median & Max & Min & SD & $\mathrm{N}$ & $\begin{array}{l}\text { PS } \\
(\%)\end{array}$ & Mean & Median & $\operatorname{Max}$ & Min & SD \\
\hline \multirow{8}{*}{\multicolumn{3}{|c|}{ Peatlands and wetlands }} & 1006 & 32 & 89.4 & 89.4 & 89.4 & 89.4 & $\mathrm{~N} / \mathrm{A}$ & 3 & 77 & 87.6 & 87.8 & 89.4 & 85.6 & 1.9 & 6 & 54 & 83.1 & 82.4 & 89.4 & 78.4 & 5.1 \\
\hline & & & 1007 & 0 & N/A & N/A & N/A & N/A & $\mathrm{N} / \mathrm{A}$ & 1 & 20 & 3.5 & 3.5 & 3.5 & 3.5 & N/A & 6 & 58 & 3.7 & 2.7 & 9.2 & 1.8 & 2.8 \\
\hline & & & 1005 & 40 & 72.5 & 72.5 & 72.5 & 72.5 & $\mathrm{~N} / \mathrm{A}$ & 3 & 40 & 67.5 & 72.5 & 80.6 & 49.3 & 16.2 & 9 & 71 & 30.8 & 9.5 & 80.6 & 1.0 & 32.7 \\
\hline & & & 2011 & 36 & 4.8 & 4.8 & 4.8 & 4.8 & N/A & 3 & 58 & 3.9 & 3.5 & 4.8 & 3.5 & 0.7 & 8 & 77 & 2.5 & 2.7 & 4.8 & 0.9 & 1.5 \\
\hline & & & 2012 & 0 & N/A & N/A & N/A & N/A & $\mathrm{N} / \mathrm{A}$ & 0 & 0 & N/A & N/A & N/A & $\mathrm{N} / \mathrm{A}$ & N/A & 4 & 44 & 3.0 & 2.9 & 5.3 & 1.1 & 1.7 \\
\hline & & & 1009 & 56 & 26.3 & 26.3 & 26.3 & 26.3 & $\mathrm{~N} / \mathrm{A}$ & 3 & 87 & 13.6 & 10.6 & 26.3 & 3.9 & 11.5 & 7 & 81 & 8.4 & 4.6 & 26.3 & 1.6 & 8.5 \\
\hline & & & 1010 & 54 & 27.4 & 27.4 & 27.4 & 27.4 & $\mathrm{~N} / \mathrm{A}$ & 3 & 68 & 27.3 & 27.4 & 51.8 & 2.7 & 24.5 & 6 & 69 & 14.4 & 2.4 & 51.8 & 1.3 & 21.0 \\
\hline & & & 2015 & 0 & $\mathrm{~N} / \mathrm{A}$ & N/A & N/A & N/A & $\mathrm{N} / \mathrm{A}$ & 0 & 0 & N/A & N/A & N/A & $\mathrm{N} / \mathrm{A}$ & N/A & 5 & 53 & 1.4 & 1.2 & 1.9 & 1.0 & 0.4 \\
\hline \multirow{7}{*}{\multicolumn{3}{|c|}{ Till Blanket }} & 1004 & 80 & 1.7 & 1.3 & 4.3 & 0.9 & 1.1 & 10 & 74 & 2.2 & 1.3 & 7.1 & 0.9 & 2.0 & 12 & 53 & 2.3 & 1.4 & 7.1 & 0.9 & 1.8 \\
\hline & & & 2004 & 100 & 2.8 & 2.8 & 2.8 & 2.8 & $\mathrm{~N} / \mathrm{A}$ & 0 & 0 & N/A & N/A & N/A & N/A & N/A & 3 & 40 & 1.7 & 1.2 & 2.8 & 1.1 & 0.9 \\
\hline & & & 2005 & 60 & 1.6 & 1.6 & 1.6 & 1.6 & N/A & 0 & 0 & N/A & N/A & N/A & N/A & N/A & 0 & 0 & $\mathrm{~N} / \mathrm{A}$ & N/A & N/A & N/A & N/A \\
\hline & & & 2006 & 60 & 1.5 & 1.2 & 3.3 & 0.7 & 0.9 & 0 & 0 & N/A & N/A & N/A & N/A & N/A & 8 & 25 & 1.7 & 1.3 & 3.3 & 0.7 & 1.0 \\
\hline & & & 2033 & 10 & 2.9 & 2.9 & 2.9 & 2.9 & N/A & 0 & 0 & N/A & N/A & N/A & N/A & N/A & 1 & 0 & N/A & N/A & N/A & N/A & N/A \\
\hline & & & 2007 & 80 & 2.1 & 2.1 & 2.4 & 1.8 & 0.4 & 3 & 60 & 2.1 & 2.0 & 2.4 & 1.8 & 0.3 & 4 & 34 & 2.0 & 2.0 & 2.4 & 1.8 & 0.2 \\
\hline & & & 2009 & 60 & 1.1 & 1.0 & 2.0 & 0.4 & 0.5 & 7 & 0 & N/A & N/A & N/A & $\mathrm{N} / \mathrm{A}$ & N/A & 8 & 25 & 1.1 & 1.0 & 2.0 & 0.4 & 0.5 \\
\hline \multirow{5}{*}{\multicolumn{3}{|c|}{ Till Veneer }} & 2018 & 20 & 3.9 & 3.9 & 3.9 & 3.9 & $\mathrm{~N} / \mathrm{A}$ & 2 & 30 & 35.0 & 35.0 & 66.1 & 3.9 & 44.0 & 3 & 64 & 27.4 & 12.3 & 66.1 & 3.9 & 33.8 \\
\hline & & & 2019 & 0 & $\mathrm{~N} / \mathrm{A}$ & N/A & N/A & N/A & N/A & 0 & 0 & N/A & N/A & N/A & N/A & N/A & 1 & 10 & 0.6 & 0.6 & 0.6 & 0.6 & N/A \\
\hline & & & 1014 & 0 & $\mathrm{~N} / \mathrm{A}$ & N/A & N/A & N/A & $\mathrm{N} / \mathrm{A}$ & 0 & 0 & N/A & N/A & N/A & N/A & N/A & 0 & 0 & N/A & N/A & N/A & N/A & N/A \\
\hline & & & 2013 & 0 & $\mathrm{~N} / \mathrm{A}$ & N/A & N/A & N/A & $\mathrm{N} / \mathrm{A}$ & 0 & 0 & N/A & N/A & N/A & N/A & N/A & 1 & 10 & 1.1 & 1.1 & 1.1 & 1.1 & N/A \\
\hline & & & 2016 & 68 & 2.4 & 1.7 & 6.3 & 1.3 & 1.8 & 8 & 100 & 2.5 & 1.8 & 6.3 & 1.3 & 1.7 & 8 & 0 & N/A & N/A & N/A & N/A & N/A \\
\hline \multirow{4}{*}{\multicolumn{3}{|c|}{ Eskers }} & 2026 & 60 & 2.9 & 3.0 & 5.2 & 0.8 & 1.6 & 7 & 100 & 2.8 & 2.9 & 5.2 & 0.8 & 1.5 & 0 & 0 & $\mathrm{~N} / \mathrm{A}$ & $\mathrm{N} / \mathrm{A}$ & $\mathrm{N} / \mathrm{A}$ & N/A & $\mathrm{N} / \mathrm{A}$ \\
\hline & & & 2008 & 60 & 4.2 & 4.0 & 5.7 & 2.7 & 1.0 & 0 & 0 & N/A & N/A & N/A & N/A & N/A & 0 & 0 & N/A & N/A & N/A & N/A & N/A \\
\hline & & & 2028 & 0 & $\mathrm{~N} / \mathrm{A}$ & N/A & N/A & N/A & $\mathrm{N} / \mathrm{A}$ & 0 & 0 & N/A & N/A & N/A & N/A & N/A & 1 & 100 & 0.7 & 0.7 & 0.7 & 0.7 & N/A \\
\hline & & & 2029 & 60 & 2.1 & 1.5 & 6.2 & 0.7 & 2.0 & 0 & 0 & $\mathrm{~N} / \mathrm{A}$ & N/A & N/A & N/A & $\mathrm{N} / \mathrm{A}$ & 0 & 0 & N/A & N/A & $\mathrm{N} / \mathrm{A}$ & N/A & $\mathrm{N} / \mathrm{A}$ \\
\hline \multicolumn{8}{|c|}{ Top $4 \mathrm{~m}$} & \multicolumn{8}{|c|}{ Top 6 m } & Top 1 & & & & & & & \\
\hline Core ID & $\mathrm{N}$ & $\begin{array}{c}\text { PS } \\
(\%)\end{array}$ & Mean & Median & $\operatorname{Max}$ & Min & SD & $\mathrm{N}$ & $\begin{array}{c}\text { PS } \\
(\%)\end{array}$ & Mean & & Median & Max & Min & SD & $\mathrm{N}$ & $\begin{array}{c}\text { PS } \\
(\%)\end{array}$ & Mean & & Median & Max & Min & SD \\
\hline 1006 & 11 & 75 & 61.1 & 79.1 & 89.4 & 1.1 & 38.0 & 12 & 54 & 56.1 & & 78.7 & 89.4 & 1.1 & 40.1 & 0 & 0 & N/A & & $\mathrm{N} / \mathrm{A}$ & $\mathrm{N} / \mathrm{A}$ & $\mathrm{N} / \mathrm{A}$ & $\mathrm{N} / \mathrm{A}$ \\
\hline 1007 & 14 & 68 & 2.1 & 1.0 & 9.2 & 0.8 & 2.2 & 0 & 0 & N/A & & N/A & N/A & N/A & N/A & 0 & 0 & N/A & & N/A & N/A & N/A & N/A \\
\hline 1005 & 19 & 76 & 15.9 & 3.0 & 80.6 & 0.9 & 26.2 & 22 & 59 & 14.6 & & 3.6 & 80.6 & 0.9 & 24.5 & 0 & 0 & N/A & & N/A & $\mathrm{N} / \mathrm{A}$ & $\mathrm{N} / \mathrm{A}$ & $\mathrm{N} / \mathrm{A}$ \\
\hline 2011 & 16 & 86 & 1.6 & 0.9 & 4.8 & 0.7 & 1.4 & 23 & 78 & 1.3 & & 0.8 & 4.8 & 0.5 & 1.2 & 0 & 0 & N/A & & N/A & N/A & N/A & $\mathrm{N} / \mathrm{A}$ \\
\hline 2012 & 11 & 60 & 1.9 & 1.3 & 5.3 & 0.9 & 1.3 & 12 & 41 & 1.8 & & 1.2 & 5.3 & 0.9 & 1.3 & 0 & 0 & N/A & & N/A & $\mathrm{N} / \mathrm{A}$ & $\mathrm{N} / \mathrm{A}$ & $\mathrm{N} / \mathrm{A}$ \\
\hline 1009 & 15 & 83 & 4.7 & 1.8 & 26.3 & 1.1 & 6.6 & 0 & 0 & N/A & & N/A & $\mathrm{N} / \mathrm{A}$ & N/A & N/A & 0 & 0 & N/A & & N/A & N/A & $\mathrm{N} / \mathrm{A}$ & $\mathrm{N} / \mathrm{A}$ \\
\hline 1010 & 15 & 83 & 6.7 & 1.5 & 51.8 & 0.7 & 14.1 & 20 & 73 & 5.4 & & 1.6 & 51.8 & 0.7 & 12.3 & 0 & 0 & N/A & & N/A & N/A & N/A & N/A \\
\hline 2015 & 0 & 0 & N/A & N/A & $\mathrm{N} / \mathrm{A}$ & N/A & $\mathrm{N} / \mathrm{A}$ & 0 & 0 & N/A & & N/A & N/A & N/A & N/A & 0 & 0 & N/A & & N/A & N/A & N/A & $\mathrm{N} / \mathrm{A}$ \\
\hline 1004 & 15 & 38 & 2.1 & 1.3 & 7.1 & 0.7 & 1.7 & 17 & 29 & 1.9 & & 1.3 & 7.1 & 0.6 & 1.6 & 0 & 0 & $\mathrm{~N} / \mathrm{A}$ & & $\mathrm{N} / \mathrm{A}$ & $\mathrm{N} / \mathrm{A}$ & $\mathrm{N} / \mathrm{A}$ & $\mathrm{N} / \mathrm{A}$ \\
\hline 2004 & 6 & 67 & 2.0 & 1.2 & 4.8 & 1.0 & 1.5 & 0 & 0 & N/A & & N/A & N/A & N/A & N/A & 0 & 0 & N/A & & N/A & N/A & N/A & N/A \\
\hline 2005 & 6 & 83 & 0.9 & 0.8 & 1.6 & 0.3 & 0.4 & 7 & 41 & 0.8 & & 0.7 & 1.6 & 0.3 & 0.4 & 0 & 0 & N/A & & N/A & $\mathrm{N} / \mathrm{A}$ & N/A & N/A \\
\hline 2006 & 10 & 24 & 1.5 & 1.2 & 3.3 & 0.6 & 0.9 & 11 & 80 & 1.5 & & 1.1 & 3.3 & 0.6 & 0.9 & 0 & 0 & N/A & & $\mathrm{N} / \mathrm{A}$ & N/A & N/A & $\mathrm{N} / \mathrm{A}$ \\
\hline 2033 & 3 & 12 & 1.7 & 1.1 & 2.9 & 1.1 & 1.0 & 6 & 18 & 1.4 & & 1.1 & 2.9 & 1.0 & 0.7 & 0 & 0 & N/A & & N/A & N/A & $\mathrm{N} / \mathrm{A}$ & $\mathrm{N} / \mathrm{A}$ \\
\hline 2007 & 5 & 22 & 2.8 & 2.0 & 6.0 & 1.8 & 1.8 & 0 & 0 & N/A & & N/A & N/A & N/A & N/A & 0 & 0 & $\mathrm{~N} / \mathrm{A}$ & & N/A & N/A & N/A & N/A \\
\hline 2009 & 9 & 40 & 1.1 & 1.0 & 2.0 & 0.4 & 0.4 & 0 & 0 & N/A & & N/A & $\mathrm{N} / \mathrm{A}$ & N/A & N/A & 0 & 0 & N/A & & N/A & $\mathrm{N} / \mathrm{A}$ & N/A & $\mathrm{N} / \mathrm{A}$ \\
\hline 2018 & 7 & 51 & 13.0 & 2.6 & 66.1 & 1.8 & 23.7 & 0 & 0 & $\mathrm{~N} / \mathrm{A}$ & & N/A & $\mathrm{N} / \mathrm{A}$ & $\mathrm{N} / \mathrm{A}$ & $\mathrm{N} / \mathrm{A}$ & 0 & 0 & N/A & & $\mathrm{N} / \mathrm{A}$ & $\mathrm{N} / \mathrm{A}$ & $\mathrm{N} / \mathrm{A}$ & $\mathrm{N} / \mathrm{A}$ \\
\hline 2019 & 5 & 25 & 0.9 & 0.8 & 1.4 & 0.6 & 0.3 & 0 & 0 & N/A & & N/A & $\mathrm{N} / \mathrm{A}$ & N/A & N/A & 0 & 0 & $\mathrm{~N} / \mathrm{A}$ & & $\mathrm{N} / \mathrm{A}$ & N/A & N/A & $\mathrm{N} / \mathrm{A}$ \\
\hline 1014 & 0 & 0 & N/A & $\mathrm{N} / \mathrm{A}$ & N/A & N/A & $\mathrm{N} / \mathrm{A}$ & 7 & 25 & 1.2 & & 1.2 & 1.5 & 1.0 & 0.2 & 19 & 47 & 1.2 & & 1.1 & 1.6 & 1.0 & 0.2 \\
\hline 2013 & 3 & 18 & 1.2 & 1.2 & 1.3 & 1.1 & 0.1 & 0 & 0 & N/A & & N/A & N/A & N/A & N/A & 0 & 0 & N/A & & N/A & N/A & N/A & N/A \\
\hline 2016 & 8 & 0 & $\mathrm{~N} / \mathrm{A}$ & N/A & N/A & N/A & $\mathrm{N} / \mathrm{A}$ & 0 & 0 & N/A & & N/A & N/A & N/A & N/A & 0 & 0 & N/A & & N/A & N/A & N/A & N/A \\
\hline 2026 & 0 & 0 & N/A & N/A & $\mathrm{N} / \mathrm{A}$ & N/A & $\mathrm{N} / \mathrm{A}$ & 0 & 0 & N/A & & N/A & $\mathrm{N} / \mathrm{A}$ & $\mathrm{N} / \mathrm{A}$ & $\mathrm{N} / \mathrm{A}$ & 0 & 0 & $\mathrm{~N} / \mathrm{A}$ & & $\mathrm{N} / \mathrm{A}$ & $\mathrm{N} / \mathrm{A}$ & $\mathrm{N} / \mathrm{A}$ & $\mathrm{N} / \mathrm{A}$ \\
\hline 2008 & 8 & 53 & 3.8 & 3.9 & 5.7 & 0.9 & 1.5 & 9 & 85 & 3.4 & & 3.7 & 5.7 & 0.4 & 1.8 & 0 & 0 & N/A & & $\mathrm{N} / \mathrm{A}$ & N/A & N/A & $\mathrm{N} / \mathrm{A}$ \\
\hline 2028 & 0 & 0 & N/A & N/A & N/A & N/A & $\mathrm{N} / \mathrm{A}$ & 2 & 100 & 0.6 & & 0.6 & 0.7 & 0.5 & 0.1 & 3 & 90 & 0.7 & & 0.7 & 0.9 & 0.5 & 0.2 \\
\hline 2029 & 8 & 70 & 1.7 & 1.2 & 6.2 & 0.4 & 1.9 & 9 & 88 & 1.6 & & 0.9 & 6.2 & 0.4 & 1.8 & 3 & 93 & 1.3 & & 0.6 & 6.2 & 0.4 & 1.6 \\
\hline
\end{tabular}


APPENDIX F3: Summary statistics of total soluble cations (meq/100 g dry soil) in the top $0.5 \mathrm{~m}, 1 \mathrm{~m}, 2 \mathrm{~m}, 4 \mathrm{~m}, 6 \mathrm{~m}$ and $10 \mathrm{~m}$ of 24 sites near Lac de Gras, N.W.T. N is the number of samples, PS (\%) is the percentage of total sampling that was considered and N/A values delineate depth intervals where no samples were recovered or core lengths that did not reach the specified depths.

\begin{tabular}{|c|c|c|c|c|c|c|c|c|c|c|c|c|c|c|c|c|c|c|c|c|c|c|}
\hline & & & & \multicolumn{6}{|l|}{ Top $0.5 \mathrm{~m}$} & \multicolumn{6}{|l|}{ Top $1 \mathrm{~m}$} & \multicolumn{7}{|c|}{ Top $2 \mathrm{~m}$} \\
\hline \multicolumn{3}{|l|}{ Terrain } & Core ID & $\begin{array}{c}\text { PS } \\
(\%)\end{array}$ & Mean & Median & $\operatorname{Max}$ & Min & SD & $\begin{array}{c}\text { PS } \\
(\%)\end{array}$ & Mean & Median & Max & Min & SD & & $\begin{array}{c}\text { PS } \\
(\%)\end{array}$ & Mean & Median & Max & Min & SD \\
\hline \multirow{8}{*}{\multicolumn{3}{|c|}{ Peatlands and wetlands }} & 1006 & 72 & 1.2 & 0.6 & 3.2 & 0.3 & 1.1 & 100 & 1.5 & 1.2 & 3.2 & 0.3 & 1.2 & 12 & 83 & 1.7 & 1.8 & 3.2 & 0.3 & 1.1 \\
\hline & & & 1007 & 60 & 0.9 & 0.6 & 2.6 & 0.3 & 0.9 & 94 & 0.8 & 0.4 & 2.6 & 0.0 & 0.9 & 12 & 73 & 0.5 & 0.2 & 2.6 & 0.0 & 0.8 \\
\hline & & & 1005 & 90 & 0.8 & 0.7 & 1.5 & 0.1 & 0.6 & 90 & 1.1 & 1.4 & 2.4 & 0.1 & 0.8 & 13 & 86 & 0.9 & 0.7 & 2.4 & 0.1 & 0.8 \\
\hline & & & 2011 & 96 & 3.0 & 2.9 & 5.4 & 0.1 & 1.6 & 84 & 2.4 & 2.9 & 5.4 & 0.1 & 1.8 & 14 & 91 & 1.7 & 1.0 & 5.4 & 0.0 & 1.7 \\
\hline & & & 2012 & 60 & 0.9 & 0.7 & 2.4 & 0.1 & 1.0 & 0 & N/A & N/A & $\mathrm{N} / \mathrm{A}$ & N/A & N/A & 10 & 59 & 0.5 & 0.1 & 2.4 & 0.0 & 0.8 \\
\hline & & & 1009 & 60 & 2.3 & 2.1 & 3.4 & 1.5 & 0.7 & 73 & 1.8 & 2.0 & 3.4 & 0.1 & 1.1 & 13 & 82 & 1.8 & 2.0 & 3.4 & 0.1 & 1.1 \\
\hline & & & 1010 & 84 & 2.7 & 2.0 & 8.1 & 0.2 & 2.4 & 10 & 2.5 & 2.0 & 8.1 & 0.2 & 2.3 & 13 & 76 & 2.0 & 1.5 & 8.1 & 0.1 & 2.2 \\
\hline & & & 2015 & 60 & 0.2 & 0.1 & 0.6 & 0.1 & 0.2 & 0 & N/A & N/A & $\mathrm{N} / \mathrm{A}$ & N/A & N/A & 11 & 68 & 0.2 & 0.1 & 0.6 & 0.1 & 0.1 \\
\hline \multirow{7}{*}{\multicolumn{3}{|c|}{ Till Blanket }} & 1004 & 80 & 0.1 & 0.1 & 0.1 & 0.0 & 0.0 & 10 & 0.1 & 0.1 & 0.1 & 0.0 & 0.0 & 12 & 53 & 0.1 & 0.1 & 0.3 & 0.0 & 0.1 \\
\hline & & & 2004 & 100 & 0.9 & 0.2 & 4.9 & 0.1 & 1.8 & 0 & N/A & N/A & $\mathrm{N} / \mathrm{A}$ & N/A & N/A & 9 & 56 & 0.8 & 0.2 & 4.9 & 0.1 & 1.6 \\
\hline & & & 2005 & 60 & 0.5 & 0.2 & 2.0 & 0.1 & 0.7 & 0 & N/A & $\mathrm{N} / \mathrm{A}$ & $\mathrm{N} / \mathrm{A}$ & N/A & $\mathrm{N} / \mathrm{A}$ & 0 & 0 & N/A & N/A & N/A & N/A & N/A \\
\hline & & & 2006 & 60 & 0.1 & 0.1 & 0.2 & 0.0 & 0.0 & 0 & N/A & $\mathrm{N} / \mathrm{A}$ & $\mathrm{N} / \mathrm{A}$ & N/A & $\mathrm{N} / \mathrm{A}$ & 8 & 25 & 0.1 & 0.1 & 0.2 & 0.0 & 0.0 \\
\hline & & & 2033 & 70 & 0.1 & 0.1 & 0.4 & 0.0 & 0.1 & 0 & N/A & N/A & $\mathrm{N} / \mathrm{A}$ & N/A & $\mathrm{N} / \mathrm{A}$ & 0 & 0 & N/A & N/A & N/A & N/A & N/A \\
\hline & & & 2007 & 80 & 0.3 & 0.1 & 1.9 & 0.1 & 0.6 & 60 & 0.3 & 0.1 & 1.9 & 0.1 & 0.6 & 10 & 18 & 0.3 & 0.1 & 1.9 & 0.1 & 0.6 \\
\hline & & & 2009 & 60 & 0.1 & 0.1 & 0.1 & 0.0 & 0.0 & 0 & N/A & N/A & $\mathrm{N} / \mathrm{A}$ & N/A & N/A & 8 & 25 & 0.1 & 0.1 & 0.2 & 0.0 & 0.1 \\
\hline \multirow{5}{*}{\multicolumn{3}{|c|}{ Till Veneer }} & 2018 & 80 & 0.8 & 0.6 & 2.2 & 0.1 & 0.7 & 57 & 0.8 & 0.5 & 2.2 & 0.1 & 0.7 & 9 & 79 & 0.7 & 0.5 & 2.2 & 0.1 & 0.7 \\
\hline & & & 2019 & 60 & 0.4 & 0.1 & 1.8 & 0.0 & 0.7 & 0 & N/A & N/A & $\mathrm{N} / \mathrm{A}$ & N/A & N/A & 7 & 25 & 0.4 & 0.1 & 1.8 & 0.0 & 0.7 \\
\hline & & & 1014 & 0 & N/A & N/A & N/A & N/A & N/A & 0 & N/A & N/A & $\mathrm{N} / \mathrm{A}$ & N/A & $\mathrm{N} / \mathrm{A}$ & 0 & 0 & N/A & N/A & N/A & N/A & N/A \\
\hline & & & 2013 & 60 & 0.3 & 0.1 & 1.6 & 0.1 & 0.6 & 0 & N/A & N/A & N/A & N/A & N/A & 7 & 25 & 0.5 & 0.1 & 1.6 & 0.1 & 0.7 \\
\hline & & & 2016 & 68 & 0.2 & 0.1 & 0.6 & 0.1 & 0.2 & 100 & 0.2 & 0.1 & 0.6 & 0.1 & 0.2 & 0 & 0 & N/A & $\mathrm{N} / \mathrm{A}$ & $\mathrm{N} / \mathrm{A}$ & N/A & N/A \\
\hline \multirow{4}{*}{\multicolumn{3}{|c|}{ Eskers }} & 2026 & 60 & 0.1 & 0.1 & 0.2 & 0.0 & 0.0 & 100 & 0.1 & 0.1 & 0.2 & 0.0 & 0.0 & 0 & 0 & N/A & $\mathrm{N} / \mathrm{A}$ & $\mathrm{N} / \mathrm{A}$ & $\mathrm{N} / \mathrm{A}$ & N/A \\
\hline & & & 2008 & 60 & 0.0 & 0.0 & 0.1 & 0.0 & 0.0 & 0 & N/A & N/A & $\mathrm{N} / \mathrm{A}$ & N/A & $\mathrm{N} / \mathrm{A}$ & 0 & 0 & N/A & $\mathrm{N} / \mathrm{A}$ & $\mathrm{N} / \mathrm{A}$ & $\mathrm{N} / \mathrm{A}$ & N/A \\
\hline & & & 2028 & 60 & 0.1 & 0.0 & 0.3 & 0.0 & 0.1 & 0 & N/A & $\mathrm{N} / \mathrm{A}$ & $\mathrm{N} / \mathrm{A}$ & $\mathrm{N} / \mathrm{A}$ & $\mathrm{N} / \mathrm{A}$ & 7 & 100 & 0.1 & 0.0 & 0.4 & 0.0 & 0.2 \\
\hline & & & 2029 & 60 & 0.0 & 0.0 & 0.0 & 0.0 & 0.0 & 0 & $\mathrm{~N} / \mathrm{A}$ & $\mathrm{N} / \mathrm{A}$ & $\mathrm{N} / \mathrm{A}$ & N/A & $\mathrm{N} / \mathrm{A}$ & 0 & 0 & N/A & N/A & $\mathrm{N} / \mathrm{A}$ & $\mathrm{N} / \mathrm{A}$ & $\mathrm{N} / \mathrm{A}$ \\
\hline \multicolumn{4}{|c|}{ Top 4 m } & & & & & \multicolumn{7}{|c|}{ Top 6 m } & \multicolumn{8}{|c|}{ Top $10 \mathrm{~m}$} \\
\hline Core ID & & $\begin{array}{c}\text { PS } \\
(\%)\end{array}$ & Mean & Median & Max & Min & SD & $\mathrm{N}$ & $\begin{array}{c}\text { PS } \\
(\%)\end{array}$ & Mean & Median & Max & Min & SD & $\mathrm{N}$ & $\begin{array}{c}\text { PS } \\
(\%)\end{array}$ & Mean & & Median & Max & Min & SD \\
\hline 1006 & 17 & $\begin{array}{l}80 \\
75\end{array}$ & 1.4 & 1.5 & 3.2 & 0.0 & 1.1 & $\overline{18}$ & $\begin{array}{c}58 \\
0\end{array}$ & 1.4 & 1.3 & 3.2 & 0.0 & 1.1 & $\overline{0}$ & $\begin{array}{l}0 \\
0\end{array}$ & $\mathrm{~N} / \mathrm{A}$ & & $\mathrm{N} / \mathrm{A}$ & $\mathrm{N} / \mathrm{A}$ & $\mathrm{N} / \mathrm{A}$ & $\mathrm{N} / \mathrm{A}$ \\
\hline 1007 & 20 & & 0.3 & 0.1 & 2.6 & 0.0 & 0.6 & 0 & & N/A & N/A & N/A & N/A & N/A & 0 & & N/A & & N/A & N/A & N/A & $\mathrm{N} / \mathrm{A}$ \\
\hline 1005 & 23 & 83 & 0.8 & 0.6 & 2.4 & 0.1 & 0.7 & 26 & 0 & 0.8 & 0.7 & 2.4 & 0.1 & 0.7 & 0 & 0 & $\mathrm{~N} / \mathrm{A}$ & & N/A & $\mathrm{N} / \mathrm{A}$ & $\mathrm{N} / \mathrm{A}$ & $\mathrm{N} / \mathrm{A}$ \\
\hline 2011 & 23 & 92 & 1.6 & 1.2 & 5.4 & 0.0 & 1.4 & 30 & 83 & 1.3 & 0.5 & 5.4 & 0.0 & 1.4 & 0 & 0 & N/A & & $\mathrm{N} / \mathrm{A}$ & $\mathrm{N} / \mathrm{A}$ & $\mathrm{N} / \mathrm{A}$ & $\mathrm{N} / \mathrm{A}$ \\
\hline 2012 & 17 & 65 & 0.4 & 0.1 & 2.4 & 0.0 & 0.7 & 18 & 46 & 0.4 & 0.1 & 2.4 & 0.0 & 0.6 & 0 & 0 & $\mathrm{~N} / \mathrm{A}$ & & N/A & $\mathrm{N} / \mathrm{A}$ & $\mathrm{N} / \mathrm{A}$ & $\mathrm{N} / \mathrm{A}$ \\
\hline 1009 & 21 & 83 & 1.5 & 1.3 & 3.4 & 0.1 & 1.1 & 0 & 0 & N/A & N/A & $\mathrm{N} / \mathrm{A}$ & N/A & $\mathrm{N} / \mathrm{A}$ & 0 & 0 & $\mathrm{~N} / \mathrm{A}$ & & $\mathrm{N} / \mathrm{A}$ & $\mathrm{N} / \mathrm{A}$ & $\mathrm{N} / \mathrm{A}$ & $\mathrm{N} / \mathrm{A}$ \\
\hline 1010 & 22 & 83 & 1.3 & 0.4 & 8.1 & 0.1 & 1.9 & 27 & 74 & 1.2 & 0.4 & 8.1 & 0.1 & 1.7 & 0 & 0 & $\mathrm{~N} / \mathrm{A}$ & & $\mathrm{N} / \mathrm{A}$ & $\mathrm{N} / \mathrm{A}$ & $\mathrm{N} / \mathrm{A}$ & $\mathrm{N} / \mathrm{A}$ \\
\hline 2015 & 0 & 0 & N/A & $\mathrm{N} / \mathrm{A}$ & N/A & $\mathrm{N} / \mathrm{A}$ & $\mathrm{N} / \mathrm{A}$ & 0 & 0 & $\mathrm{~N} / \mathrm{A}$ & $\mathrm{N} / \mathrm{A}$ & $\mathrm{N} / \mathrm{A}$ & N/A & $\mathrm{N} / \mathrm{A}$ & 0 & 0 & $\mathrm{~N} / \mathrm{A}$ & & $\mathrm{N} / \mathrm{A}$ & $\mathrm{N} / \mathrm{A}$ & $\mathrm{N} / \mathrm{A}$ & $\mathrm{N} / \mathrm{A}$ \\
\hline 1004 & 15 & 38 & 0.2 & 0.1 & 0.8 & 0.0 & 0.2 & 17 & 29 & 0.2 & 0.1 & 0.8 & 0.0 & 0.2 & 0 & 0 & $\mathrm{~N} / \mathrm{A}$ & & $\mathrm{N} / \mathrm{A}$ & $\mathrm{N} / \mathrm{A}$ & $\mathrm{N} / \mathrm{A}$ & $\mathrm{N} / \mathrm{A}$ \\
\hline 2004 & 12 & 68 & 0.6 & 0.3 & 4.9 & 0.1 & 1.4 & 0 & 0 & N/A & N/A & N/A & N/A & N/A & 0 & 0 & $\mathrm{~N} / \mathrm{A}$ & & N/A & $\mathrm{N} / \mathrm{A}$ & $\mathrm{N} / \mathrm{A}$ & $\mathrm{N} / \mathrm{A}$ \\
\hline 2005 & 12 & 41 & 0.3 & 0.2 & 2.0 & 0.1 & 0.6 & 13 & 26 & 0.3 & 0.2 & 2.0 & 0.1 & 0.5 & 0 & 0 & $\mathrm{~N} / \mathrm{A}$ & & $\mathrm{N} / \mathrm{A}$ & $\mathrm{N} / \mathrm{A}$ & $\mathrm{N} / \mathrm{A}$ & N/A \\
\hline 2006 & 10 & 24 & 0.2 & 0.1 & 0.8 & 0.0 & 0.2 & 11 & 80 & 0.2 & 0.1 & 0.8 & 0.0 & 0.2 & 0 & 0 & $\mathrm{~N} / \mathrm{A}$ & & N/A & $\mathrm{N} / \mathrm{A}$ & $\mathrm{N} / \mathrm{A}$ & $\mathrm{N} / \mathrm{A}$ \\
\hline 2033 & 9 & 17 & 0.2 & 0.1 & 0.4 & 0.0 & 0.1 & 12 & 0 & 0.2 & 0.2 & 0.4 & 0.0 & 0.1 & 0 & 0 & $\mathrm{~N} / \mathrm{A}$ & & $\mathrm{N} / \mathrm{A}$ & $\mathrm{N} / \mathrm{A}$ & $\mathrm{N} / \mathrm{A}$ & $\mathrm{N} / \mathrm{A}$ \\
\hline 2007 & 11 & 22 & 0.3 & 0.1 & 1.9 & 0.0 & 0.5 & 0 & 0 & N/A & $\mathrm{N} / \mathrm{A}$ & $\mathrm{N} / \mathrm{A}$ & N/A & $\mathrm{N} / \mathrm{A}$ & 0 & 0 & $\mathrm{~N} / \mathrm{A}$ & & $\mathrm{N} / \mathrm{A}$ & $\mathrm{N} / \mathrm{A}$ & $\mathrm{N} / \mathrm{A}$ & $\mathrm{N} / \mathrm{A}$ \\
\hline 2009 & 9 & 40 & 0.1 & 0.1 & 0.5 & 0.0 & 0.2 & 0 & 0 & $\mathrm{~N} / \mathrm{A}$ & $\mathrm{N} / \mathrm{A}$ & $\mathrm{N} / \mathrm{A}$ & $\mathrm{N} / \mathrm{A}$ & $\mathrm{N} / \mathrm{A}$ & 0 & 0 & $\mathrm{~N} / \mathrm{A}$ & & $\mathrm{N} / \mathrm{A}$ & $\mathrm{N} / \mathrm{A}$ & $\mathrm{N} / \mathrm{A}$ & N/A \\
\hline 2018 & 13 & 83 & 0.6 & 0.3 & 2.2 & 0.1 & 0.6 & 0 & 0 & $\mathrm{~N} / \mathrm{A}$ & $\mathrm{N} / \mathrm{A}$ & N/A & N/A & $\mathrm{N} / \mathrm{A}$ & 0 & 0 & $\mathrm{~N} / \mathrm{A}$ & & $\mathrm{N} / \mathrm{A}$ & $\mathrm{N} / \mathrm{A}$ & $\mathrm{N} / \mathrm{A}$ & $\mathrm{N} / \mathrm{A}$ \\
\hline 2019 & 11 & 33 & 0.4 & 0.2 & 1.8 & 0.0 & 0.5 & 0 & 0 & N/A & $\mathrm{N} / \mathrm{A}$ & N/A & N/A & $\mathrm{N} / \mathrm{A}$ & 0 & 0 & $\mathrm{~N} / \mathrm{A}$ & & N/A & $\mathrm{N} / \mathrm{A}$ & $\mathrm{N} / \mathrm{A}$ & $\mathrm{N} / \mathrm{A}$ \\
\hline 1014 & 0 & 0 & N/A & $\mathrm{N} / \mathrm{A}$ & $\mathrm{N} / \mathrm{A}$ & N/A & $\mathrm{N} / \mathrm{A}$ & 7 & 25 & 0.4 & 0.4 & 1.0 & 0.1 & 0.3 & 19 & 47 & 0.4 & & 0.3 & 1.0 & 0.1 & 0.3 \\
\hline 2013 & 9 & 25 & 0.7 & 0.1 & 1.7 & 0.1 & 0.7 & 0 & 0 & $\mathrm{~N} / \mathrm{A}$ & $\mathrm{N} / \mathrm{A}$ & $\mathrm{N} / \mathrm{A}$ & N/A & $\mathrm{N} / \mathrm{A}$ & 0 & 0 & $\mathrm{~N} / \mathrm{A}$ & & $\mathrm{N} / \mathrm{A}$ & $\mathrm{N} / \mathrm{A}$ & $\mathrm{N} / \mathrm{A}$ & N/A \\
\hline 2016 & 0 & 0 & N/A & N/A & N/A & N/A & N/A & 0 & 0 & $\mathrm{~N} / \mathrm{A}$ & $\mathrm{N} / \mathrm{A}$ & $\mathrm{N} / \mathrm{A}$ & $\mathrm{N} / \mathrm{A}$ & $\mathrm{N} / \mathrm{A}$ & 0 & 0 & $\mathrm{~N} / \mathrm{A}$ & & $\mathrm{N} / \mathrm{A}$ & $\mathrm{N} / \mathrm{A}$ & $\mathrm{N} / \mathrm{A}$ & N/A \\
\hline 2026 & 0 & 0 & N/A & $\mathrm{N} / \mathrm{A}$ & $\mathrm{N} / \mathrm{A}$ & $\mathrm{N} / \mathrm{A}$ & $\mathrm{N} / \mathrm{A}$ & 0 & 0 & $\mathrm{~N} / \mathrm{A}$ & N/A & $\mathrm{N} / \mathrm{A}$ & N/A & $\mathrm{N} / \mathrm{A}$ & $\overline{0}$ & 0 & $\mathrm{~N} / \mathrm{A}$ & & $\mathrm{N} / \mathrm{A}$ & $\mathrm{N} / \mathrm{A}$ & N/A & $\mathrm{N} / \mathrm{A}$ \\
\hline 2008 & 8 & 53 & 0.0 & 0.0 & 0.1 & 0.0 & 0.0 & 9 & 85 & 0.1 & 0.0 & 0.2 & 0.0 & 0.1 & 0 & 0 & $\mathrm{~N} / \mathrm{A}$ & & $\mathrm{N} / \mathrm{A}$ & $\mathrm{N} / \mathrm{A}$ & $\mathrm{N} / \mathrm{A}$ & $\mathrm{N} / \mathrm{A}$ \\
\hline 2028 & 0 & 25 & N/A & $\mathrm{N} / \mathrm{A}$ & $\mathrm{N} / \mathrm{A}$ & $\mathrm{N} / \mathrm{A}$ & $\mathrm{N} / \mathrm{A}$ & 8 & 100 & 0.2 & 0.1 & 0.4 & 0.0 & 0.2 & 9 & 90 & 0.2 & & 0.2 & 0.4 & 0.0 & 0.2 \\
\hline 2029 & 8 & 70 & 0.0 & 0.0 & 0.1 & 0.0 & 0.0 & 9 & 88 & 0.0 & 0.0 & 0.1 & 0.0 & 0.0 & 9 & 93 & 0.0 & & 0.1 & 0.1 & 0.0 & 0.0 \\
\hline
\end{tabular}

